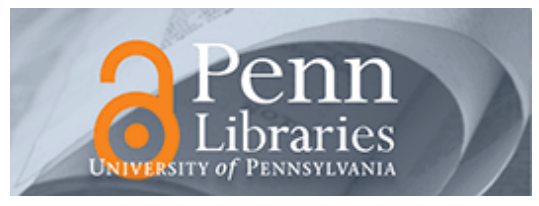

University of Pennsylvania

ScholarlyCommons

Marketing Papers

Wharton Faculty Research

4-20-1968

\title{
Long-Range Forecasting for a Consumer Durable in an International Market
}

\section{J. Scott Armstrong}

University of Pennsylvania, armstrong@wharton.upenn.edu

Follow this and additional works at: https://repository.upenn.edu/marketing_papers

Part of the Business Administration, Management, and Operations Commons, Business and Corporate Communications Commons, and the Finance and Financial Management Commons

\section{Recommended Citation}

Armstrong, J. S. (1968). Long-Range Forecasting for a Consumer Durable in an International Market. Retrieved from https://repository.upenn.edu/marketing_papers/174

This paper is posted at ScholarlyCommons. https://repository.upenn.edu/marketing_papers/174

For more information, please contact repository@pobox.upenn.edu. 


\title{
Long-Range Forecasting for a Consumer Durable in an International Market
}

\author{
Abstract \\ There has been a substantial amount of interest recently in long-range planning. One necessary \\ component of the long-range plan Is the long-range forecast. In contrast to the emphasis on the planning \\ process, however, little attention has been given to forecasting. This study considers the problem of long- \\ range forecasting in a situation which is of growing importance - forecasting sales for international \\ markets.
}

Many researchers appear to operate under the impression that causal models (i.e., models based on an analysis of underlying factors) lead to more accurate sales forecasts than those provided by naive models (i.e., projections based on historical sales data only). A survey of the research literature led to the conclusion that this confidence in causal models is virtually unsupported. One can hardly criticize firms, then, for relying primarily upon naive models for sales forecasting since these models are simpler and less expensive than causal model.

This study was based on the hypothesis that causal models are superior to naive models in certain situations. The key element of ${ }^{\wedge}$ these situations is that -there are "large changes." Long-range sales forecasting usually involves such large changes; and there are many reasons to expect that long-range forecasting for international markets is a situation in which substantial changes will occur (e.g., the Kennedy round tariff cuts and the formation of common markets.)

A causal model was developed to provide long-range forecasts of the international market for still cameras. This model provided unconditional forecasts of unit camera sales by country for year $t+n$ on the basis of $\mathrm{I}$ ) knowledge about camera sales in year $t$ and 2) predicted changes in four causal variables from year $t$ to $t+n$. These four causal variables included, in order of importance, per capita income, price of cameras, number of potential buyers and quality of cameras.

The predictive ability of the causal model was superior to that of a naive model purporting to represent current practice. Each model was used to provide backcasts of $195^{\wedge}$ camera sales in 17 countries on the basis of data from 1967 to i960 only. The mean absolute percentage error for the causal model was $2 \%$ while that for the naive model was $h \%$. This result was statistically significant $(0 ?=.05)$; but, more importantly, it appeared to have great practical significance. An evaluation, based on very conservative subjective estimates, indicated that such an improvement in accuracy would have a present value worth in excess of one percent of a typical firm's yearly sales volume.

Further support for the use of the causal model was obtained by noting that the standard errors of the estimated relationships were low (evidence of reliability), that the estimates of causal relationships from different measurement models were in rather close agreement (evidence of construct validity), and that the causal model performed well in another situation where predictions were provided for 1960-65 camera sales in 11 "new" countries (evidence of concurrent validity).

The causal relationships were initially specified by a subjective analysis. Various parts of the causal model were then updated by use of a number of measurement models including an analysis of differences among sales rates for 30 countries, of differences among changes in the sales rates from 1961 to 1965 for 21 countries, and of differences among six income categories from United States household survey data. This updating led to a modest, though valuable, gain as the mean absolute percentage error of the $195^{\star}+$ backcast was reduced from $2>Q P f 0$ to the $23 \$$ mentioned above.

Additional benefits associated with the development of the causal model included the ability to evaluate large changes in the market; to estimate current sales where trade and production figures are inadequate; 
to evaluate alternative assumptions about the future rapidly and cheaply; and to identify markets which have not been fully exploited.

In summary, the study argues that the development of better long-range forecasting models is an important problem; describes the development of causal models; and demonstrates the superiority of causal models over naive models in a case involving long-range forecasting for international markets.

\section{Disciplines}

Business Administration, Management, and Operations | Business and Corporate Communications | Finance and Financial Management 


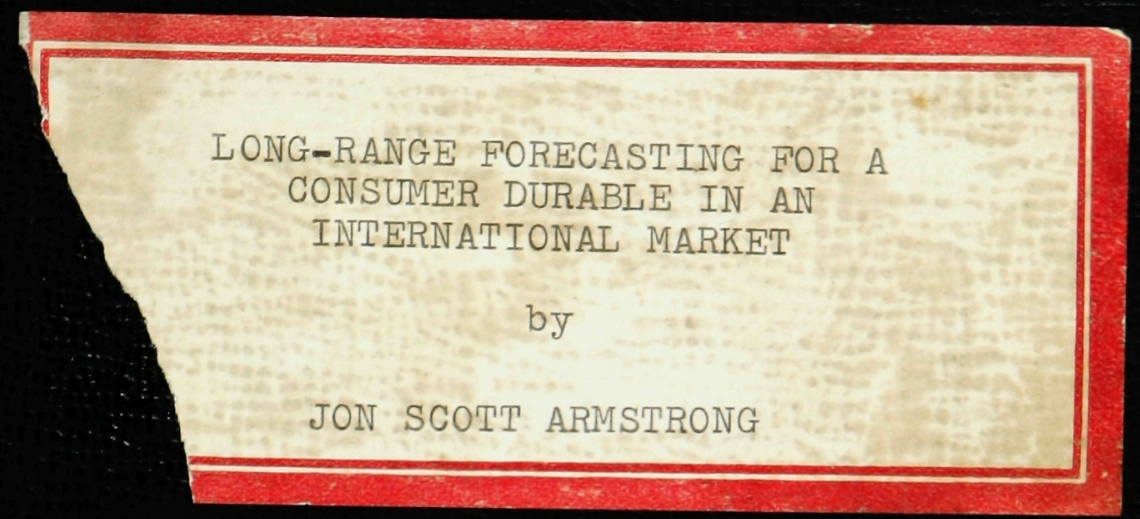







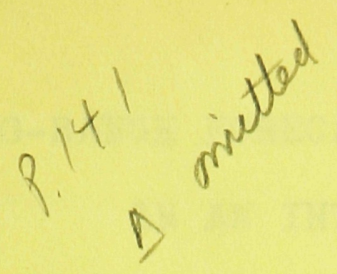


IONG-RANGE FORECASTING FOR A CONSUMER DURABLE

IN AN INTERNATIONAL MARKET

by

JON SCOTT ARMSTRONG

A.B., Lehigh University

(1959)

S.B., Lehigh University

(1960)

M.S., Carnegie-Mellon University

(1965)

SUBMITTED IN PARTIAL FULFILLMENT

OF THE REQUIREMENTS FOR THE

DEGREE OF DOCTOR OF

SCIENCE

at the

MASSACHUSETTS INSTITUTE OF

TECHNOLOGY

June, 1968

signature of Author ......tert. Comptoma.............

Alfred P. Sloan School of Management,

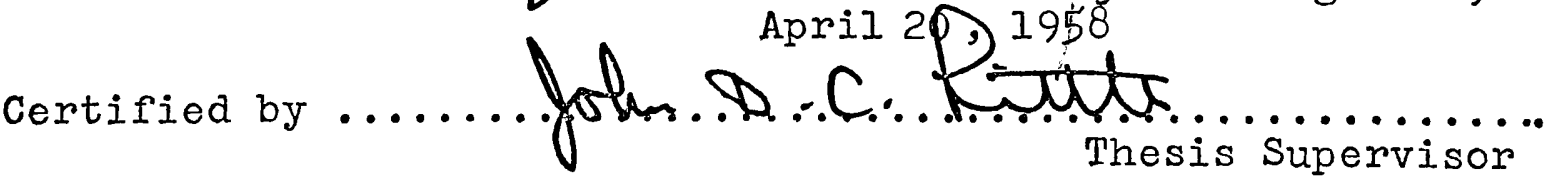

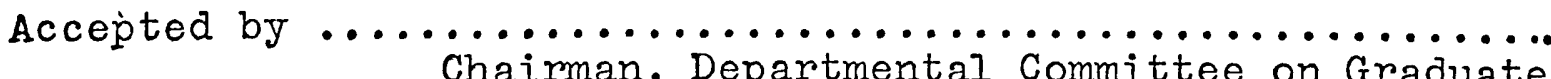
Students 
This thesis has been given limited reproduction with the permission of the Alfred P. Sloan School of Management. However, this copy is issued with the understanding that none of the data resulting from the investigation will be used for advertising or publicity purposes, and that the thesis is solely for the confidential use of the organization or individual to whom it is addressed. 


\author{
ABSTRACT \\ LONG-RANGE FORECASTING FOR A CONSUMER DURABLE \\ IN AN INTERNATIONAL MARKET \\ by \\ Jon Scott Armstrong
}

Submitted to the Alfred P. Sloan School of Management on April 20, 1968 in partial fulfillment of the requirements for the degree of Doctor of Science in Management.

There has been a substantial amount of interest recently in long-range planning. One necessary component of the long-range plan is the long-range forecast. In contrast to the emphasis on the planning process, however, little attention has been given to forecasting. This study considers the problem of long-range forecasting in a situation which is of growing importance - forecasting sales for international markets.

Many researchers appear to operate under the impression that causal models (i.e., models based on an analysis of underlying factors) lead to more accurate sales forecasts than those provided by naive models (i.e., projections based on historical sales data only). A survey of the research literature led to the conclusion that this confidence in causal models is virtually unsupported. One can hardly criticize firms, then, for relying primarily upon naive models for sales forecasting since these models are simpler and less expensive than causal model.

This study was based on the hypothesis that causal models are superior to naive models in certain situations. The key element of these situations is that there are "large changes." Long-range sales forecasting usually involves such large changes; and there are many reasons to expect that long-range forecasting for international markets is a situation in which substantial changes will occur (e.g., the Kennedy round tariff cuts and the formation of common markets.)

A causal model was developed to provide long-range forecasts of the international market for still cameras. This model provided unconditional forecasts of unit camera sales by country for year $t+n$ on the basis of 1 ) knowledge about camera sales in year $t$ and 2 ) predicted changes in four causal variables from year $t$ to $t+n$. These four causal variables included, in order of importance, per capita income, price of cameras, number of potential buyers and quality of cameras. 
The predictive ability of the causal model was superior to that of a naive model purporting to represent current practice. Each model was used to provide backcasts of 1954 camera sales in 17 countries on the basis of data from 1967 to 1960 only. The mean absolute percentage error for the causal model was $23 \%$ while that for the naive model was $43 \%$. This result was statistically significant $(\alpha=.05)$; but, more importantly, it appeared to have great practical significance. An evaluation, based on very conservative subjective estimates, indicated that such an improvement in accuracy would have a present value worth in excess of one percent of a typical firm's yearly sales volume.

Further support for the use of the causal model was obtained by noting that the standard errors of the estimated relationships were low (evidence of reliability), that the estimates of causal relationships from different measurement models were in rather close agreement (evidence of construct validity), and that the causal model performed well in another situation where predictions were provided for 1960-65 camera sales in 11 "new" countries (evidence of concurrent validity).

The causal relationships were initially specified by a subjective analysis. Various parts of the causal model were then updated by use of a number of measurement models including an analysis of differences among sales rates for 30 countries; of differences among changes in the sales rates from 1961 to 1965 for 21 countries, and of differences among six income categories from United States household survey data. This updating led to a modest, though valuable, gain as the mean absolute percentage error of the 1954 backcast was reduced from $30 \%$ to the $23 \%$ mentioned above.

Additional benefits associated with the development of the causal model included the ability to evaluate large changes in the market; to estimate current sales where trade and production figures are inadequate; to evaluate alternative assumptions about the future rapidly and cheaply; and to identify markets which have not been fully exploited.

In summary, the study argues that the development of better long-range forecasting models is an important problem; describes the development of causal models; and demonstrates the superiority of causal models over naive models in a case involving long-range forecasting for international markets.

Thesis Advisor: John D. C. Little

Title: Professor of Management 
Cambridge, Massachusetis April 20, 1968

Professor E. Neal Hartley

Secretary of the Faculty

Massachusetts Institute of Technology

Cambridge, Massachusetts 02139

Dear Professor Hartley:

In accordance with the requirements for graduation,

I herewith submit a thesis entitled "Long-Range Forecasting for a Consumer Durable in an International Market".

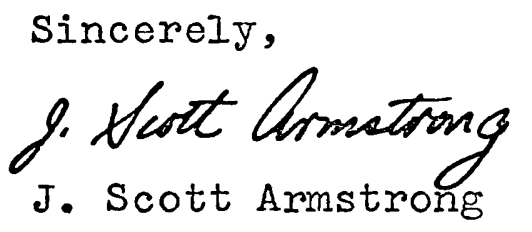


I would like to express appreciation to my thesis committee for the encouragement which they gave me to pursue my own somewhat pragmatịc interests and for furthering my belief that useful theories in the management sciences follow from studying important problems. Also, without their vigorous support at a time of crisis, this study would never have been completed. The chairman of the committee, Professor John D.C. Little, demonstrated an amazing capacity to identify important issues. He made few suggestions--but those that he made turned out to be of critical importance and left me wondering "why didn't I think of that?". Professor Paul W. MacAvoy spent many patient hours uncovering errors in logic which mysteriously crept into the thesis. He has a unique capacity to point out ways in which micro-economics really is useful in dealing with real-world data-something which I had come to doubt after repeated sampling of the literature in mioro-economics. Professor Richard D. Robinson tried to compensate for my lack of knowledge about international business and opened up many new sources of information.

I would also like to thank the Ford Foundation who assisted my wife, Kay, in supporting me over the last two years; the M.I.T. Computation Center who provided both facilities and programming assistance; David H. Pyle who spent many hours helping me to interpret econometrics and to decide what was useful in that vast literature; and, finally, and most importantly, my wife, Kay, for her many contributions-- 
like patience, useful comments, analysis, and typing. She has made this thesis the most frequently read book in our home.

I'Il take credit for the errors. And, over time, I suspect that I'II also try to take credit for the clever ideas suggested by my thesis committee and others. 


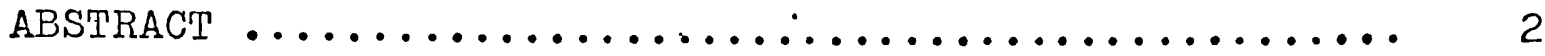

LETTER OF TRANSMTTTAL $\ldots \ldots \ldots \ldots \ldots \ldots \ldots \ldots \ldots \ldots \ldots$

ACKNOWLEDGEMIENTS $\ldots \ldots \ldots \ldots \ldots \ldots \ldots \ldots \ldots \ldots \ldots \ldots \ldots \ldots \ldots \ldots \ldots$

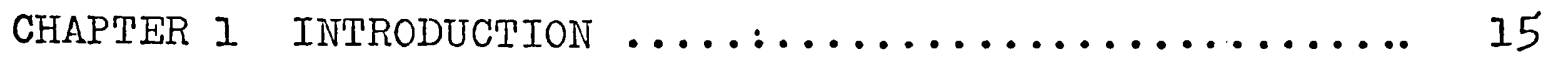

Motivation

. Objectives of the Study

- Developing Causal Models

- The Concept of a Causal Relationship

- The Use of Non-Experimental Data

-Prior Knowledge about Variables and Relationships

- The Use of Many Data Sets

- The Measurement Models

- Combining Estimates from Various Sources

- The Prediction Model

- Testing the Prediction Models

- Decision Models

- Summary

CHAPTER 2 A RBVIEN OF THE LITSRATURE ............. 38

-General Works on Methods

-Long-Range Forecasting

- The Evaluation of Forecast Accuracy

-Evaluation of Market Potentials

CHAPTER 3 A CONCEPTUAL MODEL ................ 45

- Motivation

- Basic Dimensions of the Model

-Planning Horizon

- Product Class

- Sales Measure

- Market

- Causal Variables for the Sales Model.

- Relative Importance of Causal Variables

- Relationships Among'Variables •

- Surmary

CHAPTER 4 SPECIFICATION OF THE FORECASTING IMODEJ .....

- Operational Measures

- Potential Buyers

- Economic Ability to Purchase Goods

- Price of Camera Goods 
- Availability

- Knowledge

- Ownership

- Quality

- Substitutes

- Use Opportunity.

- Summary: Operational Measures

- Relationships Among Operational Variables

- Functional Form of the Sales Forecasting Model

-The Top-Down vs. the Bottom-Up Approach

- The Use of Indices

CHAPTER 5 THE USE OF NON-EXPERIMEITTAL DATA .......

- Aggregate Data

- The Selection of Data Sets

- Criteria for Selecting Data Sets

- A Structured.Approach to Searching for Data

- The Effects of Measurement Error

- Errors in the Independent Variables

- Errors in the Dependent Variable

- The Quality of the Observations

- A Specific Problem with Multiplicative Models

-Multicollinearity

- Sources of Data

- Sales Data

- Data on Predictor Variables

- An A Priori Ranking of the Usefulness of Data Sets - Summary

CHAPTER 6 A PRIORI ANALYSIS: THE FORECASTING MODEL..

- Forecasting Camera Sales

-Population

- Age Distribution

- Iiteracy Rate

- Non-Agricultural Employment

- Personal Consumption Expenditures

- Retail Price Index for Cameras

- Quotas

- Subjective Estimate of Effects of Quality

- Households per Adult

- Proportion of Children

- Summary: Forecasting Camera Sales.

-Forecasting the Causal Variables

CHAPTER 7 THE MEASUREMENT MODEUS $\ldots \ldots \ldots \ldots \ldots \ldots \ldots . \ldots 107$

- Measurement Models vs. Prediction Models

- Nuisance Variables

- The Relative Importance of Variables

- Criteria for Evaluation of Measurement Models

- Estimating Parameters for the Price Model

- Technological Change: The Use of Time Series Data

- The Use of an International Cross-section 
- The Data

- A Priori Analysis

- Results

-Additional Testing of the Price Model

-Conclusion: Price Model

- Estimates for the Sales Model: International

Cross-Section

- Some Nuisance Variables

- Discussion of the Operational Measures

- The Data

- A Priori Analysis

- Results

- Discussion

- Estimates for the sales Model: Longitudinal Data.

- A Priori Analysis

- Results

- Estimates for the Sales Model: Household Data

- A Priori Analysis

- Results

- Integrating the Estimates of Parameters for the Sales Model

-Re-estimating the International Cross-Section

- Combining the Estimates

- Summary

CHAPTER 8 EVALUATING THE SALES FORECASTING MODEL...... 153

-Testing Construct Validity: The Consistency of the OEstimates

-Predicting 1960-65 Camera Sales for "New" Countries - Testing the Goodness of the Predictions

-A Non-Theoretical Model

- A Per Capita Adjustment

- Updating the Estimates

: Some Additional Testing of the International

QCross-Section

-Summary: Predicting Sales in New Countries

- Backcasting Sales for 1954

-The Forecasting Model

- The Current Sales Rate

- Unconditional Forecasts: The Effect of Errors in

Predictor Variables

- Backcasting the Causal Variables

- Backcasting Sales

-The A Priori Version of the Causal Model

- Naive Models

- Evaluating the Components of the Forecasting Model

- Adjusting the Causal Elasticities to Compensate for Error

- Relative Importance of the Causal Variables

- The Estimate of the Initial (1962) Sales Rate

- The Existence of National Differences

- A Note of Caution

- Surnmary 
CHAPTER 9 USING THE MODHU $\ldots \ldots \ldots \ldots \ldots \ldots \ldots$

-Forecasting Sales for 1975: An Unconditional Forecast

- Results

- The Validity of the Forecasts

- The Accuracy of the Forecasts

- Other Benefits from the Study

- Evaluation of Alternative Projections of Causal Variables

- Evaluation of Substantial and Rapid Economic Changes

- Evaluation of Industry Marketing Effort

- Summary.

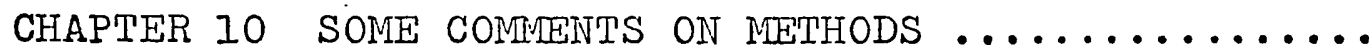

- The Value of the A Priori Analysis

- Analysis of the Sample Observations

- Selection of Important Variables

- Estimates of Causal Relationships

- Estimates of Confidence Regions

- Bias Associated with Measurement Models

- Compensating for Error in Predictions of Causal Variables

- Summary: A Priori Analysis

- The Use of the Measure of Potential Buyers

- Advantages of Using Many Data Sets

- Many Variables vs. Few Variables

- The Value of Global Indices

- Summary

CHAPTER II CONCLUSIONS $\ldots \ldots \ldots \ldots \ldots \ldots \ldots \ldots \ldots$

- Additional Testing of the Model

- The Development of the Causal Model

- Improving the liodel

- Additional Benefits of the Study

- Iimitations of the Study

- Summary

APPENDIX A: A PRIORI EVALUATION OF OBSERVATIONS ..... 231

APPENDIX B: ORIGINAL DATA AND NOTES ........... 236

- International Price Data

- International Sales Data

- Consumer Survey Data

APPENDIX C: NOTES ON METHODS ................ 251

- Factor Analysis

- The Use of a Global Index for Camera Prices

- The Value of Improved Accuracy in Long-Range Forecasting 
BIBLIOGRAPHY

- Research Methods

- Sources of Data

BIOGRAPHICAL SKETCH OF THE AUTIIOR ............ 266 
1- I Savings from Reducing Forecast Error .........

3- I Relative Importance of inine Variables to the

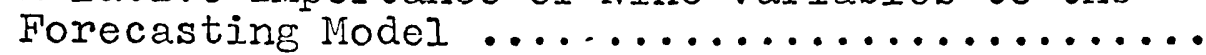

4- 1 Summary of Operational Measures: Forecasting

5- 1 A Priori Ranking of Data Sës for Parameter

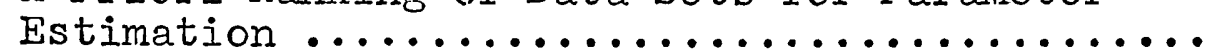

7- I Correlations Among International Price Indices.

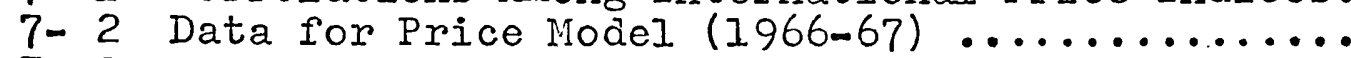

7- 3 A Priori.Estimates of Regression Coefficients: Price Model

7- 4 Price Model: Original Form

$7-.5$ Price

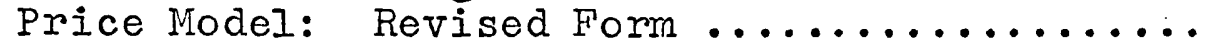

Reliability Test for Price Model Coefficients..

121

Effect of Outliers Upon Estimates for Price Model

7- 8 1960-65 Data on Factors Causing Variation in

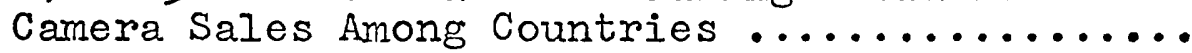

7- 9 A Priori Estimates: International Cross-Sec-

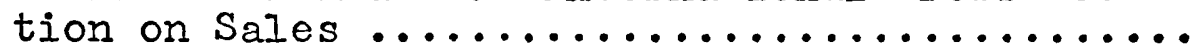

7-10 Regression on International Cross-Section:

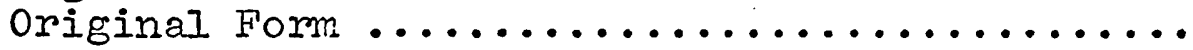

7-II Actual vs. Predicted Sales: International Cross-Section (Analysis Sarnple)

7-12 Predictions of Retail Price Index for Cameras...

7-13 A Priori Estimates: Longitudinal Model .......

7-14 Regression on Longitudinal Data: Original

7-15 . Expenditures on Camera Goods per "weighted"

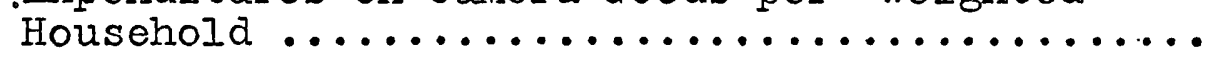

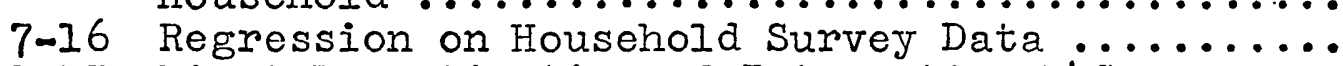

7-17. First Re-estimation of Internationali Cross-

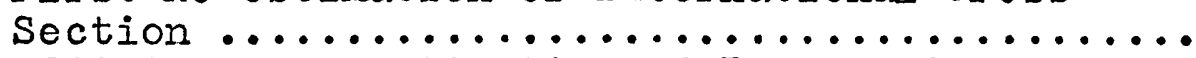

7-18 Additional Re-estimation of International

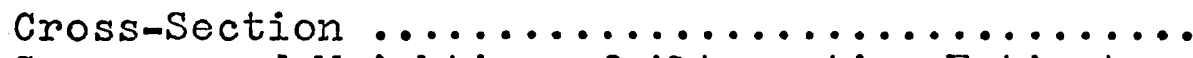

7-19 Summary and Weighting of Alternative Estimates

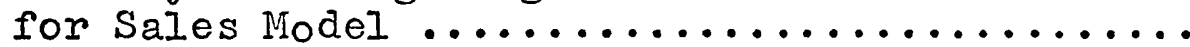

8- I Predictions of Camera Sales Rates for Valida-

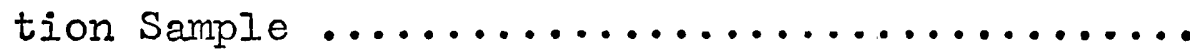

8- 2 Average Sales Rate per Capita for Country

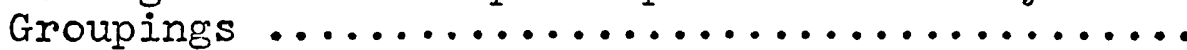

8- 3 List of "Reasonable Variables" for Predicting

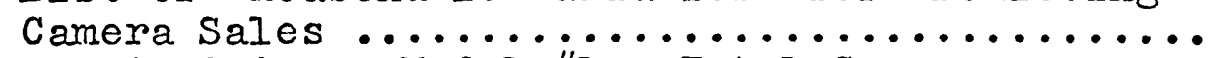

8- 4 Statistician's Model \#I: Total Camera

8- 5 Statistician's Model \#2: Camera Sales per

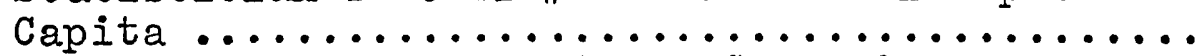

8- 6 Regression on International Cross-Section:

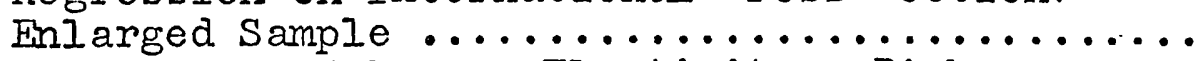

8- 7 Comparison of Income Elasticity: Rich vs.

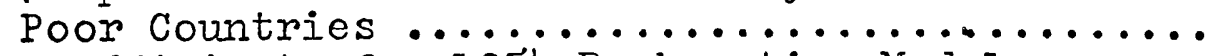

8- 8 Coefficients for 1954 Backcasting Model ......... 
Table

8- 9 Backcasting the Causal Variables for 1954 ....

8-10 Backcasting Camera Sales for 1954 ..........

8-11 1954 Backcasts from Various Naive Models .....

8-12 Changes in Causal Variables from 1962 to

1954

8-13 Forecast Error for Various Initial

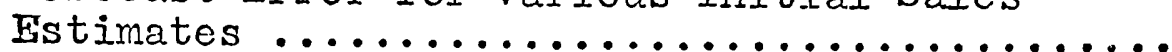

9- 1 Forecasting the Causal Variabies for $1975 \ldots$

191

9- 2 Coefficients for 1975 Forecasting Model ......

9- 3 Summary of Forecast of Camera Sales for $1975^{\circ}$

$9-4$
$0-1$

Exploitation of Camera Markets $(i 960-6 j)$

191

193

10- 1 Errors by Rated Quality of Data: Inter-

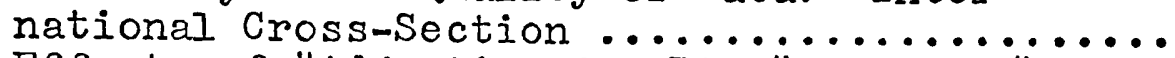

10- 2 Effects of "Adjusting for Bias" upon 1954

10- 3 Cross-Sectional Model Based on Camera Sajes

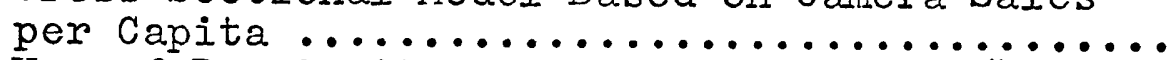

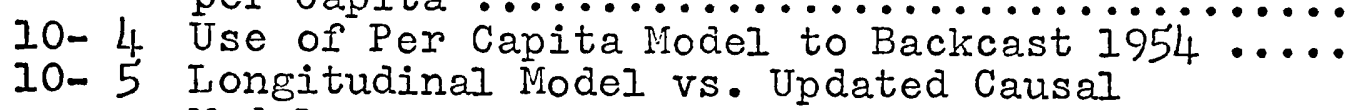

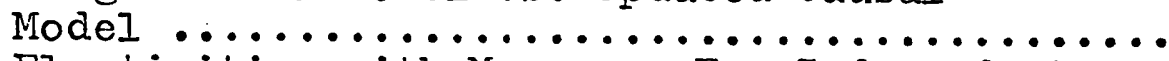

10- 6 Elasticities with Many vs. Few Independent

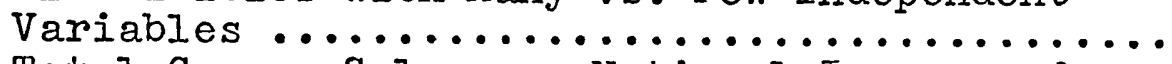

10- 7 Total Camera Sales vs. National Income and

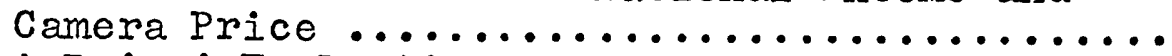

A- 1 A Priori Evaluation of Observations on

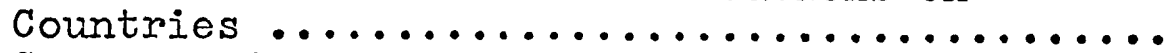

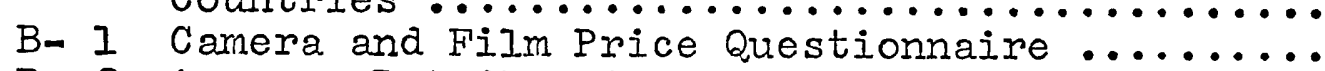

B- 2 Average Retail Prices of Cameras and Film by Country: $1966-67 \ldots \ldots \ldots \ldots \ldots \ldots \ldots \ldots . . \ldots$

B- 3 Sears Catalogue: Prices of Cameras and Film over Time: $1960-65 \ldots \ldots \ldots \ldots \ldots \ldots . . . \ldots$

B- 4 Data on Price Determinants $(i 960-67) \ldots \ldots . . . .$.

B- 5 Industry Sales: still Camera Units by Country

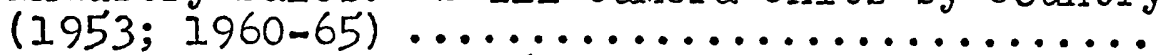

B- 6 Expenditures on Camera Goods by Househoids

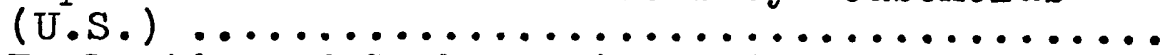

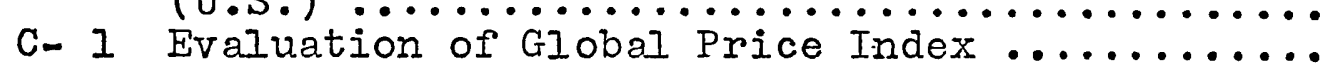

207

210

212

214

215

217

218

232

237

240

241

245

247

250

254 
Figure

I- I Developing Causal Models with Non-Experimen-

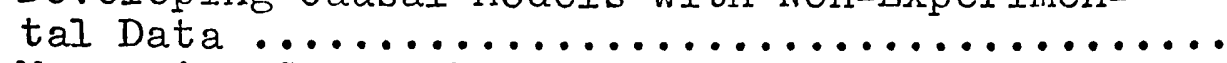

1- 2 Measuring Causal Relationships with a

5- I A General Classification Scheme for Data Sets....

6- I Camera Sales Forecasting Model: A Priori

6- 2 Camera Price Forecasting Model: A Priori ....... 102

7- I Camera Price Forecasting Model: Updated ....... 123

8- I Confidence Intervals for Estimates of Rela-

8- 2 Confidence Intervals for Estimates of Rela.

8- 3 Sales Forecasting Model (Assuming No Current

8- 4 Causal Model to Forecast Camera Säjes by Coun-

11-. I. Development of a Causal Model for Long-Range

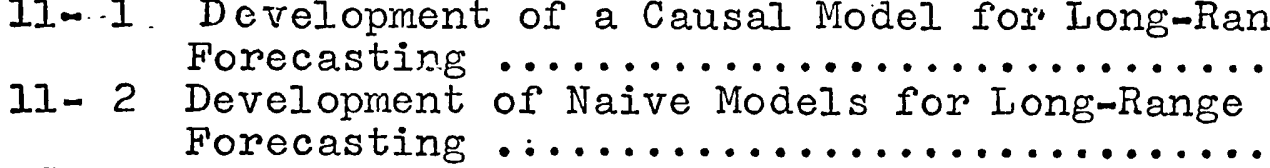

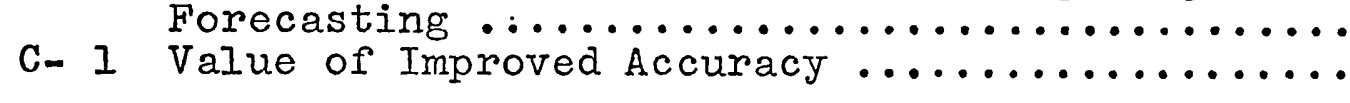

154

154

157

170

225

226

255 
CHAPTER 1

INTRODUCTION

Motivation

In recent years, there has been much interest shown in the development of long-range planning. The growth in the literature on this subject and the increasing number of. planning groups in industry attest to this interest. There has also been increasing emphasis on selling products in international markets. The following study represents one of many inputs to the long-range planning effort for a multinational firm. In particular, the concern will be with how to develop a model to provide long-range industry forecasts for each country in the market.

Long-range planning is primarily concerned with the question "given that firm $X$ can sell so much of product $Y$, what is the best strategy to follow?" Long-range forecasting is concerned with the input to the planning model--"how much of product $Y$ will firm $X$ be able to sell?" The industry forecast is considered by many to be the logical starting point in answering the latter question. How much firm $X$ can sell is partially dependent upon how much of product $Y$ will be sold by all firms.

The major contribution of long-range planning is that it enables a consistent and balanced growth of the organization. Even if the forecast of product $Y$ is relatively inaccurate, it is advantageous for the firm to have an explicit 
plan to guide the various sub-units in the firm. It does seem, however, that the accuracy of the long-range forecasts also has some bearing upon the value of the long-range plan. Since long-range forecasting models cost money to develop, one question that comes to mind is "how much is it worth to develop a more accurate forecasting model?"

By making a number of simplifying assumptions, it was possible to construct an example to demonstrate the value of improved accuracy in forecasting. The reasonableness of this example depends critically upon the reasonableness of the assumptions. As a result, it seemed. especially important to keep the example simple so that the reader might be able to alter the assumptions as he desires.

It was assumed that the firm is one of a large number of firms. Following from this, it was assumed that a given percentage improvement in the industry forecast would lead to a similar percentage improvement in the firm's forecast. Accuracy of the forecast was then interpreted as the agreement between the forecasted industry sales level and the actual sales level.I A measure of the accuracy of unconditional forecasts is desired. In other words, how well may industry sales be forecast in year $t+$ in based on information up to year t. Finally, it was assumed that the cost of change itself was negligible in this example.

IThe assumption of a large number of firms was necessary to minimize the problem of "feedback" (i.e. the forecast will presumable affect the actions by the firm which will, in turn, influence the total industry sales. If there are a large number of small firms, the influence of a single firm upon the industry will be negligiblel. 
A number of key factors enter into the evaluation of improved forecast accuracy. These factors include the size of the firm, the proportion of resources which the firm must commit now for a given year in the future, the extent to which accuracy might be improved, the dollar cost associated with forecast errors, the tax rate, and the time value of money. Subjective estimates were provided for each of these factors. to provide a ballpark estimate of the value of improved accuracy. ${ }^{1}$

a. It was assumed that the firm in the example has sales of $\$ 100,000,000$ per year. There are at least 500 firms in the U.S. with sales greater than this--so this assumption is not very restrictive. For convenience, it was assumed that the sales rate remained constant over the period of interest. Of this sales rate, it was further assumed that the firm earned ten percent profits. In other words, costs were 90 percent of sales.

b. The firm makes decisions now which affect costs in future years--e.g. plant location, size of plant, equipment, key personnel, long term contracts with suppliers and distributors, bond issues, union contracts, and research and development. It would be useful--but expensive--to examine each one of these decision areas separately. These estimates would also vary by industry and possibly even by firm. In this example, however, an attempt was made to provide averages covering all types of decisions in all types of industries.

The proportion of the (eventual) budget which a firm must commit for year $t+n$ is expected to drop off as $n$ increases. I estimated that $20 \%$ of the total costs encountered by the firm do not depend on any prior planning. It was then assumed that the curve representing proportion commitment. drops off exponentially (with the total area of the curve = 1.0). Column 2 of Table l-l summarizes these estimates.

c. The extent by which forecast error may be reduced depends, to a large extent, upon the level of accuracy achieved by current forecasting practice. If current practice is extremely accurate, little gain is possible. It would appear

$I_{\text {These verbal arguments were translated into a series }}$ of curves as shown in the Appendix, Figure C-I. The estimates of Table $1-I$ were then derived from Figure C-I. 
also, that the potential gain increases as the time horizon increases since there are generally larger changes taking place in the long-run sales rate. In view of these considerations it was assumed, very conservatively, that no improvements would be made in predicting the long-run rate of sales for forecast horizons less than five years. It was further assumed that the forecast error in year $t+5$ could be reduced by $10 \%$ (e.g. from a mean absolute percentage deviation of $30 \%$ down to $20 \%$ ); that in year $t+10$ the error could be reduced by about 20\%; and that for year $t+20$ and beyond, the error reduction could be $25 \%$.

It was assumed, for convenience, that the loss function was symmetrical-mi.e. the cost of underestimating (leading to an opportunity cost or to inefficient production) is equal to the cost of overestimating by the same percentage (and having excess resources). Column 3 of Table l-1 summarizes these estimates.

d. The dollar value associated with the forecast error would depend upon the particular decisions which utilize the forecasts. In this example, it was merely assumed that a percentage of the error in the commitment would be lost. This percentage would be rather high (perhaps 50\%) when the firm has no reaction time. As the time horizon lengthens, however, the firm gains flexibility in finding alternative uses for the commitment (or alternative means of production). At year $t+5$ only $20 \%$ of the cost of the misallocation would be lost and this falls off to $10 \%$ after 20 years. Once again, these estimates appear to be conservative. For example, excess manpower is rather hard to identify once it is there-as Parkinson ways "work expands to fill the time allotted". Column 4 of Table 1-I summarizes these estimates.

e. The time value of money was estimated at $10 \%$. This al so seems conservative since there is no "risk" associated with cost savings. A lower interest rate would make the example more dramatic.

f. Finally, a tax rate of $50 \%$ was assumed.

The present value of the savings for each year is indicated in column 6 of Table 1-1. The present value of the savings realized on commitments made in year $t$ for years $t+5$ to $t+20$ is $\$ 160,000$. This represents a continuing savings since more comitments are made each year. The present value of a continuous stream of savings of $\$ 160,000$ per year would be $\$ 1,600,000$ at a $10 \%$ rate of interest. 


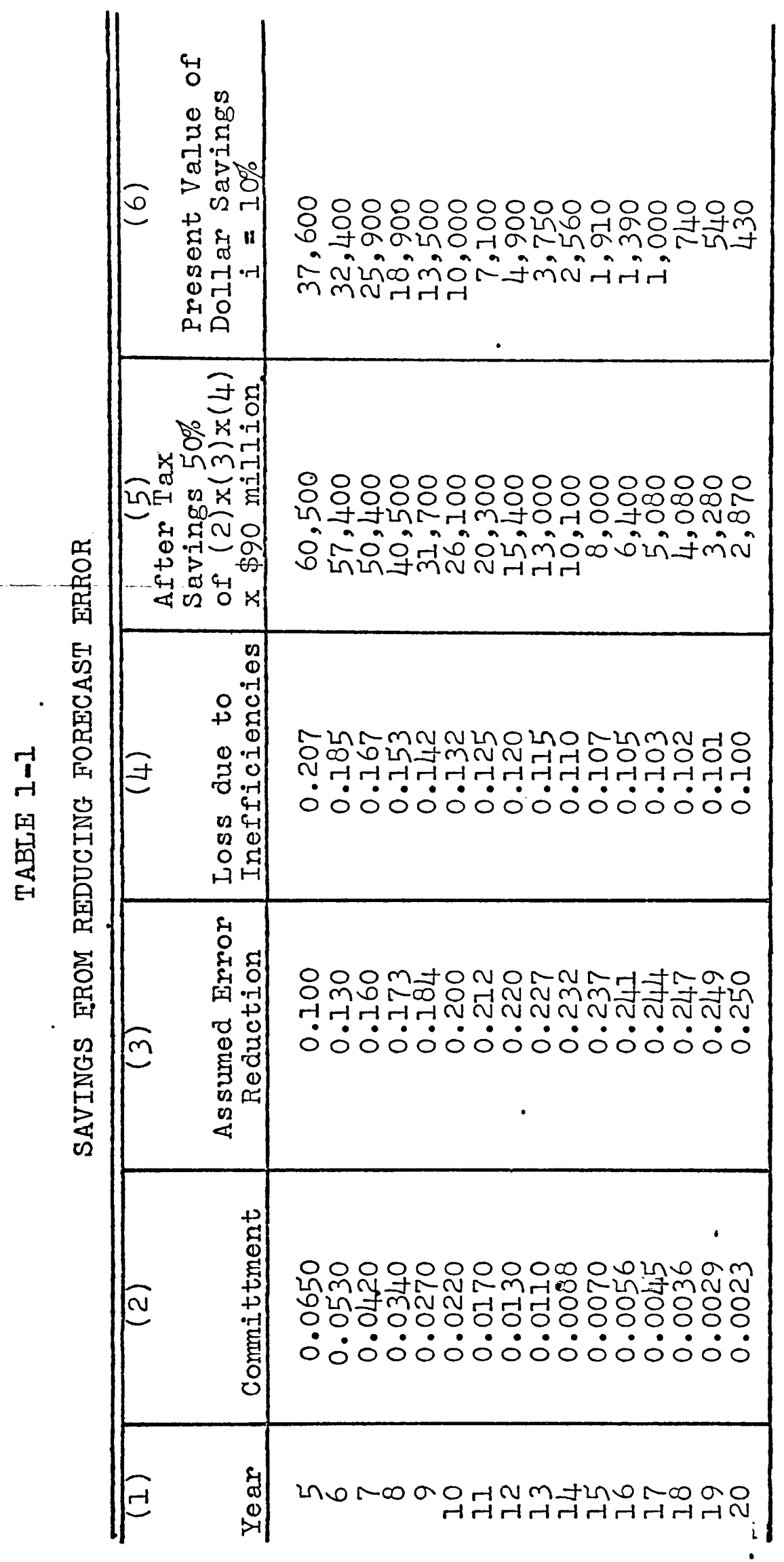


In conclusion then, the potential gain from improving the accuracy of the long-range forecast is roughly equal to one percent of the yearly sales rate. ${ }^{1}$ For a firm as large as General Motors this would imply a potential savings worth 200 million dollars.

\section{Objectives of the study}

Models for long-range sales forecasting may be classified under two categories-mnaive and causal. Naive models attempt to forecast without any presumptions as to why the rate of sales may change. Most commonly, models under this category rely solely on historical sales data for the item to be forecasted. Causal models also utilize historical sales data but they go beyond this to utilize additional variables which might cause changes in the sales rate. Key assumptions of the causal model approach are that the important causal relationships may be adequately measured and that the causal variables themselves may be forecasted with accuracy.

Existing literature on long-range forecasting and my experience in industry lead me to believe that most companies rely on the use of naive models for obtaining long-range sales forecasts. Naive models are generally much cheaper to develop and, in fact, there is little evidence that causal

I More optimistic assumptions--e.g. considering an interest rate of $6 \%$, savings from years 2 to 30 , and a committment that falls off exponentially from $10 \%$ leads to a present value savings equal to almost ten percent of one year's sales volume. 
models would lead to better unconditional forecasts. 1

A primary objective of this study is to examine whether causal models lead to better long-range forecasts of international markets than do naive models. Concern will also be given to analyzing which aspects in the development of causal models are most important.

Data on the international market for still cameras will be used. This product was chosen as a result of the author's previous experience in this industry.

\section{Developing Causal Models}

The camera model is typical of many situations in the social sciences in that experimentation is either impossible or, at least, extromely expensive. At the same time, a substantial amount of secondary or non-experimental data is available. The extreme position is held by some that one cannot. infer causality from non-experimental data (e.g. see Brownlee,1965, page 454). This position, however, puts the cart before the horse. While the general sweep of science is to infer causality from empirical data, the position of the individual scientist is to use data to test given causal hypotheses. In other words, the theory precedes the data and what the individual scientist examines is whether

IBy unconditional forecasts we mean that sales for year $t+i n$ mast be forecasted on the basis of information only up to year $t$ (year $t$ being the current year). 
or not the data are consistent with the theory. I Now whether he uses experimental or non-experimental data is beside the point. Each has its own advantages and disadvantages. In general terms, the experimental approach increases control somewhat while sacrificing generality and it is the other way around for the non-experimental approach. What does it mean to say that the data are consistent with the theory? The notion of hypothesis testing was the first major breakthrough to answering this question. One compares the results of model $X$ with the results of a null hypothesis to see whether model $X$ yields results which are "significantly different" from the null hypothesis. Significantly different is interpreted in a statistical sense. How likely is it that the null hypothesis is true in light of the data? If the likelihood is high that the null hypothesis is true, then one accepts the null hypothesis as the explanation since, presumably, the world is much simpler that way and there are advantages to following the dictates of the null hypothesis.

This classical view of hypothesis testing has apparently been very useful to the development of science--and

IFor a discussion of these points see R. G. Francis (1957). Also see Koopmans (1947) who contrasts Kepler's work on the planetary system with the work of Burns and Mitchell on business cycles. The Kepler approach started with theory and revised the theory in the light of the data. Burns and Mitchell, on the other hand, are empirical and formulate no prior hypotheses. Koopmans concluded that the Burns and Mitchell approach was highly inefficient. 
most notably, to the experimental sciences. From the viewpoint of the decision-maker, in contrast to the scientist, severe problems exist, I First, the decision-maker must rely on a deductive rather than inductive approach. Decisions must be made and the manager must deduce the best course of action from his current information. His interest is in making better decisions. Interest in the development of theory is useful only in so far as it leads to better decisions. The second major problem is that the decision maker has interest in defeating only meaningful null hypotheses. The typical null hypothesis used by classical statisticians is that "nothing is related to anything else". This hardly lends itself to meaningful action if accepted and, in the typical case, 2 is hardly worth rejecting. In other words, concluding that none of the factors examined are significantly related to the sales of cameras does not add to knowledge about how to make decisions. 3 Finally, the notion of statistical significance has only a very indirect relationship to the cost-benefit aspects upon which the decision rests. As a result of the above problems, the field of Bayesian statistics is an area of growing importance in the area of

Isome of these problems also exist for the scientist. See Bakan (1966) for an excellent review of problems associated with the use of statistical significance as a criterion.

2This implies, of course, that there is some objective for doing the research. We have nothing to say here about research which has no objectives.

3unless, of course, the study refutes common practice. Common practice could be regarded as the null hypothesis. You would like to retain it unless evidence to the contrary is strong. 
objective-oriented research. The Bayesian philosophy does not view each study as an isolated event. Rather it calls for a recognition that previous knowledge exists and that one should make use of this knowledge. In very general terms, the previous knowledge takes the place of the sterile null hypothesis. New information is used to update the model based on previous knowledge.

The Bayesian philosophy may be extended to include not only the updating of a given model but also the comparison of rather different models. Platt (1964) claims that this approach, which he calls the "method of multiple hypotheses," is the second great advance in the scientific method (the first being hypothesis testing). Such an approach, he claims has additional advantages in that it redirects the researcher to be problem oriented rather than methods oriented and that it prevents him from becoming attached to his own particular theory.

The Concept of a Causal Relationship

The use of causal relationships is a focal point of this study. The use of the term "causal" is intepreted in the common-sense notion--i.e. the causal variable, $\mathrm{X}$, is one which is necessary or sufficient to the occurrence of an effect $Y$. $X$ must also precede $Y$ in time. ${ }^{I}$ This interpretation seems

IBeardsley (1950, pp. 439-73) provides a rather readable discussion on the topic of causality. Wold and Juréen (1953, Chapters 1 and 2) relate causality to the use of regression models and Blalock (1964) relates causality to the use of non-experimental data. 
to be both meaningful and useful despite the controversy to which it inevitably leads. The term "causal" appears to be so controversial that many researchers avoid the issue by renaming the concept e.g. functionally related, structural estimate, stimulus-response, dependent upon, determinant of, etc. While most elementary statistical texts warn that "correlation does not prove causation" they do not go on to say just what does prove causation. But in the sense in which "prove" is used above, nothing proves causation. There are, however, a number of ways in which one may test whether a causal relationship is consistent with reality. These include an examination of data to determine:

a. Reliability. Does the relationship show up in repeated measures in similar situations? Does variam tion of irrelevant factors have any effect upon the measured relationship?

b. Validity. Does the relationship measure what it purports to measure? This may be examined by the use of alternative approaches. For non-experimental situations, it is important to examine situations which are as different as possible. In this way one may guard against bias or spurious relationships. As examples of "different approaches" one could list the uses of differing types of data, statistical models or operational measures. Interest here lies not only in determining whether it is legitimate to accept a causal relationship but also in determining the limits under which the relationship holds.

c. Time relationships. The causal variable should precede the events which it causes.

d. Covariation. The causal variable and its effect should vary in a systematic manner.

An attempt should be made to demonstrate that the causal relationship satisfies each of the above tests. Finally, the most important test of a causal relationship should be made-does it provide a better explanation than any alternative model? 
The Use of Non-Experimental Data

The measurement of causal relationships by means of non-experimental data contrasts somewhat with the case for experimental data. Experimental data have advantages over non-experimental data in that the researcher can a) ensure independent variation in causal factors and b) control for variation in other factors by controlling the experimental situation. I Lack of variation in the causal factors means that no estimate may be obtained of causal relationships. If variation exists but is not independent of other variables, there are problems of estimating causality. ${ }^{2}$ Finally, if there are other factors which vary, they may cause measurement problems.

Non-experimental research must find ways of compensating for the above deficiencies. One means of compensating is to utilize different data sets--i.e. different types of data. It is advantageous to find data sets in which the causal factors show substantial amounts of variation. It is also desirable to utilize different data sets since the sources of bias may be expected to differ among them--thus highlighting the presence of bias.

Subjective data are of particular importance for non-experimental research since the necessary objective data are not always available. This study made extensive use of

$I_{\text {Both the experimental and non-experimental approaches }}$ draw upon the use of randomization of sample units and measurement of other factors as means of controlling undesired, variation.

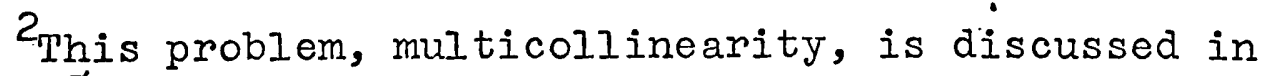
Chapter 5 . 
sub.jective data to select important variables, to estimate causal relationships, to compensate for expected biases in data sets, and to modify observations in certain data sets. Figure 1-2 outlines the approach which was used in this study to measure causal relationships.

For contrast to Figure 1-2, a "straw-man model" is provided in Figure $1-1$. This represents a rather common form for published econometric research.

\section{FIGURE 1-I}

MEASURING CAUSAL RELATIONSHIPS WITH A TYPICAL MEASUREMENT MODEL

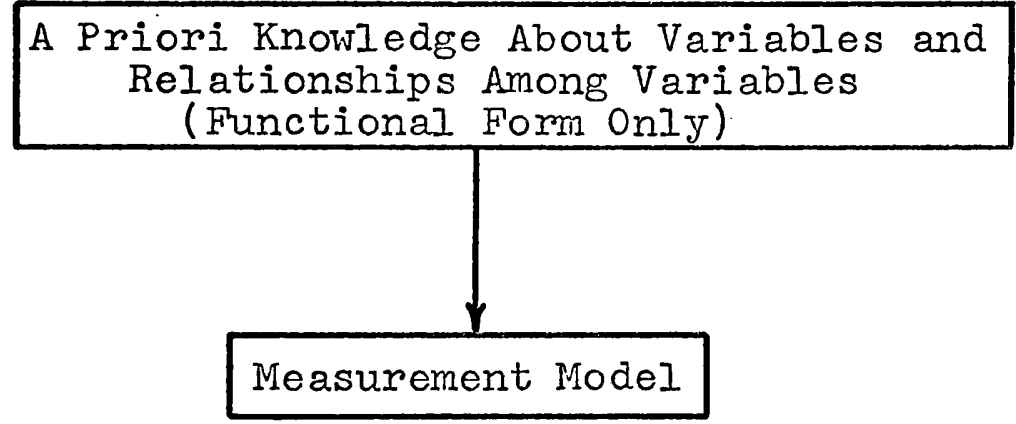

The outline in Figure $1-1$ omits many of the components of Figure 1-2. The implied assumption is that either the other components are not really. important or that other researchers will come along, integrate the bits and pieces and utilize this work in their own study. In fact, this is what was attempted in the camera study. Use was made of various studies which followed the form of Figure 1-1. (Some studies were found which omitted even the first block in Figure I-I e.g. Rayco Seat Covers, see Chapter 2.)

It is not clear why so much work of the Figure 1-I 


\section{FIGURE $1-2$}

DEVELOPING CAUSAL MODELS WITH

NON-EXPERIMENTAL DATA

Examples from Camera Sales Model

Step I

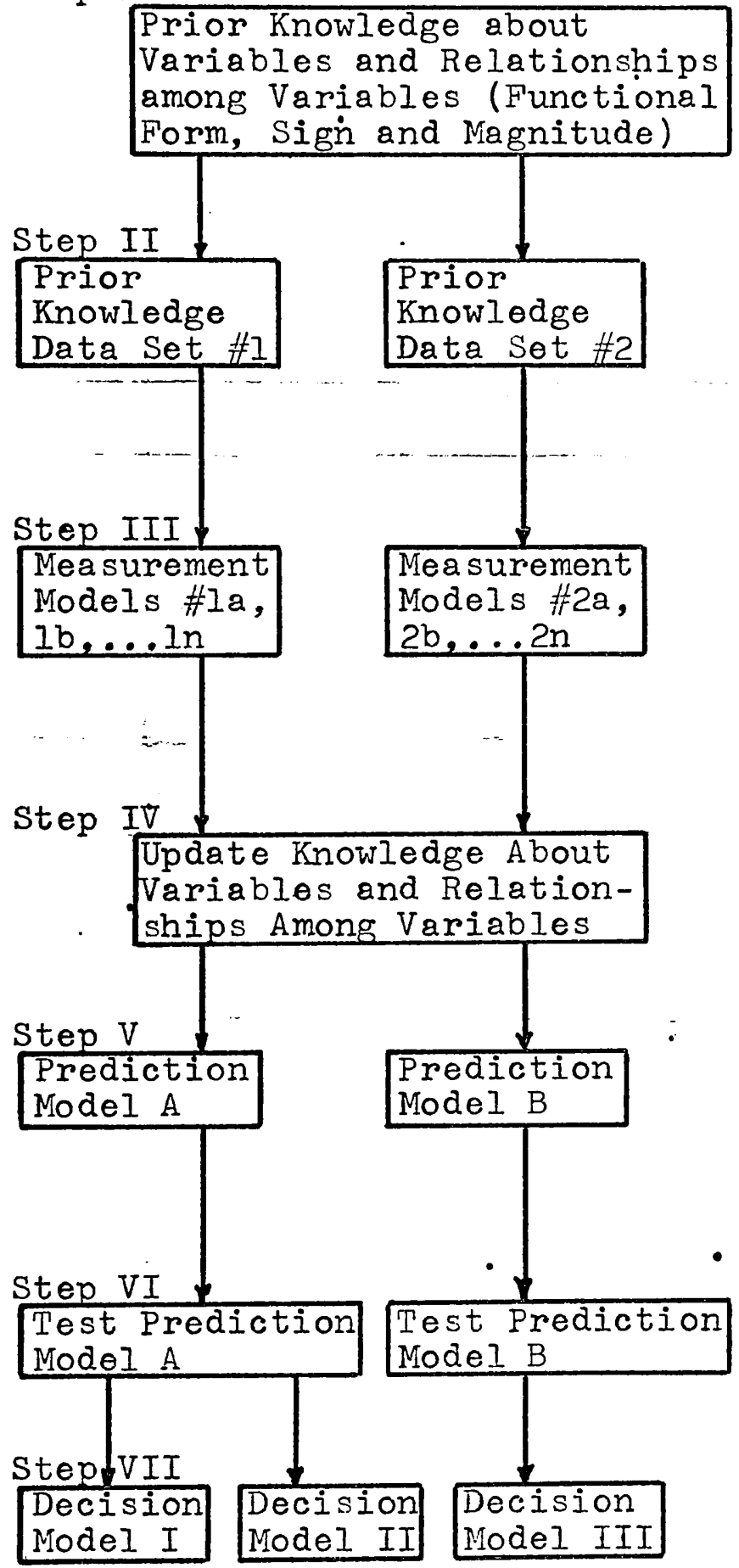

Prior Model as Outlined in Figure 6-I Based on Previous Studies, Theory and Subjective Analysis

Prior Knowledge About Observations and Prior Specification of Biases dive to Errors in Variables and Excluded Variables-fChapter 7)

Various Regression Models on International CrossSection, Longitudinal Model Across Countries and Household Survey Data (Chapter 7)

Update Relationships of Camera Price and Ability to Purchase with Sales of Cameras (Chapter 7)

Long-Range Sales Forecasting; Forecasting in Cases with No Historical Sales Data; Control; Large Changes (Chapters 8 and 9)

Backcasting 1954; Forecasting for Validation Sample (Chapter 8)

Not Considered: Would include Decisions on Investment, Plant Location, Hiring, Financing, etc. 
variety exists. A possible hypothesis is that such research is a generalization of the procedure used in experimental research. In experimental research the researcher is forced to utilize previous knowledge in structuring the experiment. Generally, the experiment is being run to test a particular decision model (e.g. does the addition of fertilizer $X$ to soil $Y$ increase the yield of type $Z$ wheat?). The situation mirrors Figure 1-I. The measurement model conforms directly to the predictive model. Since the experimenter can guard against the effects of bias and can ensure sufficient variation, Figure $1-1$ is adequate and the steps of Figure $1-2$ may be unnecessary.

The generalization of Figure I-I to non-experimental situations is rather dangerous. Seldom is one able to find data which correspond to the predictive model and in which the factors of interest display a significant amount of variation.

Figure 1-2 is used to overcome many of the problems encountered in non-experimental research. In order to provide a more complete description of and rationale for the use of Figure 1-2, the key aspects of this outline are considered below.

Prior Knowledge About Variables and Relationships (Step I) For any one study to claim that causal relationships have been measured, it is necessary that causality be postulated before the data are analyzed. In the camera model it was postulated that an increase in the ability to purchase causes an increase in camera sales. If this is a good 
representation of the world then there are many types of data by which this relationship may be measured.

In order for models to build upon previous research it is necessary that the a priori specification of causal relationships fully utilize these previous findings. This implies not only a prior specification of the important variables but also a specification of the relationships among variables. The latter should include the specification of the functional form of the relationship (e.g. constant elasticities over the relevant region), of the signs of the relationship (an increase in ability to purchase causes an increase in camera sales), of the magnitude of the relationships (the price elasticity of camera sales is expected to be -1.4), and of the confidence which we have in the prior knowledge (the price elasticity should fall within the region from 0.0 to -3.0 ).

Naturally one might expect that the prior knowledge in some situations is almost negligible. For example, when there is great uncertainty about what variables are important the prior specification may have little to say about the relationships among the variables. As the study in a particular area progresses, however, it becomes possible to develop more complete prior specifications. In experimental work, the process of utilizing previous findings is very explicit. In non-experimental work it is not so explicit. As a consequence, published studies of non-experimental data. often fail to build upon previous knowledge except for the identification of important variables, and, to a lesser extent, 
the functional form (the automobile studies are typical in this respect).

It is the position of this thesis that most economic problems (and certainly. most sales forecasting problems) have been well studied. There is wide agreement that measures of price, income, and market size are important. Rather than rediscovering these facts, then, it is important to incorporate the knowledge into the current problem and to do so at as detailed a level as possible. Furthermore, to increase the probability that this information is independent of the data collected for the current study it is important to utilize this subjective data on an a priori basis.

The stress upon the use of subjective data is not new. Most practicing forecasters claim that the subjective data are an important input in their approach. ${ }^{I}$ That subjective data be used on an a priori basis is much less common, however. Theil and Goldberger (1961) present one of the few published studies which goes so far as to provide a priori estimates of the magnitudes and standard errors of causal relationships. 2

The subjective data come from many sources. In the camera study, knowledge is obtained from study of other consumer durables (e.g. refrigerators, automobiles), from

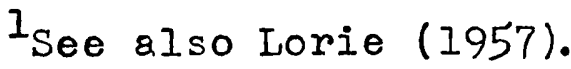

2 Ferber (1956) advocates the use of a priori judgment as a result of his evaluation of some forecasts which did not utilize such information. 
survey information on camera owners, from general economic theory, and, when all else fails, from subjective impressions. The a priori specification is particularly important in cases where there are many important causal variables. Non-experimental data do not generally provide independent variation for each of these variables (thus the problem of multicollinearity). The influence of some variables may be accounted for by means of a priori knowledge. If a factor is expected to have an important influence upon the data set, an attempt should be made to account for this influence.

The Use of Many Data Sets (Step II)

As a substitute for control, an attempt may be made to randomize all sources of variation. One way to accomplish this in non-experimental research is to utilize different data sets. Data sets may differ with respect to the type of data, the aggregation involved, or the composition of the sample. An additional and fairly obvious advantage is that more data sets provide more information.

The selection of useful data sets represents an important step in the development of the model. A structured approach will be presented later to assist in the search for such data sets.

The Measurement Models (Step III)

In estimating causal relationships attempts will be made to utilize as mach information as possible. Since the process of evaluation will be separated from the process of 
measurement there will be no need to be restricted by the mules applicable to statistical testing. Loosely stated, the philosophy is that anything goes in estimation as long as the method is fully disclosed and replicable.

Relative to the other components of the modeling process, the development of estimation techniques is most advanced. This is likely to be the case.for some time in the future since estimation problems receive most of the attention of econometricians.

Extensive use will be made of regression models in this study. While there are a substantial number of restrictive assumptions made for the use of regression models, this approach does provide a powerful and relatively low cost method for dealing with situations in which there are many causal variables and only a moderate sample size. As long as a heavy reliance must be placed on aggregate economic data, i.t appears that regression models will be useful.

Other measurement models, primarily multi-level cross classifications, offer substantial benefits if large samples of micro-data are available. For the camera model, this would imply the existence of data by individual (or household) which examine camera purchasing behavior. Such data were not available for this study.

A common assumption which is made by measurement models is that the estimates are unbiased. This did not seem to be a reasonable assumption in the camera study primarily due 
to the effect of measurement error in the independent variables. To compensate for the possibility of serious bias two steps were taken. The first was to estimate the expected bias on an a priori basis. The second, mentioned above, was to attempt to randomize the sources of bias by using different data sets.

Combining Estimates from Various Sources (Step IV)

In cases where estimates of a single parameter are obtained from more than one measurement model, it is necessary to use some method to obtain a single weighted estimate. Ideally, the weighting should reflect our degree of confidence in each pitce of information. This implies that one should be concerned about both the validity and reliability of each estimate. The classical approach assumes away the problem of validity and weights each estimate by a measure of reliability. This study uses a modified Bayesian approach in an attempt to recognize problems with both validity and reliability.

The Prediction Model (Step V)

It is important to distinguish between measurement models and prediction models. Measurement models are used to measure one or more causal relationships while prediction models utilize estimates from measurement models to provide predictions in a given situation. This distinction is especially important in non-experimental research where it may be difficult to find a measurement model which corresponds closely to the prediction model. 
Prediction models may differ from measurement models in a number of ways. Different causal factors may be important--depending, for example, on which factors are expected to change in the prediction model versus which factors did change in a given measurement model. The effects of errors in the independent variable $\$$ may also differ between the prediction model (where the independent variables must of ten themselves be forecast) and the measurement model (where the independent variables are usually based on direct measurement).

Testing the Prediction Models (Step VI)

How well does the model predict? The classical null hypothesis which assumes that no prior information exists (e.g. nothing is related to sales) is not a useful model for most problems in economic forecasting. The strategy of comparing a set of reasonable models offers far more promise. One of these models should, hopefully, be representative of the best in current practice or theory.

Once again, the distinction between measurement models and prediction models must be stressed. Satisfactory performance in a particular measurement model may not have any relevance to prediction. In this study, a linear and symmetrical loss function will be used to evaluate errors of scale in country forecasts. This means that the cost varies in direct proportion to the size of the loss; that overestimating is no better and no worse than underestimating; and that our interest is in percentage rather than abgolute errors. 
Decision Models (Step VII)

One research strategy is to. start out with the objective of dereloping models to make particular decisions. This has the advantage of making it easier to judge the value of the resulting prediction models and also provides a clear focus for the research effort.

The approach in this study does not go to such a detailed level. Instead, some prediction models are developed which, historically, appear to have been used in making numerous decisions. The fact that specific decisions are not considered does make it more difficult to judge the value of the predictive models. On the other hand, the emphasis upon prediction does make this study somewhat easier to evaluate than those econometric studies which restrict their interest to measurement.

\section{Summary}

The importance of the trends toward long-range planning and toward international marketing are apparent from the literature. One aspect of the long-range plan, the longrange market forecast, is singled out in this study. The importance of improved accuracy is argued by means of a very simple example. Potential gains appeared to be substantial.

The primary objective of this study is to examine whether causal models may lead to better long-range forecasts of international markets than do naive models. Data on the international markets for still cameras will be used to 
examine this hypothesis.

The key aspects of developing causal models from nonexperimental data were discussed. This situation was contrasted to the case where experimental data are available. Figure 1-2 provided a sumrary of this discussion. Succeeding chapters follow the outline of Figure 1-2.

The discussion of the key aspects of the approach to be used in this study should have made it apparent that this study will not be neat from a statistical viewpoint. With the exception of the estimation techniques used in measurement models, the techniques are not well developed. The guiding philosophy has been stated well by Tukey (1962)-- "Far better an approximate answer to the right question which is often vague than an exact answer to the wrong question which can always be made precise." 


\section{A REVIEW OF THE LITERATURE}

In this chapter, references which were most useful in a general sense will be cited. The literature is vast and the survey here makes no pretense to be a comprehensive review.

Price (1963) has commented on the inability of researchers to go beyond their particular speciality in their reading of the literature. They only have time to communcate with about 100 other researchers. In addition, the language is often so specialized in each field that it is difficult to understand people from other specialties without an inordinate amount of effort. One of the objectives of this thesis is to integrate much of the previous work on long-range forecasting so that it is available to researchers in marketing. It is interesting to note that cross-references in the literature surveyed for this thesis virtually never go outside of the researcher's special field.

\section{General Works on Methods}

Probably the work which was most useful in the development of this study was Blalock's Causal Inferences in NonExperimental Research (1964). This book is short, well-written and discusses a number of relevant problems associated with non-experimental research. From the point of view of specific methods, Johnston's Econometric Methods (1963) and Ferber and Verdoorn's Research Methods in Economics and Business (1962) 
were very useful. The former covers topics which have been discussed in a number of textbooks. The latter covers topics which are not so commonly found but which are important for data analysis.

\section{Long-Range Forecasting}

While the problem of long-range forecasting has apparently been studied by many, this fact is not evident from the published literature. Much of what has been done never gets published. In those studies which are published, the data are often disguised to protect the innocent so that the value of the study is limited (e.g. Quandt, 1964). On the other hand, there is a vast amount of literature which is not directed to long-range forecasting but which is relevant to certain aspects of the problem. Jantsch (1966) lists a bibliography of 413 items which are pertinent to the related area of technological forecasting; the literature on economic demand studies is substantial--Wold and Jureen (1953) Iist about 280 references; and Rogers (1962) Iists about 500 references which are pertinent to the related field of diffusion of innovations. In addition, there is a vast literature in econometrics which is more recent than that cited by Wold and Jureen.

A substantial amount of survey type literature exists on business forecasting-a small proportion of which is relevant to long-range forecasting. Current forecasting practices have been surveyed by Butler and Kavesh (1966) and by the National Industrial Conference Board (1963). Related 
to this are a large number of how-to-do-it books of which the more recent have been Wolfe (1966), Reichard (1966), and Murdick and Schaefer (1967). This literature is, in general, directed to the manager and would seem to be of little help to technicians who engage in long-range forecasting.

The increasing interest in long-range planning might be expected to lead to an increase in the publication of studies on long-range forecasting. Casual observation indicates only a slight tendency in this direction. Roos (1.957) provided forecasts for the U.S. up to 1975. Stone, Brown, and Rowe have done a similar (but more limited) forecast for Britain to 1970. Houthakker and Taylor (1966) provide forecasts for major expenditure categories in the U.S. up to 1970. In general, however, long-range forecasting receives little emphasis relative to the rest of the long-range planning problem.

The forecasts mentioned in the previous paragraph relate to broad categories of expenditures. Studies of narrow product categories have been less cormon--possibly because the data are not so readily available. The big exception here is automobile studies as a substantial number of studies have been made of the U.S. demand for automobiles.

Two studies of specific agricultural products are especially pertinent to the current study. Goreau's (1957) study "Long-Range Projections of Food Consumption" was an 
international study which was similar to the study reported here in many respects. Demand Analysis by Wold and Jureen (1953) provided long-range forecasts of food consumption for Sweden. An evaluation of sorecast accuracy demonstrated that their econometric model provided better forecasts than that provided by a naive extrapolation. It is important to note, however, that large changes had been introduced into the market by the government. They removed rationing and the causal model had been able to capitalize on information about this change.

The Evaluation of Forecast Accuracy

of those studies which had long-range forecasting as an objective, very few were concerned with the evaluation of the accuracy of the forecasting model. Most studies were concerned about the ability of the model to fit historical data-generally by use of the coefficient of determination $\left(R^{2}\right)$. Ferber (1956) questioned the relevance of this criterion. He concluded that, in the empirical studies which he examined, higher $\mathrm{R}^{2}$ were not related to better forecasts.

A study by Rosenzweig (1957) is of particular interest here as one of the main objectives of this study was to obtain a long-range forecast. While Rosenzweig evaluated a number of models only on the basis of the fit to historical data, it happens that his eleven year forecast was for 1965. The results are now in and an evaluation can be made of Rosenzweig's models. 
Rosenzweig suggested three different models which might be used to forecast the demand for aluminum in the U.S. in 1965 (demand in 1954 was 3.0 billion pounds):

Model \#I was a simple trend projection. Data from 1910 to 1954 showed a 9.9 percent annual increase. An extension of this trend indicated U.S. aluminum consumption for 1965 would be 8.5 billion pounds.

Model \#2 was based on a regression of aluminum consumption on GNP from 1919 to 1954. The $R^{2}$ for this model was over $98 \%$. Since numerous predictions of GNP were available for 1965, Rosenzweig selected one of the more conservative predictions. This yielded a forecast of 8.4 billion pounds for 1965.

Model \#3 was based on separate estimates of output and aluminum usage penetration for end use categories-packaging, transportation, military, building materials, electrical, and consumer durables. Recent rates of growth and "expert" subjective estimates were made for each category. By summing over all categories, a prediction of 8.9 billion pounds was obtained for 1965 .

The reader may wish to consider which one of the three models above would lead to the best forecast before he reads further.

Rosenzweig himself seems to prefer the regression model (\#2) although the justification for this selection is not entirely clear. In fact, this model did provide the best forecast. According to Metal Statistics, 1966, the U.S. consumption of aluminum in 1965 was 7.2 billion pounds. It should be noted, however, that Rosenzweig used a GNP forecast of $\$ 480$ billion for 1965 (in 1953 dollars). The actual GNP was $\$ 543$ billion. ${ }^{1}$ Had Rosenzweig been correct

${ }^{1}$ It is also interesting to note the accuracy of the ten year forecasts of GNP. Rosenzweig's estimate of a $34.5 \%$ increase in GNP was, he said, conservative in the light of several estimates for a $50 \%$ increase. These median forecasts were surprisingly close to the actual increase of $52 \%$. 
on his GNP forecast, the regression model would have led to the poorest forecast.

On the basis of the studies which we have been able to find, the evidence that causal models lead to improved forecasts is rather modest.

\section{Evaluation of Market Potentials}

In the late 1930 's there was a fair amount of interest shown in the evaluation of geographical market potentials. Brown (1937) compared the use of a regression model with nine other approaches to explain variations among sales of 12 products in states of the U.S. The regression model provided the best fit to the data. Cowan (1936) recommended the use of regression models for control purposes--e.g. how many salesmen should be placed in each region? Weld (1939), who claims to have been the first to use multiple correlation to identify sales potentials, argues that multiple correlation had been very useful in evaluating market potentials.

In each of the above publications, the implication was that one should experiment with a number of possible explanatory variables and select the model which provides the best fit to the data. A certain disdain seemed to exist for the use of subjective information.

Since this brief interest in the late 1930 's the publications have apparently dropped off. However, judging from my experience and from the "how-to-do-it literature", it appears that regression models are now widely used for evaluating market potentials. It is not clear whether the state of the 
art has improved since the late 1930's. Hummel (1961) reports an attempt by the Rayco Seat Cover Company to estimate market potentials: This case leads to some pessimism on the progress of the past twenty years.

In the Rayco case, 300 variables were selected to relate to automobile seat cover sales per square mile. By plotting each of the 300 variables against sales for each of the 150 sales offices in 51 cities it was possible to throw away 226 variables which showed little relationship to sales. A stepwise regression was then man to select the best 37 variables. This model was shown to provide an excellent fit to the data-which wasn't surprising. The problems with this non-theoretical approach are serious. An attempt was made to examine the power of such an approach in this study.

It seems likely that regression models are currently being used to evaluate international markets. The more common means of evaluation, however, would appear to be the rule of thumb that markets for the firm exist where industry sales are high at the current time. Obviously, this is not the only rule of thumb since one does observe that new markets open up in various countries. 


\section{A CONCEPTUAL MODET}

The term "conceptual model" implies two things. First that the concepts or higher order variables are described and, second, that the relationships among these concepts be described. This chapter provides a rationale for the use of conceptual models and then presents a model for use in forecasting camera sales.

\section{Motivation}

A number of advantages result from the structuring of conceptual (as contrasted to operational) models. The most obvious advantage is parsimony or the ability to summarize a great deal of information in a very short statement. This parsimony, in turn, is useful in communicating the nature of the model and also in assisting people to deduce results in new situations.

The a priori specification of a conceptual model, in particular, leads to a number of benefits. It enables one to utilize previous findings in the most efficient manner; to ensure that the subjective or outside information provides an independent input to the model; to simplify the problem so that it is of a manageable size; and, finally, to expand the researcher's outlook on operational means for testing the model. As an example of the latter, the use of a higher order concept such as "ability-to-buy" suggests more operational measures (e.g. income, standard-of-living, price, wealth) 
than the lower level concept "income".

The stress upon the development of conceptual models is especially important in non-experimental research. Seldom does one find exactly the type of data in which he is interested. Rather he finds vast amounts of data collected by other people for a variety of reasons. Some guide is required to assist him to systematically sort through these data to pick out those items relevant to the problem and to enable the integration of this diverse information. There are many ways in which the current study might be structured. A substantial amount of literature exists in which various conceptual models are proposed for use in forecasting--as in the breakdown into initial, replacement, and multiple ownership or the use of priority patterns for demand of durables (see Brown, Buck, and Pyatt, 1965). The key points to make, however, are that a conceptual model be developed, that it be done prior to the analysis of the data in the study, and that it be explicit and detailed.

\section{Basic Dimensions of the Model}

Some of the key dimensions of the study are discussed in this section. The boundaries depend primarily upon the objectives of the study but also upon the type of data which are available, and upon the desire to limit the size of the problem. 


\section{Planning Horizon}

This study will have a planning horizon of from roughly 5 to 15 years in the future (the example in table: 1-1 indicated that the years 16 to 20 accounted for only $3 \%$ of the cost savings over the period from 5 to 20 years). In considering this long-range horizon, we are explicitly ruling out sales variations resulting from short term factors. This is not to imply that short term variations are unimportant (in fact, year to year variations appear to be very large judging from trade and production figures). The objectives of the study do not require a study of short run variations. There is also a substantial gain in terms of analytical convenience which comes from ignoring short-run factors.

The analytical convenience of ignoring short-range factors comes from two sources. First, the cost of examining the relationship between short run causal factors and variations in the camera sales rate would be very high; and, second, there is serious doubt that the values of the shortrange factors could be forecast with any useful degree of accuracy for periods from 5 to 15 years in the future.

For purposes of decision making it may be useful to have information on the probable range of forecast values for camera sales. In this sense, then, it is important to take account of the variation introduced by the short-range factors. This variation could then be superimposed upon variations expected in the long-range forecast. Only a forecast of variation is required, however; there would be 
little concern over how the short-range factors affect the expected value of sales for year $t+n$.

The concern over long-range sales forecasts combined with the fact that there are many firms in the camera industry make the problem rather simple if viewed under the wellknown conceptual framework in economics--supply and demand. Under these conditions it may be assumed that there is no relationship between price and the number of cameras which firms are willing to supply. This yields a horizontal supply curve when viewed on the price-quantity graph. ${ }^{1}$ Further consideration will be given to how reasonable this formulation is in Chapter 6.

\section{Product Class}

Still cameras were selected as a result of the author's past experience in the field. By still cameras we mean any portable device for making permanent two-dimensional visual fixed images of three dimensional objects.

For studies in long-range forecasting it might be useful to define the product in terms of the need which it satisfies for the consumer. By focusing on the need, alternative means of satisfying this need may be more easily identified. It seems apparent from survey data that still

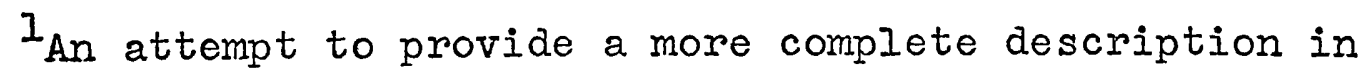
terms of the supply-demand framework did not seem to add to this presentation. In fact, it seemed just as useful and less confusing to ignore this framework altogether in this study. This is largely a matter of taste. 
cameras are used to provide permanent visual records of, primarily, family activities. From this approach, it is immediately apparent that movie cameras provide a close substitute for still cameras. In addition, video tape recorders might be expected to become a strong substitute in a few years (Printers Ink, 1966). The problem of drawing a sharp dividing line for the product class is not easily solved. It appears, however, that the definition presented in the preceding paragraph is broad enough so that the effects of substitute products will not be great over the current planning horizon of up to 15 years.

\section{Sales Measure}

The decision was made to forecast unit rather than dollar sales. Unit sales would seem to be the more useful first step in the industry forecast since most production and distribution decisions must have a unit sales forecast. MacGowen's (1952) survey indicated the vast majority of manufacturers prepare forecasts first on the basis of physical rather than dollar volume. This also seems true for the photographic industry.

The unit sales measure does not distinguish among cameras in terms of price class, type, new vs. replacement, or, as was mentioned, end-use. All cameras are created equal for this study. The data were not available in more detail. (Even if they had been, such breakdowns would have seriously complicated the analysis.) Sales of new cameras to final consumers will be considered. 
Market

As stated earlier, this study is concerned with providing a forecast of the international market. Forecasts are desired of sales by country. The prime objective will be to obtain estimates of the scale of operation in each country.

\section{Causal Variables for the Sales Model}

Three major factors were hypothesized to be important for the long-range forecast of still cameras-market size, ability to purchase, and consumer needs. Similar models have been widely mentioned in the how-to-do-it literature.

For market size, particular attention will be paid to the identification of potential bujers for cameras. Such an approach appears to be widely used by marketing managers but is not so common in econometric studies (except in the food studies). In most econometric studies, it is held to be sufficient to merely put sales on a per capita basis. Ability to purchase refers to the ability of each potential buyer to purchase cameras. This concept has been broken down into four lower level conceptual variables:

Economic Ability to Purchase Goods--What is the purchasing power of each purchasing unit?

Price of Cameras--What is the cost of buying and maintaining a camera in money terms? (Assume constant quality.)

Availability of Cameras--How much effort is required by the potential buyer in order to buy and maintain the camera?

Knowledge of Cameras--Does the purchaser know what to buy and where to buy? This would be a function of selling effort as well as personal communication. 
The concept of consumer needs may also be stated in terms of four lower level concepts:

Ownership--.Does the purchasing unit own a camera(s)? If, so, what are the capabilities of this camera(s)?

Quality of Cameras--What needs does the camera serve and how well does it serve these needs? This would seem to be dependent to a large extent upon the physical attributes of the camera; however, the important consideration is quality as perceived by the consumers.

Substitutes--What means other than buying a camera does the potential purchaser have of satisfying his needs? How do these substitute means compare with still cameras?

Use Opportunity--How much use might the purchaser get from a still camera?

\section{Relative Importance of Causal Variables}

As a result of the above breakdown, the model included nine lower level conceptual variables. In order to decide how to allocate our efforts to the study of these nine variables, an evaluation was made of their expected importance. This evaluation was made prior to the analysis of the data with the idea that it might help in deciding which variables to include in the measurement models and what types of data would be most important.

Three considerations were made in order to assess the importance of each variable--the importance of the variable to the consumer decision, the amount of change expected in this variable over the next 5 to 15 years, and the accuracy with which future changes may be predicted. ${ }^{I}$ A scale of

lother criteria could have been added--e.g. ease of interpretation, cost of obtaining the data, and the ability to measure the causal relationship between the variable and camera sales. 
0 (no change or no effect) to 5 (very important) was used to rate each variable on each criterion. The criteria are interdependent. For example, a zero on any one of the critsria would render the other ratings to be superfluous: To combine the ratings then, a multiplicative approach was used. The three ratings were multiplied to provide a single index for each variable. Table 3-1 presents the results of this admittedly rather crude analysis.

\section{TABLE $3-1$}

RELATIVE IMPORTANCE OF NINE VARIABLES

TO THE FORECASTING MODEL

\begin{tabular}{l|l|c|c|c|c}
\hline \hline Rank & Variable & $\begin{array}{c}\text { Amount } \\
\text { of } \\
\text { Change }\end{array}$ & $\begin{array}{c}\text { Importance } \\
\text { to Consumer } \\
\text { Decision }\end{array}$ & $\begin{array}{c}\text { Accuracy } \\
\text { of } \\
\text { Forecast }\end{array}$ & $\begin{array}{c}= \\
\text { Overall } \\
\text { Rating }\end{array}$ \\
\hline 1 & Potential Buyers & 4 & 5 & 5 & 100 \\
2 & Price of Cameras & 5 & 5 & 4 & 100 \\
3 & Economic Ability to & 5 & 5 & 4 & 100 \\
4 & Purchase & 4 & 5 & 3 & 60 \\
5 & Ouality & 3 & 3 & 27 \\
6 & Ownership & 3 & 5 & 20 \\
7 & Uubstitutes & 3 & 3 & 3 & 18 \\
9 & Availability & 3 & 2 & 2 & 8 \\
\hline
\end{tabular}

Despite the heroic assumptions required for Table 3-1, the procedure does seem useful since there are very large differences among the variables in terms of the overall ratings. By repeating the ranking procedure at different times and by trying other methods of forming indices, it was found that similar results were obtained. In particular, the number of potential buyers, price of cameras and 
ability to purchase were always in the top three variables and knowledge was always last. It appears that differences among variables are so great that the differences will show up with very crude ranking procedures.

\section{Relationships Among Variables}

Starting again at the highest conceptual level, some consideration may be given as to the relationships among the variables. If, as the model is stated, each variable is necessary but not sufficient for the determination of camera sales then a multiplicative model would seem appropriate. On the other hand if each variable is sufficient but not necessary an additive model would be appropriate. For the camera model it would seem that market size, ability to purchase, and consumer needs are each necessary but not sufficient. The necessity of each variable may be seen by examining what would happen to camera sales if the given variable took the value of zero $(e . g$. if ability to buy is zero then total camera sales will be zero). The fact that each variable is not sufficient to determine camera sales by itself follows from the fact that there are three necessary variables. To summarize:

$$
\begin{aligned}
\text { Long-Range Sales }= & \text { (Market Size) } x \text { (Ability to Buy) } x \\
& \text { (Consumer Needs) }
\end{aligned}
$$

A more detailed specification will be deferred until Chapter 4. 
Summary

The importance of the use of conceptual models for non-experimental research was stressed. In particular, the advantages of providing an explicit a priori specification were stressed--primarily that it systematizes and simplifies the analysis of the overwhelming amount of non-experimental data which are available.

The objective of the forecasting model is to provide long-range unit sales forecasts for new still cameras which are sold to final consumers in each country in the world. 
In this chapter consideration will be given to various measures which might be used in the international forecasting model. Operational measures will be considered for each of the nine "lower level" conceptual variables from the previous chapter (see Table 3-I for a listing of these variables). For purposes of exposition, discussion of what types of data are available has been deferred to Chapter 5. For reasons which will become obvious, however, it is not possible to carry out the analysis of this chapter without some consideration of the availability of data.

The relationships among the variables will also be considered in very general terms. A more specific analysis will be provided in Chapter 6 .

\section{Operational Measures}

The discussion of operational measures will follow the order of presentation which was used in Chapter 3. Since our concern is with forecasting, interest will center on measures of change in each variable.

\section{Potential Buyers}

Who are the potential camera buyers? The basic strategy will be to start out with the total population and try to eliminate all those whose probability of purchase is very low. Since the probability of purchase is dependent to some extent upon ability to buy and consumer needs, there will be 
some problems in defining the boundaries of this factor. It turns out, however, that the approach of eliminating all those with very low probabilities has been rather easy to carry out. The purchase probability is expected to be related to the position in the life cycle, to level of education and to income. An aggregate measure for countries which stands as a proxy for life cycle is the age distribution of the population. The literacy rate could be used to measure minimum education levels. The proportion engaged in agriculture stands as a proxy for the minimum income level since more direct measures of the income distribution were not available. In summary, the measure of potential buyers would include everyone except the very young and the very old, the illiterate, and the farmers. Simple projections of the change in each of these factors will be used to forecast the change in the number of potential buyers.

\section{Economic Ability to Purchase Goods}

A substantial number of alternative measures exist which might be used as indicators of economic ability to purchase goods. There are per capita measures of income based on personal consumption expenditures, GNP, national income or discretionary income. There are also measures of the standard of living. As might be expected, these measures show a substantial correspondence. Changes in any one of. these indicators would be expected to correspond with changes in any other indicator. For purposes of the forecasting model then, it would seem to make little difference which 
measure was used. The decision rests primarily upon what data are available. Measures of personal consumption expenditures and of standard of living were considered.

\section{Price of Camera Goods}

The measure of the price of camera goods should include not only the initial price of the camera but also the operating cost--for film and processing primarily--since it would seem that both factors enter into the consumer decision to purchase a camera. The most useful weighting for each of these price components is far from obvious. Some attempt will be made to include both components in the development of a single retail prive index for cameras.

By definition, it was stated that the price of camera goods would refer to goods of constant quality. The effects of quality changes upon sales will be considered separately.

The price variable is of particular interest since it is subject to rather large and sudden changes. Simple projections of trends are not likely to be adequate in forecasting price changes. As a result, it was decided to construct a model to forecast changes in camera prices. In a manner analagous to the use of a causal model to forecast camera sales, it was felt that price could be forecast more accurately by relating it to causal factors.

Factors which are hypothesized to cause changes in the price of cameras included technology, tariffs, sales taxes, trade controls and competition. Two other factors, transportation costs and economies of scale were considered but 
then dropped--transportation costs since they are small relative to total costs ${ }^{1}$ and economies of scale since the effects are expected to be small and the complications in the model which result from including this factor are great.

Under technology, changes in manufacturing and distribution may lead to price reductions. Simple projections may be used to forecast the effects of these technology changes although engineering estimates should yield more accurate projections. The remaining variables are largely the result of political decisions. Since these decisions are often made somewhat prior to the implementation of the change, the forecasting of changes is simplified. The Kennedy Round of tariff reductions makes it rather easy to obtain good forecasts of tariff changes for the next few years. Similarly, the effects of Common Markets upon tariffs, taxes and trade controls are also easy to project.

Measures of competition are difficult to develop since there are many aspects to the competitive picture. This study will concentrate on one of the most important factors-resale price maintenance. This factor has also been subject to much change over the past ten years. Further changes are also expected--partially due to pending legislation and partly due to secondary effects of common markets.

$I_{\text {Hong Kong produces virtually no cameras yet the price }}$ of cameras transported to Hong Kong is generally lower than in the producing country. One estimate placed transportation costs from the U.S. to Hong Kong at about $2 \%$. 
Availability

Not all of the costs to the buyer are represented in the price variable. Some consideration might also be given to the time and effort required to purchase and service the camera. This cost is to some extent dependent upon the facilities which are available--such as camera and film retail outlets, repair shops, film processing.labs, and mail service.

There is insufficient cross-national data to enable the direct measurement of facilities. We could obtain this information by sample surveys. Since the facilities are a response to demand we would then have to face the problem of forecasting facilities while recognizing the interaction between facilities and demand.

There is a way around the above dilemna. The interest is in long-mun determinants. Therefore, one can ask what factors will contribute to low distribution and service costs. One of the major determinants would seem to be distance from the consumer to the service facility. This suggests a proxy measure such as urbanization. Unfortunately changes in urbanization are expected to be highly related to changes in the standard of living. There are two theories on this relationship. One says that people are attracted to cities by growth of economic opportunity in the city and the other that people are driven from rural areas due to an increase in poverty. Due to the theoretical ambiguity involved with the use of urbanization and to the expected difficulty in measuring the influence of urbanization upon sales, little 
further analysis was carried out in this area. ${ }^{1}$

There is one other factor which influences availability. This is the import quota. In countries where there is little or no domestic production the influence of the quota may be severe. While an attempt will be made to compensate for quotas in the calculation of price, this will not be adequate where the effect of the quota is severe. The strategy in. this case will be to eliminate these countries from our analysis. The decision of what is "severe" will be made before the data analysis is carried out.

\section{Knowledge}

One of the necessary conditions for a person to buy a camera is that he be aware of cameras. Knowledge of a product such as cameras could come about either through personal contact or through mass communication.

Personal contact, through ownership or through acquaintances who own cameras, would appear to be of great importance as a factor causing camera sales (Katz and Lazarsfeld, 1955; Whyte, 1954). Measures of ownership could provide a means of estimating how much contact people have with camera goods. Higher ownership would lead to greater knowledge about cameras which would, in turn, lead to a higher rate of camera sales.

There are many measures of mass communication--newspaper circulation, number of radios in the country, etc.

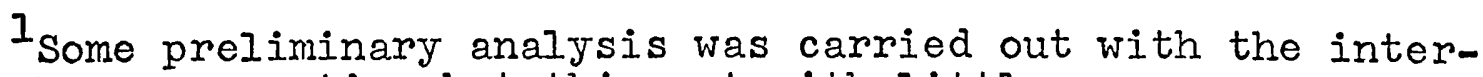
national cross-section but this met with little success. 
Although these measures are expected to be related to knowledge about cameras, the nature. of the relationship is not at all obvious. In view of this fact and the relatively low importance of knowledge to the model (Table 3-l) further consideration of this measure was dropped.

\section{Ownership}

Ownership was proposed as one aspect of consumer needs. If a person owns a camera, his need for a new camera is reduced since old cameras are rather good substitutes for new cameras. The hypothesis then is that higher ownership is related to a lower rate of new camera sales. Note, however, that this is exactly opposite the hypothesis developed under "knowledge" above. Rather than complicate the causal model by the introduction of a variable in which not even the sign of the relationship is known, it was decided to eliminate consideration of the level of camera ownership as a variable.

- The above decision removes consideration of the knowledge factor as well as the ownership factor. Neither of these variables had been expected to be of high importance to the model (Table 3-I).

\section{Quality}

Quality refers to the attributes of the cameras as perceived by the consumers. This measure is to account only for those effects of quality which have not already been accounted for by price changes. 
The price variable is not expected to compensate completely for changes in product attributes since the new attributes may serve to satisfy different needs which attract new buyers. As an example, it is claimed that the instant loading cameras served to interest many women who did not feel previously that they were competent to take pictures. While instant loading cameras have had an immense impact upon camera sales (Sheehan, 1965), their effect upon the prices of other cameras has apparently been rather small. Subjective estimates will be used to account for the influence of quality changes upon future camera sales. Better estimates might be obtained by identifying which attributes will change ${ }^{I}$ and how soon they will be introduced to the market ${ }^{2}$. The effects of these changes upon camera sales must then be evaluated--possibly by using shopping experiments. All in all, it would be a rather expensive proposition to go to a more sophisticated analysis here and it is not at all clear that the benefits justify the costs.

\section{Substitutes}

By substitutes we mean how can a potential buyer satisfy his needs without the purchase of a new still camera.

$I_{\text {This }}$ is part of what is known as technological forecasting. Jantsch(1966) provides a state-of-the-art report on this area.

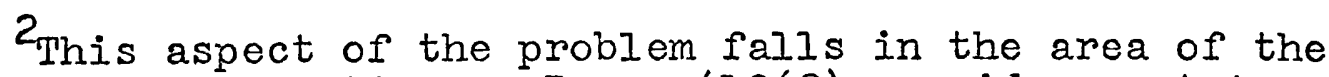
diffusion of innovations. Rogers(1962) provides a stateof-the-art report on this area. In addition, the literature is kept up to date on a yearly basis (Rogers, 1966). 
Since the study is attempting to examine a rather broad product class (in contrast, say, to a particular brand of camera), the effects of substitutes have been substantially reduced. No concern need be given to prices of "other brands". This simplification is one of a number of advantages that accrue from using the industry study as the first step in long-range forecasting.

In spite of the use of a broad product class, some attention should be paid to possible substitutes. One substitute for a new camera, ownership of an older camera, was considered above. Other substitutes are also apparent-movie cameras, professional photographers, the second-hand market, and the borrowing of cameras.

Since the study is dealing with unit camera sales, the effect of professional photographers appears to be negligible. Sales to professionals represent less than one percent of total camera sales in the U.S. (Photo Dealer, 1965, P. 41). Furthermore, it is the change in sales which is of concern in forecasting and professional sales are not expected to show a substantially different pattem than amateur sales. The effects of the second hand market were not considered since it was not clear how to introduce this effect into the current model--and, in addition, existing data on second hand markets are negligible.

Movie camera sales would appear to be about ten percent as large as still camera sales. The data which we have are extremely limited, however. To obtain more accurate data. would have been a time consuming and expensite process and 
was not deemed to be justified for this study.

The key question with respect to movie camera sales is whether the growth in sales will have a serious effect upon the growth in still camera sales. Two historical observations would indicate that this effect will not be strong. The first is that, for the U.S. at least, movie camera sales have not demonstrated any strong tendency to change as a percentage of still camera sales. The second observation is that price changes in movie cameras seem to follow a pattern similar to that of still cameras. In view of these considerations and the cost of the data, the problem was simplified by ignoring the effects of movie camera sales.

Borrowing of cameras appears to be a common substitute. There is some survey evidence for this in that $22 \%(n=269)$ of the families without cameras said that they secure photographs by "other means" (Lemberg, 1964).

Most borrowing probably takes place within the family. A survey of Boys Iife readers indicated that $60 \%(n=573)$ of non-owners use a camera belonging to someone else in the family (Photo Dealer, December 1966, p.36). Manufacturers seem to believe this as they tend to work with sales-per-household statistics. ${ }^{1}$

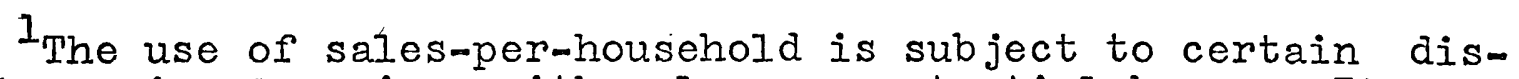
advantages in comparison with sales-per-potential-buyer. It does not specifically account for the influence of household size. By breaking this measure into two components:

$\frac{\text { Sales }}{\text { Household }}=\frac{\text { Sales }}{\text { Potential Buyer }} \times \frac{\text { Potential Buyer }}{\text { Housohold }}$ one may estimate the effects of each component separately and avoid the assumption that effects of each component are equal. In addition, it is more difficult to incorporate a priori infomation on households (as had been done in the section on potential buyers). Finally, the data on households are generally poorer in quality than data on population. 
To measure the extent to which borrowing is possible; it was assumed that the borrowing within the household is the key factor. As the number of households increases for a population of given size, sales of cameras would be expected to increase. The number of households per adult was used as a measure of this borrowing factor.

Projections of households per adult may be made on the basis of historical trends. In some cases, however, the number of households could be significantly altered by large scale government efforts to increase the number of houses available.

\section{Use Opportunity}

To examine this variable, one might consider the types of pictures taken by camera users. A survey by Lemberg (1964) indicated that most pictures dealt with family related activities. This was supported by an executive of Eastman Kodak who claimed that "the home often provides the best photographic setting for the subjects that people like to picture most--children, family groups, and pets. Collectively, these three subject categories account for more than 60\% of all amateur pictures taken " (Photo Dealer, December, 1966, p.35).

One measure suggested by the above description is the proportion of children in a population. If the proportion of children were increased (all other things constant) sales of cameras should increase. Support for this is found in survey data in which $10 \%(n=269)$ of the families without 
cameras said that this was because they did not have children and, therefore, did not have occasions to take pictures (Lemberg, 1964).

Summary: Operational Measures

The use of the conceptual model has guided the search for operational measures. This a priori analysis of the model has led to some simplifications in the model. Two of the lower level conceptual variables--knowledge and ownership--have been omitted since the operational measures available do not lead to unambiguous hypotheses. The remaining variables and their associated operational measures are summarized in Table 4-I.

TABLE 4-1

SUMMARY OF OPERATIONAI MEASURES: FORECASTING MODEL

\begin{tabular}{|c|c|c|}
\hline $\begin{array}{l}\text { Higher Level } \\
\text { Concepts }\end{array}$ & $\begin{array}{l}\text { Lower Level } \\
\text { Concepts }\end{array}$ & Operational Measures \\
\hline Market Size & Potential Buyers & $\begin{array}{l}\text { Total Population } \\
\text { Age Distribution } \\
\text { Literacy Rate } \\
\text { Agricultural Employment }\end{array}$ \\
\hline \multirow[t]{3}{*}{ Ability to Buy } & $\begin{array}{l}\text { Economic Ability } \\
\text { to Purchase }\end{array}$ & $\begin{array}{l}\text { Personal Consumption Ex- } \\
\text { penditures or } \\
\text { Standard of Iiving Index }\end{array}$ \\
\hline & $\begin{array}{l}\text { Price of Cameras } \\
\text { Goods }\end{array}$ & $\begin{array}{l}\text { Retail Price Index of } \\
\text { Cameras and Film } \\
\end{array}$ \\
\hline & Availability & Quotas \\
\hline \multirow[t]{3}{*}{ Consumer Needs } & Quality & $\begin{array}{l}\text { Subjective Estimates of } \\
\text { Effects of Quality }\end{array}$ \\
\hline & Substitutes & Households per AduIt \\
\hline & Use Opportunity & $\begin{array}{l}\text { Proportion of Chilaren in } \\
\text { Population }\end{array}$ \\
\hline
\end{tabular}


- Relationships Among the Operational Variables

The predicted direction of the relationship between camera sales and each of the operational measures was unambiguous. The form of the relationship was not so evident, however.

The selection of a functional form for the forecasting model should be distinguished from the selection of a functional form for a measurement model. A common research strategy in developing measurement models has been to postulate a number of possible forms and then select the one which gives the best fit to the data. This procedure has some drawbacks. Most importantly, it assumes that the fit of the measurement model has a close relationship to the performance of the foreasining model--a tenuous assumption for non-experimental research. Another problem arises if this procedure is followed for each measurement model since the variation in functional forms among measurement models complicates the problem of combining estimates from these models. Also, the use of different functional forms adds to the job of measurement since that many more alternative models must be considered. Finally, the use of models other than the multiplicative or log-log model makes it more difficult to integrate a study with other econometric studies. The log-log model is perhaps the most commonly used model in econometric research and is especially useful in that one may generalize from such studies without having to worry about the scaling of variables.

While differences exist between the forecasting and 
measurement models, it is useful to consider what may be done with the latter since it will be necessary to integrate results of measurement models into the forecasting model. For example, if a multiplicative model is selected for purposes of forecasting then it would be convenient to also use multiplicative measurement models.

In working with measurement models it is highly advantageous if the model may be stated in a form which is linear in the parameters. ${ }^{I}$ In simple terms, is it possible to make the model look like an additive model? This restriction is really not too severe since much may be accomplished by transformations of the variables. For example, if logs are taken of each variable the result is a multiplicative model. A number of publications are available which discuss the use of transformations for achieving different functional forms (Prais and Houthakker, 1955, p.79-88; Johnston, 1963, p.44-52; and Frank, 1966, p.247-53). This study will restrict itself to models which may be stated in terms which are linear in the parameters.

Other considerations which enter into the selection of a functional form include what type of data are available (e.g. the multiplicative model assumes data measured on a ratio scale $^{2}$ ); and what is the objective of the research (e.g. the multiplicative model assumes that questions of scale or

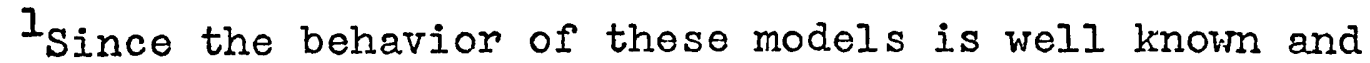
since programs for handling such models are widely available.

${ }^{2}$ Stevens(1959) provides an excellent discussion of measurement scales. 
percentage differences are important while the simple additive model assumes that absolute differences are important).

Functional Form of the Sale's Forecasting Model

In Chapter 3, theoretical arguments were presented for use of the multiplicative relationship in the camera forecasting model when the model was stated in terms of the higher level conceptual variables. A similar analysis in terms of the operational measures led to the conclusion that the multiplicative model is still applicable.

The multiplicative model meets all of the criteria mentioned above. Estimates from measurement models may be easily cast in this form; the use of previous research is facilitated; the data approximate ratio measurement; and the objective of this study is to measure percentage changes in the market in each country.

\section{The Top-Down vs. the Bottom-Up Approach}

The approach in this study starts with higher order concepts and works down to the operational level. An alternative approach, common in "exploratory" studies, is to start with operational measures and work up to higher level constructs. This is, in short, the deductive versus the inductive approach. Various arguments have been presented in support of using the deductive approach in this study. It is important to note, however, that if similar studies may serve as a guide, not all researchers would take this approach. For one thing it is very time consuming; for another, it lacks precision. 
Researchers who take the empirical or bottom-up approach have made extensive use of two techniques-factor analysis and step-wise regression analyais. The use of factor analysis has been especially popular in analyzing international data. A critique of this work is presented in Appendix C. Step-wise regression will be evaluated as an alternative model in Chapter 8 .

\section{The Use of Indices}

Some conceptual variables may suggest a number of operational measures. In such cases one may try to select the best measure, or may combine the measures into a single index. ${ }^{1}$ The selection of the best measure may be based on theoretical grounds (a priori analysis) or may be based on statistical criteria (e.g. by step-wise regression). The constmuction of indices may also follow a theoretical or statistical approach (e.g. factor analysis).

In this study, the theoretical approach was used to select "best indicators". This was one reason for the extensive a priori analysis. In one case, the measurement of camera sales, an index was constructed from theoretical weights on two measures.

${ }^{I_{A}}$ third strategy, suggested by Curtis and Jackson(1962), is to use each measure. separatelys This approach is advantageous for demonstrating construct validity. 


\section{CHAPTER 5}

THE USE OF NON-EXPERIMENTAL DATA

This chapter provides a general discussion of problems associated with the use of non-experimental data and concludes with a discussion of the data which are available for use in the camera forecasting model.

\section{Aggregate Data}

The forecasting model in this study is very much dependent upon existing analytical techniques and upon the current availability of data. While there appears to be substantial merit in disaggregated forecasting models (e.g. the "accounting type" of simulation model ${ }^{1}$ ), current attempts to forecast international markets would seem to be restricted to aggregate-data models. More specifically, this means that the sales forecast will be presented by country and no further detail will be available within the country. This places some limitations upon the uses of the model. A more detailed forecast did not appear to be feasible since little data were available at a more detailed level. 2

The use of aggregate data poses a number of problems for analysis. Aggregation may lead to reduced variation in

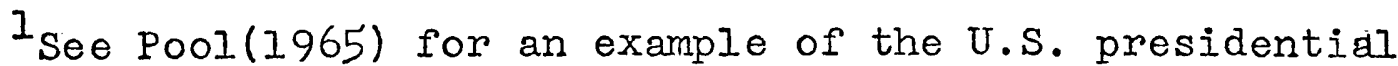
forecast in 1960. Such models attempt to identify small homogeneous clusters of people whose behavior may be forecast with some accuracy.

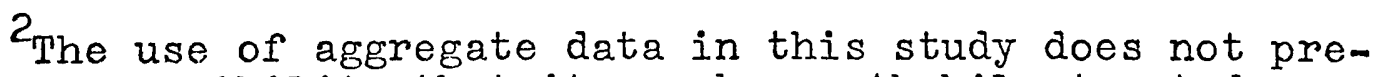
clude the possibility that it may be worthwhile to study larger markets, such as the U.S., by means of more expensive disaggregated data models. 
certain key variables, to a distortion of functional relationships (Estes, 1957), to a confounding of the effects of variables, and, obviously, to a loss in sample size. There is also the problem as to whether one should try to start out with hypotheses about individual behavior and then rigorously derive aggregate hypotheses. Such an approach calls for a detailed knowledge of how the individual behaves and then requires some strong assumptions to move from the individual to the aggregate level. The current study provides no formal link between the individual and aggregate levels. Hypotheses are developed which, it is hoped, will be useful at the aggregate level. Farrell (1954) presents a study of automobile demand which is based upon hypotheses on individual behavior. He then procedes gorously to the aggregate level. The benefits of such an approach were far from obvious since a simple naive model led to better predictions than those provided by Farrell's model. 1

The quality of data on countries has been improving, the cost of collecting such data has been decreasing, and methods for analyzing such data have become cheaper and more widely available. Still, the problems of aggregate data remain serious. The seriousness of these problems. must be judged in terms of how well the model performs.

\section{The Selection of Data Sets}

For most problems in non-experimental research, a substantial amount of data is available. In cases of economic forecasting, one may utilize household survey. data, data on

${ }^{1}$ It is also assumed here that one desires predictions of aggregate data. 
political or geographical units, time series data for households or for political units, etc. In this section, a general approach will be presented for the selection of appropriate data sets.

Criteria for Selecting Data Sets

The primary objective is to measure causal relationships that will be of some value to a prediction model. An absolutely necessary condition for measuring a relationship between $X$ and $Y$ is to have data in which both $X$ and $Y$ vary. The more variation there is in each variable the easier it will be to measure the relationship. In the multivariate case, the additional criterion is added that variations among the independent variables should not be highly correlated. This latter point will be discussed in greater detail below in the section on multicollinearity.

The second criterion is that there be a "reasonable" number of independent observations. What is reasonable depends upon many factors--e.g. the number of variables in the model, the power of the statistical model, the extent of multicollinearity, the size of the effect being measured, and the desired level of accuracy. In general, however, one can conclude that the more independent observations the better. The third criterion is that the data should not contain a substantial amount of variation which is due to factors which are irrelevant to the model. If this irrelevant variation is substantial, there may be means of compensating for the effects of this variation. Some of the strategies which 
may. be used here include aggregating or grouping observations, obtaining larger sample sizes, or introducing measures of the "nuisance" variables into the measurement model. The preceding criteria may be stated with more rigor by considering how they afiect data analysis when the regression model is used. The variance of the parameter estimate in a regression model is:

$$
\operatorname{Var}(b)=\frac{\operatorname{Var}(y \mid X)}{\sqrt{\sum_{i=1}^{N}\left(x_{i}-\bar{x}\right)^{2}}}
$$

Therefore, to reduce the variance of our estimate (i.e. to increase reliability of the estimate) one may:

a. Increase the denominator by increasing the spread $\left(x_{i}-\bar{x}\right)$; i.e. find data sets in which there is much variation in each causal variable.

b. Increase $\mathrm{N}$; i.e. increase the sample size.

c. Decrease $\operatorname{Var}(Y \mid X)$; $i . e$. reduce the variation in $Y$ which is due to factors other than $x$ by--

1. chosing more homogeneous sample points

2. ensuring that "other factors" do not vary

3. measuring the other factors

4. grouping observations

- In summary, the ideal data set should provide many independent observations in which the variables of interest show wide variations and the effects of all other factors are small.

A Structured Approach to Searching for Data

In order to decide what types of data may be used to obtain estimates of causal relationships, it is useful to describe what types of data are available. Figure 5-1 presents a general way of looking at data sets. 


\section{FIGURE 5-1}

GENERAL CLASSIFICATION SCHEME FOR DATA SETS

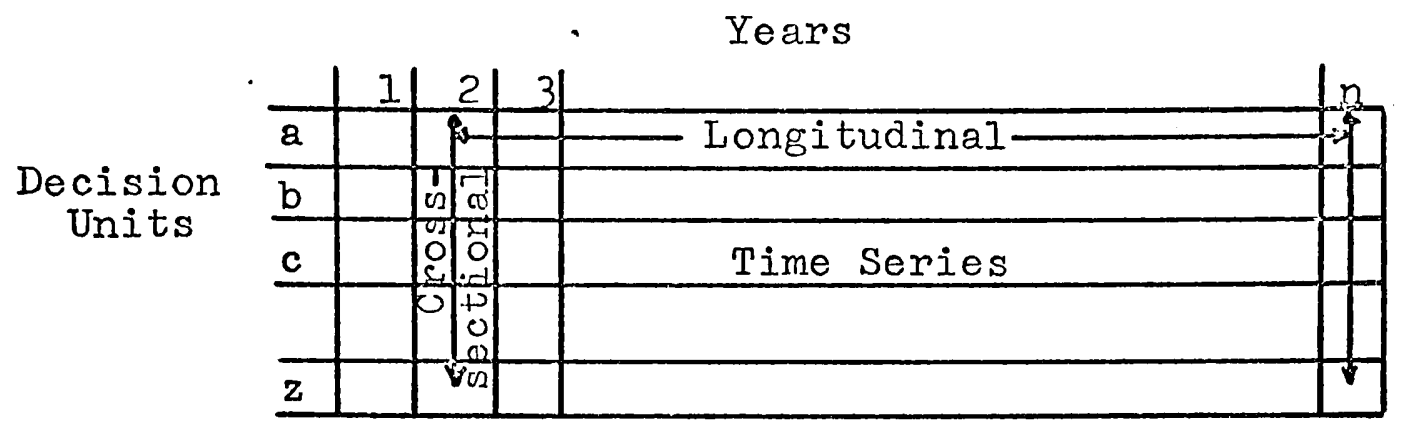

Three basic types of data may be noted in Figure 5-1. Cross-sectional (e.g. column 2 which looks at differences between decision units at a point in time), time series (e.g. row $c$ which looks at differences between time units for a given decision unit), and longitudinal (e.g. differences between column $\mathrm{n}$ and column 2 for each decision unit). Variations on each of these three types may be achieved by grouping--grouping by time periods, grouping over decision units, or grouping both ways.

It is my impression that the data analysis is greatly simplified if each type of data is considered separately. The reason is that parameter estimates from each type of non-experimental data are subject to differing sources of bias. By handling each type of data separately it is possible to examine the effects of bias and, in some cases, to take steps to correct for this bias. The alternative procedure is to throw the whole data matrix into a single re gression model (or a variant of regression such as a covariance model). This approach has been used by Houthakker (1965)--who analyzes yearly data from 1948 to 1959 for 
13 European countries-and by Schipper (1964) who analyzes household survey data.

The implied assumptions of the procedure of throwing all of the data into the hopper at once is that either the biases associated with each data set (i.e. type of data) are negligible or that the resulting mix happens to be optimum for the particular prediction model in which the estimated parameters will be used. For the current study neither of these assumptions appears to be realistic. In fact, such assumptions would, in general, appear to be rather strong for studies utilizing non-experimental data. ${ }^{I}$

\section{The Fiffects of Measurement Error}

Morganstern (1963) has tried to estimate the probable level of precision of some of the more commonly used types of economic data. If one generalizes from his findings to the type of data used in this study, the errors would seem to be vary large in relation to the mean of each series. It is appropriate then to consider what are the effects of measurement errormand what are the cures for these problems. The discussion will consider first errors in the independent variable and then errors in the dependent variables.

Errors in the Independent Variables

Errors in the independent (or predictor) variables have serious implications for both measurement and prediction.

$I_{K u h(1959)}$ and Meyer and Kuh(1957) discuss the combination of cross-sectional and time series estimates in more detail. 
These errors are imposed upon the prediction of the dependent variable. This happens since there is no way to distinguish between true variations and variations resulting from measurement error. Bulmer (1965, pp. 193-196) provides an excellent and intuitive discussion of this problem.

What may be done to compensate for measurement errors in the predictor variables? In general terms, when a predictor variable contains information of poor quality less reliance should be placed upon this information. (Poor quality should be interpreted here as random measurement error--or, at least, error in which there is no prior knowledge of systematic effects.) To place less reliance upon information means that the causal relationship between the predictor variable and the independent variable should be modified by reducing its absolute value. This reduction in the prediction coefricient is accompanied by compensating changes, in the constant term of the prediction model. The constant is adjusted toward the mean value of the dependent variable. The net effect is to hedge on the forecast by drawing the prediction closer to the expected value of the sample.

The extent of the adjustment for measurement error (under the assumption that the error may be considered to be random) has been determined for the regression model (see Johnston, 1963, p.150). It may be summarized by the following relationship:

Forecast Coefficient $=\left(\frac{1}{I+E}\right)$ (Causal Elasticity) 
where $E$ is the ratio of the error variance ta the true variance. A serrious problem exists with this formulation since neither of the constructs--"error variance" nor "true variance" is capable of being 'observed directly.

The regression model estimates forecast coefficients rather than causal relationships. These forecast coefficients are equivalent to estimates of causal relationships only in cases where the measurement error in the independent variables is negligible. For most, studies using non-experimental data there will be a substantial amount of measurement error. In such situations, it may be necessary to compensate for the resulting bias if the objective is to measure causal relationships. In this study, a priori estimates will be used to estimate the amount of bias due - to measurement error. 1

A more direct way for handling measurement error is to obtain better data. To some extent this problem is being taken care of as the quality of international data is improving over time. A different approach is to form indices from a number of different measures of the same variable. This latter, approach was utilized with the selection of Beckerman's Index as a measure of ability to purchase (see Chapter 6). Finally, a still different approach is to utilize repeated measures of the same operational variable.

$I_{A}$ practice which is sometimes used to account for messurement error is to regress $X$ on $Y$ and then $Y$ on $X$ to get a sort of confidence interval. This approach does not make sense for causal models since the cause and effect are not symmetrical. 
Errors in the Dependent Variable

Errors in the dependent variable have different implications than do errors in the independent variables. No bias is introduced into the estimates of a regression model from random errors in the dependent variable. But the reliability of the estimates is reduced. To improve the reliability of the estimates, strategies will be considered for reducing errors in the dependent variable.

As was true in the case of the independent variables, the most direct method of reducing the effects of measurement error is to obtain better data. The same options are available for improving the data--better measurement, use of different measures, and the use of repeated measures. The current study utilizes the latter two approaches by combining different operational measures'and by averaging a series of measures from consecutive years.

A particular problem arises when causal relationships * are measured from data in which the error variance of the dependent variable is not constant over the range of the independent variables. This is the well-known (to those who know) problem of heteroscedastivity. A common situation is where large prediction errors would be associated with large values of the dependent variable. This problem leads to a loss in efficiency but does not introduce bias. An often recommended solution here is to use a variance stabilizing transformation. This leads to a more powerful use of the data. The danger of this solution is sometimes 
ignored. Transformations generally lead to different types of causal relationships. Thus if one originally had a linear model and switched to a log-log model to increase efficiency, he also changes the causal assumption from constant marginal propensities to constant elasticities. It would apear more reasonable to select the causal relationship which seemed most appropriate rather than making efficiency the primary goal. The practice of getting a more precise estimate of the wrong relationship would seem hard to defend.

In the camera study, it is rather fortunate that the multiplicative model is preferred on a priori grounds since this model also appears to stabilize variance in the measurement models.

The Quality of the Observations

It is often the case with non-experimental data that some observations contain more information than others. It would seem reasonable, then, that measurement models based on such data would place more emphasis upon those observations which are more accurate. One approach which has been commonly suggested (but used much less frequently) is the use of weighted regressions. Each observation is weighted inversely by its error variance. But what is its error variance? Seldom is it possible to obtain estimates of the error variance for the observations in non-experimental data. Subjective estimates might be used to accomplish this--but such estimates would be difficult to make. Strategies other than the use of weighted regressions 
wail be considered in this study. One strategy is to provide ratings of quality for each observation. A second strategy is to examine each observation in an effort to accourt for the effects of excluded variables. In each case the analysis will be carried out prior to examining the formal measurement models.

Ratings of the quality of observations have been advocated by many (e.g. Morganstern, 1963). This information may be useful in estimating the extent of bias expected from measurement error. Beyond this, however, it is not clear what value such information has for data analysis. One of the more common suggestions has been to group the sample observations according to varying levels of quality. Dumny variables are assigned to each grouping and a regression is performed on the total data set. In effect, this allows for different intercepts for each quality group but assumes that the slopes are the same over the total data set. (A related approach is to run separate regressions on each quality grouping--thus allowing both intercept and slope to vary across the groupings:) Statistical tests are then performed to see whether there are statistically significant differences among the quality groupings. If not, the dummy variables are dropped and the data are reanalyzed as one group. But since it is known that the estimates in the lower quality group will be biased more severely toward zero, this rationale is difficult to follan. In addition, the choice of the significance level is usually arbitrary. In this study, consideration will be given to the 
use of subjective weightings for the sample observations in the measurement models. This procedure seems pertinent due to the wide variations in quality for international data. Richer countries seem to keep much better records than do poorer countries.

Since the number of observations used in this study was not large, it was possible to examine the effects which excluded variables might have upon each observation. ${ }^{I}$ An example of this might be knowledge that tourist sales are very high in Switzerland. Since tourist sales are not explicitly considered in the sales model, one might desire to adjust the data for Switzerland to compensate for tourist sale.

The analysis of each observation required an extensive amount of reading about each observation. Business International publications were useful here, as well as Carson (1967), Far Eastern Economic Review (1961 through 1967), Fink and scott Index of Corporations and Industries (1966), World Economic Review and Forecast (New York Times, 1965), Photo Marketing, and various U.S. Department of Commerce publications (primarily the Overseas Business Reports). Appendix A presents the results of this effort. Twenty-nine of the 60 original countries were excluded from the measurement models as a result of this analysis. Reservations about each observation were explicitly listed and strategies were also formulated as to what action to take if various countries proved to be outliers. The strategies included

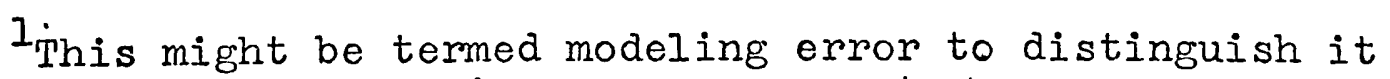
from the earlier discussion on measurement error. 
dropping the observation, trimming (removing equal numbers of high and low observations), Winsorizing (setting extreme observations of questionable value equal to the nearest extreme observation about which we have confidence), grouping observations of dubious quality, and searching for additional information about questionable observations.

Once again, it is important to stress the a priori nature of the analysis. The researcher has a vast amount of control over results. The a priori analysis puts controls over this flexibility. It is much too easy to find reasons for extreme observations after the analysis of the data--but this can be very misleading. An interesting example of such a posteriori evaluation is found in Solow(1957). He presented an explanation for some deviant observations and drew upon other research to support these claims. It turned out that the deviant observations resulted from an arithmetic error (Hogan, 1958).

\section{A Specific Problem with Multiplicative Models}

The use of the multiplicative model assumes that ratio data are available--i.e. a known zero point and meaningful intervals. A practical implication here is that values close to zero take on a particular importance. The estimating techniques break down, of course, if an observation takes the value of zero since the $\log ^{1}$ of zero is minus infinity. Values close to zero may take on extremely large (negative) values

$I_{\text {The }}$ log transiormation is required to express the multiplicative model as a linear combination of variables. 
and small measurement errors could lead to wide fluctuations. The effects on a least squares measurement model can be very serious. As a result, careful attention is required for small values since these are very likely to be outliers.

\section{Multicollinearity}

A particularly difficult problem with non-experimental data is to find data sets in which the variations among the independent variables are not highly correlated. This problem of having "everything move together" is the problem of multicollinearity. It has been widely discussed in the econometric literature. Blalock (1963) presents a well-written summary .

Multicollinearity does not lead to any bias in the estimation of causal relationships but it does make it difficult for the measurement model to decide which variable should get credit for causing variations in the dependent variable. In the extreme case, where say the independent variables $X_{1}$ and $X_{2}$ are perfectly correlated, there is no way to determine the specific contributions of $x_{1}$ and $x_{2}$. Where $x_{1}$ and $x_{2}$ are highly correlated (but less than 1.0 ) it is possible to get estimates of specific contributions but these estimates tend to lack reliability (i.e. the standard errors are high).

The use of different data sets is one useful way of coping with multicollinearity. If $x_{1}$ and $x_{2}$ move together 
in one data set (and if it is not possible to experimentally manipulate $x_{1}$ or $x_{2}$ ) then it will be useful if another data set might be found in which $x_{1}$ and $x_{2}$ do not move together. For example, assume $x_{1}$ and $x_{2}$ were correlated in data set \#1 but uncorrelated in data set \#2 (e.g. $\mathrm{X}_{2}$ was a constant in the latter). Data set \#2 might be used to estimate the relationship between $X_{1}$ and $Y$. This estimate could then be inserted into data set \#I to adjust $Y$ so that the relationship of $X_{2}$ and $Y$ might be estimated.

A related approach for handling multicollinearity is to use a priori estimates which are based on subjective data. If one's subjective information were weak, he might use a form of sensitivity analysis (sometimes called conditional regressions). A range of feasible values might be inserted into the regression model as the coefficient for, say, $x_{1}$ in order to examine how the calculated coefficient of $x_{2}$ varies. There are many other strategies for dealing with multicollinearity; but primary reliance in this thesis will be placed on the strategies outlined above--i.e. the use of different data sets, a priori estimates, and sensitivity analysis.

Econometrics textbooks may prove misleading when the effects of multicollinearity upon forecasting. are discussed. It is commonly said that multicollinearity does not cause a problem if forecasting is the objective providing that there are no "structural changes" in the future. The assumption is made that the prediction is to be made on the same type of data (i.e. same sample unit and same type of data 
grouping). Above, it was noted that the measurement model may not correspond to the forecasting situation. The objective in this study is to forecast camera sales-not to forecast inter-household or inter-country differences.

\section{Sources of Data}

Data which were examined for use in measuring parameters of the camera forecasting model included cross-sectional, longitudinal, and time series types and fell into two classes of aggregation-- by country and by household income group. This section discusses problems in selecting data sets for the measurement models. The data themselves will be presented later.

\section{Sales Data}

To measure the rate of new still camera sales to final consumers, an excellent source of data would be the consumers themselves. A sample survey could be made of consumers in each country to determine what percentage of the population purchased cameras in a recent time period. There are problems in having such surveys done in the lesser developed countries since they often have no capabilities for carrying out the survey work (Scheuch, 1966). However, data, could be obtained for most countries by this method. The problem of comparability of the surveys across countries should not pose a serious problem due to the simplicity of the information desired.

While the above approach would be available to large multi-national companies, it was too costly for this study. 
As an alternative approach, yearly data were obtained from public sources and sales were computed as follows: ${ }^{1}$

Sales by Country = Production + Imports - Exports

The U.S. Department of Commerce can provide the above data for a large number of countries over many years. Unfortunately, a substantial amount of work is required to gather this data for analysis. 2 The data are not conveniently summarized nor are the units of measure always comparable (e.g. some countries report data by number of units and others by dollar value).

The sales data are presented in Appendix B (Table B-5).

Data on Predictor Variables

Data for the predictor variables come from a wide variety of sources. In recent years, in response to the interest being shown in international afiairs, a number of convenient summaries of international data have appeared. These include Business International's annual listing of market. indicators, the Gallatin Statistical Annual (1966), Atlas of Economic Development (Ginsburg, 1961), and the World Handbook of Political and Social Indicators (Russett and Alker, 1964). The World Handbook is one product of a continuing data collection program at Yale known as the Yale Political Data Program (YPDP).

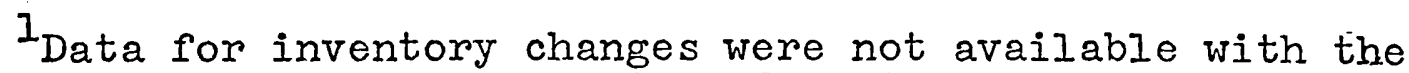
exception of Japan which experienced a sizable inventory increase.

The World Trade Annual (1963) which was started in 1963 by the Statistical Office of the United Nations, represents an attempt to simplify data collection and to develop uniform classifications. 
For purposes of this study, the World Handbook was extremely useful. The YPDP itself has gone beyond previous data collection efforts. This data bank provides information for over 600 variables with an average of 80 political units per variable. ${ }^{I}$ An attempt has been made to ensure comparability of data across countries and information is provided as to the quality of the data.

Perhaps of greater long-range importance than the effort on secondary data banks is the expanding role of the United Nations in primary data collection. The U.N. encourages the collection of socio-economic data by each country and provides guidelines for standardization. The participation of countries in various data collection efforts has been increasing. About 100 countries participated in the 1935-44 round of censuses. Corresponding figures for $1945-54$ and 1955-64 were 186 and 200 respectively (McGranahan, 1966). There also seems to be a consensus that the quality of cross-national data has been improving.

Data on camera prices were not available from secondary sources. An international survey was used to collect this data.

An a Priori Ranking of the Usefulness of Data Sets

In view of the criteria presented earlier in this chapter, a ranking was obtained for each of the data sets considered relevant to the study. Table 5 - I presents the results of this ranking procedure. The table should be read by rowi.e. the relative usefulness of each data set in estimating

$I_{\text {The complete data file is not presented in the World }}$ Handbook but is available from the YPDP on punch cards. 
the causal relationship between camera sales and the indicated variable was considered. ${ }^{1}$ The numbers indicate ranking (with $I$ = most useful). A dash indicates that no estimate was considered.

\section{TABLE 5-1}

A PRIORI RANKING OF DATA SETS FOR PARAMETER ESTIMATION

\begin{tabular}{|c|c|c|c|c|c|}
\hline & & Data & y count & ry & Data by \\
\hline $\begin{array}{l}\text { Opera- Set } \\
\text { tional } \\
\text { Measure }\end{array}$ & $\begin{array}{l}\text { Sub jec- } \\
\text { tive } \\
\text { Data } \\
\end{array}$ & $\begin{array}{l}\text { Cross- } \\
\text { Section- } \\
\text { al }\end{array}$ & $\begin{array}{l}\text { Longi- } \\
\text { tudinal }\end{array}$ & $\begin{array}{l}\text { Time } \\
\text { Series }\end{array}$ & $\begin{array}{l}\text { Household: } \\
\text { Cross-Sec- } \\
\text { tional } \\
\end{array}$ \\
\hline Market Size: & & & & & \\
\hline Population & 1 & 2 & -- & - & - \\
\hline Age Distribution & 1 & 2 & - & $-\infty$ & - \\
\hline Iiteracy Rate & 1 & 2 & - & $-\infty$ & - \\
\hline Farm Employment & 1 & 2 & $-\infty$ & $-\infty$ & -- \\
\hline Ability to Buy: & & & & & \\
\hline Economic Ability & 4 & 1 & 3 & 5 & 2 \\
\hline Camera Price & 3 & 1 & 2 & 4 & - \\
\hline Consumer Needs: & & & & & \\
\hline Quality & 1 & $-\infty$ & 2 & $-\infty$ & - \\
\hline Household/Adults & 2 & 1 & $-\infty$ & - & - \\
\hline $\begin{array}{l}\text { Proportion Child- } \\
\text { ren }\end{array}$ & 2 & 1 & -- & $-\infty$ & -- \\
\hline
\end{tabular}

On the basis of the analysis in this section, the use of time series data was eliminated. In particular, the time series data suffered from substantial irrelevant variation

$I_{\text {The rankings across a row are not independent of the }}$ other rows since the effects of collinearity must be considered. If two factors are expected to "move together" in a given data set--such as "economic ability" and "camera price" in times series by country-a choice must be made as to which factor the researcher is most interested in assessing in the particular data set. In other words, the decision might be made to use this time series data primarily for the estimation of price effects; outside estimates of the income coefficjent could be inserted into the model. 
(due to factors such as inventory fluctuations, mistakes in data collection, and promotional factors), from the lack of a sufficient number of independent observations, and from the expectation that true variations among the variables in the model were neither large nor independent (i.e. multicollinearity was expected to be high). In short, time series did rather poorly on all criteria.

In contrast to time series data, the international cross-section did very well against the criteria. Wide variations were found in the measures of economic ability to purchase and camera price. The variation in prices is especially noteworthy since econometric studies in general have had much difficulty in finding non-experimental data which may be used for estimating price elasticity. Political decisions in different countries have led to wide variations in price levels. The international data had additional advantages in that the sample size was moderately large and in that measures were available for a number of nuisance variables. As a result, it was possible to account for irrelevant variation. On the negative side there was a problem with multicollinearity. ${ }^{1}$

It came as no surprise that subjective data were considered to be very important. Many researchers have stressed the need for incorporating subjective data into the forecasting

${ }^{1}$ Sawyer(1967) in part of the "Dimensionality of Nations" project points out that three variables--size, wealth and politics explain 40 percent of the variance associated with 236 measures on 82 countries. 
model. The importance of subjective data was stressed in Chapter 1 with particular emphasis given to such data when used on an a priori basis.

\section{Stummary}

It was suggested that aggregate data will provide the basic input to forecasting international markets for some years in the future. This does not mule out the possibility that disaggregated data might be used to study the more important markets such as the U.S. But this study is limited to the use of aggregate data.

Some criteria were presented for use in selecting data sets. In brief, these called for a substantial amount of independent variation in each causal variable, a large number of independent observations, and a small amount of variation from nuisance variables.

A method of classification was presented which utilized the common types of data--time series, cross-sectional and Iongitudinal. It was suggested that for non-experimental data, it is better to analyze each type of data separately rather than mixing them in a single measurement model.

The effects of measurement error are of great importance in non-experimental research. In particular the bias resulting from measurement error in the independent variables was discussed. Strategies for dealing with various types of measurement error were discussed.

Multicollinearity was discussed in some detail since this problem. is generally serious when non-experimental data are 
used. A number of suggestions were made for handling this problem--the key suggestion being the use of many data sets. The sources of data for use in this study were discussed. An a priori ranking was provided of the usefulness of each data set. This ranking is intended to help decide where effort should be allocated in parameter estimation. 
A PRIORI ANALYSIS: THE FORECASTING MODEL

In this chapter, the a priori analysis ${ }^{l}$ will be carried. to such a detailed level that it will be possible to present an operational forecasting model. A priori estimates will be presented as to the magnitudes of the causal relationships. Where necessary for subsequent analysis, confidence intervals are also specified.

The subjective information upon which the a priori analysis is based comes from an appraisal of previous studies, knowledge of the camera market, economic theory, and "hunches".

The presentation of a model for forecasting camera sales will be followed by a discussion of how each of the causal variables will be forecast.

\section{Forecasting Camera Sales}

Each of the operational measures is considered below and its relationship to the sale of cameras is specified. These measures were discussed eariier (Chapter 4) and a summary 1 isting was presented in Table 4-I.

The use of the multiplicative model turns out to be very convenient for the a priori analysis. Causal relation-

$I_{A}$ priori meaning prior to the use of the measurement models (see Chapter 7). This contrasts with many econometric studies where subjective information is supplied after formal estimation (one finds statements in demand studies such as "the coefficient of $X$ appears to be high"; "equation \#10 appears most reasonable"; "the estimate of the coefficient of $Z$ was revised downward"; etc.) Some controversy. exists over whether it is best to utilize subjective information before or after analysis (Binder, 1964). 
ships may be expressed as elasticities-i.e. a one percent change in one of the causal variables will cause a specified percentage change in the dependent variable.

\section{Population}

It was assumed here that all people are equal with respect to purchasing cameras--except on those variables which have been explicitly included in the model. This implies an elasticity of 1.0 for the causal elasticity of population.

Age Distribution

According to household surveys, the very young and the very old each appear to have a low probability of purchasing cameras. Private surveys have indicated that the probability of camera purchase is very low (relative to other age groups) for people under 10 or over 70. Circumstantial evidence is provided by some published studies. For example, Photo Dealer (December, 1966, p.37) reports data on number of exposures taken by people in various age groups. By considering the number of people in each age group it was found that people between 10 and 19 took pictures at about $1 / 3$ of the overall average rate while people over 60 took pictures at $1 / 4$ of the overall rate.

It turns out that, with the exception of some of the more developed countries, it was very difficult to obtain breakdowns by age for the categories which were desired. Instead, an age breakdown of people between 15 and 64 was available. It was assumed that only people in thi's age bracket were potential buyers. 


\section{Literacy Rate}

The use of literacy rate is based primarily upon an appeal to face validity. There is, however, some circumstantial evidence which is consistent with the hypothesis that illiterate people do not buy cameras. Photo Dealer (1958) reports that the "percent of camera users" is three times as high among people who finished college than among people who did not attend high school. But, unfortunately, this survey does not report the effects of education with other causal factors held constant.

The use of illiteracy can also be justified as a proxy measure for people living at the subsistence level. People living at the subisistence level would appear to be poor prospects for purchasing cameras.

Non-Agricultural Employment

The use of non-agricultural employment was proposed primarily as a proxy measure for the income distribution. This measure would provide a more refined measure than does the literacy rate. It is thought that farmers over the world are much more likely than non-farmers to be living at a subsistence level.

Much evidence exists from household surveys in the U.S. and in countries of the European Cormon Market ${ }^{l}$ that farmers are less likely to purchase photographic goods than non-farmers.

$I_{\text {Business Europe (published by Business International }}$ Corporation) reports on household surveys of various consumer durables including cameras. See issues of March 16,1966; July 6, 1966; October 6, 1966; and February 1, 1967. 
It seemed rather extreme, however, to say that no farmers purchase cameras. Some elasticity. Iess than one but greater than zero was called for.

Subjective reasoning was used to place an a priori estimate upon the elasticity for the proportion of non-farm employment in a country. The specific nature of this reasoning is of little importance. The general procedure was to ask questions about hypothetical countries which took on various values of percent employed in non-agricultural employment. The specified elasticity of 0.3 corresponds very closely to weighting farmers at one-half the weight assigned to non-farmers (over the range of interest).

Personal Consumption Expenditures

There are many previous studies on the income elasticity $^{l}$ of consumer durables. These studies will be used to provide some ballpark estimates for the income elasticity of camera goods.

Unfortunately, there is a great amount of variation among estimated income elasticities--even for the same good. The many studies of automobile sales provide an excellent example. Time series estimates here give widely differing results-from Dyckman's(1965) estimate of 1.1 to Suits'(1960) estimate of 4.2 Such variation is truly amazing. If income doubled, Dyckman would forecast an increase in auto sales of $110 \%$ while Suits would forecast that auto sales would

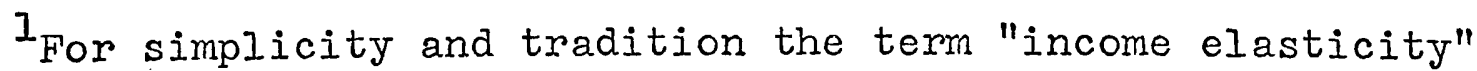
is being used. 
increase by 420\%. Nerlove(1960) reviews the results of several of these auto studies as does the U.S. Judiciary(1958).

Bandeen(1957) uses a longitudinal model with data on each state in the U.S. for the years 1940 and 1950 to obtain an estimated income elasticity for auto consumption of about 0.9 .

A number of studies have been done on other types of consumer durables. Roos(1957) refers to elasticities of various goods (based on time series estimates from 1929-1956) which include radios (income elasticity $=1.4$ ), jewelry and watches (1.2), and appliances (1.1). Mack(1954) refers to an income elasticity of 1.27 for "recreation goods" based on 1935 - 1936 household survey data. The Survey of Current Business (January, 1950) presented expenditure elasticities of 1.4 for durable toys and sports equipment.

The above studies represent only a sampling of the many demand studies. To compare them with income elasticity for camiera sales, particular interest was paid to studies which, were concerned with unit rather than dollar volume, long-range rather than short-range, durable goods, well defined product classes, and measures of total income. In addition, attention was also paid to the care with which the study was done. For example, did it appeaf that all important variables were included in the model? In view of these criteria, Burstein's(1959) study of unit purchases of refrigerators was of particular interest. He used a cross-section of the states in the U.S. and concluded that the income elasticity was between 1.0 and 2.0 for unit purchases of refrigerators. 
A qualitative evaluation of these previous studies on consumer durables led me to conclude that the income elasticity for camera sales is in the neighborhood of 1.3. The confidence region for this estimate ranges from 1.0 to 2.0 . This represents a 3 -sigma limit ${ }^{1}-$ i.e. there is only a 0.3 percent chance that the true value is not within this interval.

\section{Retail Price Index for Cameras}

Previous research on price elasticities is not so readily available as that on income elasticities. The automobile studies referred to earlier showed more agreement on price elasticity than they had on income elasticities with most estimates farling in the range from -1.2 to -1.5 (time series estimates). Burstein's (1959) study of refrigerators, which made an explicit attempt to control for quality, obtained an estimate of between -1.0 and -2.0 for price elasticity. In general the price elasticities appear to be of the same order of magnitude as the income elasticities.

Some attempt was made to see whether economic theory would assist in the a priori analysis of price elasticity. The Slutsky theorem breaks price elasticity into income and substitution effects. While a priori estimates may be obtained for income effects (see preceding section), it was not at all clear what questions one might ask in order to obtain substitution effects. The only argument which

${ }^{I}$ In retrospect, it did not seem that the a priori estimates were this accurate. 
occurred is that the camera study is based on such a broad class of goods that the effect of near substitutes is negligible. Only income effects need be considered. This would argue that the price elasticity should be about the same as the income elasticity (i.e. 1.3).

Other than postulating that the price elasticity is negative, economic theory did not seem to be particularly helpful in specifying a price elasticity. From my evaluation of previous demand studies, I have specified a price elasticity of -1.4 . This is slightly greater in magnitude than the income elasticity. A confidence interval of -1.0 to -2.2 was also specified. These estimates were highly subjective--but then so is the classical null hypothesis which would specify 0.0 .

\section{Quotas}

The effect of quotas is rather clear. ${ }^{1}$ Camera sales are limited to a certain level. If a quota was expected to go into effect during the forecast horizon a comparison must then be made between predicted sales and the quota level. The smaller of these two values would be used as the forecast.

Subjective Estimate of Effects of Quality

It is expected that improvements in the quality of cameras will lead to continued increases in sales and that these changes will not be fully reflected in the retail

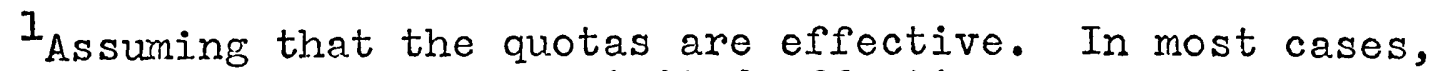
however, quotas have only a limited effectiveness as smugging becomes a profitable industry. 
price index. ${ }^{1}$

The most important quality innovation which has occursed in the past ten years in the international camera market has been the fool-proof loading system. The first such system was the Kodak Instamatic which was announced on February 28, 1963 and was on the market by May. Agfa-Gevaert responded with the "Rapid system" in the summer of 1964. Polaroid's "instant picture" stands as a potential breakthrough. Its effect on the U.S. market has been very strong; however, its effect in the international market has been small despite the fact that the Polaroid instant picture was first produced around 1948. There has been an almost endless stream of quality improvements of lesser importance. The flashcube simplifies indoor picture taking; automatic exposure control has taken the quesswork out of exposure setting; the quality of color films has been greatly improved; etc.

A subjective estimate of a $2.0 \%$ per year increase in camera sales will be used to account for the effects of improvements in quality over the next 15 years. The lowest value that would be consistent with prior expectations is 0.0 and the highest 4.0 .

\section{Households per Adult}

The elasticity of this measure would be expected to be positive but less than 1.0, (e.g. if the number of households doubled, the camera sales would not be expected to double). problem.

${ }^{\text {I }}$ See Ruggles (196I) for a general discussion of this 
An a priori estimate of 0.8 was used for this measure. The lowest value that would be consistent with prior expectations would be about 0.4 and the highest about 1.2 .

This variable is not expected to be very important to the forecasting model unless great changes occur. Such changes might result from a change in the age distribution of the population or perhaps from massive government efforts to increase the availability of housing.

\section{Proportion of Children}

The proportion of children was of minor importance to the forecasting model and would only have strong effects if substantial changes were expected in the age distribution of the population. An a priori estimate was obtained for this measure by asking hypothetical questions; (e.g. if two countries were alike in all respects except that in one country $40 \%$ of the people were under 15 years while in the other country only $20 \%$ were under 15, what differences might be expected in camera sales?)

This variable was expressed as the proportion of the population under 15 and an elasticity of 0.2 was specified. The lowest elasticity that seemed reasonable was 0.0 and the highest 1.2 .

\section{Summary: Forecasting Camera Sales}

Subjective estimates were provided as to the magnitudes of all of the causal relationships for the camera sales forecasting model. Where relevant, estimates were also provided as to confidence regions for the estimates. The 
bases for the subjective information were previous studies, economic theory, or just simple hunches on the part of the author.

Figure 6-1 presents a surimary of the camera sales forecasting model. This model, as expressed, is intended as a conditional forecasting model for sales in year $t+n$ for a given country.

\section{FIGURE 6-1}

CAMERA SALES FORECASTING MODEU: A PRIORI VERSION

$$
R_{t+n}=(1.02)^{n}\left(\frac{E_{t+n}}{E_{t}}\right)^{1.3}\left(\frac{P_{t+n}}{P_{t}}\right)^{-1.4}\left(\frac{H_{t+n}}{H_{t}}\right)^{0.8}\left(\frac{C_{t+n}}{C_{t}}\right)^{0.2} \quad\left(R_{t}\right)
$$

where the constant term is due to quality changes and $R$ is camera sales per potential owner

$E$ is personal consumption expenditures

$P$ is retail price index for cameras

$H$ is the ratio of households to adults

$C$ is the proportion of the population less than 15

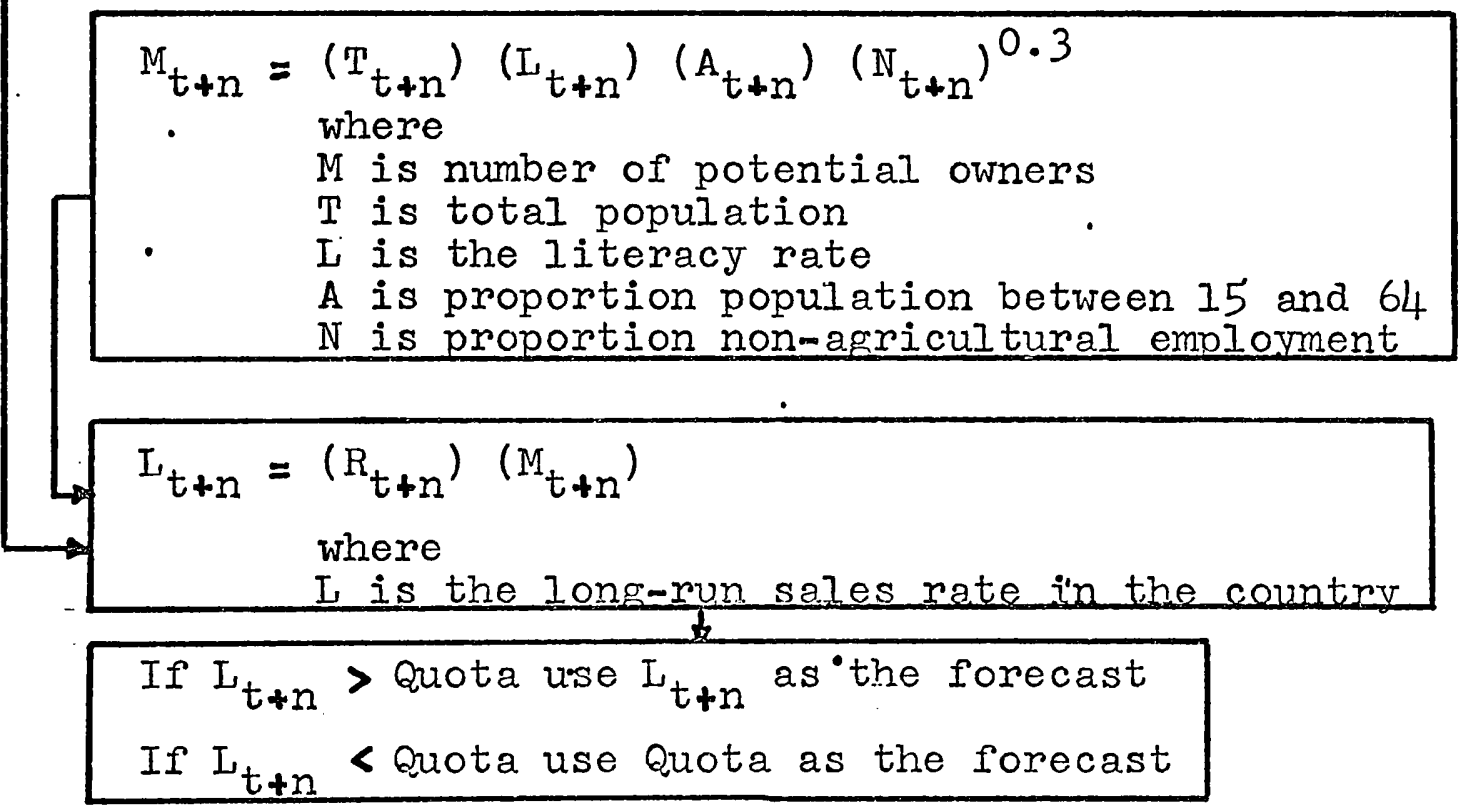




\section{Forecasting the Causal Variables}

Figure 6-I above presents a conditional forecasting model. Since the firm has negligible control over the values of the causal variables, a conditional forecasting model is of little direct use to the firm--predictions must be made for future values of the causal variables. In short, the firm requires an unconditional forecasting model.

Predictions of the causal variables will, with one exception, be based on simple projections of past trends. In other words, naive models are used to predict the causal variables. The one exception refers to the prediction of price. A causal model has been developed to predict price. The key variables for the price model were discussed in Chapter 4. An analysis of the functional form of the model followed the same pattern as that for the sales model (see Chapter 4). Once again it appeared that the multiplicative model was most appropriate--e.g. the effect on price of a tariff increase of ten percent could be most easily thought of in percentage rather than dollar terms. The multiplicative model is also advantageous to the price model in that it corrects for expected heteroscedasticity--thus leading to more efficient estimates in the measurement model. The a priori analysis was, in some cases, based on very limited information. This was especially true in the case of estimating technological change for camera manufacturing. It was estimated that the reduction in camera price (in constant dollars) which results from technological change is in the neighborhood of three percent per year. 
This was based on a general impression of what has been happening recently to prices of consumer durables ${ }^{I}$ (e.g. see paper on prices and quality of automobiles by Ruggles,1961).

The situation with respect to non-tariff trade controls was also subject to much uncertainty. In cases where controls were severe (such as a total ban on the import of photographic goods) the country was not included in the sample. Where controls were not severe, each country was placed into one of two categories-mstrong controls or weak controls. Strong controls included such things as moderate quotas, use of licensing to restrict imports, or use of extremely high prior deposits on the value of imports. The effect of these controls upon the price of cameras was then estimated to be equal to ten percent.

The reduction of prices resulting from the lowering of tariffs is expected to be less than proportional to the reduction in the tariffs. There are a number of reasons for this. There is a belief among some people in the photographic industry that companies absorb some of the tariffs when they export to other countries: This is in agreement with economic theory which would predict that part of the incidence of an ad valorem (i.e. percentage) tax falls upon the producer in the case of imperfect competition. Another

In retrospect, further a priori analysis might have been justified here. Errors in judgement in the a priori analysis seemed likely after the measurement models were examined. No attempt has been made to "correct" the a priori analysis since it would then no longer be an a priori analysis. Some argument might be made to revise the a priori analysis if the evidence were compelling--e.g. in the case of mistakes or logical errors. 
reason why tariff reductions do not lead to a proportional decrease in price is that high tariffs are never completely effective in the first place. Tariffs make smuggling a profitable industry. Smuggling tends to lead to a lower effective price level than would otherwise exist.

By asking questions such as "what effect would an increase of $100 \%$ in tariffs have upon the price of cameras?" it was possible to obtain a ballpark estimate for the tariff elasticity. An estimate of 0.6 was selected, (in other words a $100 \%$ increase in tariffs would lead to a $52 \%$ increase in price). Some consideration was also given to using different estimates depending upon the level of comestic production in a country since, in cases where domestic production is high, it is likely that the internal market is competitive without even considering imports.

The analysis for sales taxes was similar to that for tariffs. Sales taxes, of course, fall upon both domestic and imported goods whereas trade barriers affect only the imports. Since only minor problems would be expected with tax avoidance, the elasticity for sales taxes was expected to be larger than that for tariffs--perhaps 0.7 .

The effect of resale price maintenance (RPM) was judged by reference to two case histories where RPM was removed from the sale of cameras. The recent removal of RPM on Kodak films in Britain was claimed to lead to a $20 \%$ reduction in price (Financial Times, August 9, 1966). An earlier removal of RPM in Sweden produced similar results (Squires, 1965). 
- The above analysis enabled the development of an operational model to forecast camera prices in each country. The conditional price forecasting model is shown in Figure 6-2.

$$
\text { FIGURE 6-2 }
$$

CAMERA PRICE FORECASTING MODEL: A PRIORI

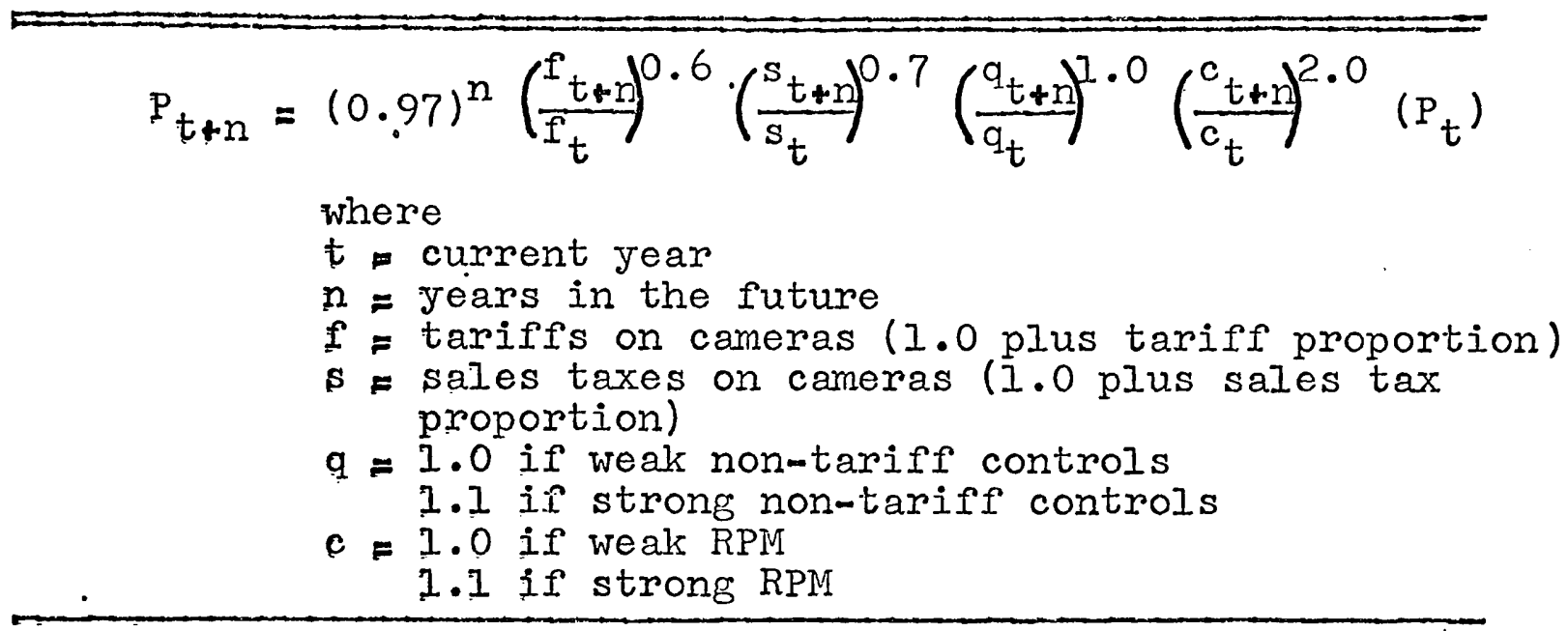

The price model will be useful not only in forecasting price changes over time but also for supplying missing data. This latter need arises since the retail price survey data did not cover all countries. 


\section{CHAPTER 7}

\section{THE MEASUREMENT MODELS}

The forecasting model was updated by use of some formal measurement models. Cross-sectional data by country and time series data for the U.S. were used to update parameters of the price model. The parameters of the sales model were updated by use of cross-sectional and longitudinal data on countries and by cross-sectional data on households.

\section{Measurement Models vs. Prediction Models}

Hopefully, the measurement models provide better estimates for the sales model. It is also felt that the measurement models provide a better understanding as to the generality of the measured relationships--i.e. for what population, time, and space are the relationships useful?

Nuisance Variables

Up to this time attention hiad been centered on a discussion of variables for use in the forecasting model. In the measurement models some consideration was also given to "nuisance variables". The question of just what is a nuisance variable depends on the objectives of the model. Nuisance variables are expected to have no' influence in the prediction model and thus are irrelevant to any decisions based on the prediction model. The reasons why these variables are expected to be unimportant is that either they do not change or that the effects of their changes are randomized over the aggregate data that make up each observation. 
Examples of the former would be the use of climate in the cross-sectional model; and, of the latter, would be the effects of the so-called short-mun factors.

The fact that nuisance variables are unimportant for the prediction situation does not imply, however, that they are unimportant for the measurement models. The general conceptual framework of Chapter 3 was used to search for possible nuisance variables in each data set.

The Relative Importance of Variables

Which variable is most important? This problem arises frequently in multivariate research. Generally the answer is provided on the basis of results from a given measurement model. The position of this study is that such a question is not really meaningful unless the objective is clearly stated-i.e. important for what purpose? Since forecasting is of utmost concern, here, the importance of each variable will be evaluated for its effect upon the forecast. ${ }^{1}$

The importance of variables in a measurement model depends upon a number of issues. Does the variable fluctuate widely and independently of other variables in the sample data? Is it statistical or practical importance which is of concern? If it is statistical importance, then another series of questions is raised. (See Baken, 1966, for a summary of these problems.) If it is practical importance, then one is forced back into an analysis of the objectives of the study.

$I_{A}$ better approach, where feasible, would be to tie in the effects of the variable to the decisions which it affects. 
In summary, to go beyond a descriptive statement of level of significance or of "variance explained" and to discuss importance does not generally turn out to be a meaningful exercise for measurement models. The relative importarice of variables in this study was judged by examining the effects of each variable upon a set of forecasts (see Chapter 9).

\section{Criteria for Evaluation of Measurement Models}

For each data set, a number of model formulations was considered. There were problems such as which observations should be retained in the sample, which variables should be included in the model, which functional form was most appropriate, or was there an alternative indicator of a conceptual variable which would provide a better description. This experimentation with various model formulations plays havoc with the classical notions of hypothesis testing. But the concern in this chapter was with measurement-not hypothesis testing. Measurement is not tied down by the rules of hypothesis testing.

What criteria should be used then to evaluate different formulations of a measurement model? First, one might ask whether the estimates are consistent with prior knowledge. For example, the theory about direction of the relationship is so clear-cut that any estimate with an incorrect sign will be rejected. I This was one of the reasons for

$I_{\text {This }}$ is not a common procedure for demand studies although it is advocated by some (e.g. Houthakker and Taylor, 1966). It is not clear to me what is the justification for the use of arbitrary significance levels to decide whether a variable belongs in a model. 
being explicit about a priori knowledge. Second, there is the question of how well the model fits the data. Such measures as $R^{2}$ (the square of the correlation between actual values and values "predicted" by the model) or mean absolute deviations are useful here. Third, what is the reliability of the estimated relationships (e.g. are the standard errors of the regression coefficients small; do split samples yield similar results?) Finally, there is the extent to which the assumptions of the measurement model appear to be reasonable approximations of reality (e.g. are the assumptions for the regression model satisfied).

\section{Estimating Parameters for the Price Model}

Chapter 6 identified six variables which might be important in forecasting the retail price of cameras. These included technology, tariffs, sales taxes, non-tariff import controls, and resale price maintenance. A seventh variable, proportion of market supplied by imports, was also suggested as having a possible influence on sales.

The effects of each of the above variables, with the exception of technological change, were estimated by means of cross-sectional data over countries. The effect of technological change was estimated from time series data.

Technological Change: The Use of Time Series Data

The relationship between technology and camera price was estimated in a number of ways. The basic approach was to find a situation in which the price of a basket of constant quality cameras could be observed over time and where 
"all other things" were constant. Data for the U.S. were convenient. They also seemed to fill the criterion of "all other things constant" to a reasonable degree. Over the period of time which we examined (1960 to 1967) the changes in tariffs, taxes, non-tariff controls, and resale price maintenance in the U.S. were not large.

Data from the U.S. Bureau of Labor Statistics (BLS) were first examined. The Wholesale Price Index for Photographic Equipment and Supplies showed only a slight decrease over the 1960-66 period--about $0.6 \%$ per year. The BLS Consumer Price Index was more relevant to our study but it had only very limited information. This index covered only color film and black and white film--and these goods were covered for only 1963-67. The color film index showed a decrease of roughly 4 percent per year while the black and white film index was virtually constant.

The BLS data were also deficient in that it was difficult to ensure that the quality of the goods had remained constant. Weak conclusions drawn from the study of BLS data were that camera prices were decreasing at about 0.6 percent per year and film prices were decreasing by about 2 percent per year (weighting color, and black and white films equally).

Sears-Roebuck catalogues provided substantially better information. Indices were built for cameras and for films. Each index was developed by comparing the same camera (or film) types for two successive years. The prices for these two years were adjusted by the general price level (as had 
also been done for the BLS data) and compared to each other. Thus a series of year-to-year indices was developed. These were converted to a common base to provide an index series for the period 1960 to 1966. I'he camera index showed a decrease of about $1.6 \%$ per year while the film index showed a decrease of $1.7 \%$ per year. The film index was not, however, based on constant quality as there had been a substantial improvement in quality. Thus, the price of constant quality film would have deçreased by substantially more than $1.7 \%$ per year. (Details of the analysis of Sears data are presented in Appendix B.)

Overall, an estimate of $2 \%$ per year decrease in the film price index seems reasonable while a change of roughly 1.5\% per year in cameras and other equipment might be obtained from the Sears index (allowing a slight downward adjustment for the BLS analysis). Our general rule has been to weight camera data more heavily than film data by about a 4 to 1 ratio. This yields an overall estimate for technological change of a $1.6 \%$ per year decrease in the price of photographic goods. This compared with the a priori estimate of $3.0 \%$ per year. The estimate of $1.6 \%$ was used as the a priori estimate had been based on extremely limited information. The Use of an International cross-section

Parameters of the price model other than technological change were estimated by means of cross-sectional data for 26 countries. These include only countries which did not have extreme trade restrictions. 
It was first necessary to develop a price index for each country. A non-probability sample was used to obtain the necessary data. Mail questionnaires were sent to one importer in each country in Fail 1966. A follow-up questionnaire, made in Spring 1967, indicated that the results had high reliability. Details on the questionnaire are provided in Appendix $B$.

Three indices were developed from the survey. A Kodak Index was developed by considering the prices of a Kodak Instamatic 104 (or 100) camera and ten packs of type $126 \mathrm{black}$ and white film. A Polaroid Index was based on the Polaroid Model 104 camera and ten packs of Type 107 (black and white) film. A Japanese Index was based on the Canon QL25 camera. Each of these indices was normalized by dividing by the average over all countries. These data are presented in Table 7-2.

Since these three indices purport to measure the same thing, it seemed reasonable to evaluate how.they agreed among themselves. The intercorrelations were very high as may be seen in Table 7-1. (The major diagonal shows the square of the multiple correlation between each index and the other two indices.)

TABLE 7-1

CORRELATIONS AMONG INTERNATIONAI PRICE INDICES

Kodak

(.94)

Kodak

Polaroid

Japanese
Polaroid

.95

$(.90)$
Japanese

.89

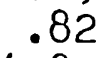


It was desirable to obtain an overall price index for further analysis. Since the Kodak Index had been included on both the Fall 1966 and Spring 1967 questionnaires and since the Kodak Index represents the largest selling items over the world, it was weighted twice as heavily as were the Polaroid and Japanese components. A harmonic mean was used to combine the components. This approach assumes that constant dollar amounts would be spent on each component of the index (rather than assuming that an equal number of units would be purchased). The harmonic mean has intuitive appeal since it assumes that people purchase more lower priced than higher priced units.

The price index showed substantial variations among countries. The highest price index was over three times as large as the lowest index and the coefficient of variation was about $25 \%$. $^{1}$

Tariffs were broadly defined to include all charges which are placed by the government on imported goods. It did not include charges which are applied equally against domestic and imported goods. Measurement was difficult as tariffs are not specified in uniform terms from country to country. Most countries specify taxes in ad valorem terms but some use specific taxes based on weight. Most countries use different rates according to the source country--i.e. preferential rates are accorded to "favored countries". Product definitions also varied among countries. Special

${ }^{I_{\text {Coefficient }}}$ of variation $=$ standard deviation $/$ mean 
taxes are also applied intermittently in some countries.

As a result of the many serious measurement problems, the index used to represent tariffs was subject to much error. A substantial amount of subjective input was required to obtain this index.

The index was expressed as a ratio of price after application of tariffs to the C.I.F. (cost including freight).

Sales taxes include all charges which are applied by the government to both domestic and foreign goods. In an attempt to make this series comparable with the tariff series as well as comparable over countries, sales taxes were expressed as a ratio of price after application of sales tax to price before application.

Resale price maintenance and non-tariff controls were specified as dummy variables. Each country was classified as having either "strong" or "weak" effects.

\section{The Data}

Data for the variables in the price model are presented in Table 7-2. Description and notes on these data are presented in Appendix $B$.

\section{A Priori Analysis}

A priori estimates were made as to what biases might be associated with estimates from this particular measurement model. The source of bias which was expected to be most important was that resulting from random errors in the independent variables. The effect of such errors and the method of estimating the extent of the bias were discussed 


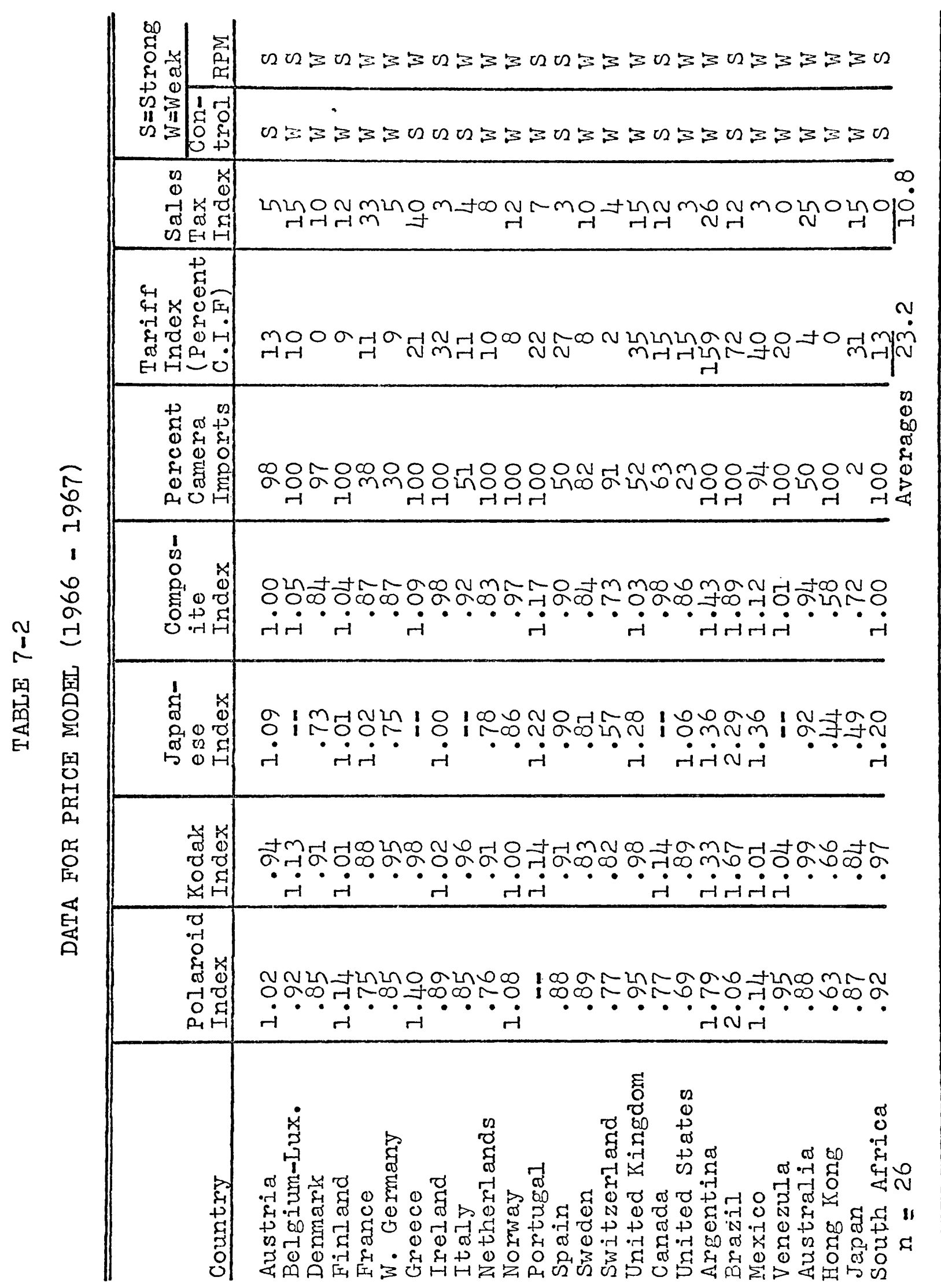


in Chapter 5. Other sources of bias vere not considered to be important.

The consideration of bias associated with this measurement model made it possible to translate the a priori estimates of causal relationships (Chapter 6) into a priori estimates of the regression coefficients. These estimates are summarized in Table 7-3. No a priori estimate was made of the constant term since this has no particular importance to the model and since there was insufficient a priori knowledge.

\section{TABLE 7-3}

A PRIORI ESTIMATES OF REGRESSION COEFFICIENTS: PRICE MODEL

\begin{tabular}{l|c|c|c}
\hline & $\begin{array}{c}\text { Causal } \\
\text { Elasticity }\end{array}$ & $\begin{array}{c}\text { Bias due } \\
\text { to Errorsin } \\
\text { Variables }\end{array}$ & $\begin{array}{l}\text { Regression } \\
\text { Coefficient }\end{array}$ \\
\hline Tariffs & 0.6 & 0.8 & 0.5 \\
Sales Taxes & 0.7 & 0.8 & 0.6 \\
Non-Tariff Controls & 1.0 & 0.5 & 0.5 \\
RPM $^{a}$ & 2.0 & 0.5 & 1.0 \\
\hline
\end{tabular}

${ }^{\theta_{T}}$ These dumm variables were set at a level which would yield an expected regression coefficient of 0.5 for controls and 1.0 for RPLI. The choice of a value for dummy variables is arbitrary although it is necessary to use positive values for multiplicative models (see Suits, 1957, for a discussion of dummy variables).

$\mathrm{b}_{\text {Proportion; }} 1.0$ indicating no bias, 0.8 indicating biased estimate is $80 \%$ of unbiased estimate, etc.

Results

The results were presented first in their original form. Table 7-4 summarizes these results. 
TABLE 7-4

PRICE MODEL -- ORIGINAL FORM $(n=26)$

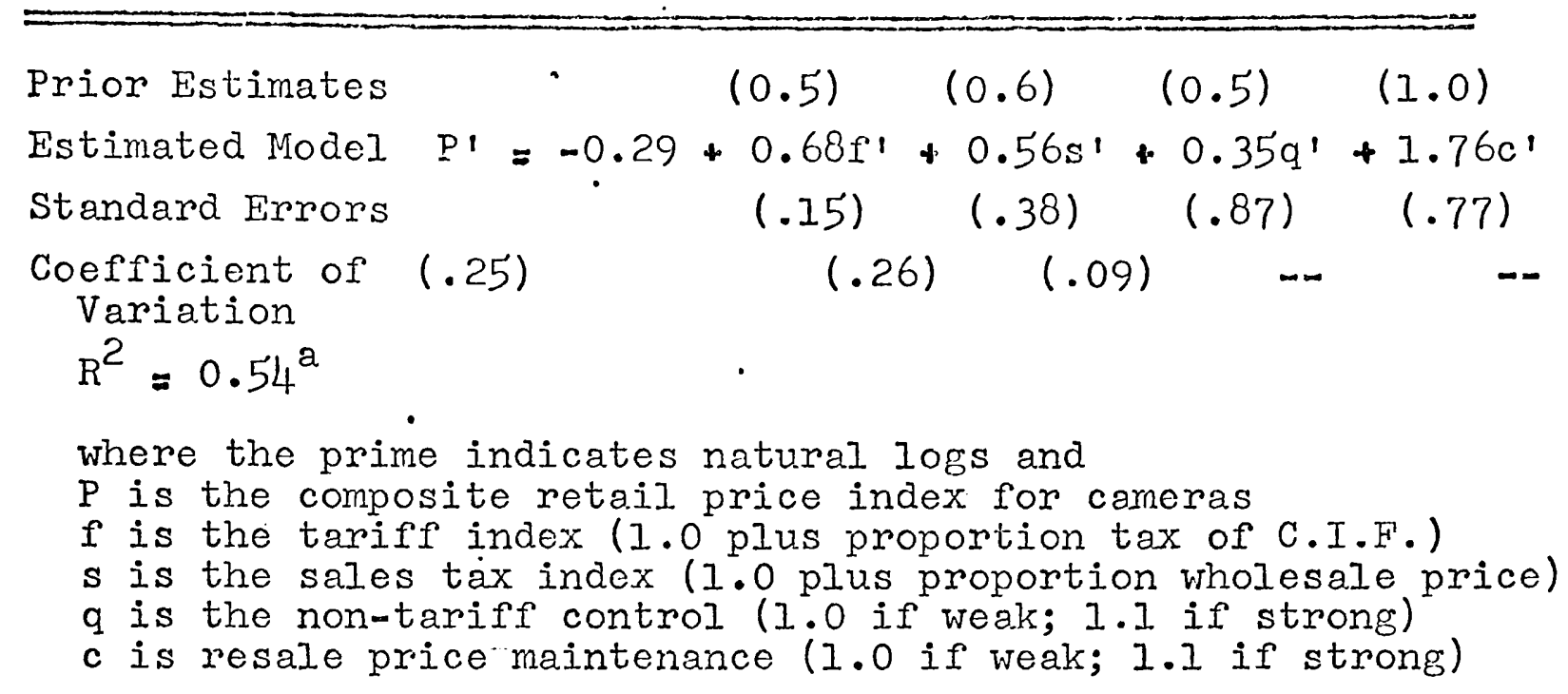

$a_{R^{2}}$ is adjusted for loss in degrees of freedom. This adjustment attempts to evaluate what fit would be obtained if the model were used on new data (of the same type).

The coefficients in Table 7-4 agreed rather closely with the a priori estimates. In no case was the calculated coefficient more than two standard deviations from the a priori estimate. Partly, of course, this was due to the large standard errors in the regression model.

It was apparent from the original model that the effect of the proportion of cameras imported could not be effectively dealt with by splitting the sample into groups as had been originally planned. The combination of small sample size and multicollinearity ${ }^{I}$ led to unreliable estimates. To

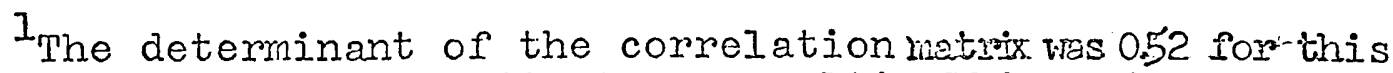
model. A value of 1.0 indicates no multicollinearity while a value of 0.0 indicates such high intercorrelation that at least one independent variable can be explained by variations. in the other independent variables. 
divide the sample would compound this problem by further reducing sample size. Instead, it was decided to reformulate the model to make better use of information about proportion of cameras imported. It was reasoned that if a country has a very large proportion of its market supplied internally the effect of tariffs is not so great. In fact, tariffs would have a negligible effect if the market within the country was highly competitive and if the market was supplied primarily by domestic production. Since the effect of tariffs is expected to increase as the proportion of cameras imported goes up, the tariff index was calculated as follows:

Ad justed Tariff Index $=1.0+$ (Tariff Rate $x$ Proportion Imported)

Empirical support for this approach was gained by observing that the proportion imported was positively correlated with the residuals in the model of Table 7-3, i.e. higher imports are associated with higher prices (with the linear effects of other variables accounted for). It was also noted that if countries were split into two samples on the basis of whether or not they had any camera production, the coefficient for tariffs was slightly lower in the sample with production $(0.4 \mathrm{vs} \cdot 0.6)$. This difference was not statistically significant, however,

It was additionally argued that the effects of the adjusted tariff index and the sales tax index should be roughly the same since the former had been weighted to apply to the "average camera" and since the latter already applied 
to the average camera. A composite index was then formed as follows: ${ }^{1}$

Taxation Index = Adjusted Tariff Index + Sales Tax Index The results of the revised model are shown in Table 7-5. The revised model provided a substantially better fit $\left(R^{2}\right.$ corrected for degrees of freedom was increased from 0.54 to 0.69$)$.

\section{TABLE $7-5$}

PRICE MODEJ」: REVISED FORM

The revised model provided estimates of the price index which, while not outstanding, appeared to be of some usefulness. The average absolute error in "predicting" price differences among countries was about $10 \%$.

Additional Testing of the Price Model

The multiplicative model, preferred on a priori grounds, also proved to be superior to the arithmetic model on its ability to fit historical data. Further analysis of the

$I_{\text {The indices were added rather than multiplied since it }}$ was thought desirable to reduce the influence of the extreme observations. 
arithmetic model indicated that the estimates for the elasticity at the mean corresponded rather closely with the elasticities estimated in the multiplicative model. It is reassuring that these "two models are in agreement at the mean. A simple test of reliability ${ }^{l}$ was performed by splitting the sample into two parts. This yielded two rather small samples (each $n=13$ ). The results of this test were not impressive as can be seen in Table 7-6.

\section{TABLE 7-6}

RELIABILITY TEST FOR PRICE MODEH COEFFICIENTS

(Standard errors in parantheses)

Coefficient

Sample \#I

Sample \#2

Taxation

Controls

Resale Price Maintenance

$1.35(.18)$
$-.17(.67)$
$.89(.61)$

$.73(.14)$

$.59(1.09)$

$1.85(1.06)$

The results of Table 7-6 might have been due to an unfortunate split in the data. A stratified sampling plan had, however, been used to reduce the probability of a bad split. (This plan first grouped by whether or not the country produced cameras, then by continent, then by alphabetical order. Every other country from the resulting list was placed in a different subsample.) The presence of two outliers in the sample--Argentina and Brazil-- seemed to

$1_{\text {Standard errors also provide an indicator of relia- }}$ bility. The technique of splitting the sample simply offers a different approach for testing reliability. This approach helps guard against the efiects of outliers or mistakes. 
be responsible for the apparent lack of reliability. There was no justification for eliminating either of these countries yet their presence in the reliability subsamples was of overwhelming importance.

The sensitivity of the total model to the presence of Argentina and Brazil was tested. The results are presented in Table 7-7. The parameter estimates did not differ substantially from one another. This lack of sensitivity to which sample observations are used provided some reassur.. ance for the decision not to exclude any observations.

\section{TABLE 7-7}

EFFECT OF OUTLIERS UPON ESTIMATES FOR PRICE MODEL

\begin{tabular}{|l|c|c|}
\hline \multirow{2}{*}{ Variable } & \multicolumn{2}{|c|}{ Estimate of Parameter } \\
\cline { 2 - 3 } & Total Sample & $\begin{array}{c}\text { Sample excluding Brazil } \\
\text { and Argentina }\end{array}$ \\
\hline Taxation Index & $0.8(0.1)$ & $1.0(0.2)$ \\
Resale Price Main.- & $1.6(0.6)$ & $1.3(0.5)$ \\
tenance & $0.5(0.7)$ & $0.2(0.6)$ \\
\hline
\end{tabular}

Unfortunately, the sample size had been regarded as too small to allow for some countries to be set aside for a test of concurrent validity. Some support was gained, however, as data for Thailand were received after the model had been developed. The actual price index of 1.03 agreed exactly with the model prediction.

Conclusion: Price Model

Price is but one of a number of important variables which were used in the camera sales forecasting model. Due 
to its importance and to the inadequacy of a simple trend extrapolation, a causal model was developed to predict price changes. The results of the model were encouraging in spite of some very serious measurement problems. The price model will be used not only to provide long-range price forecasts but also to supply missing data for use in the sales model. This latter function is es- . pecially important since historical data on camera prices are not available for many countries prior to 1966 and, in some countries, not even for 1966.

The estimates for countries in which no retail survey was made will be calculated directly from the model of Table 7-5. Estimates relating to changes over time are found from the model in Figure 7-I. This model was intended to be an updating of the a priori model in Figure 6-2. The structure of the model was revised somewhat, however, and the coefficients are based primarily upon the measurement models.

\section{FIGURE 7-1}

CAMERA PRICE FORECASTING MODEL: UPDATED

$$
\begin{aligned}
& P_{t+n}=\left(f_{t+n}\right)\left(i_{t+n}\right)+\left(s_{t+n}\right) \\
& \text { where } t \text { is the current year; } n \text { is the years in the future and } \\
& T \text { is the taxation index } \\
& f \text { is the tariff index } \\
& \text { i is imports as proportion of total consurntion } \\
& s \text { is the sales tax } \\
& P_{t+n}=(0.984)^{n}\left(\frac{T_{t+n}}{T_{t}}\right)^{0.8}\left(\frac{q_{t+n}}{q}\right)^{0.5}\left(\frac{c_{t+n}}{c_{t}}\right)^{1.5} \\
& \text { where } P \text { is the retail price index } \\
& q \text { is the presence (I.I) or absence (I.0) of strong } \\
& \text { trade controls } \\
& \text { c is the presence (1.I) or absence (1.0) of RPII }
\end{aligned}
$$


Estimates for the Sales Model:

International Cross-Section

The cross-sectional data over countries was expected to be an especially useful data set for estimating parameters of the sales model. As a result, much effort went into an analysis of this data set.

Some Nuisance Variables

Under the heading of consumer needs, it appeared that climate would lead to differences in camera sales among countries. Sepcifically, it was hypothesized that where temperature is high camera sales will be high and where rainfall is high camera sales will be low. The observation that a seasonal pattern of camera sales exists is consistent with these hypotheses (e.g. Photo Dealer, December 1966, p. 53, 58). The average yearly temperature for a major city was used as the operational measure of temperature while the average rainfall per year in a major city was used as the operational measure of rainfall. These variables exhibited wide variations across countries. Year to year variations were, of course, expected to be negligible.

Another variable which could lead to differences among countries is the rate of change of economic ability to purchase. This variable might lead to changes in aspirations of consuners-..i.e. desire to step up to a new type of good or to a newer model of a good. A measure of rate of change in gross national product per capita (at constant prices) was used as the,operational measure. Substantial differences 
existed among countries with respect to this measure.

Discussion of the Operational Measures

All of the variables of the sales forecasting model, with the exception of quality ${ }^{\mathcal{L}}$, varied substantially in the international cross-section. That implied that the effects of each of these variables should be accounted for in the measurement model. Measures were available for most countries for each of these variables.

The measure of camera sales, discussed in Chapter 5, showed substantial variation among years for any given country. To dampen out the effects of random measurement error in this sales measure, an average of six years was used. The number of potential buyers in each country was obtained on the basis of a priori estimates only. The dependent variable was then expressed in terms of camera sales per potential buyer.

An attempt was made to obtain estimates for the elasticities of personal consumption expenditures, camera price, number of households per adult, proportion of children, temperature, rainfall and rate of growth of income. A description of the operational measures had been provided earlier. Some further discussion was called for, however, with respect to economic ability to purchase since there are serious problems in obtaining measures which are comparable across countries. These problems do not arise

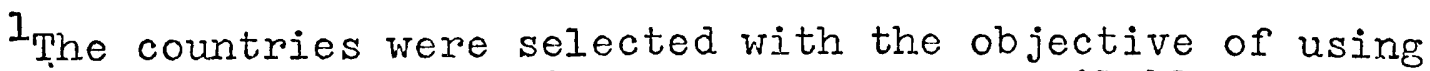
only countries in which similar cameras were available for purchase. 
when the concern is with forecasting changes over time for a specific country.

The problem of comparability of income measures across countries has been widely discussed. McGranahan, 1966, provides a good summary. Briefly stated, the major problems are that the proportion of non-market transactions varies widely among countries and such transactions are seldom included in the national income; the exchange rate used to convert all currencies to a common base does not always represent a true market rate; and, finally, the accuracy of data collection varies widely with lesser developed countries often having inadequate data collection capabilities. The net result of these problems is to introduce both random and systematic errors into the estimate of income elasticity. The random error leads to a lack of precision and to a bias toward zero. The systematic error leads to a lack of precision (due to heteroscedasticity) and to a bias towards zero (due to overstatement of the differences between rich and poor countries).

In view of the problems discussed above it was decided that alternative measures of economic ability to buy should be considered. A number of researchers have dealt with the problem of cross-national comparisons of ability to buy by arguing that what is really needed is a measure of the standard of living. Such an approach would seem useful for getting around some of the measurement problems in that the standard of living indices are generally based on physical outputs which are more easily measured than expenditures. 
The measurement of standard of living is not an easy task. ${ }^{I}$ There is a wide variety of indicators that one might chose from in creating such an index. A decision must also be made as to how these indicators should be combined. Three basic approaches have been used-- subjective weightings, factor analysis, and regression analysis.

Subjective weightings lack in sophistication but would seem to be the logical first candidate as an approach to measuring standard of living. The work of Cseh-Szombarthy (1962) is especially noteworthy. He uses consumption of food, clothing, housing, transportation, communication, health, entertainment, and education and has weighted each component by its proportion of total expenditure in a typical country. Unfortunately, work in this area has not been very extensive and adequate data were not available for the camera study.

Factor analysis is currently receiving a great deal of attention for the analysis of international data. Most of these studies identify one factor as a measure of standard of living. Problems with this non-theoretical approach are discussed in more detail in Appendix C. The conclusion from Appendix $C$ was that factor analysis had little to offer this study.

Regression models generally use a measure of income as the dependent variable and have a wide variety of independent variables. Beckerman's(1966) non-monetary index

$I_{\text {Beckerman(1966) has provided an excellent review of }}$ the attempts to measure standard of living. 
of real. private consumption uses such an approach. This approach appears to be most suitable for the camera study in that biases due to measurement error are not expected to be so serious.

The measurement problem for ability to buy was not quite so serious as it may appear above due to the fact that differences among countries were very large. The richest country (U. S.) was about 25 times as rich as the poorest country (Thailand) in this sample. You do not need a very accurate ruler to learn that an elephant is taller than a mouse.

\section{The Data}

The original sample of 31 countries was randomly split into two subsamples of sizes 20 and 11 . To obtain the subsamples, the data were first grouped by the three quality classes of Appendix A. Within each quality grouping the data were ordered by camera sales. Every other country was then selected from the two highest quality classes. The former subsample was used for analysis while the latter was retained to test concurrent validity.

Data for the 31 countries are presented in Table 7-8. A further description may be found in Appendix $B$.

\section{A Priori Analysis}

A subjective evaluation was made of the potential sources of bias associated with the international cross-section. Errors in the independent variables were a prime source of bias. There were systematic sources of error 
TABLE 7-8

1960-1965 DATA ON F'ACTORS CAUSING VARIATION IN CAMERA SALES AMONG COUNTRIES

\begin{tabular}{|c|c|c|c|c|c|c|c|c|}
\hline Country & 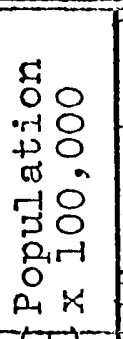 & 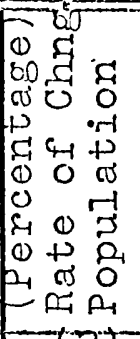 & 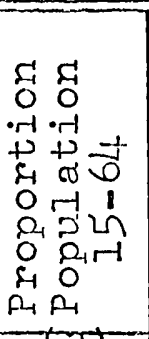 & 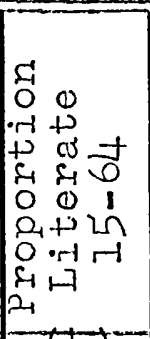 & 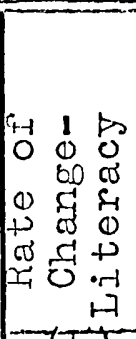 & 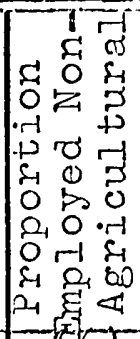 & 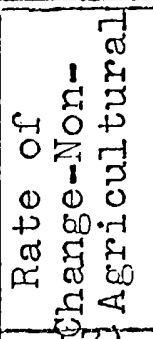 & 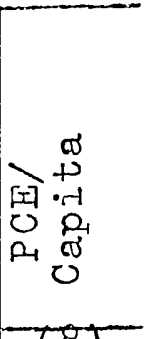 \\
\hline & $(I)$ & $72)$ & (3) & $(4)$ & (5) & -6 & (रेग) & $(8)$ \\
\hline Austria & 7] & 0.4 & .665 & .985 & 0.0 & .70 & 0.2 & 617 \\
\hline Belgium $L$ Lux. & 96 & 0.7 & .646 & .980 & 0.2 & - & 0.2 & 1018 \\
\hline Denmark ${ }_{\mathrm{b}}^{\mathrm{b}}$ & 46 & 0.7 & .639 & .985 & $0.1^{\circ}$ & .7 & 0.4 & 999 \\
\hline Finl and & 46 & 0.9 & .626 & .985 & $0 . \overline{9}$ & .6 & 1 & 676 \\
\hline France & 468 & 1.2 & .624 & .980 & 0.1 & .76 & 0 & 961 \\
\hline W.Germany & 550 & 1.2 & .677 & .985 & 0.1 & & 0 & 890 \\
\hline eland & 28 & -0.2 & $\cdot 5$ & .900 & 0 & .66 & 0 & 551 \\
\hline aly & 500 & 0.7 & .662 & .916 & & .71 & 0 & 466 \\
\hline therl ands & 118 & 1.3 & .6 & .985 & & .89 & & 653 \\
\hline Norway & 36 & 0.8 & .632 & .985 & & $\bullet$ & & 843 \\
\hline Portugal & 91 & 0.7 & .634 & .565 & 0 & .53 & . & 242 \\
\hline Spain & 309 & 0.8 & .644 & .870 & 0 & .50 & & 265 \\
\hline Sweden ${ }^{b}$ & 76 & 0.6 & .660 & .985 & & .87 & 0 & 1096 \\
\hline Switzerland & 56 & 1.8 & .662 & .985 & 0. & .88 & 0 & 1082 \\
\hline U. Kingdom & 534 & 0.6 & .653 & .985 & 0.1 & .96 & 0.1 & 957 \\
\hline Canada & 189 & 2.2 & .591 & .980 & 0 & .88 & .1 & 1271 \\
\hline S. & 1881 & 1.6 & .597 & .980 & 0 . & .92 & 0 & 1867 \\
\hline Argentina & 208 & 1.7 & .649 & .870 & 0 & .75 & 0 & 234 \\
\hline Brazil & 767 & 3. & .556 & .540 & & & & 127 \\
\hline Guatemala & $4]$. & 3 & .553 & .350 & 0 。 & & & 144 \\
\hline Mexico & 381 & 3.6 & .522 & .600 & 0 . & .43 & & 259 \\
\hline Peru & 112 & 2. & $=529$ & .500 & 0.5 & .40 & 0.3 & 150 \\
\hline Venezuela $a^{b}$ & 80 & 3.6 & .553 & .587 & 1 . & .68 & 1. & $4 \longdiv { 4 6 }$ \\
\hline Australia & 108 & 2.1 & .614 & .985 & & .88 & & 1024 \\
\hline N. ZeaI and & 25 & 2 & .585 & .985 & & 6 & & 1082 \\
\hline Japan & 955 & 1.0 & .642 & . 980 & & .61 & & 287 \\
\hline Thail and & 284 & & .553 & .680 & 1 . & .18 & & 80 \\
\hline Iraq & 76 & $J$ & .499 & .150 & 0.1 & .19 & 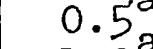 & 153 \\
\hline Israel & 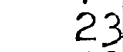 & - & .591 & $. 8 \longdiv { 4 2 }$ & 1. & .8 & & 610 \\
\hline S. Africa & 168 & 2 & .5 & .400 & & & & 287 \\
\hline Yugoslavia & 18 & 7 & & .770 & & & & \\
\hline$(n=31) c$ & 274 & 1.7 & .608 & .815 & 0.4 & 68 & . & U \\
\hline & & & & & & & & \\
\hline
\end{tabular}

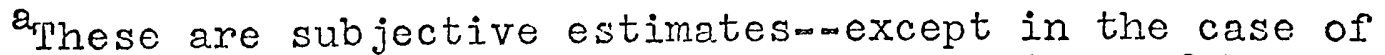
price where it refers to estimates from the price model.

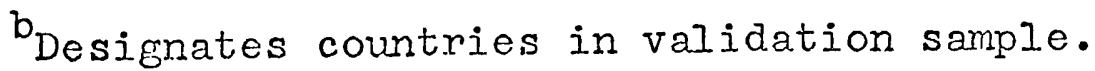

${ }^{c}$ Averages pertain only to the 30 countries used in the international cross-section (i.e. Spain is excluded). 
TABLE 7-8--Continued

\begin{tabular}{|c|c|c|c|c|c|c|c|c|}
\hline Country & 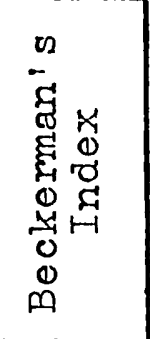 & 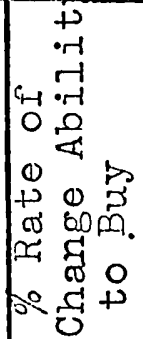 & 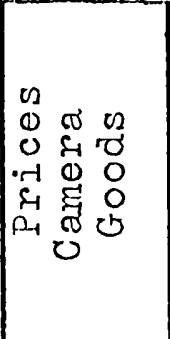 & 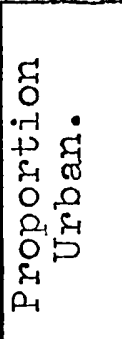 & 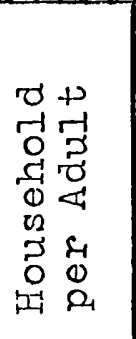 & 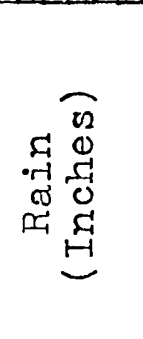 & 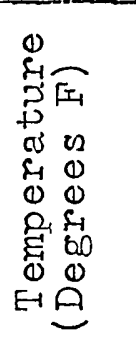 & 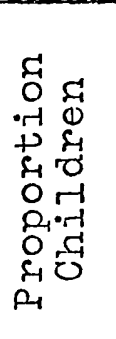 \\
\hline 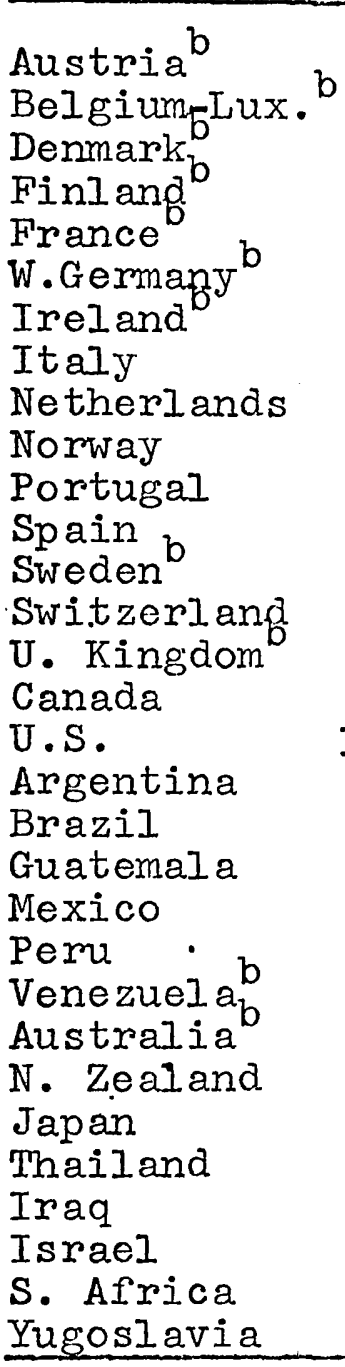 & $\begin{array}{l}(.91 \\
.454 \\
.594 \\
.659 \\
.465 \\
.605 \\
.645 \\
.244 \\
.353 \\
.503 \\
.634 \\
.193 \\
.195 \\
.855 \\
.645 \\
.659 \\
.811 \\
1.057 \\
.238 \\
.126 \\
.107 \\
.149 \\
.088 \\
.199 \\
.689 \\
.612 \\
.356 \\
.040 \\
.102 \\
.324 \\
.282 \\
.161 \\
\end{array}$ & $\begin{array}{l}(10) \\
4 \cdot 4 \\
4 \cdot 2 \\
4 \cdot 4 \\
4 \cdot 9 \\
4 \cdot 4 \\
5 \cdot 7 \\
4 \cdot 2 \\
5 \cdot 6 \\
4 \cdot 6 \\
4 \cdot 1 \\
5 \cdot 2 \\
5.9 \\
4 \cdot 1 \\
3.5 \\
2.7 \\
2.1 \\
2.3 \\
0.0 \\
1.6 \\
2.7 \\
4 \cdot 4 \\
3.2 \\
2.1 \\
2.1 \\
1.7 \\
9.0 \\
3 \cdot 5 \\
5.1 \\
6.3 \\
3.4 \\
7.3 \\
\end{array}$ & $\begin{array}{l}111) \\
1.02 \\
1.05 \\
.86 \\
1.09 \\
.92 \\
.90 \\
1.10 \\
.94 \\
.93 \\
1.03 \\
1.17 \\
.95 \\
.83 \\
.81 \\
1.19 \\
.99 \\
.87 \\
1.50 \\
1.55 \\
1.15 a \\
1.07 \\
1.26 a \\
1.01 \\
.94 \\
1.119 \\
.76 \\
1.03 \\
.919 \\
1.56 a \\
1.00 \\
1.33 a \\
\end{array}$ & $\begin{array}{l}(12) \\
.39 \\
.32 \\
.49 \\
.33 \\
.32 \\
.48 \\
.36 \\
.32 \\
.50 \\
.36 \\
.17 \\
.45 \\
.41 \\
.30 \\
.67 \\
.39 \\
.53 \\
.50 \\
.29 \\
.12 \\
.30 \\
.14 \\
.47 \\
.60 \\
.60 \\
.47 \\
.08 \\
.24 \\
.61 \\
.33 \\
.19 \\
\end{array}$ & $\begin{array}{l}.13) \\
.51 \\
.51 \\
.54 \\
.50 \\
.52 \\
.53 \\
.42 \\
.42 \\
.45 \\
.53 \\
.40 \\
.43 \\
.54 \\
.45 \\
.51 \\
.44 \\
.51 \\
.42 \\
.35 \\
.37 \\
.38 \\
.38 \\
.33 \\
.43 \\
.50 \\
.37 \\
.31 \\
.47 \\
.46 \\
.54 \\
.40 \\
\end{array}$ & 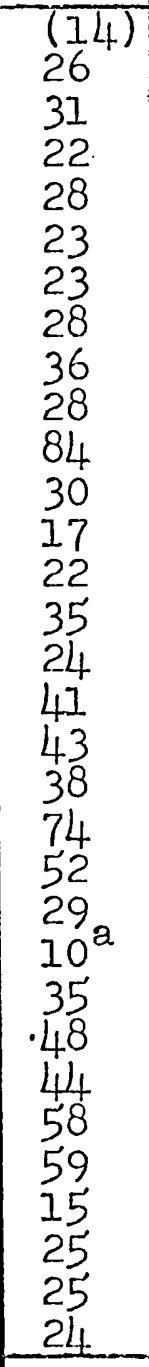 & 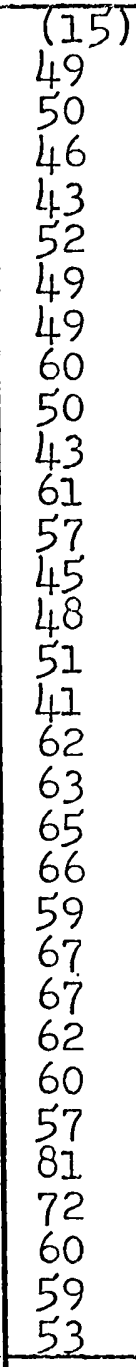 & $\begin{array}{l}(16) \\
.22 \\
.23 \\
.25 \\
.30 \\
.25 \\
.22 \\
.30 \\
.25 \\
.30 \\
.26 \\
.29 \\
.27 \\
.22 \\
.23 \\
.23 \\
.34 \\
.31 \\
.30 \\
.42 \\
.42 \\
.44 \\
.44 \\
.45 \\
.30 \\
.33 \\
.29 \\
.45 \\
.45 \\
.36 \\
.37 \\
.32 \\
\end{array}$ \\
\hline $\begin{array}{l}(\mathrm{n}=31) \\
\text { Averages }\end{array}$ & .420 & & 1.06 & $\cdot 38$ & .44 & 35 & 56 & $\cdot 32$ \\
\hline
\end{tabular}


which might also lead to bias. The systematic measurement error in Beckerman's index is expected to lead to a bias in the elasticity of roughly -0.3. In addition, bias is expected to exist for the measures of households per adult and proportion of children since each of these variables is also a measure of ability to buy. The elasticity of the former is expected to be increased slightly $(+0.1)$ while the latter's. elasticity is expected to be reduced slightly (-0.1). Temperature is also a measure of ability to buy since it is cheaper to live in warmer climates. This bias was estimated at -0.8 .

Another source of systematic error which was considered was the influence of "simultaneous causality". I In particular, it was thought that an increase in camera sales may lead to production and distribution economies within a country such that a reduction occurs in camera prices. This reduction in camera prices in turn leads to a further increase in sales-. then to further economies, etc. In the international cross-section only the net effect of such changes would be observed. The effect upon the estimate of price elasticity may be interpreted in terms of an excluded variable--sales--which is negatively correlated to price. This would result in the price elasticity "getting credit" for economies due to sales increases. The resulting price elasticity would be biased negatively.

A rather lengthy consideration of the effects of simultaneous causality led to the conclusion that a subjective estimate of such effects would be sufficient for this study. There were two reasons for this conclusion. First; it was

${ }^{1}$ Also referred to as feedback loops or as the "identification problem". 
expected that the economies of scale were not substantial; and, second, the available estimating techniques to account for simultaneous causality make assumptions which are not realistic for the camera model. In particular, the assumption is made that there is no measurement error. Morganstern (1963, pp. 107-16) presents some interesting examples as to what happens when measurement error is present and simultaneous estimation techniques are used. Also of importance is the fact that the current simultaneous estimation techniques are developed to provide consistent estimators--i.e. estimators which are unbiased for an infinitely large sample size. The cross-sectional sample could hardly be called large.

The subjective estimate of the bias due to simultaneous causality between price and sales was .0 .1 (i.e. the estimated price elasticity will be reduced by 0.1 ).

Table 7-9 summarizes the a priori estimates of bias. The a priori estimates of causal elasticities ${ }^{l}$ were adjusted by adding the systematic error and then multiplying by the bias factor for error to provide a priori estimates of the regression coefficients.

$I_{A}$ priori estimates for the nuisance variables are of minor importance. They were obtained by asking hypothetical questions-what differences in camera sales are expected between country $I$ which is highest on variable $Z$ and country 2 which is lowest on variable $Z$-assuming that the countries are equal in all other respects. The primary goal here was to ensure that the estimates were reasonable. 
TABLE 7-9 A PRIORI ESTIMATES: INTERNATIONAL
CROSS-SECTION ON SALES

\begin{tabular}{|c|c|c|c|c|}
\hline Variable & $\begin{array}{l}\text { Causal } \\
\text { Elasticity }\end{array}$ & $\begin{array}{l}\text { Bias due to } \\
\text { Systematic } \\
\text { Errors }\end{array}$ & $\begin{array}{l}\text { Bias due to. } \\
\text { Errors in } \\
\text { Variables }\end{array}$ & $\begin{array}{l}\text { Regression } \\
\text { Coefficients }\end{array}$ \\
\hline & & (EIasticity) & (Proporticr) & \\
\hline $\begin{array}{l}\text { Beckerman's Index } \\
\text { Camera Price } \\
\text { Households/Adult } \\
\text { Proportion Children } \\
\text { Temperature } \\
\text { Rainfall } \\
\text { Growth in Income }\end{array}$ & $\begin{array}{l}+1.3 \\
-1.4 \\
+0.8 \\
+0.2 \\
+0.6 \\
+0.1 \\
+4.0\end{array}$ & $\begin{array}{l}-0.3 \\
-0.1 \\
+0.1 \\
-0.1 \\
+0.8 \\
-\infty- \\
-\infty-\end{array}$ & $\begin{array}{l}0.9 \\
0.6 \\
0.8 \\
0.8 \\
0.8 \\
0.8 \\
0.7\end{array}$ & $\begin{array}{l}+0.9 \\
-0.9 \\
+0.7 \\
+0.1 \\
+1.7 \\
+0.1 \\
+3.0\end{array}$ \\
\hline
\end{tabular}

Note: All values rounded for presentation

$\underline{\text { Results }}$

Spain was excluded from the sample since it was an outlier on an initial run. This reduced the analysis sample to 19. The exclusion of this outlier resulted in a sizable increase in $\mathrm{R}^{2}$ but did not have much effect upon the parameter estimates. Table 7-10 presents the results for the original formulation of the international cross-section.

\section{TABLE $7-10$}

REGRESSION ON TNTERNATIONAL CROSS-SECTION: ORIGINAL FORM $(\mathrm{n}=19)$

Prior Estimates

$$
(0.9)(-0.9)(0.7)(1.1)(-0.1)
$$

Estimated Model $R^{\prime}=5.73+0.88 E^{\prime}-2.10 P^{\prime}+0.9 B^{\prime}+0.2 T^{\prime}-0.5 W^{\prime}$

Standard Errors

$$
(0.13)(0.25)(0.61)(0.43)(0.10)
$$

Coef. of Variation (0.94)

$$
(0.79)(0.22)(0.15)(0.16)(0.48)
$$

$$
\mathrm{R}^{2}=0.975 \quad \text { Standard Error }=0.20
$$

where the prime notation indicates natural logs and

$R$ is camera sales per year per potential buyer (average for 1960-1965)

$E$ is Beckerman's standard of living index

$P$ is the price of camera goods

$B$ is potential borrowing: the number of households per adult

$T$ is the average yearly temperature (degrees Farenheit)

$W$ is the average rainfall per year 
The signs (or direction of relationship) for each of the seven variables were in agreement with the a priori analysis. Two of the seven variables were excluded from this criginal formulation, however, due to serious problems with multicollinearity. These two variables were "the rate of change in personal consumption expenditures per capita" and "the proportion of the population under 15".

The agreement of the magnitudes of the regression coefficients with a priori estimates was only fair. Estimates for income and households per adult were very close to the a priori estimates but the case for the other variables was not nearly so favorable. The most serious deviation was in the estimation of price elasticity. Relationships among the various estimators are discussed in more detail in Chapter 8.

On the basis of the fit to the data these results appeared to be impressive. The model explained $97.5 \%$ of the variance among countries in terms of the natural $\mathrm{log}$ of the sales rate. I To provide a more useful measure of fit, the data were converted from logs back to the original units-and then the estimate of market size was used to estimate total camera sales for each country. Table 7-II shows the "actual" (based on trade and production statistics) and the "predicted" camera sales for each of the 19 countries.

$I_{\text {This measure of }} \mathrm{R}^{2}$ appears to be rather high for cross-sectional data. This is largely a result of the wide variation displayed by the dependent variable. ( $R^{2}$ is a measure of the ability of the model to explain deviations from the sample mean.) 
The $\mathrm{R}^{2}$ between actual and predicted was $99.614 \%$. A more meaningful statistic is the average absolute percentage error which was $13 \%$ (or, if you prefer, the standard deviation was $16 \%$ ).

TABLE $7-11$

"ACTUAI" VS. "PREDICTED" CAMERA SALES: INTERNATIONAL CROSS-SECTION ORIGINAL FORM- - (ANALYSIS SAMPLE)

\begin{tabular}{l|r|r|r|r}
\hline Country & $\begin{array}{c}\text { Actual } \\
\text { Sales }\end{array}$ & $\begin{array}{r}\text { Predicted } \\
\text { Sales }\end{array}$ & Difference & $\begin{array}{r}\text { Percent } \\
\text { Errorb }\end{array}$ \\
\hline Guatemala & 2,600 & 2,600 & 0 & 0 \\
Iraq & 5,300 & 4,400 & 900 & 19 \\
Israel & 13,000 & 11,800 & 1,200 & 10 \\
Thailand & 13,100 & 12,300 & 800 & 6 \\
Peru & 17,700 & 16,200 & 1,500 & 9 \\
Portugal & 25,300 & 27,000 & $-1,700$ & -6 \\
Brazil & 40,800 & 38,700 & 2,100 & 5 \\
Yugoslavia & 49,300 & 46,700 & 2,600 & 5 \\
Norway & 50,800 & 54,300 & $-3,500$ & -7 \\
Argentina & 56,100 & 71,100 & $-15,000$ & -23 \\
New Zealand & 66,300 & 42,900 & 23,400 & 43 \\
Mexico & 69,000 & 86,000 & $-17,000$ & -22 \\
South Africe & 89,200 & 98,500 & $-9,300$ & -10 \\
Switzerland & 264,000 & 220,000 & $4,4,000$ & 10 \\
Netherlands & 301,000 & 286,000 & 15,000 & 5 \\
Canada & 435,000 & $4,2,000$ & $-7,000$ & -2 \\
Italy & 513,000 & 692,000 & $-179,000$ & -30 \\
Japan & $1,600,000$ & $1,400,000$ & 200,000 & 13 \\
United States & $7,500,000$ & $9,300,000$ & $-1,800,000$ & -21 \\
\hline
\end{tabular}

Aifference $=$ Actual - Predicted

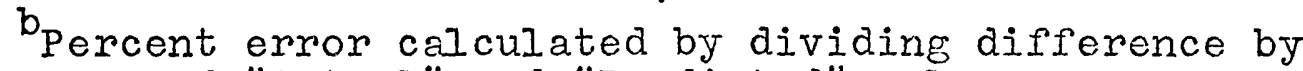
the average of "Actual" and "Predicted" sales.

Discussion

The international cross-section suffered seriously from problems with multicollinearity. The determinant of the correlation matrix was rather low (0.I) and there were high standard errors for some of the regression coefficients. The multicolinearity problem is due largely to the 
relationship between the measure of households per adult and Beckerman's Index. Not only are they correlated $(r=0.80)$, but it would seem that the latter variable would be a cause of the former. If so, the current formulation may not be the best way to handle such a relationship (a recursive system may be preferable for such a causal chain). The key issue revolves around how much of a distortion arjses from this simplification of reality. Certainly the use of the single equation model is simpler and less costly.

There are numerous strategies for coping with the problem of multicollinearity. The approach which will be utilized later in the chapter is to fix additional variables on the basis of outside information. This procedure reduces the number of paraineters to be estimated.

Plots of the residuals of the model against each of the independent variables did not show any patterns that would lead to a rejection of the multiplicative model. Furthermore, it was found that the fit of the multiplicative model was superior to those provided by linear, logistic or semi-log models.

An evaluation was carried out to see what gains were made by using Beckerman's Index rather than personal consumption expenditures per capita ( $P C E)$. Similar model formulations were used which included six independent variables. The elasticity for PCE was lower than that for Beckerman's Index $(0.64 \mathrm{vs} \cdot 0.90)$. This difference is very close to the prior expectation specified above. On the other hand, the standard error for PCE was slightly lower than that for 
Beckerman's Index $(0.24$ vs. 0.28) which was contrary to that predicted.

Each of the above measures led to a strong positive relationship between ability to buy and camera sales. Since each measure purports to measure the same conceptual variable, this agreement may be viewed as one indicator of construct validity.

The use of the proportion of farm employment in the estimate of market size was also evaluated by comparing it with a similar model which did not utilize that information. There were slight advantages in terms of the fit of the model for the use of farm employment but the gain was small. In summary, the assumptions upon which the original form of the international cross-section were based seem to have been reasonable. The analysis satisfied the major assumptions of the regression model and there was no reason to modify this measurement model in any major way.

Estinates for the Sales Model: Longitudinal Data

The longitudinal model had a great deal of intuitive appeal for use in the development of a forecasting model in that its structure was similar to that of the forecasting model. Many of the variables which led to differences among countries were controlled form-in contrast to the cross-sectional model where these variables had to be explicitly introduced into the model. The disadvantages of the longitudinal model were serious, however. Changes in the independent variables (over the four year time span which was used) were not large relative to the measurement error. In addition, 
quality, which was constant for the intemational cross-section, changed over the period considered and these changes were extremely difficult to measure. Finally, the sample size of 21 was not large.

In view of the problems associated with the longitudinal data, an attempt was made to estimate only the elasticities for price and PCE. The effects of quality and of changes in the number of potential buyers were handled by means of a priori estimates. There were no nuisance variables of any importance in this data set.

The measure of change in PCE was obtained from two different sources (see notes in Appendix B). Discrepancies among these two sets of estimates led to the conclusion that a substantial amount of measurement error exists. Russett et al (1964) discuss the measurement problems associated with this variable. Probably the most serious problem is that the measures usually relate only to growth in the industrialized sector of the economy. Thus, if the industrialized sector is small relative to the non-industrialized sector, growth rate does not really provide a good general measure of change in ability to buy.

In order to obtain estimates of camera prices, it was necessary to collect data on the causal var:ables from the price model for the periods $1964-65$ and 1960-61. Camera. prices were then estimated by using 1966-67 measured prices and computing changes in prices which resulted from changes in the causal factors. The camera price model (Figure 7-I) was used to predict prices for 1960-61 and 1964-65. 
A summary of the price estimates used in the longitudinal model is presented in Table 7-12. The number of potential buyers was estimated for each year by using data on the trends in population, literacy rate, and non-agricultural employment. Data on these rates of change as well as the change in PCE may be found in Table 7-8. Data on camera sales are presented in the Appendix in Table $B-5$.

\section{TABLE 7-12}

PREDICTIONS OF RETAIL PRICE INDEX FOR CAMERAS

\begin{tabular}{lcc}
\hline & $\begin{array}{c}\text { Camera Prices } \\
1964-65\end{array}$ & $\begin{array}{c}\text { Camera Prices } \\
1960-61\end{array}$ \\
\hline Austria & 1.00 & 1.14 \\
Belgium-Lux. & 1.04 & 1.16 \\
Denmark & 0.84 & 0.98 \\
Finland & 1.03 & 1.24 \\
France & 0.96 & 0.99 \\
W. Germany & 0.99 & 1.23 \\
Italy & 0.94 & 1.11 \\
Netherlands & 0.85 & 1.11 \\
Norway & 1.01 & 1.17 \\
Portugal & 1.20 & 1.24 \\
Spain & 0.94 & 1.16 \\
Sweden & 0.83 & 0.96 \\
Switzerland & 0.78 & 0.93 \\
U. Kingdom & 1.20 & 1.36 \\
Canada & 0.98 & 1.09 \\
U.S. & 0.86 & 0.92 \\
Mexico & 1.09 & 1.16 \\
Venezuela & 1.01 & 1.09 \\
Australia & 0.94 & 1.02 \\
Japan & 0.75 & 0.84 \\
Thailand & 1.03 & 1.10 \\
\hline
\end{tabular}

A Priori Analysis

The prime source of bias is that caused by errors in the independent variables. An additional source of bias, excluded variables, is expected to influence the estimate of PCE to a small extent since most excluded variables are 
expected to be correlated positively with income changes over this time period.

Since the longitudinal model is concerned about percentage changes rather than absolute levels, the constant term is of special interest. The constant represents a general percentage change in camera sales which occurs for the countries in the sample. It was expected that the constant term would reflect primaxily the effects of changes in quality. Therefore, the a priori estimate of the effect of quality was used--i.e. two percent per year increase in camera sales or eight percent over the given time period. I

While errors in variables cause bias toward zero for the independent variables, the bias in the constant term is toward the mean value of the dependent variable. In the current case this would mean a bias towards the average change in camera sales for the sample of countries. Balanced against this, however, is the fact that when excluded variables are positively correlated with included variables (as argued above) the constant term is underestimated. The net effect on the constant was thus uncertain; my expectation was that the constant term would be biased positively but not to any significant degree.

Table 7-13 presents the a priori estimates of bias and the resulting estimates of the regression coefficients for the longitudinal model.

I In operational terms, the constant term was fixed at the log of 1.08 (to approximate a two percent increase per year over the four year period). This value was subtracted from the log of the dependent variable for each country in the sample. 
TABLE $7-13$

A PRIORI ESTIMATES: IONGITUDINAL MODEL

\begin{tabular}{|c|c|c|c|c|}
\hline Variable & $\begin{array}{c}\text { Causal } \\
\text { Elasticity }\end{array}$ & $\begin{array}{l}\text { Bias } \\
\text { due to } \\
\text { Systematic } \\
\text { Error }\end{array}$ & $\begin{array}{l}\text { Bias due } \\
\text { to Errors } \\
\text { in Variables }\end{array}$ & $\begin{array}{l}\text { Regression } \\
\text { Coefficient }\end{array}$ \\
\hline $\begin{array}{l}\text { (Constant) } \\
\text { PCE } \\
\text { Price }\end{array}$ & $\begin{array}{l}1.08 \\
1.30 \\
1.40\end{array}$ & $+\ddot{0.1}$ & $\begin{array}{l}(+) \\
0.8 \\
0.6\end{array}$ & $\begin{array}{l}1.08^{+} \\
1.1 \\
0.8\end{array}$ \\
\hline
\end{tabular}

Results

The original form of this model fixed the constant term at a level equivalent to an increase in camera sales of two percent per year. Table $7-14$ presents the results of this analysis.

$$
\text { TABLE } 7-14
$$

REGRESSION ON LONGITUDINAL DATA: ORIGINAL FORM $(n=21)$

Prior Estimates Estimated Model Standard Errors

$$
\angle R^{\prime}=\begin{array}{ll}
(1.1) & (-0.8) \\
\left(1.6 \Delta \mathrm{E}^{\prime}\right. & -0.41 .0) \\
(1.0)
\end{array}
$$

Where the primes indicate natural logs, the $\Delta$ indicates changes between the 1960-61 average and the 1964-65 average and $R$ is the rate of camera sales per potential buyer $E$ is Beckerman's standard of living index $P$ is the price of camera goods

The results from the longitudinal model were disappointing. The coefficients were consistent with the prior estimates-but the standard errors of each estimate were so wide that the results would be consistent with substantially different prior estimates. The poor performance of this model was consistent with our expectations as outlined earlier. The model was re-run in free form (i.e. wi.thout fixing 
the constant) to examine the effect upon the parameter estimates and to test the reasonableness of fixing the constant term. The results showed some differences in parameter estimates. The PCE elasticity was 2.1 (vs. the 1.6 above) and the price elasticity was -0.64 (vs. the -0.41 above). In view of the low reliability of these estimates, the results were not surprising. On the other hand, the constant term did prove to be surprising. It indicated a yearly decrease in sales of $1 \%$ per year (vs. the prediction of a $2 \%$ increase).

The fit of the model in free form was very poor. The coefficient of determination, $\mathrm{R}^{2}$, was only 0.25 . This is equivalent to a reduction of only $15 \%$ in the standard error of the dependent variable.

In summary, the results for the longitudinal model were far from impressive. Improvements in this measurement model would seem dependent upon gaining more observations and more reliable data. The yearly collection of data on camera sales and camera prices would be expected to lead to substantial improvements in the quality of these data. To reconstruct events years later from secondary data appeared to be less than satisfactory.

Estimates for the Sales Model: Household Data

In contrast to data on countries which were obtained from records on the movement of goods, data in this section were obtained from statements by the consumers themselves. Since the emphasis was upon predicting behavior or consumers (or potential buyers) this approach had intuitive appeal. 
- The use of consumer survey data in a particular market is advantageous for the study of demand factors in that effects of market factors (e.g. price, quality, promotion, etc.) are held constant. Note the key assumption that the market factors are the same for all consumers. If households from different markets are used this advantage is lost--and one must then try to control for market differences by obtaining measures on these differences.

The use of consumer data is very promising for the development of a long-range sales-forecasting model. In addition to holding market factors constant, there are wide variations in some of the independent variables-most notably, income but also age distribution, household size, non-farm employment, and presence of children. Unfortunately, the ability to utilize consumer data was extremely limited in this study as the data were not available by individual ${ }^{l}$ but only in aggregate form (i.e. the data were average measures for groups of households). The aggregation reduces sample size and increases multicollinearity.

$I_{\text {The use of regression analysis for data by individual }}$ household has proven to be rather disappointing--e.g. Sultan, 1965, who studied purchases of durable goods used many predictor variables but obtained measures of $R^{2}$ which were generally less than $5 \%$. His measures of income elasticity were unrealistic-. from 0.1 to 0.4 . These results are not atypical. The problem seems to be that the assumptions of regression analysis are not suitable for such data (see Morgan and Sonquist, 1963). But then there is no need to restrict the analysis to the use of regression models. The so-called simulation approaches utilize multi-level cross-classifications rather successfully when dealing with such data. Comparisons of regression analysis with cross-classifications are provided by Montgomery and Armstrong (1968) and by Morgan and Sonquist (1963). 
Problems in dealing with grouped data have been discussed by Blalock (1964). The benefits of grouping lie in the possibility that factors which influence the dependent variable, but which have not been measured, may be brought under control. This problem is especially prevalent when dealing with household data since households differ on many dimensions while one usually has measures of only a few of these. In the camera model, the grouping had already been performed. The concern here was to try to evaluate the biases which might have been introduced by the particular manner of grouping. The household data set was used only to provide an estimate of income elasticity. It was desirable, however, to control for other sources of variation. In particular controls were used for education and life cycle. The education measure, percent of household heads completing high school, and the life cycle measure, percent of household heads between 25 and 54, were both used to identify potential buyers.

The method in which the data have been grouped--by income class--was convenient for this study since it ensured that there was variability in the income measure. But what effect did this grouping have upon estimates for the other variables? If these other variables were not correlated with income then nothing would be lost by grouping. In fact, there would be a gain since the random variation from these other variables is dampened by grouping. Unfortunately, the other variables were not expected to be uncorrelated-nvariables such as household size, age, and presence of children are related to income. The use of age and education measures in 
this model was an attempt to untangle some of these confounded effects. Still the effect of confounded variables was expected to be serious so that confidence in the income estimate from this measurement model was not high--even though the statistical significance was expected to be high.

\section{A Priori Analysis}

Data for this analysis were taken from the 1960-61 Life Study of Consumer Expenditures (Linden, 1965). These data are presented in the Appendix, Table B-6.

The operational measures for this data set differed substantially from those used in the data by country. The dependent variable was "household expenditures for camera goods per weighted household" in contrast to "unit camera sales per potential buyer". The measure of ability to buy was household income rather than PCE per capita or Beckerman's Index.

Assuming that richer people buy higher priced cameras the income elasticity for expenditures would be higher than the 1.3 estimated for unit sales. Burstein (1959), in his study on refrigerators, obtained an income elasticity with respect to unit price ranging between 0.25 and 0.50 . Our impression is that income elasticity for unit expenditure on cameras would not differ substantially from this estimate. An estimate of 0.3 for the income elasticity for unit price would bring the a priori estimate of the regression coefficient up to about 1.6 .

The effects of confounded variables were also expected 
to add to the estimated income elasticity. In particular, temporary yearly variations in incorne for a family aje expected to be related to the timing of durable goods purchases (Smith, 1962 presents some empirical evidence consistent with this hypothesis). The net effect was judged to add 0.2 to the estimated income elasticity--increasing the regression coefficient to 1.8 . Since the random measurement error was expected to be negligible (due to aggregation over many households) the a priori estimate of the income elasticity in this measurement model was 1.8 .

The effects of the age and education variables were completely specified on an a priori basis. The basic idea was to place a smaller weight upon household heads who fell outside of the 25 to 54 age bracket or who had not completed high school. The following weighting scheme was used; if the household head was between 25 and 54 and had completed high school, a weight of 1.0 was used; if he fit into neither category, a weight of 0.2 ; all other households received a. weight of 0.5 . Summary data are provided in Table 7-15.

\section{TABLE $7-15$}

EXPENDITURES ON CAMERA GOODS PER "WEIGHTED" HOUSEHOLD (1960-61 DATA FROM 12,000 HOUSEHOLDS IN U.S.)

Camera Goods Expenditures (Weighted HH/Year)
Average Income for that Income Category

$\begin{array}{rr}0.62 & \$ 2000 \\ 3.65 & 4000 \\ 6.77 & 6200 \\ 8.87 & 8700 \\ 12.33 & 12000 \\ 16.20 & 17000\end{array}$


Results

The regression estimate was based on a multiplicative relationship as in the previous measurement models. Table 7-16 summarizes the results.

TABLE 7-16

REGRESSION ON HOUSEHOLD SURVEY DATA $(n=6)$

Prior

$(1.8)$

Estimated Model

$R^{\prime}=-11.3+1.47 E^{\prime}$

Standard Error

$(0.20)$

Coefficient of Variation (0.66)

$$
R^{2}(c)=0.90
$$

where the prime indicates natural logs and

$R$ is the rate of expenditures on camera goods per weighted household

$E$ is the average income in that income category

The estimated income coefficient agreed reasonably well with the a priori estimate. The income coefficient also appeared to be very reliable (as the standard error is small). This must be viewed with caution since the high reliability does not imply high validity.

A plot of the residuals against income indicated that the multiplicate model had certain deficiencies. There were indications that the elasticity decreased as the level of income increased. This would call for some concern about Brecasts in the high income countries.

\section{Integrating the Estimates of Parameters for the Sales Model}

Four basic sources of data had been used to provide 
estimates for the sales forecasting model. First there was subjective information (on the part of this researcher) which was specified on an a priori basis. Then there were the three measurement modelsmon the cross-section and longitudinal data sets for countries and on the household survey data from the United States.

In order to utilize all of the above information in the sales model; a procedure was required for combining different estimates of the same parameters. The classical method for combining estimates from different measurement models has been presented by Durbin (1953). Each estimate is weighted inversely by its variance. This approach makes two basic assumptions; first that the estimates of the variance are unbiased and, second, that the estimates of the means are unbiased. ${ }^{I}$ The latter assumption, in particular, seems unreasonable for the camera forecasting model.

Bayesian statisticians are currently working on techniques for integrating various estimates. I am not, however, aware of any schemes which are both satisfactory and operational. As a result, a rather simple scheme was used. First, the estimate from each data set was adjusted by an a priori estimate of bias and then it was weighted inversely by its st andard error (instead of the sample variance).

In more general terms, the estimates are weighted by their reliability and it is assumed that the estimates are valid. This is a very tenuous assumption for non-experimental data. 
Re-estimating the International Cross-Section

Armed with a means for combining estimates, it was possible to go back to the international cross-section to incorporate two additional variables. These variables had been excluded due to lack of sufficient information (i.e. small sample size and high multicollinearity). By incorporating outside information to fix certain variables, it was possible to obtain estimates for the variable "proportion of children" (which appeared in the camera forecasting model) and "rate of growth in PCE per capita" (a nuisance variable).

An iterative procedure was used to carry out the re-estimation. Measures of minor importance --rainfall, temperature and households per adult-were fixed at the value in column 5 of Table 7-19 or at their estimated level from the original formulation of the international cross-section, whichever was closest to zero. ${ }^{1}$

The results for this "complete model" are presented in Table 7-17. The elasticity of households per adult was fixed at +0.8 ; of temperature at +0.2 ; and of rain at -0.2 in this model.

$I_{\text {The effect of random measurement error is to bring }}$ the estimate closer to zero. It was reasoned that if the cross-sectional estimate were higher than the weighted estimate, the discrepancy could not be attributed to the random measurement error in the cross-sectional model; if the cross-sectional estimate were lower, then the difference may be due to random measurement error. In the latter case the cross-sectional estimate itself was used since one must be concerned about the effects of measurement error in this cross-sectional model. (The regression coefficient compensates for measurement error in this particular data set.) 


\section{TABLE 7-17}

FIRST RE-ESTIMATION OF INTERNATIONAL CROSS-SECTION $(n=19)$

Prior Estimates $\quad(0.9)(-0.9)(0.1)(3.0)$

Estimated Model $R^{\prime}=5.14+0.95 \mathrm{E}^{\prime}-2.02 \mathrm{P}+0.5 \mathrm{C}+3.3 \mathrm{G}$ '

Standard Errors (0.11) $(0.33)(0.4)(3.3)$

Where the primes indicate natural logs and

$R$ is camera sales per year per potential buyer (ave. 1960-65)

$E$ is the price of camera goods

$C$ is the proportion of the population under 15

$G$ is the rate of growth of $P C E$

The two additional variables appeared to be consistent with a priori estimates. On the other hand, these estimates were not at all reliable as indicated by the sizes of the standard errors.

The procedure was carried further to improve the estimation of the price and income elasticities. Outside information was used to fix all other parameters of the model. Thus the coefficients of $C$ and $G$ were fixed (at the levels in column 5 Table 7-19) and only price and income elasticities were estimated. Finally, the price elasticity was fixed to yield an estimate for only income elasticity. Table 7-18 provides a brief summary of these results.

\section{TABLE $7-18$}

ADDITIONAL RE-ESTIMATION OF INTERNATIONAL CROSS-SECTION

Price and Income Only: $(C=0.2$ and $G=3.0)$

Estimated Model $R^{\prime}=4.87+0.91 \mathrm{E}^{\prime}-2.01 \mathrm{P}^{\prime}$

Standard Errors $\quad(0.07) \quad(0.29)$

Income Only: $\quad(P=-1.85)$

Estimated Model $R^{\prime}=4.87+0.93 E^{\prime}$

Standard Errors

$(0.06)$ 
By comparing the final version to the original formulation it may be noted that the standard error in the final version was lower for the income estimate, but that neither the price nor income elasticities differed substantially (the income estimate is up 0.05 while the price estimate is down $0.09)$.

Combining the Estimates

Table 7-19 presents a summary of the coefficients from each measurement model as well as the a priori estimates. It also provides weighted estimates which resulted from adjusting each coefficient for the a priori estimate of bias and then weighting inversely by the standard exror of estimate. For comparison the last column shows what estimates would have been obtained if no adjustment had been made for expected bias. In general, the differences were not large although the price elasticity showed an important difference.

\section{TABLE 7-19}

SUMMARY AND WEIGHTING OF ALTERNATIVE ESTIMATES FOR SALES MODEL (STANDARD ERRORS IN PARENTHESES)

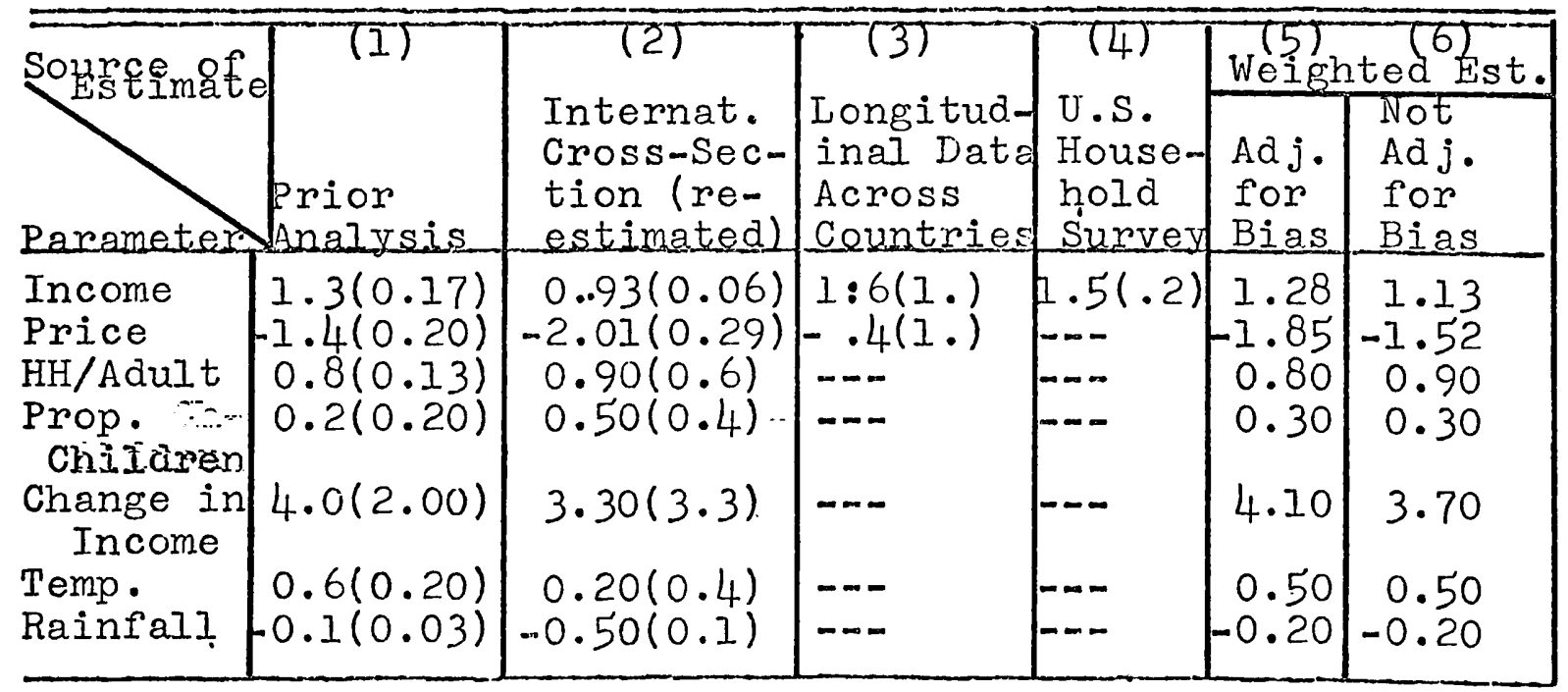




\section{Summary}

The price forecasting model was updated by using time series data from the U.S. (based on 1960-65 data from Sears Catalogues) to estimate the rate of technological change and also by analyzing the factors leading to differences in camera prices among 26 countries. The estimated effects of the causal factors in the price model--tariffs, taxes, percentage imports, resale price maintenance, and trade controls-agreed fairly well. With prior estimates although the fit of the model to the data was only moderate. The mean absolute percentage error in predicting price differences among countries was about 10 percent.

- Three measurement models were used to update estimates of the sales forecasting model. Regressions were used to analyze differences in the camera sales rates among 19 countries, differences in changes in camera sales from 1961 to 1965 for 21 countries, and differences among expenditures for camera goods among a sample of six income groups in the U.S: The models provided very close fits to the historical data with the exception of the Iongitudinal data where the $\mathrm{R}^{2}$ was only $25 \%$. 


\section{CHAPTER 8}

EVALUATING THE SALES FORECASTING MODEL

Tn Chapter 6 (and earlier) an appeal was made to "face validity". In other words, did the model proposed in this paper provide one reasonable way of structuring the problem? Chapter 7 demonstrated that the ability of the selected relationships to explain historical variations was rather high, that reliable estimates were obtained, and that the assumptions required by the statistical models were met. These are necessary ingredients of a good forecasting model--but they are far from sufficient to demonstrate that the model is useful.

In this chapter two approaches are used to evaluate the validity of the model. The first, a test of construct validity, examines how well the estimates from the different approaches agreed with one another. The second approach examines predictive validity. Predictions were made of sales in eleven "new" countries for 1960-65 and for seventeen countries in 1954.

\section{Testing Construct Validity: The Consistency of the Estimates}

In comparing estimates from different sources one must be concerned about both the reliability and validity of the estimates. Standard errors were used as an indicator of reliability. The a priori estimates of bias were subtracted to improve the validity of the estimates. These "adjusted" estimates were then considered to be unbiased and confidence intervals for each estimate were obtained from the standard errors. Comparison of various estimates of the same parameter 
were then made to test constmict validity. ${ }^{1}$

Price and income were the only variables of importance for which various estimates were available. Results for these two causal relationships are presented in Figures 8-1 and 8-2. FIGURE 8-1

CONFIDENCE INTERVAISS FOR ESTIMATES OF REUATIONSHIP BETWEEN INCOME AND SALES

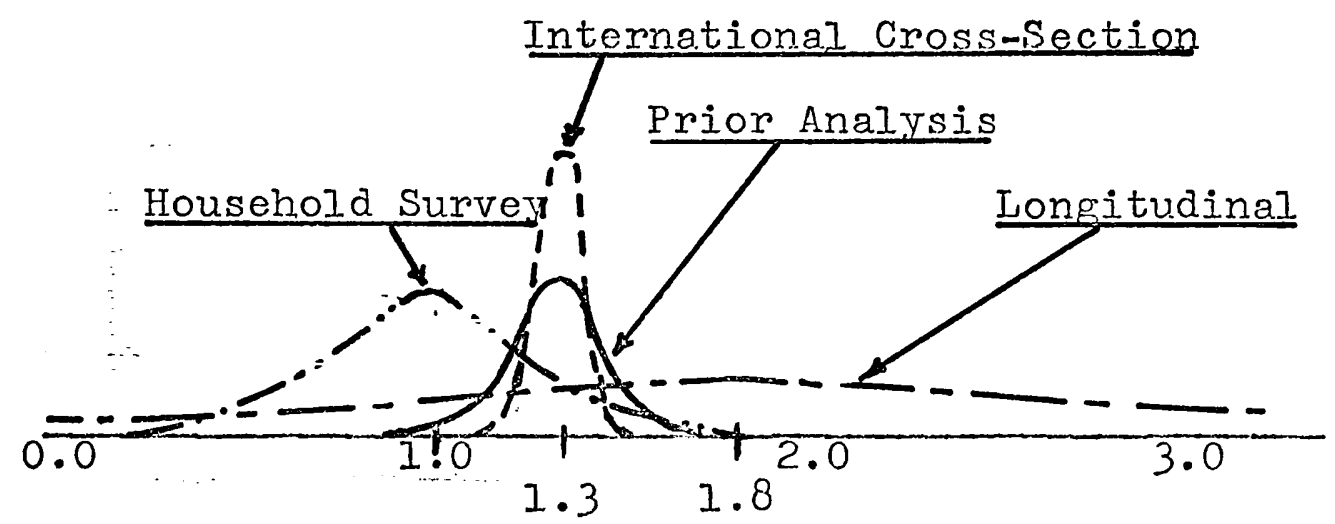

Estimated Elasticity

FIGURE 8-2

CONFIDENCE INTERVALS FOR ESTIMATES OF RELATIONSHIP BETWEEN PRICE AND SALES

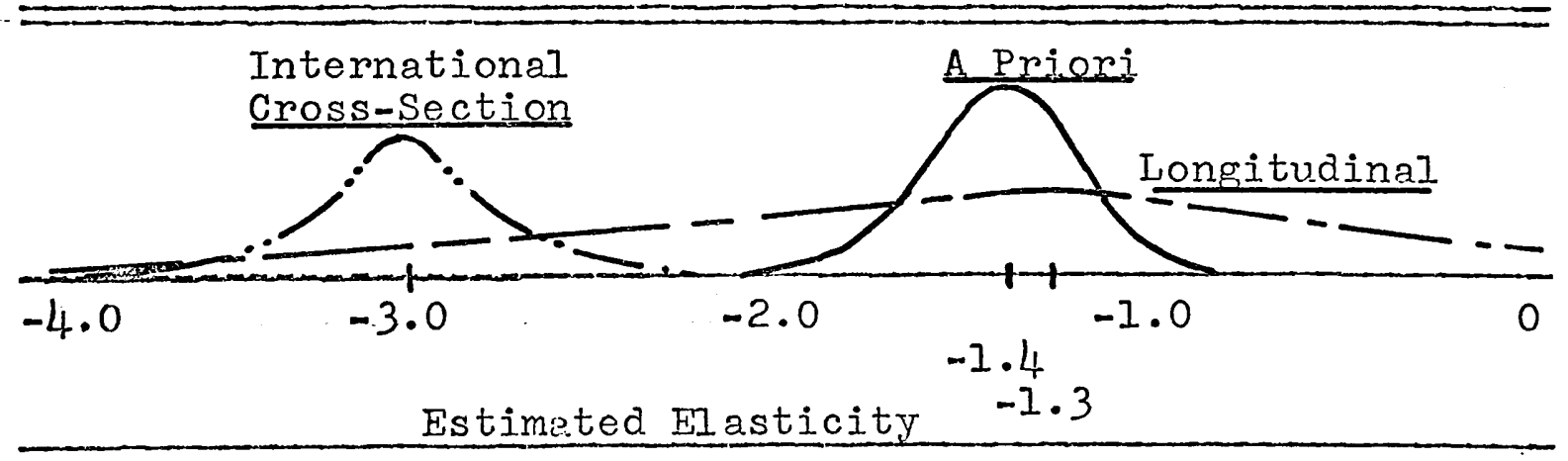

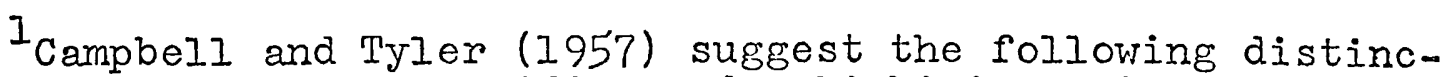
tion between construct validity and reliability. Construct validity refers to the agreement among results from approaches which are "as different as possible"; reliability refers to the agreement among axproadies which are "as similar as possible". 
The results in Figure $8-1$ for economic ability to purchase were in exceptionally close agreement. The probability that the true parameter lay, in the region from 1.0 to 1.6 appeared to be rather high.

The situation for price elasticity (Figure 8-2) was not so favorable. The a priori estimate did not appear to be consistent with the estimate from the international cross-section. There was no value for the price elasticity which would seem consistent with all of the data sets. Such a result lessened confidence in the measurement of the relationship between price and sales.

The above analysis indicated that it was reasonable to generalize about the relationship between ability to buy and camera sales. It also indicated that, while the relationship between camera prices and camera sales was strong, there were differences among the estimates which could lead to important differences in any long range forecasts based on these estimates.

There did not seern to be much of a problem in obtaining reliable estimates-but there were problems in obtaining valid estimates. Validity may be improved by a more intensive analysis of each data set. My impression, howeyer, is that, for the same expenditure of research funds, greater gains might beobtained by searching for more different types of data sets. For example, to gain further estimates of price elasticity one might use data from shopping experiments, ask people what they would do if prices of cameras changed, search for accurate time series data in a geographical region where substantial 
changes occurred in the prices of cameras, or analyze data kased on different types of aggregation (e.g. states in the U.S.).

\section{Predicting 1960-65' Camera Sales for "New" Countries}

Eleven countries had been selected from the original international cross-section to be saved for a test of predictive validity. There was a problem associated with this test in that sources of bias which were present in the analysis sample of the international cross-section were quite likely to be present in about the same degree in the "validation" sample. In line with Campbell and Tyler's distinction (1957) it may be more reasonable to view this as a test of reliability than as a test of validity. Whatever one calls this evaluation, it did serve some useful functions. The first, and most important, was to guard against chance relationships in the fitting process. This was important in cases where there were many predictor variables, few observations, and the data were non-experimental. A second reason was to guard against "mistakes". Mistakes could easily have occurred in data collection or in calculations and could have led to "significant" results. Finally, the use of this virgin data allowed for the use of statistical tests of hypotheses. The prediction of the $1960-65$ sales for the eleven countries corresponded to the situation where no historical sales data were available. Figure 8-3 summarizes the sales forecasting model. It will be noted that the coefficients in this model are not the estimated causal elasticities. This is because the causal elasticities would only yield optimum 
forecasts if there were no error in the predictions of the independent variables. This is analagous to the discussion of bias from errors in the independent variables (see Chapter 5). It turns out that the forecast coefficients were based on the regression coefficients from the international cross-section. I These coefficients compensate for the errors in the independent variables. In fact, it should now be evident that this type of bias is not all bad. The regression coefficients are not unbiased estimates of causal elasticities but they are optimum forecasting coefficients when the forecasting situation conforms exactly to the measurement situation.

\section{FIGURE 8-3}

SALES FORECASTING MODEL (ASSUMING NO CURRENT SALES DATA)

$R^{\prime}=4.87+0.93 E^{\prime}-1.85^{\prime}+0.8 B^{\prime}+0.2 T^{\prime}-0.2 R^{\prime}+0.3 C^{\prime}+3.0 G^{\prime}$

where primes denote natural logs and

$R$ is camera sales per potential buyer

$E$ is Beckerman's standard of Iiving index

$P$ is price of camera goods

$B$ is the buying units index (households per adult)

$T$ is temperature

$R$ is rainfall

$C$ is proportion of children in the population

$G$ is growth in per capita income per year

$M=(T)(L)(A)(N)^{0.3}$

where

$M$ is number of potential buyers

$T$ is total population

$L$ is literacy rate

$A$ is proportion of population 15-64

$\mathrm{N}$ is proportion of non-agricultural employment

$L=(R) \quad(M)$

where

$I$ is the long-mun camera sales rate

${ }^{I}$ Specifically, the estimates were those used in the final version of $\mathrm{T}_{\mathrm{a}}$ ble $7-18$. 
The application of this causal model to predict camera sales for the eleven countries in the validation sample yielded the results in column $\mathrm{A}$ of Table $8-1.1$ The mean absolute deviation of $31 \%$ was substantially higher than the $13 \%$ found in the analysis sample (see Table 7-II). It was expected that the error in the analysis sample would be smaller, of course, since the estimates were chosen to minimize errors in that sample. The size of the difference in errors was surprising, however. This difference could not be explained by having observations which were outside the range of the analysis data as this did not occur in the validation sample.

In passing, it might be pointed out. that the $R^{2}$ (between actual and "predicted" sales) for the analysis sample was over $99 \%$ while the $\mathrm{R}^{2}$ for the validation sample was only 88\%. There are a number of reasons for this (e.g. the variance among sales in the validation sample was smaller) but the key point is that, if it wasn't already obvious, the measure $R^{2}$ has serious problems if used as an indicator of predictive ability.

While the relative sizes of the errors were surprising, the magnitude of the error (i.e. $31 \%$ on the average) was not. Random measurement error was expected to be substantial. In view of the large effect of measurement error in the dependent

$I_{\text {Measured price data were used in this test. It would }}$ have been more appropriate, but of minor importance, to use predicted prices from the price model (Table 7-5). When predicted prices were used, the predictions were improved slightly (mean absolute percentage error $=27 \%$; average percentage error $=$ $-6 \%)$. This result was, of course, contrary to expectations. 


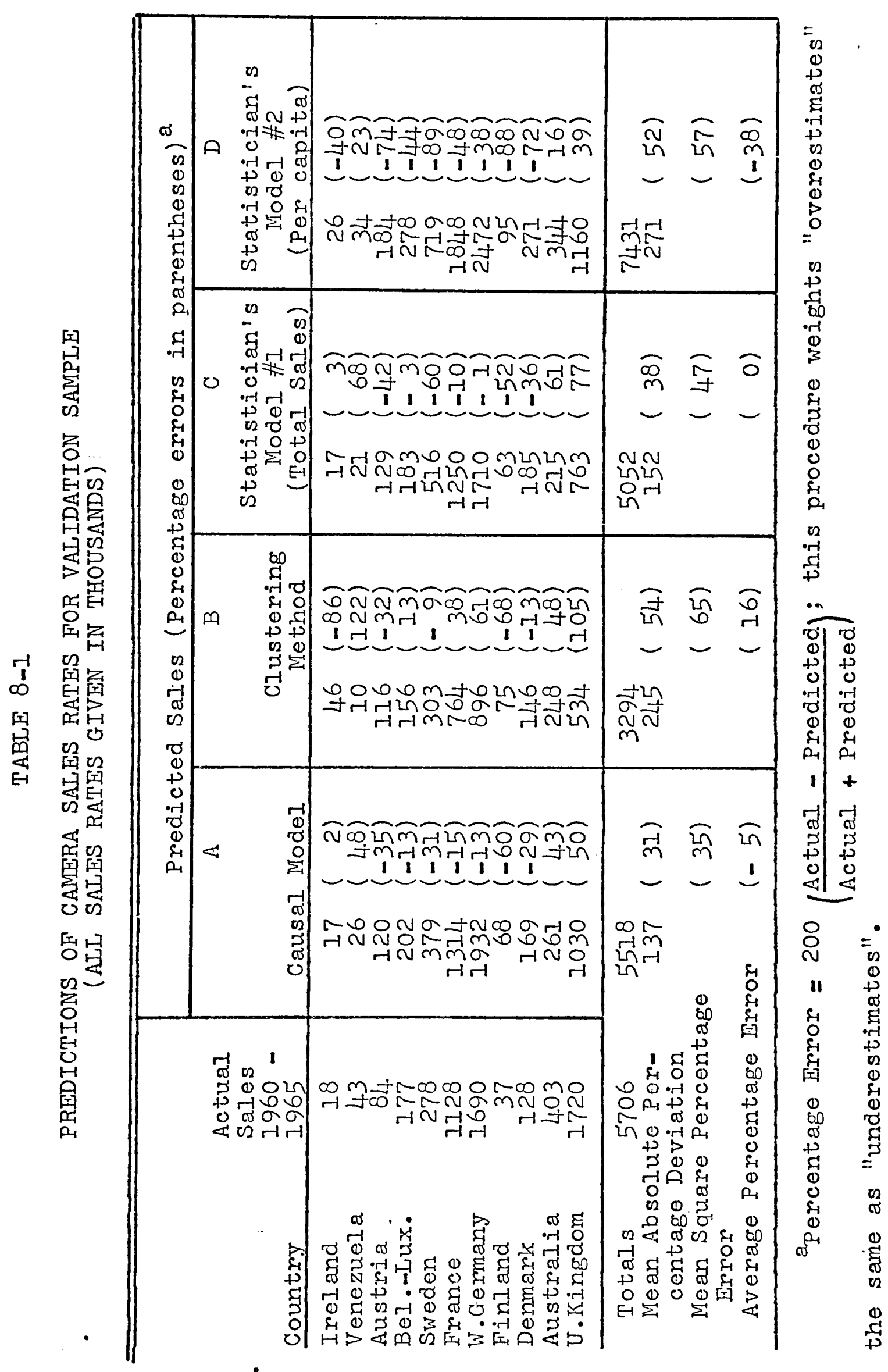


variable, it is difficult to believe that the $13 \%$ average absolute error obtained from the analysis sample was realistic.

Testing the Goodness of the Predictions

How good are these results? While the value of the results depends on the cost-benefit relationships in decisions which utilize the forecașts, comparative statements could be made about forecast accuracy. In more specific terms, did the causal model developed in this study provide better forecasts than any alternative model?

To set up some reasonable alternative hypotheses, it was first asked how managers might predict in the current situation. One possibility is that they group "similar" countries. Unfortunately, if they were asked to perform such a grouping now, they would be influenced by their knowledge of camera sales. One way to simulate this would be to assume that managers could keep track of a number of categories. One might use a type of cluster analysis to obtain groupings of "similar countries" within which the camera sales rate would be equal for each country.

A simple scheme was developed to obtain clusters of countries. Income was divided into three categories as was price to yield nine categories in all. Within each of these categories the sales rate per capita was calculated. These results are presented in Table $8 . .2$. The mean sales rate for each cell was then used as the prediction for any "new country" falling in that cell. (The categories "low income-medium price" and "low. income-high price" were collapsed to.yield prediction of 1.4 ) 
TABLE 8-2

AVERAGE SALES RATE PER CAPITA ${ }^{2}$ FOR COUNTRY GROUPINGS (ANALYSIS SAMPLE)

\begin{tabular}{|c|c|c|c|}
\hline & $\begin{array}{c}\text { tail Price Inde } \\
\text { Low } \\
(.90 \& \text { lower }) \\
\end{array}$ & $\begin{array}{c}\text { for Cameras } \\
\text { Medium } \\
(.91-1.19)\end{array}$ & $\begin{array}{c}\text { High } \\
\text { (1.20\& up) }\end{array}$ \\
\hline $\begin{array}{l}\text { High } \\
(.60 \text { \& up })\end{array}$ & $\begin{array}{l}39.8 \\
\text { U.S.S. }\end{array}$ & $\begin{array}{l}23.0 \\
\text { Canada }\end{array}$ & $\begin{array}{l}10.0 \\
\text { (sub jective } \\
\text { estimate) }\end{array}$ \\
\hline 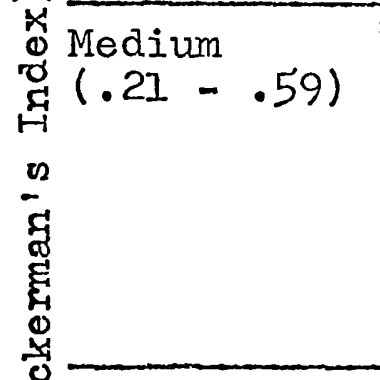 & $\begin{array}{l}31.7 \\
\text { Japan } \\
\text { Switzerl and }\end{array}$ & $\begin{array}{l}\text { 16. } 3 \\
\text { New Zeal and } \\
\text { Nomay } \\
\text { S. Africe } \\
\text { Netherlands } \\
\text { Italy }\end{array}$ & $\begin{array}{l}4.1 \\
\text { Argentina } \\
\text { Israel }\end{array}$ \\
\hline 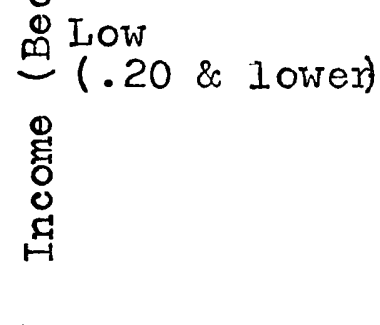 & $\begin{array}{l}30 \\
\begin{array}{c}\text { (subjective } \\
\text { estimate) }\end{array}\end{array}$ & $\begin{array}{l}\text { 1.3 } \\
\text { Portugal } \\
\text { Guatemala } \\
\text { Mexico } \\
\text { Thailand } \\
\text { Iraq }\end{array}$ & $\begin{array}{l}1.6 \\
\text { Peru } \\
\text { Yugoslavia } \\
\text { Brazil }\end{array}$ \\
\hline
\end{tabular}

actualiy expressed as sales per thousand people.

The clustering model seemed like a reasonable one in that it did utilize the three most important causal variables-. market size, price and income-and it also made few assumptions about the nature of the causal relationships. On the negative side it might be noted that the sample size was rather small making it difficult to obtain good estimates within some of the cells.

The performance of the causal model in forecasting new countries was clearly superior to that of the clustering model. The mean absolute percentage error was 23\% lower ( $31 \%$ vs. $54 \%$ ). The model also performed better on all other criteria. 
One might question whether these results were likely to occur by "chance"--after all, the sample size of eleven was not large. So adopting the role of the classical statistician, we assumed that unusual events do not happen to us and chose an alpha level of $5 \%$ to test the null hypothesis that the percentage errors of the causal model do not differ from those of the clustering model. A one-tail test was used since it was predicted that the causal model was superior. The student $t$ test was used to test the above hypothesis. The hypothesis that the models did not differ was rejected at the $5 \%$ level (calculated significance level $=4 \%$ ). Since it was possible that an extreme observation might dominate the comparison, the Wilcoxon Matched-pairs Signed Ranks test was also used (see Siegel, 1956). This test also rejected the null hypothesis at the 5\% level.

More important than the use of statistical significance was the general pattern of the results against multiple criteria. The causal model was superior to the clustering model in terms of mean absolute deviation of unit error, mean absoIute deviation of percentage error, average squared percentage error, average error, and total camera sales to the eleven countries.

\section{A Non-Theoretical Model}

To evaluate the benefits of the a priori analysis an alternative model was developed which utilized little prior knowledge. The only prior knowledge which was used involved the selection of sixteen "reasonable" causal variables. The 
UCLA Biomedical Stepwise Kegression Program $02 R^{I}$ was used to select from this list of variables (see Table 8-3).

\section{- TABLE 8-3}

LIST OF "REASONABLE VARIABLES" FOR PREDICTING CAMERA SALES (DATA BY COUNTRY)

1. Rate of change (per year) in total population

2. Proportion population between 15 and 64 years of age:

3. Proportion literate of those between 15 and 64

4. Proportion non-agricultural employment (of total employment).

5. National income

6. Beckerman's index of standard of living

7. Personal consumption expenditures per capita

8. Rate of change in personal consumption expenditures per capita

9. Proportion of population in cities over 20,000

10. Average yearly rainfall (inches)

11. Average temperature (degrees farenheit)

12. Number of households

13. Quality of data $(2=$ lower; 3 = medium; 4 = higher $)$

14. Price index for.camera goods

15. Population ....... . . : i.

16. Proportion of population less than 15 years of age

Statistical criteria were used to develop the model. Only variables which had a $t$ statistic of 2.0 or more were retained in the model. The "best" model was defined to be the model with the highest $R^{2}$ (adjusted for degrees of freedom). The data from the analysis sample of the international cross-section were used. Table $8-4$ presents the model which was developed. This was labeled Statistician's Model \#l.

It is evident that the seven predictor variables provided a close fit for the data as the $\mathrm{R}^{2}$ was $99.76 \%$ (slightly better than the $99.64 \%$ obtained for Table 7-11).

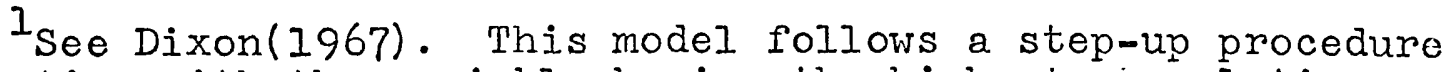
by starting with the variable having the highest correlation with the dependent variable and then entering the variable with the highest partial correlation in a step-by-step procedure. 
STATISTICIAN'S MODEL \#I: TOTAL CAMERA SALES

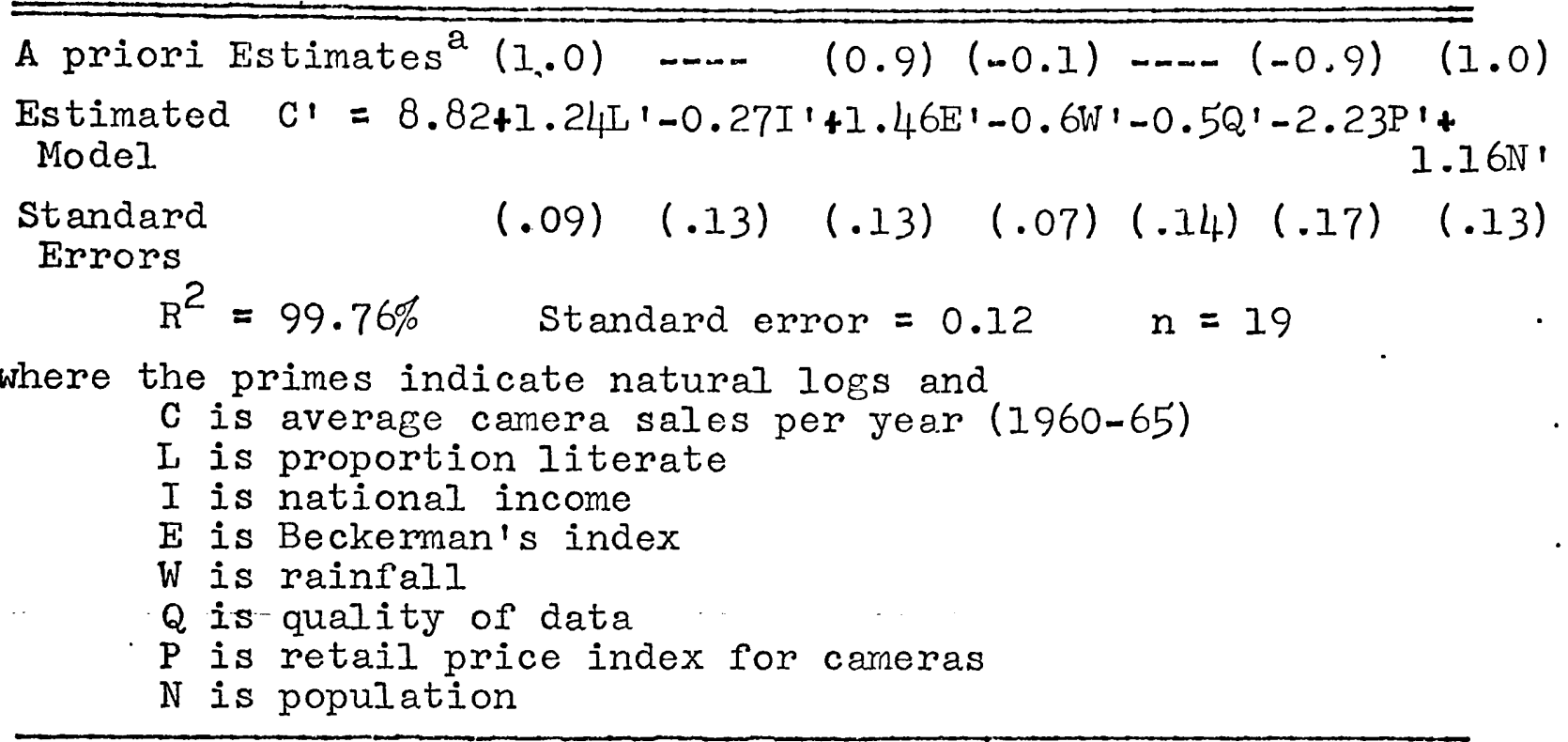

a These estimates, from Chapter 7, are put in for comparison.

The statistician's model did a decent job. The coefficients for literacy and population were not too different from the a priori estimates. The difference in the coefficient of Beckerman's index was rather large, however, in that it could lead to substantially different long-range forecasts. The coefficient of camera price also seemed to be on the high side, while the coefficient for national income was hard to rationalize (the sign was incorrect). Overall, this model did not perform as well as did the causal model in terms of agreement with a priori estimates.

The Statistician's Model \#l was then used to forecast sales in each of the countries of the validation sample. The results are presented in column $C$ of Table 8-1. This model dominated the clustering model on every criterion. In comparison with the causal model, however, it was inferior on 
all criteria with the exception of the average percentage error.

\section{A Per Capita Adjustment}

Since statisticians often follow the practice of ad.justing the data for scale, the analysis was repeated using camera sales per capita as the dependent variable. This was expected to lead to substantial improvements in the model. Table 8-5 presents the estimates derived from the analysis data.

TABLE 8-5

STATISTICIAN'S MODEL \#2--CANARA SALES PER CAPITA

A Priori Estimates

$(1.0) \ldots(0.9)(-0.1) \ldots(0.9)$ Estimated Model ${ }^{a} C^{* 4}=7.48+1.21 L^{\prime}-0.1 I^{\prime}+1.3 E^{\prime}-0.5 W^{\prime}-0.4 Q^{\prime}-2.2 P^{\prime}$ Standard Errors $\mathrm{R}^{2}=99.78 \%$ $(.09)(.03)(.05)(.06)(.14)(.17)$

The notation corresponds to that in Table $8-4$ except that the $C^{*}$ is camera sales per capita.

The model based on camera sales per capita selected the same variables but yielded estimates which were closer to the a priori estimates than those in Table 8.4 . In addition, the standard errors of the estimates were substantially lower. But these estimates were still quite different than those obtained in the causal model.

Predictions for the countries in the validation sample are presented in column $D$ of Table $8-1$. The per capita transformation yielded results which were poorer than the model based on total sales. This model was inferior on all criteria. Thus, this model was also quite inferior to the causal model 
in this situation. In fact, there seemed to be little to chose from in comparing Statistician's Model \#2 with the simple clustering technique. The reasons for the poor performance of this model were not obvious.

\section{Updating the Estimates}

It was possible to utilize the validation sample to update the parameter estimates. The validation sample was added to the analysis sample. The regression was computed and then outside estimates were brought in to fix parameters of lesser importance. The procedure was the same as that used at the end of Chapter 7. Table 8-6 presents the final version of this model.

\section{TABLE 8-6}

REGRESSION ON INTERNATIONAL CROSS-SECTION: ENLARGED SAMPLE $(n=30)$

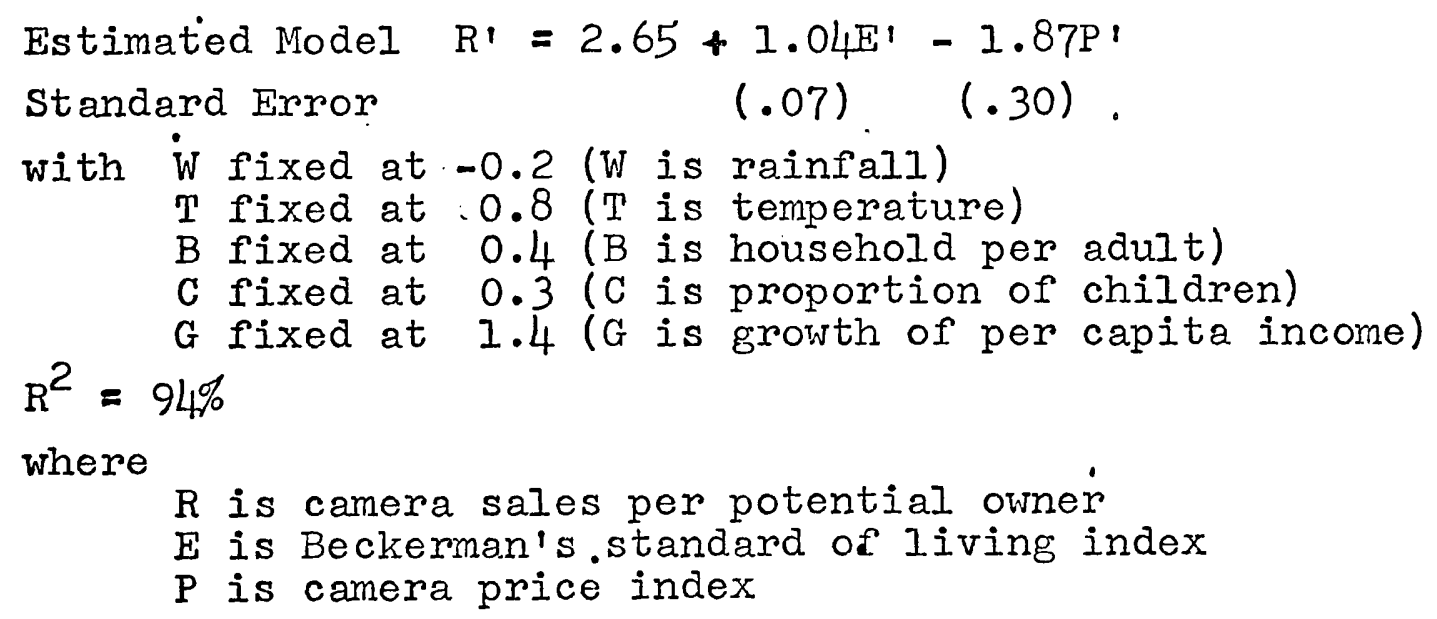

The mean absolute deviation of the percentage errors in 
this model was equal to 21 . percent. ${ }^{1}$ The income elasticity was higher than previously (1.04 vs. 0.93) and the price elasticity was smaller, in absolute value (-1.87 vs. -2.01$)$. The re-estimation procedure which was used at the end of Chapter 7 to incorporate outside information resulted in estimates for price and income elasticities which were closer to the estimates in the larger sample. By this rather limited criterion, the more complete model led to better estimates.

On the basis of the additional information, the estimates of causal elasticities for the forecasting model were updated to yield 1.34 for income, -1.80 for price, 0.4 for households per adult, and 0.3 for proportion of children.

Some Additional Testing of the International Cross-Section

It was possible at this point to test the assumption of constant elasticities. This question was especially relevant for the income variable so the sample was split into high and low income groupings. From the analysis of the household survey data there had been some indication that the elasticity might be lower at higher levels of income. Of course, the household survey data has an upper limit which is much higher than that in the international data. Inus, lack of constant elasticities for the household data does not imply a lack of constancy over the range of values forecast for countries.

$I_{\text {This updated model would improve the "prediction" of }}$ the countries in the validation sample. The average absolute percentage error would be reduced from $31 \%$ to $27 \%$. This gives a rough idea of the effect of "predicting" on data which was used to develop the prediction model. 
The international cross-section was divided evenly into high and low categories on the basis of Beckerman's index. The values of all parameters except for Beckerman's index were fixed at their updated values. Table 8-7 presents the results of this analysis.

\section{TABLE 8-7?}

COMPARISON OF INCOME ELASTICITY: RICH VS. POOR COUNTRIES (STANDARD ERRORS IN PARENTHESES)

\begin{tabular}{l|c|c}
\hline $\begin{array}{l}\text { Elasticity for } \\
\text { Beckerman's } \\
\text { Index }\end{array}$ & $\begin{array}{c}\text { Richer Countries }(n=15) \\
1.01(0.35)\end{array}$ & $\begin{array}{c}\text { Poorer Countries }(n=15) \\
1.03(0.11)\end{array}$ \\
\hline
\end{tabular}

There did not appear to be any decrease in income elasticity as countries become richer. This does not guarantee, of course, that this result would hold in the region of the long-range forecast.

Summary: Predicting Sales in New Countries

The retention of $I I$ countries from the international cross-section allowed for comparisons of the predictive ability of the causal model with that of a manager's model. The causal model proved superior on every criterion and the average absolute percentage error was less than 60 percent as large as that for the manager's model. 'Despite the small sample size, this difference was significant at the 5 percent level. The causal model was also superior to two non-theoretical quantitative models.

\section{Backcasting Sales for 1954}

Since a substantial time lag would resilt if one were 
to evaluate the accuracy of a long-range forecasting model directly, an attempt was made to overcome this shortcoming by backcasting to 1954. Insofar as possible, it was assumed that nothing was known prior to 1960. The values of the causal variables were then extrapolated back to 1954. This situation conforms rather closely then to the case of unconditional forecasting.

The Forecasting Model

The causal model to provide unconditional sales forecasts is summarized in Figure 8-4. This model corresponds to that in Figure 6-1 except that the model parameters have been updated by tine data analyzed in Chapters 7 and 8 . The measures of households per adult and proportion children were excluded due to lack of reasonably accurate backcasts, to the expectation that their effects upon camera sales would be small over the forecast period and to the uncertainty associated with the estimates of the relationships. Also excluded were effects from changes in the age distribution of the population.

The base period for the 1954 backcast was the end of 1962. Thus $\mathrm{n}$, the backcast period, was 8.5 years. Data back to 1960 were used, however, to develop the backcasts.

Three main elements of the 1954 model are considered below-the choice of an initial or base sales level, the effects of errors in the predictor variables, and the predictions of the causal variables. 


\section{FIGURE 8-4}

CAUSAL MODEI TO FORECAST CAMERA SALES BY COUNTRY

(ASSUME CURRENT SALES DATA AVAILABLE)

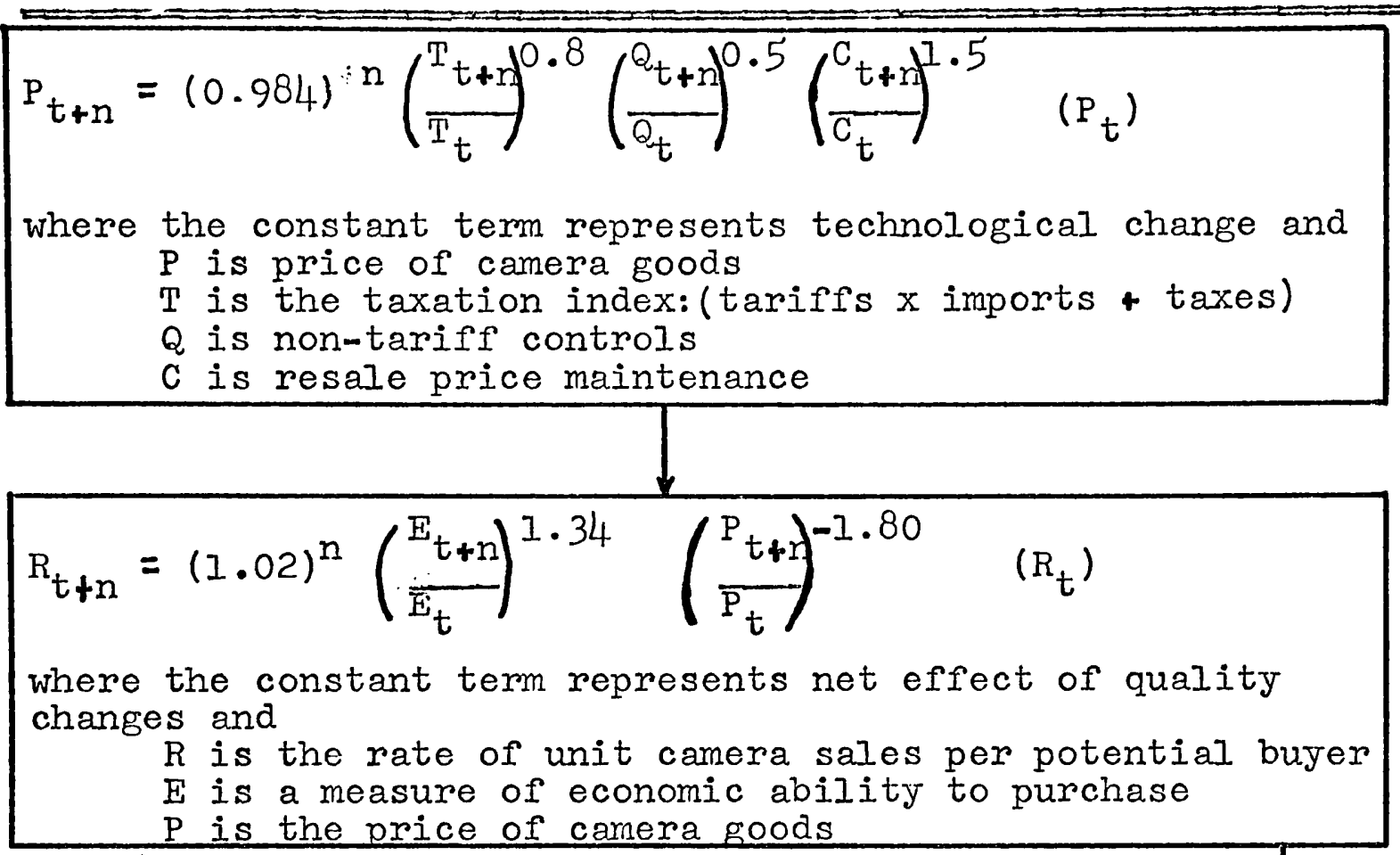

$M_{t+n}=\left(T_{t+n}\right)\left(L_{t+n}\right) \quad\left(A_{t+n}\right) \quad\left(N_{t+n}\right)^{0.3}$

where

$M$ is the number of potential buyers

$T$ is total population

$I$ is Iiteracy rate for population $15-64$

A is proportion of population 15-64

$\mathrm{N}$ is proportion of non-agricultural employment

$L_{t+n}=\left(R_{t+n}\right) \quad\left(M_{t+n}\right)$

where

$I$ is the long-mun rate of camera sales 
The Current Sales Rate

The updated model (Figure. 8-4) was used to provide forecasts for 1954. One important question was what to use as the estimate of current sales--the sales rate as measured by the trade and production figures or the sales rate as predicted by the international cross-section model? It would seem that "truth" lay somewhere between these extremes.

Since the method of reporting camera sales in each country may tend ta remain constant over time the measurement error might also tend to remain constant. If so, the use of "measured" sales (trade and production) would be preferred as the estimate of current sales. On the other hand, if one assumed that measured sales included short-term variations which are uncorrelated from year to year, (e.g. inventory charges, mistakes in reporting, new product introduction) it would be best to estimate current sales without this random component. This would argue for the use of sales as predicted by the cross-sectional measurement model. In other words, the use of "measured sales" assumes that the differences between predicted and measured sales in the international cross-section are peculiar to that country--and that these differences will remain constant over time. The use of "predicted sales" assumes that. the differences are due to transient events such that differences in year $t$ are uncorrelated to differences in year $t+n$.

The model which was used to forecast 1954. compromised between the above extremes by choosing a weighted average of measured and predicted sales. The adjusted current sales 
estimate weighted measured sales twice as heavily as predicted sales. This compromise was based on subjective grounds and was made prior to doing the 1954 backcasts.

Unconditional Forecasts: The Effect of Errors in Predictor Variables

The problem of error in the predictor variables has been of prime importance throughout this study. The errors in historical data were substantial and were specifically accounted for in the measurement models. The errors in forecasting certain of the predictor variables for 1954 were al so expected to be substantial. If errors are expected in the predictor variables and if the direction of these errors is unknown they may be compensated for by reducing the absolute value of the causal elasticity, ${ }^{1}$ while making a compensating adjustment in the constant term. This procedure is analogous to that carried out in regression analysis and was discussed when the prediction of sales in new countries was carried out. The reduction of the elasticity may be estimated by use of the bias factor which was discussed previously (Chapter 5).

Table 8-8 summarizes the model parametens which were adjusted for error. Adjustments were only provided where the effects of error were expected to have a significant effect upon the forecasts.

IAlternatively, one might decide to hedge on the forecasts of the independent variables in a direct manner (i.e. making them fall closer to their original level). 
TABLE 8-8

COEFFICIENTS FOR 1954 BACKCASTING MODEL

\begin{tabular}{lcc}
\hline Coefficient & $\begin{array}{c}\text { Causal } \\
\text { Elasticity }\end{array}$ & $\begin{array}{c}\text { Forecast } \\
\text { Coefficient }\end{array}$ \\
\hline Economic Ability to Purchase & 1.34 & 1.00 \\
Price of Camera Goods & -1.80 & -0.90 \\
\hline
\end{tabular}

Some consideration was also given to the constant term in the model. This term had been set a priori at a two percent increase per year to account for changes due to quality. The longitudinal measurement model provided little support for this as it yielded a constant with a one percent decrease. An average of these estimates yielded a constant of +0.5 . The effect of errors in variables had been accounted for in the longitudinal measurement model, of course. However, there was expected to be slightly greater measurement error in the forecasting situation so a further adjustment of +0.5 was made. This provided a very rough estimate of 1.1 .0 percent per year for the constant in the sales forecasting model.

The approach used above was eclectic and subjective. A completely a priori approach could have been used by taking the effect due to quality change and adding to that the effects of exrors in the independent variables. This a priori approach would require estimates of the expected rate of change in camera sales and of the expected rates of change in each of the causal variables. In total, it would have led to a constant term which was somewhat greater than the two percent due to quality changes.

In contrast to the a priori approach, one might have 
relied completely upon the empixical approach. All available outside information would be entered into the longitudinal model and an "optimum", constant term would be provided by the regression.

The a priori approach made excessive demands upon a priori knowledge. The empirical approach led to an unrealistic estimate. This unfortunate state of affairs led us to the subjective approach used above.

The constant term represented an extremely important part of the forecasting model. Some estimate was required to complete the model. The approach that was used, however, represented a rather weak link in the development of the causal model.

Backcasting the Causal Variables

With the exception of the price variable, the predictions of the causal variables were based on extrapolations or naive methods. In the case of price, of course, a causal model was developed. The causal variables in the price model were themselves based on extrapolations.

The use of naive methods to predict the causal variables put the causal model at somewhat of a disadvantage in the 1954 backcast. Generally some outside'information exists which will help to predict the causal variables. For example, predictions of tariff changes for 1975 can capitalize upon scheduled changes due to the Kennedy Round or to various common markets. The use of naive methods, then, made it more difficult to demonstrate the superiority of the causal model. 
Table 8-9 summarizes the rules which were used to backcast each of the causal variables.

- TABLE 8-9

BACKCASTING THE CAUSAI VARIABLES FOR 1954

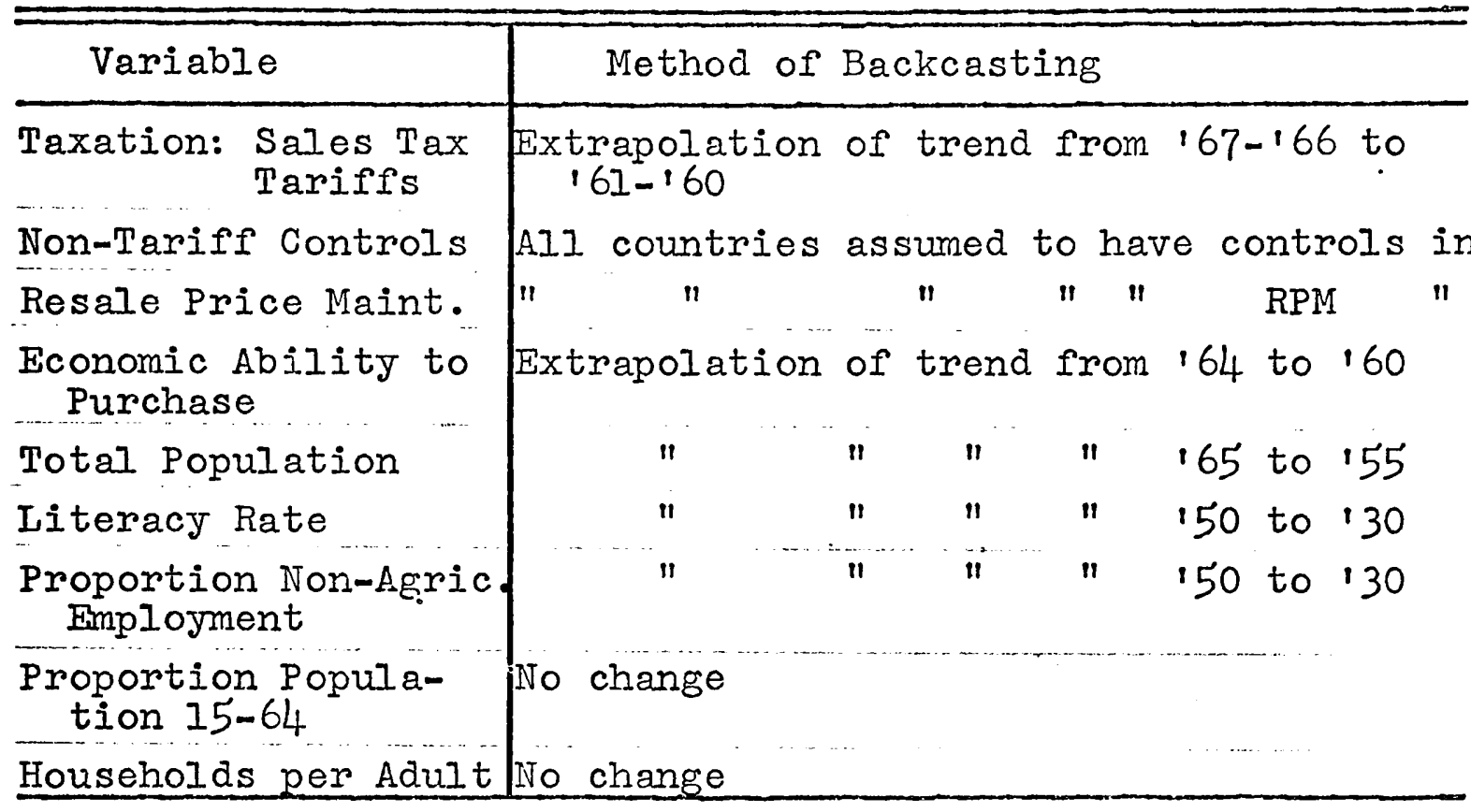

Backcasting Sales

The backcasts of each variable were entered into the forecasting model-mi.e. the model of Figure $8-4$ as adjusted to provide unconditional backcasts. The resulting backcasts of camera sales by country are presented in column $A$ of Table 8-10. The mean absolute percentage deviation of the forecast was 23\%. This appeared to be rather low in view of the low reliability of the sales measure. (See data on sales in Appendix, Table B-5.) A consideration of the direction of the errors indicates that the model overshot the mark. on the average, the causal model predictions were $12 \%$ too low. There were any number of explanations which might explain this systematic error. The objective at this point, . 


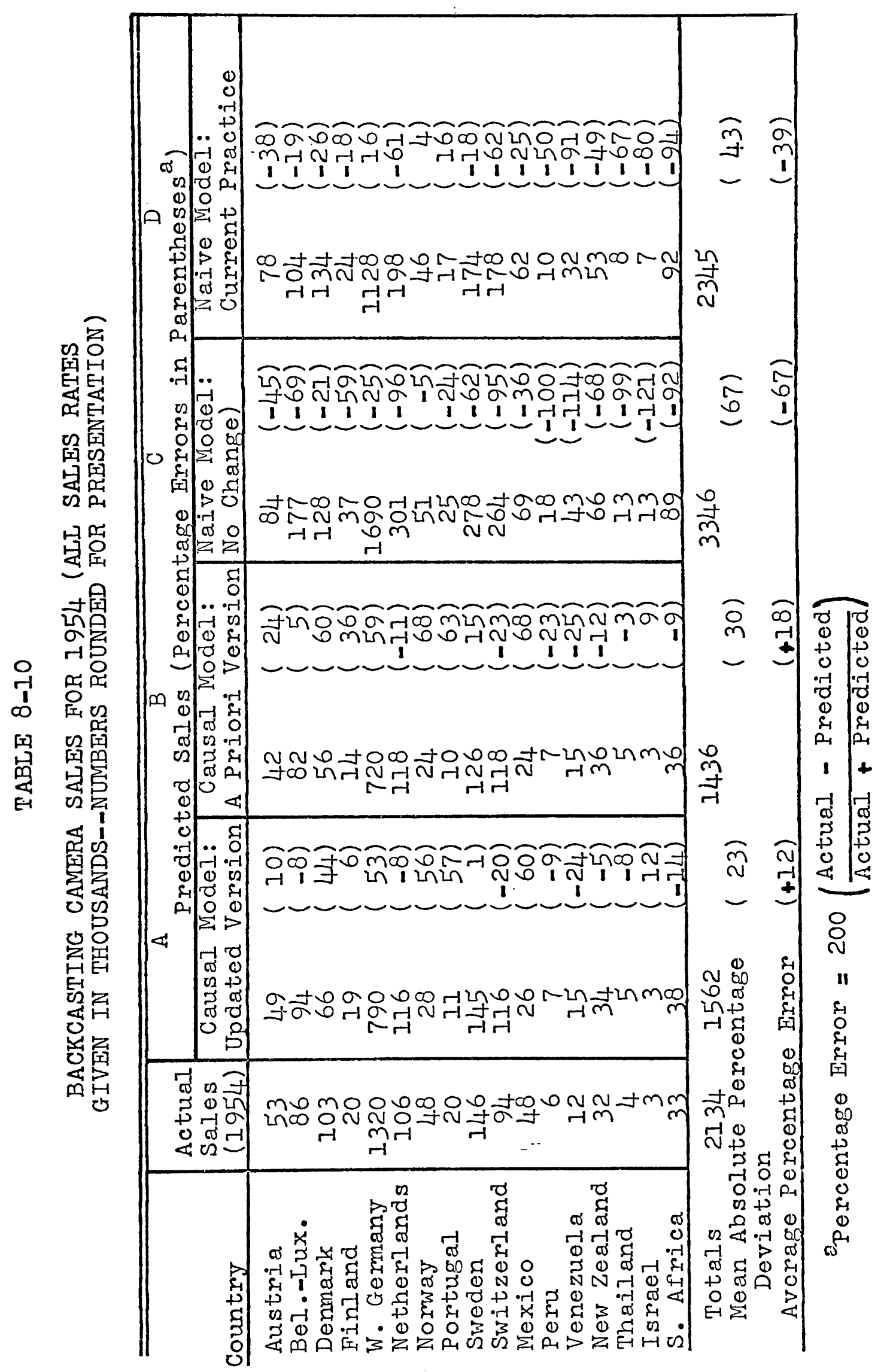


however, was not to fit the model to the data but rather to evaluate the model.

The causal model has its limitations. It was not designed to forecast more accurately for large markets than small markets as it attempts to minimize percentage errors. This is useful for some decisions--but has short-comings for other decisions. One problern.was brought out in the 1954 backcast for West Germany. Sales in West Germany make up over half of the total sales in this particular sample. If the decision depended on total sales for this sample of countries, the causal model would perform poorly since it misses the mark substantially in West Germany. I

The ultimate criterion for the evaluation of a forecasting model depends on what decisions are to be based upon forecasts from the model. If such decisions depend upon overall estimates of world-wide sales, then it would seem reasonable to use an approach which studies the larger markets more intensively. This could mean going out to secure more accurate data for the larger countries to use in the causal model developed in this study; or it could mean the use of disaggregated data to develop models in large markets such as the U.S. (see comments in Chapter 5 relating to the use of disaggregated data).

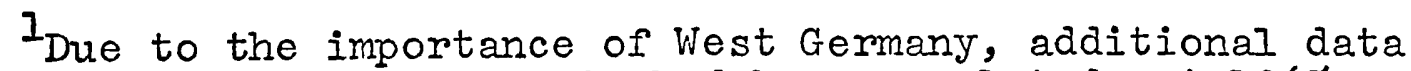
were sought after the analysis had been completed. A 1965 study by Fry (1965) yielded an estimate for 1955 unit camera sales of 9560 . This was more in line with the model prediction. 
The A Priori Version of the Causal Model

To examine the gain due to use of the formal measurement models, the a priori version (Figure 6-1) of the causal model was used to backcast sales for 1954. This model differed from the updated version with respect to all of the forecast coefficients (including the constant term) and also with respect to the estimate of initial sales. It did not, however, differ on predictions of the causal variables.

Forecasts from the a priori model are presented in column $B$ of Table 8-10. The mean absolute percentage error was only $7 \%$ higher than that of the updated model. A further analysis of the two models indicated that the advantage of the updated model was due primarily to the improvement in the estimate of initial sales. Updating in the other components of the model could not be shown to lead to any substantial improvements once the initial sales estimates were updated.

Naive Models

A crucial question was whether the causal model leads to "improved accuracy". To evaluate this, it was necessary to develop a model to represent current practice. In Chapter $I$ it had been argued that current practice in long-range forecasting relies heavily upon the use of naive models.

A number of naive models were considered in this study.

Two basic naive models were considered. These included:

a. The "no-change" model. This model, which has been used successfully in short-range forecasting, says that current sales rates provide the best predictor of the future sales rate. 
b. The "constant-change" model. This nodel, also used successfully in short-range forecasting, says that the future sales rate may be predicted from knowledge of the current sales rate and the trend in this sales rate. There were, of course, many ways in which each of these approaches could have been made operational. The no-change model simply used $1960-65$ sales rates ${ }^{l}$ to backcast 1954 sales rates. The constant-change model was formulated in two versions. One version used $1960-65$ sales rates and estimated the trend in the sales rate by considering each country separately and using the change from the 1965-64 average to the 1961-60 average. That is, there were assumed to be constant trend rates within each country. The second version also used the 1960-65 sales rate but estimated the trend by taking the change between 1965 and 1960 for the 31 countries in our sample (see totals in Appendix, Table B-5). This yielded an average rate of change of 11.7 percent per year.

Prior to using the naive models for backcasting, a decision was made as to what particular formulation would be used as the best representation of current practice. It did not seem that the formulation should restrict itself to any single approach. A model which averaged the forecasts of the no-change model and the model based on constant trend rates in each country was selected to represent current practice. 2

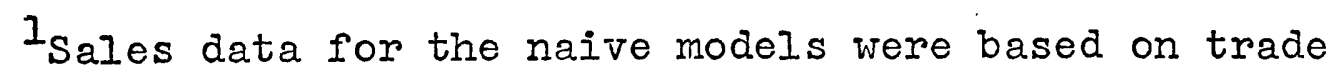
and production statistics.

While this decision was made prior to the analysis of the data, the study did not provide evidence that such an approach really does represent current practice. 
Results for the no-change model are presented (see column $\mathrm{C}$ of Table 8-10) since these results also provided information on the size of the actual changes between 1960-65 and 1954. Sales were lower in 1954 for all countries and the extent of the changes was substantial in all countries except for Norway.

Results for the naive model purporting to represent. current practice are presented in column D of Table 8-10. A comparison of the backcasts from this model with those. from the updated causal model indicated that the latter was superior on all criteria except for the prediction of total sales for this sample. ${ }^{I}$

The mean absolute percentage error for the causal model was roughly half that of the model representing current practice. Viewed in another way, the error was reduced by about 20\%. This reduction in error is slightly greater than that suggested in the example of Chapter 1. Thus the estimate that the present value of the savings would be equivalent to about one percent of the firm's yearly sales volume stands up as being conservative.

The above result was based on a rather small sample size ( $n=17)$ and one might legitimately be concemed here about statistical significance. Student's t-test was used to test the null hypothesis that there was no difference between the mean absolute percentage errors from each model.

$I_{\text {This superiority was due primarily to the prediction }}$ for West Germany. 
A one-tail test was used since it was predicted that the causal model was superior. The null hypothesis was rejected at the pre-specified level of $5 \%$ (calculated level of significance was 3\%). The non-parametric Wilcoxon matched-pairs signed-ranks test (Siegel, 1956) was also used as an alternative to the t-test in an effort to guard against the possibility that the significance was due to one or two extreme observations. This test also rejected the null hypothesis at the $5 \%$ level (calculated level of significance was $3 \%$ ). In summary, then, it seemed unlikely that the superiority of the causal model was due to "chance".

The superiority of the causal model might have been due to an "unfortunate" choice of a naive model. It was useful, therefore, to look at the forecasting ability of other naive models. Surmaries of the no-change model and of the two constant change models are presented in Table 8-11. The model which assumed that each country has its own trend provided a substantial improvement over the no-change model. The assumption that the total market trend will predict the trend for each country leads to a still better forecast. The performance of the latter model was surprising in that it did better than the model purporting to ropresent current practice.

In view of the above results it was then possible to search for an "optimum" naive model. This was done in order to examine what would have happened if the researcher was very lucky in developing the naive model. After some search it was determined that a model based on a simple average of the 
backcasts from models 2,3 and 4 provided a near optimum weighting and yielded the results of model \#5. Note that backcasts from this so-called "best" model did not match up to those from the causal model. The latter had an average absolute percentage error which was ten percent lower $(23 \%$ vs. $33 \%)$ and the average error was about half the size $(+12 \%$ vs. $-23 \%)$.

TABLE 8-11

1954 BACKCASTS FROM VARIOUS NAIVE MODETS

\begin{tabular}{llll}
\hline Model & & $\begin{array}{l}\text { Mean } \\
\text { Absolute } \\
\text { Percentage }\end{array}$ & $\begin{array}{l}\text { Average } \\
\text { Percentage } \\
\text { Error }\end{array}$ \\
\hline Number & Description & 43 & -39 \\
2 & "Current Practice" & 67 & -67 \\
2 & No Change & 51 & +23 \\
3 & Constant Change by Country & 37 & +28 \\
4 & Constant Change over All & 37 & -23 \\
5 & countries & 33 & \\
\hline
\end{tabular}

There are, of course, many other naive formulations which could have been tried. ${ }^{I}$ Undoubtedly, a sufficient amount of search would lead to a model which would perform better than the causal model. But this would provide no guarantee that such a model would be better in new prediction situations. This study attempted to sample from the types of naive models which are in use today. This "sampling" did not lead to any naive model which could match the performance of the causal model in backcasting 1954 .

Ione of these formulations was based on the exponential amoothing model which has been so popular in short-range forecasting (see Brown, 1960). This model performed somewhat better than the "current practice model" but not so well as the "best naive model". 
The causal model not only performed better than the naive models but also offers more promise for further improvements. Improvements in the forecasts of the causal variables, in the measurement of causal relationships, or in the measurement of current sales could lead to better forecasts. Means for improving the naive models would seem to be limited to better measurement of sales.

To evaluate the improvement made possible by better predictions of the causal variables, improved measures were used for the rate of change of PCE per capita between 1962 and $1954^{1}$ and backcasts of 1954 were recalculated. While the data still contained substantial amounts of measurement error, they should have been superior to the predictions used previously.

The results of the above test were discouraging. While the systematic or average error was reduced from $10.6 \%$ to 7.9\% and four of the five extreme deviations were reduced, the mean absolute percentage deviation increased from $20.0 \%$ to $21.0 \%$. Forecasts for eight countries improved, eight were worse and there was one tie. In summary, the use of improved forecasts for one of the causal variables did not improve the sales backcasts for 1954--contrary to our hypothesis.

\section{Evaluating the Components of the Forecasting Model}

Since the different components of the forecasting model

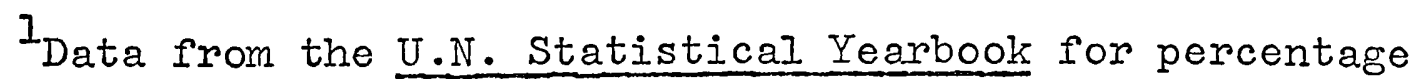
change in per capita product at constant prices were used to update the estimate previously used in the model by forming a simple arithmetic average of the two indicators. 
were interrelated it was difficult to determine which ones were most closely related to the success (and deficiencies) of the model. An attempt was made to determine relative contributions by removing certain components from the model and observing the effects upon the prediction error.

Adjusting the Causal Elasticities to Compensate for Error

The model was re-run with the causal elasticities used directly rather then having them reduced in magnitude to hedge against error. Forecast error increased from $23 \%$ to 43\%. Despite the highly subjective means of adjusting for error, substantial gains resulted. Further experimentation with the model indicated that the 1954 backcast error was not highly sensitive to the size of the adjustment. Any adjustment in the region of the one selected would have led to comparable results. As it turned out, the selected adjustments were close to optimum for the 1954 backcasts.

No adjustment had been made to compensate for errors in predicting changes in potential buyers as had been done with the measures of price, ability to purchase and quality. Had this been done, the model would have shown less of a tendency to overestimate the changes in camera sales. Experimentation with coefficients to compensate for error showed that the mean absolute deviation was not very sensitive to this adjustment. However, with a coefficient of 0.8 rather than the implied 1.0, the average error would be reduced by about $6 \%$ $($ to $+6 \%$ ) and the extreme errors would be reduced (i.e. the mean square error was reduced). The conclusion was that only 
a very small adjustment need be made for errors in the forecast of potential buyers.

Relative Importance of the Causal Variables

In order to guide further efforts to improve the causal model it is useful to ask which variables were most important in forecasting 1954 sales. Table 8-12 summarizes how much change occurred in each of the causal variables. Since the forecast elasticities are all near 1.0 the figures give a good indication of the resulting influence upon the camera sales forecast.

TABLE 8-12

CHANGES IN CAUSAI VARIABLES FROM 1962 to 1954

\begin{tabular}{|c|c|c|c|}
\hline Variable & Range across Countries. & Median & $\begin{array}{l}\text { Average } \\
\text { Net Effect } \\
\text { on Sales }\end{array}$ \\
\hline $\begin{array}{c}\text { Potential } \\
\text { Buyers }\end{array}$ & $\begin{array}{l}0.94 \text { to } 0.62 \\
\text { (Austria) (Israel) }\end{array}$ & $\begin{array}{l}0.84 \\
\text { (Switzerland) }\end{array}$ & $-15 \%$ \\
\hline Price & $\begin{array}{l}\text { I.II to } 1.60 \\
\text { (Israel) (S. Africa) }\end{array}$ & $\begin{array}{l}1.24 \\
\text { (Norway) }\end{array}$ & $-18 \%$ \\
\hline $\begin{array}{l}\text { Ability to } \\
\text { Purchase }\end{array}$ & $\begin{array}{l}0.87 \text { to } 0.61 \\
\text { (N.Zeal and) (Israel) }\end{array}$ & $\begin{array}{l}0.71 \\
\text { (Belgium) }\end{array}$ & $-29 \%$ \\
\hline Quality & No Variation & 0.92 & $-8 \%$ \\
\hline
\end{tabular}

Changes in ability to purchase were most important in terms of average effect although each of the factors led to a substantial amount of change. Another way to view the importance of the various factors is in terms of differences among countries. From the ranges listed in Table 8-12, it appears that the first three factors-potential buyers, price, and ability to purchase--had roughly the same importance in 
predicting differences among countries.

The above results may be compared with the prior estimates of importance of variables (Table 3-I) where potential buyers, camera prices and ability to purchase were all expected to be of about equal importance and quality was of somewhat lesser importance. The most important difference, was that ability to purchase goods turned out to be more important than any, of the other causal factors.

\section{The Estimate of the Initial (1962) Sales Rate}

It was mentioned above that the estimate of initial sales which utilized information from both the trade and production statistics and from the predictions of the international cross-sectional model was superior to an estimate based only on measured trade and production figures. The original weighting placed twice as much emphasis upon the measured as the predicted sales. This was responsible for an improvement in forecast accuracy from $30 \%$ to $23 \%$. Improvement was noted in the forecasts of 13 countries while only three showed an increased error (there was one tie).

The above result was tested for statistical significance against the null hypothesis that the errors were equally Iikely to increase or decrease as a result of the use of the global index. A five percent level of significance was chosen and a one-tailed test was used. The sign test led to a rejection of the null hypothesis (calculated level of significance $=.01$ ). The use of measured sales led to poorer predictions than did use of the global index. 
Experimentation revealed that any subjective weighting of predicted sales would improve the baclicasts. The a priori were not far from the optimal weightings as the backcast error was not particularly sensitive to the weights. Table 8-13 presents a summary of this search.

\section{TABLE 8-13}

FORECAST ERROR FOR VARIOUS INITIAL SALES ESTIMATES

Initial Sales Estimate

Mean Absolute

Percentage Error

Measured Sales Only

$2 / 3$ Measured and $1 / 3$ Predicted $^{2}$

$1 / 3$ Measured and $2 / 3$ Predicted

Predicted Sales Only

${ }^{a}$ Indicates the a priori weights

The Existence of National Differences

The analysis of the preceding section may also be interpreted as asking whether there are stable national differences. Do "tastes" differ among countries? For example, it has often been suggested that the Japanese are very "camera conscious". 1

If stable differences were of great importance then the use of measured sales would have been expected to provide the most accurate backcasts. This was not the case, of course. The data did not suggest the presence of strong and stable national differences--other than for those differences in variables explicitly included in the measurement model.

In fact, sales in Japan were lower than "predicted" by the regression across countries. The difference was minor (7\%) but the direction was opposite to that expected. 


\section{A Note of Caution}

It would seem worthwhile, at this point, to remind the reader about an assumption which was presented very briefly earlier in this study. The assumption was that the percentage improvement in the industry forecast would lead to a comparable improvement in the firm's forecast. The use of the industry forecast must be accompanied by a market share forecast. Since the market share forecast is subject to some error, it would have been interesting to examine naive models which avoid this step by projecting company sales directly. In other words, does any gain result in the firm's forecast by first studying industry sales? This assumption was not examined.

\section{Summary}

Comparison of different approaches to measuring the causal relationships for the forecasting model provided some evidence for construct validity. Although important differences did exist, the various estimates tended to cluster in the same regions. Differences among estimates of price elasticity provided cause for some concern.

The causal model performed well in predicting 1960-65 sales for eleven "new" countries. The mean absolute percentage error for this model was less than $60 \%$ that of a clustering model which purported to represent current practice. The causal model was also superior to two "non-theoretical" statistical models. These models utilized statistical criteria to develop a causal model. 
The eleven countries of the validation sample were combined with the original 19 countries in order to update the estimates of the causal relationships. Testing of this model provided support for the assumption of constant income elasticities in the sales forecasting model.

A test of predictive validity was carried out by backcasting sales in 17 countries for 1954. This test conforms rather closely to the case of unconditional forecasting. The causal model performed well in comparison with a naive model purporting to represent current practice. The mean absolute percentage error for the causal model was a little more than half that of the naive model. This result was significant in both a statistical and a practical sense. Experimentation with various formulations of naive models did not lead to any backcasts which were as good as those provided by the causal model.

The performance of the causal model is noteworthy in view of the rather crude estimating techniques required for parts of the model (e.g. the constant term and the predictions of the causal variables). In fact, estimation techniques were found to play only a modest role since an "a priori model", which used only subjective estimates, led to backcasts which were also superior to those provided by any of the naive models. 
USING THE MODEL

In this chapter, specific forecasts are provided for camera sales in 1975. This is followed by a consideration of some of the additional benefits which may be derived from this study of the camera market.

\section{Forecasting Sales for 1975: An Unconditional Forecast}

The causal model was used to provide forecasts of camera sales in 30 countries for 1975. To do this it was first necessary to obtain forecasts of the causal variables. The basic procedure followed that used for the 1954 forecast in that naive projections were generally used. In some cases, however, it was possible to use additional information. Tariff predictions were aided by knowledge of scheduled changes resulting from the Kennedy Round and from the many common markets which have been formed (the European Common Market, the European Free Trade Association, the Central American Common Market, the Latin America Free Trade Association, etc.). Some changes in resale price maintenance were predicted from recent passage or scheduled passage of laws against RPM. Proportion of imports benefited slightly from knowledge about plant construction (Kodak plans to produce cameras in Argentina). A summary of the methods used to forecast the causal variables for 1975 is presented in Table 9-1. The forecasting model for 1975 conformed in structure to that used for 1954 (see Figure 8-4). The estimate of initial sales was revised to weight measured sales (trade and produc- 
tion statistics) by $I / 3$ and predicted sales (intermational cross-section) by $2 / 3$. The coefficients of the causal variables were revised to adjust for forecasting error as shown in Table 9-2, (it was expected that the outside information on the causal variables would lead to more accurate predictions than was the case for 1954). The constant term was retained at +1.0 percent per year.

\section{TABLE 9-1}

FORECASTING THE CAUSAL VARIABLES FOR 1975

\begin{tabular}{|c|c|}
\hline Variable & Method of Forecasting \\
\hline $\begin{array}{c}\text { Taxation: Sales Tax } \\
\text { Tariffs } \\
\text { Proportion } \\
\text { of Imports } \\
\end{array}$ & $\begin{array}{l}\text { Linear extrapolation of trend } 160 \text { to } 167 \\
\text { Published information on Kennedy Round } \\
\text { and Free Trade Agreements } \\
\text { No change unless indicated by published }\end{array}$ \\
\hline Non-tariff Controls & $"$ \\
\hline Resale Price Maint. & Assume no countries will have RPM in 175 \\
\hline $\begin{array}{l}\text { Economic Ability to } \\
\text { Purchase }\end{array}$ & Linear extrapolation from 160 through $16 \mathrm{l}$ \\
\hline Total Population & 155 through 165 \\
\hline Literacy Rate & 130 through 150 \\
\hline $\begin{array}{l}\text { Proportion Non-Agric. } \\
\text { Employment }\end{array}$ & 130 through 150 \\
\hline \multirow[t]{3}{*}{ Note: } & mentioned here were assumed to remain \\
\hline & TABLE 9-2 \\
\hline & FOR 1975 FORECASTING MODEU \\
\hline Variable & Causal Elasticity Forecast Coefficient \\
\hline $\begin{array}{l}\text { Potential Buyers } \\
\text { Ability to Purchase } \\
\text { Price of Camera Goods }\end{array}$ & $\begin{array}{r}1.00 \\
1.34 \\
-1.80\end{array}$ \\
\hline
\end{tabular}


It is important to note that the adjustments to the forecast coefficients do not have to be constant across countries. It may be desirable to use a separate adjustment for each country if the forecasts of the independent variables are expected to differ in accuracy. This could have the effect of placing more emphasis upon the more reliable data. This study, however, used the same coefficients for all countries.

\section{$\underline{\text { Results }}$}

Forecasts for 1975 are presented in column A of Table 9-3. The most obvious point to make is that very substantial changes are expected to occur in the still camera market. Overall the market will grow from less than 18 million units per year for the 30 countries in this sample $e^{1}$ to almost 50 million units-not quite a three-fold increase. Or, in other words, total unit sales are expected to grow a little faster than eight percent per year.

The second major point is that the growth in camera markets does not procede uniformly across all of the countries. (See column $C$ of Table 9-3). Growth in camera sales will be slowest in the U.S. and Australia ( 1975 sales will be 2.2 times the 1962 sales) and fastest in Israel (1975 will be 7.0 times 1962).

The pattern of growth also differs widely among countries. In some countries the growth is due primarily to a growth in

$I_{\text {This sample of thirty countries represented about }}$ $85 \%$ of total world sales in 1960-65. 
TABLE 9-3

SUMMARY OF FORECAST OF CAMERA SALES FOR 1975

\begin{tabular}{|c|c|c|c|c|c|c|}
\hline \multirow[b]{2}{*}{ Country } & \multirow{2}{*}{$\begin{array}{l}\text { A } \\
\text { Forecast } \\
\text { of } 1975 \\
\text { Camera } \\
\text { Sales } \\
x 1000 \\
\end{array}$} & \multicolumn{2}{|c|}{$\begin{array}{l}\text { Changes in Sales } \\
\text { from } 1962 \text { to } 1975\end{array}$} & \multicolumn{3}{|c|}{$\begin{array}{l}\text { Changes in Fodel Com- } \\
\text { ponents } 1975 \text { as a } \\
\text { ratio to } 1962^{\mathrm{a}}\end{array}$} \\
\hline & & $\begin{array}{l}\text { Increase } \\
\text { in Camera } \\
\text { Sales } \mathrm{x} \\
1000 \\
\end{array}$ & $\begin{array}{l}1975 \text { as } \\
\text { a ratio } \\
\text { to } 1962\end{array}$ & $\begin{array}{l}\text { Poten- } \\
\text { tial } \\
\text { Buyers }\end{array}$ & Income & Price \\
\hline $\begin{array}{l}\text { U. States } \\
\text { Japan } \\
\text { W.Germany } \\
\text { U. K. } \\
\text { France } \\
\text { Italy } \\
\text { Canada } \\
\text { Netherlands } \\
\text { Sweden } \\
\text { Australia } \\
\text { Switzerland } \\
\text { Bel.Lux. } \\
\text { Denmark } \\
\text { Mexico } \\
\text { S.Africa } \\
\text { Austria } \\
\text { Yugoslavia } \\
\text { Finland } \\
\text { Norway } \\
\text { Argentina } \\
\text { Brazil } \\
\text { N. Zealand } \\
\text { Venezuela } \\
\text { Portugal } \\
\text { Israel } \\
\text { Thailand } \\
\text { Ireland } \\
\text { Peru } \\
\text { Iraq } \\
\text { Guatemala } \\
\end{array}$ & $\begin{array}{r}18700 \\
8480 \\
5740 \\
3540 \\
3250 \\
2100 \\
1240 \\
877 \\
845 \\
725 \\
601 \\
585 \\
424 \\
369 \\
344 \\
324 \\
270 \\
226 \\
181 \\
156 \\
155 \\
148 \\
133 \\
102 \\
89 \\
59 \\
51 \\
46 \\
22 \\
13 \\
\end{array}$ & $\begin{array}{r}10500 \\
6800 \\
4010 \\
2200 \\
2130 \\
1500 \\
800 \\
605 \\
500 \\
400 \\
389 \\
387 \\
258 \\
288 \\
257 \\
221 \\
223 \\
165 \\
182 \\
92 \\
107 \\
96 \\
96 \\
77 \\
76 \\
45 \\
36 \\
32 \\
18 \\
10 \\
\end{array}$ & $\begin{array}{l}2.2 \\
5.0 \\
3.3 \\
2.6 \\
2.9 \\
3.5 \\
2.8 \\
3.3 \\
2.4 \\
2.2 \\
2.8 \\
3.0 \\
2.6 \\
4.6 \\
4.0 \\
3.2 \\
5.7 \\
3.7 \\
3.0 \\
2.5 \\
3.2 \\
2.9 \\
3.6 \\
4.0 \\
7.0\end{array}$ & $\begin{array}{l}1.23 \\
1.17 \\
1.17 \\
1.08 \\
1.19 \\
1.22 \\
1.34 \\
1.18 \\
1.12 \\
1.29 \\
1.26 \\
1.11 \\
1.11 \\
1.76 \\
1.56 \\
1.06 \\
1.35 \\
1.18 \\
1.12 \\
1.28 \\
1.70 \\
1.28 \\
1.95 \\
1.27 \\
1.68 \\
1.82 \\
1.09 \\
1.48 \\
2.26 \\
1.71 \\
\end{array}$ & $\begin{array}{l}1.34 \\
3.07 \\
2.06 \\
1.41 \\
1.75 \\
2.02 \\
1.31 \\
1.78 \\
1.68 \\
1.31 \\
1.57 \\
1.71 \\
1.75 \\
1.75 \\
1.54 \\
1.75 \\
2.49 \\
1.86 \\
1.68 \\
1.00 \\
1.22 \\
1.25 \\
1.31 \\
1.94 \\
2.22 \\
1.57 \\
1.71 \\
1.50 \\
1.90 \\
1.41 \\
\end{array}$ & $\begin{array}{l}.85 \\
.81 \\
.83 \\
.66 \\
.81 \\
.80 \\
.72 \\
.74 \\
.87 \\
.86 \\
.79 \\
.73 \\
.86 \\
.77 \\
.69 \\
.67 \\
.66 \\
.68 \\
.72 \\
.59 \\
.73 \\
.65 \\
.82 \\
.70 \\
.60 \\
.78 \\
.62 \\
.74 \\
.77 \\
.64 \\
\end{array}$ \\
\hline $\begin{array}{l}\text { Totals } \\
\text { Averages } \\
\text { Ranges }\end{array}$ & $\begin{array}{l}49795 \\
--\infty-\infty \\
--\infty\end{array}$ & $\begin{array}{l}32138 \\
-\infty-\infty \\
--\infty\end{array}$ & -7.0 & $\begin{array}{c}1 .-\overline{3} \\
1.1-2.3\end{array}$ & $\begin{array}{r}---- \\
1.70 \\
0-3.1\end{array}$ & $\begin{array}{c}-.-5 \\
.59-.87\end{array}$ \\
\hline
\end{tabular}

Quality changes were the same for each country with 1975 sales having a ratio of 1.138 to 1962 sales. 
the number of potential buyers (e.g. Venezuela, Iraq); in other countries the reduction in camera prices is the major source of growth (e.g. Argentina); while in still others it is increased income which is the prime factor (e.g. Japan). These patterns may be observed in the last three columns of Table 9-3.

Further improvements to the model may be guided by an evaluation of the relative contribution of the model components. By considering the average effect and the range of variation across countries, some rough conclusions were drawn. The effects of changes in income are most important (as they had been for the 1954 forecast) while the effects of changes in camera prices and number of potential buyers are roughly about half as important and the effect of quality improvements was about one-fourth as important. The average effects may be noted at the bottom of columns $D, E$, and $F$ while the columns themselves provide data on variation among countries. The results are similar to those for the 1954 forecast.

Improvements to the forecasts might also be guided by further studies of particular countries. Of particular interest would be the countries with the largest expected markets for 1975--the U.S., Japan, and West Germany. These countries represent over half of the total world camera market. Also of interest would be the countries which are expected to experience very large increases in the scale of operation. These would include Israel, Yugoslavia, Iraq, Japan and Mexico. The Validity of the Forecasts

A primary concern here is whether the relationships 
which were estimated will hold over time--especially in view of the fact that some of the forecasts lie outside the range of the analysis data. .

With respect to the dependent variable, camera sales per 1000 potential owners, 13 of the 30 countries have a sales rate which exceeds the previous high for 1960-65 (79 sales per year per 1000 potential owners in the U.S.). The highest sales rate of 161 occurs in Sweden. There are also five countries at about the 140 level (the U.S., Denmark, West Germany, Japan and Switzerland).

In the forecasts of the causal variables, the measures of camera price and of income are of key importance. For price, 16 of the 30 countries have prices which fall below the lowest price index for 1960-65 (0.76 in Japan); the predictions for price are not far outside the range, however; the lowest price index in 1975 is 0.66 in Switzerland. For income, only five countries--U.S., Sweden, Germany, Denmark and Canada--exceed the previous high of 1.06 in the U.S. The highest standard of living for 1975 was 1.42 in the U.S. While fewer countries are outside the range on income than on price, the deviations are greater for income.

The prediction for 1954 did not provide much information as to what happens when the causal model is used to predict in cases outside the range of the data. Only 3 of the 17 countries in the 1954 forecast were outside the range of the analysis data. Errors for these three countries tended to be lower than those for the other countries ( $10 \%$ vs. $22 \%$ mean absolute percentage error).

Analysis of household data had indicated that when the 
income level gets very high, the incone elasticity seems to decrease. This should lead to some caution in accepting the forecasts of the very high income countries.

The Accuracy of the Forecasts

How accurate is the sales forecast? A measure of the accuracy of the forecast may be useful for the timing of long-range commitments. In cases where the forecasts are subject to much uncertainty the firm might prefer to put off decisions until more information becomes available. They would like to balance the cost of waiting against the value of the information gained. One approach to measuring the uncertainty in the prediction of sales is to assume that the values of the causal variables are known with certainty. Confidence intervals may then be calculated about the regression line. This may be referred to as measurement of forecast reliability.

Little concern has been paid to forecast reliability in this study. The primary reason for avoiding this issue is that what is really desired is a measure of overall forecast accuracy. Forecast accuracy includes problems due to both reliability and validity. To ignore the latter (by assuming the forecast will be valid) and to concentrate only on measuring reliability may be misléading. ${ }^{1}$

Some argument might be made for evaluating forecast

$I_{\text {This argument might also be discussed in terms of }}$ measures of conditional forecasting ability (reliability) versus unconditional forecasting ability (encompassing both reliability and validity). 
reliability since techniques are available for examining this aspect of the problem--namely, the use of confidence intervals about the regression line. But this argument does not hold when, as is often the case in non-experimental research, the regression which was used as the measurement model does not conform to the forecasting model. In the camera study it would be rather presumptuous to assume that confidence intervals for the international cross-section would be useful for the 1975 forecast. The technical problems are compounded since a number of measurement models were used to develop the 1975 forecast. Finally, it should be pointed out that it is important whether the decision rests on the accuracy of the estimate of the long-mun rate of sales at a given point in time-or whether it is variability in yearly sales which is of interest. If it were the latter, it would be necessary to impose the variance due to short-mun factors upon the viaiance due to uncertainty in the long-range forecast.

There is one operational approach to measuring accuracy which seems to have merit for the type of problem being studied here. Distributions rather than expected values may be forecast for each of the causal variables in each of the countries. Distributions could also be used to represent each of the coefficients of the model. Random selections could then be made from each of these distributions in the manner of a Monte Carlo simulation to provide distributions of the sales in each country. I Fluctuations from short-run

$I_{\text {Hertz(1964) privides a good explanation of such a }}$ procedure. 
factors could then be superimposed as random error to provide an overall estimate of variability. for a given year in the future.

The simulation approach was not used in this study. Instead, a more direct and much simpler appraoch to measuring overall forecast accuracy was used. This approach was to ask how the model had done in similar forecasting situations. The forecast accuracy for 1954 backcasts (mean absolute percentage deviation of $23 \%$ ) would provide some clue as to how accurate the 1975 forecasts will be.

\section{Other Benefits from the Study}

The prinary objectives of this study were to develop and evaluate a long-range forecasting model. One additional benefit has already been mentioned--the study has led to a better estimation of the current sales rates in each country. other benefits of the study are discussed in this chapter.

Evaluation of Alternative Projections of Causal Variables

The previous section described an unconditional forecast. Since there is some uncertainty about the future one might desire to use different projections of the causal variables in order to determine the effect upon camera sales. Once the model has been developed, these alternative projections may be evaluated rapidly and inexpensively. ${ }^{1}$ Such an exercise may be useful in the formulation of alternative strategies or

In contrast to the simulation approach for determining reliability, the interest here is in specific results for specific projections. 
merely for updating the model as more information becomes available about the causal variables.

Evaluation of Substantial and Rapid Economic Changes

The camera model may be used to determine what would be the effect of substantial and rapid economic changes. Such changes might be the introduction of camera production within a country; the formation of common markets; the removal of resale price maintenance (as done in the Netherlands); the discovery of natural resources (oil in Kuwait); a large government program to improve housing; the introduction of an effective mass education program to improve literacy (as in Cuba); or, and probably most important, the effect of large changes in trade barriers. Changes in tariffs and quotas on cameras occur often around the world and it would seem useful if a firm could evaluate each major change as it is anticipated.

It is in cases where substantial changes in the market are expected that the causal model should be especially advantageous to the naive model. An example of the use of the causal model was provided by an analysis of the Kennedy Round tariff reductions.

The conditional forecasting model was used to evaluate the effects of the Kennedy Round upon 1975 camera sales. It was assumed that the announced changes would, in fact, be made; that they would be made as scheduled (by 1972); and that the measurement error in the current data on tariffs was not large. The effects of the tariff changes upon the price of camera goods was first evaluated using the camera price model. The 
effect of this price change upon camera sales was then evaluated by means of the causal price elasticity of -1.80 . Forecasts for 1975 for the 30 countries from Table 9-3 were used as a sales base.

It had been expected that the effect of the Kennedy Round reductions upon camera sales would be substantial. The analysis indicated otherwise. While the effect in some countries was substantial (e.g. a $37 \%$ increase in Brazil), the average increase in sales was about $11 \%$. It also turned out that the larger changes occurred in countries where the camera market was small. As a result, the total camera market would be only 3.5\% larger with the Kennedy reductions than without.

Evaluation of Industry Marketing Effort -

The measurement model used for the international cross-section might be used in a manner analgous to the use of quality control charts. Are there some countries in which the potential camera market has not been fully exploited?

Deviations between measured camera sales and sales as predicted by the regression model (see Table $8-6$ ) were examined. Countries in which measured camera sales were lower than predicted were called Underexploited Markets. Countries with the reverse situation were colled Saturated Markets. Table 9-4 presents the five extreme cases in each classification. The criterion for "extreme" was simply based on percentage deviation. If one is going to look for trouble, he should look where the deviations are substantial. However, 
it may be noted that the standard deviation for the forecast error over all countries is about 26\%. It appears, therefore, that for the countries in Table 9-4, the probability that the search would be in vain is fairly high (e.g. about $15 \%$ for the United Kingdom). The question as to how large a probability should be tolerated for fruitless search depends, of course, upon the costs of looking and the possible gain from finding something. It may be that search would be useful even if there was a $90 \%$ chance that the search would be in vain.

\section{TABLE $9-4$}

EXPLOITATION OF CAMERA MARKETS (1960-65)

\section{Underexploited Markets (Actual ( Predicted)}

Country \% Difference ${ }^{a}$

Finland

Denmark

Sweden

Austria -64
-38

Norway

Saturated Markets (Actual > Predicted)

Country $\%$ Difference $^{a}$

Hes Zealand

Peru

United Kingdom

Australia.

Switzerland

43

42

39

35

33

apercentage difference $=200\left(\frac{\text { Actual }- \text { Predicted }}{\text { Actual }+ \text { Predicted }}\right)$

An examination of the countries represented in Table 9-4 brought up, once again, the possibility that there might be national or cultural differences. Four of the five underexploited markets were Scandanavian countries while three of the five saturated markets were in the British Commonwealth. But if these deviations did represent cultural differences 
one would expect them to exist also in the backcasts for $1954 .^{1}$ In fact, there is a reversal in all eight countries from Table 9-5 which permitted comparison. Countries which were high in 1960-65 were low in 1954 and vice versa.

Whatever the causes of the differences between measured and predicted sales, the suggestion is that further study may be in order. Further study may imply any one of a number of things--e.g. consumer surveys, studies of the distribution system, or more effort to obtain information on the causal variables. The results of such studies may lead to the identification of additional factors which are important to the development of the market for still cameras.

\section{The Model as a Focus for Research}

The development of a model as an activity also has substantial merit over the development of forecasts. The latter focuses attention on the forecasts themselves and is very specific to the particular situation. The development of the model acts as a unifying focus to integrate large amounts of data from various sources in an explicit and rational manner. As data are obtained and as the model performance is evaluated it is possible to continuously update the model

Besides providing a means for integrating data about an industry, the model also helps to indicate what types of data should be collected. Judging from a correspondence with firms in the photographic industries two things stood out. The

I Assuming that initial sales in the forecast were based on trade and production statistics. 
firms did not seem to have a good grasp on the causal relationships discussed in this study (especially with respect to price elasticity for the industry). And, with minor exceptions, the firms had no historical data readily available on such variables as retail prices of cameras; tariffs, taxes, and quotas on cameras; or industry sales of cameras by country.

Finally, the use of the model makes the forecasting effort less dependent upon the "expert" in the firm as experience is gained.

\section{Summary}

The use of the model was illustrated by providing forecasts of camera sales for 30 countries for 1975. The changes from 1962 to 1975 are expected to be substantial. The total market is expected to be almost three times as large in 1975 as in 1962. The growth rates vary markedly among the countries, however. The market will double in the U.S. but increase by seven times in Israel. The accuracy of the 1975 forecasts was judged to be about the same as that for the 1954 backcasts.

The major source of growth in the camera market was due to changes in income. Changes in camera price and in number of potential owners were each about half as important as changes in income and quality changes were about $1 / 4$ as important.

A number of other benefits of the study were also considered. These included evaluations of alternative projections of causal changes, of various large and sudden changes in the market, and of the industry marketing effort. The latter evaluation may lead to identifying unexploited markets. 


\section{SOME COMMENTS ON METHODS}

In this chapter, consideration is given to the aspects in the development of the causal model which appeared to be most useful. The conclusions which were reached were of a rather tentative nature. They were based on a study of only one product--still cameras. Also the parts of the model were inter-related and it was difficult to consider each part separately. Finally, as the model is broken down into various parts, there is a loss of sensitivity since the associated changes attributed to each part become smaller.

\section{The Value of the A Priori Analysis}

Great reliance was placed on using subjective information on an a priori basis. This usage took many forms-analysis of the sample observations, of the important variables, of the causal relationships, and of bias in the measurement models. In overall terms, the a priori analysis appeared to be rather valuable. The model based only on an a priori analysis provided better backcasts for 1954 than were obtained from any of the naive models. Below, an attempt is made to determine which aspects of the a priori analysis were most useful.

\section{Analysis of the Sample Observations}

The theoretical justification for analyzing each sample observation is that it is not always possible to include enough variables in the measurement model to capture all important sources of variation. For example, smuggling was 
not a variable in the international cross-section yet it might well have been a source of variation in the measured camera sales in Italy; or tourists might affect sales in Switzerland.

The most obvious use of a priori information on observations in this study was to screen the data and eliminate observations which were thought to be misleading (Appendix A). This is a rather standard procedure in non-experimental research and this study provided no way to judge the value of such a procedure. But it is hard to imagine how it could be avoided.

Since the number of observations was not large, it was possible to examine each one in detail. Some observations were revised to improve comparability over the data set (e.g. data on camera sales in Japan were adjusted for large inventory changes). This procedure was followed only where the required action was clearcut (see Appendix B, Table B-5). An effort was then made to record any reservations which existed about the data for a given country and to state what effect this would have upon the results of the measurement model (see Appendix A, Table A-I). The purpose of this latter procedure was to assist in making changes in the measurement models. ${ }^{1}$

The a priori reservations about sample observations were examined for the international cross-section. If, in

$I_{\text {Fisher (1962, Chapter 1) provides a rather interesting }}$ rationale for the use of a priori information on observations as a guide for analysis. 
fact, we did have information which had not been accounted for in the model, this information might be used to predict how each country's trade and production estimate of sales will differ from the model prediction of sales. The results were disconfirming. The predictions were correct on 5 countries and incorrect on 9.

Another form of prior evaluation was to rate each observation on quality. Presumably, higher quality observations suffered less from extraneous variation. As a result, model predictions for higher quality observations should be subject to less error. This hypothesis was evaluated in two situations--the international cross-section measurement model and the 1954 backcasts.

Data for the international cross-section were divided into three categories--low, medium, and high quality. Quality was based on an overall rating of the information for all. variables. ${ }^{1}$ This rating scheme was subjective but the distinctions did not appear to be difficult to make. Table 10-1 presents the results of this analysis. (Table A-I in the Appendix indicates the quality rating for each country.) The results of Table 10-I obviously were not consistent with the hypothesis.

Data for the 1954 forecast were then rated by quality of the data on camera sales only. The following quality rating was as follows: countries for which the 1954 estimate

${ }^{1}$ Some information on the quality of observations on the causal variables for different countries may be found in the World Handbook (Alker, et al., 1964). 
was based on three years--1953, 1954 and 1955--were rated as high quality; countries where fewer than three years of data were used were rated as low quality. Thirteen countries fell in the high quality class while only four fell in the low quality class. Results indicated that the mean absolute percentage error was 22 percent for each class. Thus, once again, the results did not support the hypothesis.

TABLE 10-1

ERRORS BY RATED QUALITY OF DATA:

INTERNATIONAL CROSS-SECTION

\begin{tabular}{l|c|c|c|}
\hline & $\begin{array}{l}\text { Number of } \\
\text { Rated Quality } \\
\text { Countries } \\
\text { Gin Class }\end{array}$ & $\begin{array}{l}\text { Mean Absolute } \\
\text { Percentage } \\
\text { Error }\end{array}$ & $\begin{array}{l}\text { Average } \\
\text { Percentage } \\
\text { Error }\end{array}$ \\
\hline Low & 9 & 19 & +9 \\
Medium & 12 & 27 & -5 \\
High & 9 & -7 & -7 \\
\hline
\end{tabular}

In this particular case then, a priori information on the observations--beyond screening and ensuring comparability across the data set--was found to be of negligible value. This was indeed a disappointing result in view of the effort expended in this area.

Selection of Important Variables

The a priori analysis of which variables are important to forecasting ( see Table 3-1) proved to be helpful in simplifying the problem. There is no alternative here--one must make an a priori evaluation of which variables will be important. The only question is whether this step is carried out in an explicit or implicit manner. 
The primary danger of the implicit approach is that inadequate criteria may be employed for the selection. In particular, it seems most likely that confusion may result between variables which are important to the prediction model and variables which are important to one of the measurement models.

Results from the forecasting tests indicated that the explicit a priori evaluation had been reasonably accurate-although, to a certain degree, this may be due to a "self-fulfilling phrophesy". Each variable for the 1975 forecast showed a fair agreement with Table 3-I. A stronger argument may be made by comparing the results of the causal model with the results of the non-theoretically derived causal model (see Table 8-1). The latter, designated as Statisticians' Models \#1 and \#2, did not perform as well as did the causal model based on theoretically chosen variables. Substantial gains were made then, by specifying a small set of causal variables on an a priori basis.

Estimates of Causal Relationships

A priori estimates of the signs of relationships received overwhelming support from the measurement models. The estimates of the magnitudes of relationships received moderately strong support despite obvious problems with bias. The strongest argument for the use of such a priori estimates is provided by the creditible showing of the a priori model. Further support came from the agreement among various estimates of the same relationships (see the price and income 
estimates in Figures 8-1 and 8-2). Finally, the various measurement models in this study provided support for the use of constant elasticities.

Some concern might be voiced about the subjective nature of the a priori estimates and the fact that other scientists cannot replicate these estimates. It is true that very poor a priori choices would have lod to a poor forecasting model. Our argument is that some a priori choice must be made and that it would be surprising indeed if the researcher could not select better a priori estimates than those used by our mythical friend the classical statistician (i.e. that all coefficients equal zero). The performance of the model was not particularly sensitive to the exact values of the a priori estimates and the dependence of the model upon the a priori estimates decreased as formal estimation was carried out. The final version of the model performed better by incorporating the a priori estimates than by excluding them.-but this difference was not great (see the longitudinal model results below).

Estimates of Confidence Regions:

Since it was necessary to integrate the a priori estimates with estimates from the measurement models, it was necessary to have some measure of confidence for the a priori estimates. Such estimates were arrived at through subjective evaluation. While the estimates were very crude, performance of the model was not extremely sensitive to the particular weights. 
Bias Associated with Measurement Models

The a priori analysis of bias associated with each measurement model was intended to restrict the flexibility of the researcher when the results of the model are interpreted. This procedure is suggested to keep the researcher honest. If he really does have more information than exists in the particular data set, he should declare this information prior to the analysis of the measurement model.

In fact, the use of subjective estimates of bias did not yield estimates of causal relationships which were substantially different than those obtained without such estimates (see Table 7-20).

An evaluation was carried out to see whether these smali differences led to better or poorer backcasts for 1954. Table 10-2 provides a summary of the differences in the model coefficients and of the differences in the backcasts obtained for the 17 countries for 1954 .

- TABLE $10-2$

EFFECTS OF "ADJUSTING FOR BIAS" UPON 1954 BACKCAST $^{2}$

\begin{tabular}{l|c|c}
\hline & $\begin{array}{c}\text { No Bias } \\
\text { Estimated }\end{array}$ & $\begin{array}{c}\text { Bias } \\
\text { Estimated }\end{array}$ \\
\hline Coefficients which Differ: & 0.85 & -0.76 \\
$\begin{array}{l}\text { Income } \\
\text { Price }\end{array}$ & $\begin{array}{r}1.00 \\
-0.90\end{array}$ \\
\hline $\begin{array}{l}\text { Results from 1954 Backiast: } \\
\text { Mean Absolute Percentage Error }\end{array}$ & $23.4 \%$ & $21.4 \%$ \\
Average Percentage Error & $-2.0 \%$ & $5.8 \%$ \\
\hline
\end{tabular}

$a_{\text {This }}$ comparison is based on a revised backcast in which initial sales are weighted $2 / 3$ "predicted" and $1 / 3$ "measured", and in which the change in number of potential owner has an elasticity of 0.8 . 
It seems apparent that, in this particular situation, the a priori estimates of bias associated with each measurement model were of little value. This result may be due to a lack of sensitivity of the tests used here.

Compensating for Error in Predictions of Causal Variables

While the adjustments for errors in the measurement were not of obvious value, those for the forecasting model were as had been discussed in Chapter 8 .

\section{Summary: A Priori Analyses}

While none of the a priori analyses were harmful to the model, some did not lead to any substantial gains. The most useful aspects of the a priori analysis appeared to be the selection of a small set of important causal variables, the estimates of causal relationships, and the adjustment for error in the predictions of causal variables. Necessary, but of lesser importance, were the screening of observations and the estimation of confidence regions for causal relationships. Estimates of bias in measurement models did not lead to any significant gains--contrary to expectations.

One dominant theme that ran through the a priori analyses was that the attempt to make estimates, however crude, generally paid handsome dividends. The performance of the model was not particularly sensitive to the exact a priori estimates as long as they were near the region of those values selected in this study. 


\section{The Use of the Measure of Potential Buyers}

The conceptual variable of market size or number of potential buyers was justified on a priori grounds. It seems reasonable to ask, however, whether the rather intensive approach to estimating the number of potential buyers was advantageous to common practice--i.e. "adjusting the model for scale". 1

To make the evaluation, it was desirable to hold constant the choice of causal variables. Thus, the same variables which were used for the causal model were regressed against camera sales per capita. Table 10-3 presents the results for the analysis sample of the international cross-section. For comparison, the results for the identical regression against camera sales per potential buyer are presented.

\section{TABLE $10-3$}

CROSS-SECTIONAL MODEL BASED ON CAMERA SALES PER CAPITA

Prior Estimate

$$
(0.9)(-0.9)(0.7)(1.1)(-0.1)
$$

Estimațed Model R*1 $=4.4+1.8 \mathrm{E}^{\prime}-1.3 \mathrm{P} \cdot-1.4 \mathrm{~B}^{\prime}-0.0 \mathrm{~T}^{\prime}-0.4 \mathrm{~W}^{\prime}$

Standard Errors

$$
(0.3)(0.6)(1.4)(1.0)(0.2)
$$

$$
\mathrm{R}^{2}=0.935
$$

Standard Error $=0.46$

$$
\mathrm{n}=19
$$

Estimated Model Camera.

Sales/Potential Buyer $R^{\prime}=5.7+0.9 E^{\prime}-2.1 P^{\prime}+0.9 B^{\prime}+0.2 T^{\prime}-0.5 W^{\prime}$

$$
\mathrm{R}^{2}=0.975 \quad \text { Standard Error }=0.20 \quad \mathrm{n}=19
$$

where the primes denote natural logs and '

R is unit camera sales per capita; $R$ is sales/potential buyer

$E$ is Beckerman's Index

$P$ is the retail price index for cameras

$B$ is households per adult

$T$ is temperature

$W$ is rainfall

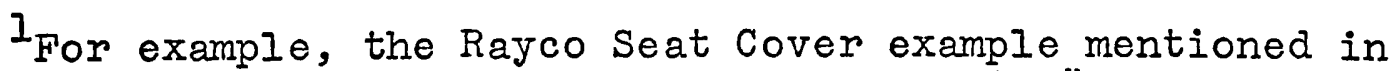
Chapter 2 used "seat cover sales per square mile". 
- In terms of the fit to the analysis sample, then, the model utilizing camera sales per capita does not perform nearly as well as does the model based on camera sales per potential owner. The standard error of the former model was much greater. Also, the sign of the coefficient for the index of buying units was in the wrong direction. While the income and price elasticities differed substantially from those of the model using camera sales per potential buyer, it did not seem that they are any less reasonable in the light of a priori knowledge.

Further testing of this per capita model was carried out. Predictions for the Il validation countries of the international cross-section yielded surprising results. The average percentage error was only $21 \%$. This is lower than the $31 \%$ of the causal model. While the average error of $11 \%$ was higher than the $-5 \%$ for the causal model, the attempt to demonstrate the value of the use of the potential buyer concept clearly failed here.

The estimates from the per capita model were used to update the causal model and to then obtain backcasts for 1954. Table 10-4 presents a summary of this evaluation. Obviously this test was not very sensitive as the coefficients were similar.

As suspected, the lack of sensitivity in the test prohibits us from drawing any firm conclusions. The model based on the number of potential buyers performs better but the difference is not statistically significant nor would it seem of great practical importance. 
TABLE 10-4

USE OF PER CAPITA MODEL, TO BACKCAST 1954

\begin{tabular}{l|c|c}
\hline \hline & $\begin{array}{r}\text { Per Capita } \\
\text { Model }\end{array}$ & $\begin{array}{c}\text { Per Potential } \\
\text { Buyer Model }\end{array}$ \\
\hline $\begin{array}{l}\text { Coefficients which Differ: } \\
\text { Income }\end{array}$ & $\begin{array}{r}1.08 \\
\text { Price }\end{array}$ & $\begin{array}{r}1.00 \\
-0.90\end{array}$ \\
\hline Results from 1954 Backcast: & $\begin{aligned} 21.6 \% \\
\text { Mean Absolute Percentage Error }\end{aligned}$ & $\begin{array}{r}21.4 \% \\
5.6 \%\end{array}$ \\
\hline
\end{tabular}

In summary, the attempt to demonstrate the value of a precise definition of the potential buyer did not succeed. Grosser definitions of potential buyers appeared to be adequate.

\section{Advantages of Using Many Data Sets}

- Various data sets were used to provide estimates for different parameters of the sales forecasting model. The value of such an approach was apparent in some cases--e.g. for assessing the construct validity of the relationships, for obtaining improved estimates of current sales, for evaluating the current industry marketing effort or for obtaining estimates of factors affecting camera prices. One particular aspect of the use of many data sets deserved further consideration, however. The question here was whether any gain resulted in the estimates of the forecasting, coefficients in the sales model--i.e. the constant term and each of the elasticities.

The basic approach taken in this study was to estimate each forecasting coefficient separately and then to build up the forecasting model. This required estimates of causal relationships and then subjective adjustments to compensate 
for errors. A simpler approach would have been to estimate the forecasting coefficients directly by means of the longitudinal model. The longitudinal model across countries conformed to the forecasting model and provided an optimum set of forecasting coefficients for the time of the analysis data. One might be willing to assume that any biases associated with this measurement model would be constant over time so that it could be used directly as the forecasting model. Kuh (1959, p.212) makes a similar argument for time series data.

A comparison was made between the updated causal model and the longitudinal model for backcasting 1954. The results are presented in Table 10-5. It should be emphasized that the models utilized much of the same information. The estimates of initial sales are the same as are the forecasts of the independent variables. The only differences lie in the coefficients of the forecasting model.

\section{TABLE $10-5$}

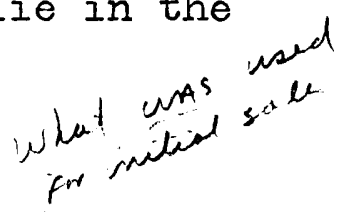

IONGITUDINAL MODEU VS. UPDATED CAUSAL MODEU

\begin{tabular}{l|r|r}
\hline & Longitudinal & $\begin{array}{r}\text { Updated Causal } \\
\text { Model }\end{array}$ \\
\hline Coefficients which Differ: & & \\
Constant & 1.093 & 0.918 \\
Income & 2.100 & 1.000 \\
Price & -0.640 & -0.900 \\
\hline Results from 1954 Backcast: & $26.3 \%$ & $21.4 \%$ \\
Mean Absolute Percentage Error & $-19.7 \%$ & $-5.8 \%$ \\
Average Percentage Error & & \\
\hline
\end{tabular}

It may be seen from Table 10-5 that the coefficients based on information from many data sets were superior to 
those based on the longitudinal model. I These results are consistent with the notion that is is useful to break the forecasting model down so that different data sets may be utilized to estimate the different components of the model. The gain in this situation was an important one but was not statistically significant at the 5\% level. (The superiority of the use of many data sets would have been obvious, of . course, if account had also been taken of the gains from the estimates of initial sales).

The above analysis should not lead one to overlook the benefits of the longitudinal model. This data set offers mach in that it may be used to integrate the various parts of the forecasting model. One promising strategy would be to introduce all outside estimators into the longitudinal measurement model to obtain a consistent set of forecasting coefficients. Such a strategy would benefit greatly from improvements in the longitudinal data.

\section{Many Variables vs. Few Variables}

It was suggested earlier that there are often many important factors in non-experimental data which cause variation in a dependent variable. For this reason, it would seem worthwhile to try to include each of these important variables in a given measurement model. The inclusion of more variables leads to increased costs and to certain measurement problems, however. The question then is just how does

$I_{\text {The free-form of the longitudinal model was used for }}$ this analysis. 
one determine whether a variable is important enough to justify its inclusion in a measurement model. In more general terms, how "complete" should a measurement model be in non-experimental research?

This problem of many versus few regressors seems to be an old one. Wold (1953) pointed out that this problem first arose in the literature when R. Frisch conjectured in 1934 that "if many regressors are introduced a regression coefficient has a tendency to return to the value obtained with a small number of regressors". The results of the camera study are in agreement with this hypothesis. Estimates of the price and income elasticities did not change substantially with the addition of more variables in the analysis sample of the international cross-section. The standard error of the price elasticity was reduced substantially with more variables, however. These results are presented in Table 10-6.

\section{TABLE 10-6}

EJASTICITIES WITH MANY VS. FEW INDEPENDENT VARIABLES $(n=19)$ (STANDARD ERRORS IN PARENTHESES)

\begin{tabular}{l|c|c}
\hline & $\begin{array}{c}\text { No Other } \\
\text { Variable }\end{array}$ & $\begin{array}{c}\text { With Three Other } \\
\text { Independent Variables }\end{array}$ \\
\hline Price & $-2.04(0.45)$ & $-2.10(0.25)$ \\
Beckerman's & $0.90(0.11)$ & $0.88(0.13)$ \\
\hline
\end{tabular}

The comparison of models in Table 10-6 did not account for the fact that a priori estimates for some variables had al ready been entered (i.e. to account for the number of potential buyers). An even simpler model was developed which regressed total camera sales against only income and price. 
Table 10-7 presents the results for this model as estimated against the analysis sample of the international cross-section.

\section{TABLE $10-7$}

TOTAL CARERA SALES VS. NATIONAL INCONE AND CAMERA PRICE

Priori Estimate

$$
(0.90) \quad(-0.90)
$$

Estimated Model. $C^{\prime}=-5.92$

$+1.16 I^{\prime}-.1 .74 \mathrm{P}^{\prime}$

Standard Errors

(0.11) $\quad(0.77)$

$$
\mathrm{R}^{2}=91 \% \quad \text { Standard Error }=0.62 \quad \mathrm{n}=19
$$

where the primes denote natural logs and

$C$ is total camera sales per year (1960-65 average)

$I$ is national income

$P$ is price index for camera goods

While the fit of this model to the analysis data was not nearly as close as were the previous models (i.e. the mean absolute percentage deviation was $47 \%$ ), the coefficients seem to agree reasonably well with the a priori information. Both coefficients are on the high side but the overall picture is about as favorable as that obtained. in the more complete causal model (Table 7-10). The standard errors of the coefficients were large in comparison to those in the complete model.

The performance of this simple model in predicting sales for the eleven countries in the validation sample was surprisingly good. The mean absolute percentage deviation of $27 \%$ was lower than that of the causal model (31\%). The average error of $+24 \%$ was, however, not nearly so good (vs. $-5 \%$ for the causal model).

The value of using more complete models was not demonstrated 
in this study. It is difficult to provide any rule of thumb as to when one should stop entering variables. The results of this study would seem consistent with the rule of thumb referred to by Ball (1965) that one needs ten observations for each coefficient estimated in a multiple regression. One conclusion which does seem reasonable is that the benefits of finding additional causal variables for use in a measurement model drop off sharply (when aggregate data are used).

\section{The Value of Global Indices}

One of the theoretical positions taken in this study was that it is possible to improve the measurement of conceptual variables by utilizing operational measures which are derived fror different approaches. This position received support when the two measures of camera sales--one based on the prediction from the regression across countries-were combined to estimate current sales.

There are two additional situations which allow us to examine the value of using different approaches for measurement. The first situation relates to the measurement of camera prices. It would appear that a combined measure based on the measured prices and on the prediction from a regression across countries would be superior to the use of measured prices only. This hypothesis was tested in the regression against the $I l$ countries of the validation sample. The details are provided in Appendix $C$. The combined measure led to improved predictions of sales for 7 out of 11 countries. The second situation was to use a combined index of 
economic ability to purchase which was based on Beckerman's Index and on personal consumption expenditures per capita. This index was used in the regression on the international cross-section to see whether the prediction of sales was improved. The results for the 30 countries indicated that there was no gain from using a combined measure.

In summary, the position that gross indices are superior received moderate support. In none of the situations did it lead to poorer results. One situation showed marked imporvement, one moderate improvement and one negligible change.

\section{Summary}

An analysis of the usefulness of various aspects in the development of the causal model led to a number of conclusions. These conclusions are of a rather tentative nature since it was rather difficult to isolate the interdependent parts of the model. Some caution is also called for inasmuch as only one product was considered in this study.

The value of the a priori analysis was demonstrated both in overall terms and with respect to many of the operational procedures involved. A dominant feature of this analysis was that the performance of the model was not sensitive to the particular choice of a priori estimates as long as they were near the region of those values which had been selected. Substantial benefits were derived from most a priori estimates.

The value of using many data sets was shown to hold even for the estimation of the forecasting coefficients. The study also provided support for the hypothesis that it is useful to combine different types of indicators into global indices. 
Iittle empirical support was gained for the argument that it is worthwhile to obtain precise measures of the number of potential buyers. Finally the question of how many variables should be included in the measurement model went unresolved. 


\section{CONCLUSIONS}

A causal model was developed to provide long-range sales forecasts of still cameras for the international market. The performance of this model supported the hypothesis that causal models are superior to naive models for unconditional long-range sales forecasting.

It was not possible to test the forecasting ability of the causal model directly. Primary reliance was placed upon a test of unconditional backcasting. Data from 1967 to 1960 were used to backcast 1954 camera sales for each of 17 countries. The average absolute percentage error of the backcasts provided by the causal model was $23 \%$ in contrast to the $43 \%$ for a naive model purporting to represent current practice. The dollar value of such an improvement in accura.cy would be substantial if these results might be generalized to the forecasting situation. It was estimated to be on the order of a $\$ 1,000,000$ savings for a firm with sales of $\$ 100,000,000$. This savings would appear to be rather large in comparison to the costs of developing the model. ${ }^{1}$

The superiority of the causal model over the naive model was also found to be statistically significant at the $5 \%$ level. In view of the size of the potential gains, it appears that it would be worthwhile developing such a model even if there was a $5 \%$ chance that the effort would result in failure.

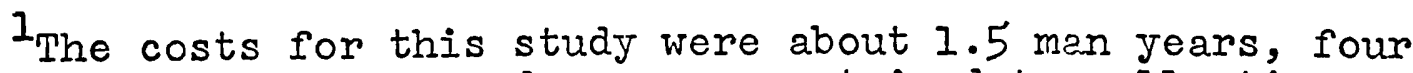
hours of IBM 7090 time, and some support in data collection. 
Actually, the results might be viewed with somewhat more caution in that only a single product was studied.

\section{Additional Testing of the Model}

While predictive validity was of utmost concern, there were additional methods for evaluating the causal model. Construct validity of the more important causal relationships was examined by comparing estimates from different data sets. Close agreement was found among the various estimates of income elasticity. These estimates came from subjective data (used in an a priori manner), from cross-sectional data over 30 countries, from longitudinal data over 21 countries, and from U.S. household survey data from over 12,000 families. The case for estimates of price elasticity was encouraging but not so strong as that for income elasticity.

Concurrent validity was examined by retaining data on Il countries from the international cross-section. Predictions for the level of camera sales in each country were substantially better under the causal model than under the naive "manager's model" used to simulate current forecasting practice. The mean absolute percentage error of the causal model was about $60 \%$ that of the naive model (31\% vs. $54 \%$ ). This difference was significant at the $5 \%$ Ievel.

Finally, the model was able to explain historical variations to a rather close degree. This was especially true for explaining differences in camera sales among countries where the $R^{2}$ between actual and predicted sales for the 30 countries was over 99 percent. A close fit was also obtained for explaining differences among household groupings where 
$\mathrm{R}^{2}$ was 90 percent. The explanation of changes in camera sales for a group of countries was not so good, however, as the $\mathrm{R}^{2}$ was only $25 \%$.

\section{The Development of the Causal Model}

The basic stages in the development of a causal model for long-range forecasting are outlined in Figure 11-1. These stages may be contrasted with those required for the development of naive long-range forecasting models as presented in Figure 11-2. The complexity of the causal model would appear to be a disadvantage since poor measurement at any stage of development would affect the performance of the model. The results of the camera study indicated, however, that the model was not extremely sensitive to measurement errors at each stage despite the fact that some of the measurement techniques were very crude.

A heavy reliance was placed upon the use of subjective data to provide an a priori specification of the causal relationships. In short, it was possible to completely specify. the causal relationships without any formal estimation. This a priori model yielded forecasts which were superior to those provided by any of the naive models.

It should be noted that while a substantial amount of work went into the various measurement models, the improvement in the accuracy of the forecasts resulting from this estimation was only moderate. The mean absolute percentage error was $30 \%$ when the a priori version of the causal model was used. When the estimates were updated by using the 
FIGURE $11-1$

DEVELOPMENT OF A CAUSAL MODEL FOR

LONG-RANGE FORECASTING

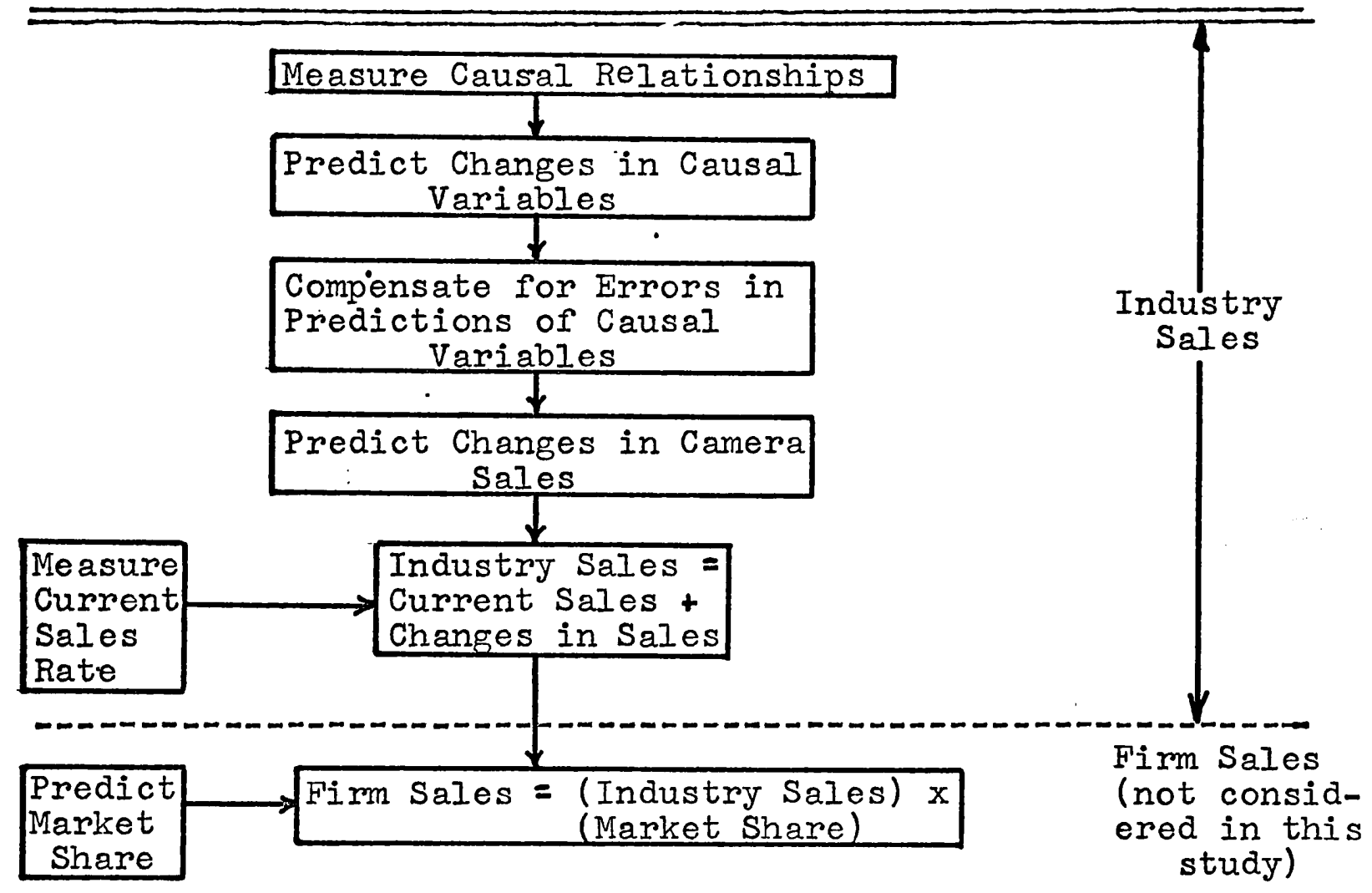

measurement models the error was reduced to $23 \%$. The improvement in the estimate of the current sales rate was the primary factor leading to the improved forecasts of the updated model. To state this another way, the a priori estimates of the causal relationships performed almost as well as did the updated estimates in the unconditional backcast of 1954. Of course, the formal measurement also served to improve our confidence in the model, to make the model less dependent upon the a priori estimates of a single researcher, and to satisfy. a number of secondary objectives of the study. 
FIGURE $11-2$

DEVELOPMENT OF NAIVE MODELS FOR

LONG-RANGE FORECASTING

A. Direct Firm Forecast

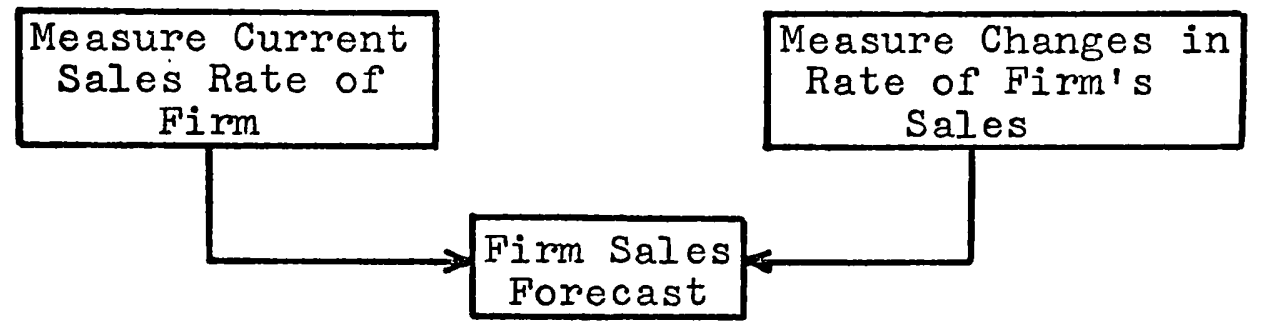

B. Industry-Firm Forecast

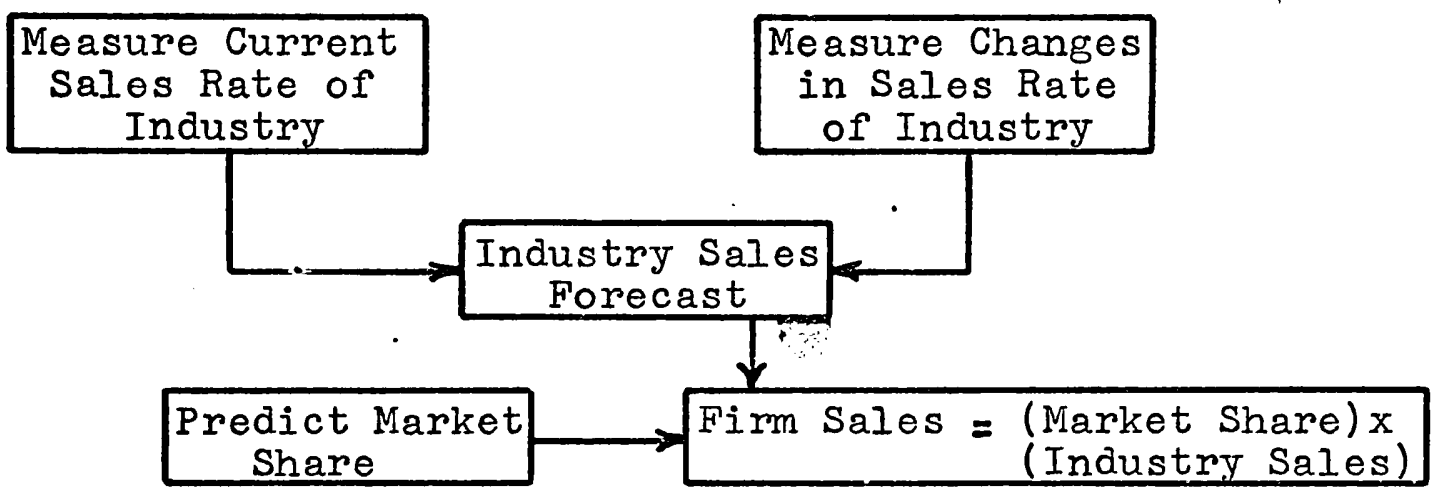

The causal variables which proved useful in forecasting changes in camera sales included, in order of importance, per capita income, retail prices of cameras, number of potential buyers, and the quality of still cameras.

Changes in the causal variables themselves were predicted primarily by naive methods augmented by certain outside information. One exception to this was the prediction of camera prices where a causal model was employed. This model predicted changes in camera prices on the basis of changes in tariffs, taxes, resale price maintenance, trade controls, and the proportion of camera consumption represented by imports. The causal factors from the price model were, in turn, predicted 
by use of naive projections and outside information.

While the parameter estimates from the price model were based only on a single, measurement model, they showed close agreement with a priori estimates. The reliability of the estimates was not overly impressive but, on the other hand, it was not so bad as to render the estimates useless. The ability of the model to explain differences in prices among countries was modest. The $\mathrm{R}^{2}$ between actual and predicted price for 26 countries was about $70 \%$ and the average error was $10 \%$.

The price model proved useful not only in predicting price but also in helping to supply missing data on prices for. other measurement models. This was of particular importance since no adequate data on camera prices could be found for years prior to 1966. In some countries, data for 1966 were not even available.

The compensation for errors in the prediction of the causal variables was carried out by using subjective information to adjust the coefficients of the causal variables. Experimentation with the longitudinal data set was used to test out the reasonableness of these adjustments.

The current rate of camera sales was based on the average yearly sales rate for six consecutive years. These data were aggregated over time to dampen out short run factors. Two indicators--one based on trade and production statistics and the other on sales as predicted by the regression across 30 countries--were weighted to provide a single estimate of the current sales rate. 


\section{Improving the Model}

One of the more desirable features of causal models, in contrast to naive models, is that the path to future improvernents is clearer. Both approaches would benefit substantially from better estimates of the current sales rate, of course. The causal model can benefit additionally from further measurement of the causal relationships, from better methods of predicting the causal variables, and from better methods for adjusting the forecast coefficients to compensate for error in the prediction of the causal variables.

The improvement which is possible from having a better estimate of current sales would appear to be substantial. Surveys of consumers and/or retailers seem to provide an obvious means for improving the estimate of the current sales rate. Such surveys might be conducted periodically in each country. Even without such surveys the situation is expected to improve since the quality of international trade and production data has been improving rapidly.

Improvement in the measurement of causal relationships should result as more and better data become available for both sales and causal variables. It would also be useful to seek out additional data sets such as data by state in the U.S., time series data on one or more countries, survey studies to determine why people purchase cameras, consumer panel data which includes camera purchases, or shopping experiments. Improvements in the longitudinal data set would be of particular importance--e.g. observations on additional countries, longer time span, and more reliable measures. Emphasis should 
be placed upon measurement of the effects of price and quality changes.

Better predietions of changes in the causal variables would also appear to lead to improvements in forecasting. This is especially true with respect to predictions of camera price changes. Improvements in this area would, in turn, lead to less of a problem in deciding how much to adjust the forecast coefficients to compensate for errors in predictions of eausal variables.

\section{Additional Benefits of the Study}

While the primary emphasis in this study was on long-range ferecasting, a number of side benefits were considered. The stuidy provided a means for:

a. examining the impact of "large changes" in the market upon eamera sales. One example, the Kennedy Round tariff reductions, was considered in some detail.

b. measuring the current rate of camera sales in a country Where, for some reason, trade and production figures are not avaijable.

e. evaluating the effect upon camera salès of alternative projections of the future in a rapid and inexpensive manner.

d. evaluating the industry marketing effort with special emphasis upon the identification of markets which have not been fully exploited.

\section{Limitations of the Study}

The most important limitation of the current study was that it was restricted to the study of a single product. There does not appear to be any reason why the approach used in this study could not be extended to the study of other products. 
Another limitation was that the model restricted itself to aggregate data (by country). While the promise of the future is expected to lie with disaggregated data, models for international markets will probably be limited to aggregate data for a number of years.

Finally, it should be noted that the study was restricted to the industry level. It was assumed that improvements in the industry forecast would lead to corresponding improvements in the firm's forecast.

\section{Summary}

The occurrence of numerous large changes in international markets, the improvement in the quality and availability of data on international markets, and the existence of low cost multivariate statistical measurement models led to the belief that causal models would be of substantial value in the study of international markets. Support for the value of causal models was received by an intensive study of the international market for still cameras. The margin of superiority of causal models over naive models representing current practice appeared to be of great practical importance and the likelihood that the results were due to luck on the part of the researcher seemed low. 


\section{APPENDIX A}

\section{A PRIORI EVALUATION OF OBSERVATIONS}

Data from 60 countries were considered for possible use in the international cross-section. ${ }^{1}$ These included, with minor exceptions, all countries which had a 1964 National Income of over one billion U.S. dollars. (As reported in "Indicators of Market Size for 89 Countries" in the December, 1966 issues of Business International.)

The data for each of these 60 countries were then carefully evaluated with the net effect that an additional 29 countries were eliminated. The most important screening mues were those pertaining to severe trade controls. The objective was to retain a sample of countries over which a comparable. mix of cameras was for sale.

A summary of the analysis is presented in Table A-I. The countries were divided into four categories: class 1 countries were eliminated; class 2 countries were retained with strong reservations; class 3 countries were retained with mild reservations; and class 4 countries were retained with no significant reservations. Brief notes are provided about these "reservations". For each class 2 and 3 country, a priori predictions were also made as to what would be the net effect of these reservations.'

Initially, strategies had also been proposed as to what to do if the a priori reservations were justified. Since this whole analysis, beyond the screening of the data, proved to

the analysis was also of some use to the longitudinal model. 
be of no measureable value, the details on strategy were dropped from the presentation.

\section{TABLE A-I}

A PRIORI EVALUATION OF OBSERVATIONS ON COUNTRIES

\begin{tabular}{|c|c|}
\hline & Class 1--Countries Excluded \\
\hline Country & Reasons for Exclusion \\
\hline Turkey & $\begin{array}{l}\text { Low import quotas; very high tariffs; low } \\
\text { camera sales rate }\end{array}$ \\
\hline Chile & $\begin{array}{l}\text { Low import quotas; wide fluctuations in camera } \\
\text { sales }\end{array}$ \\
\hline Columbia & $\begin{array}{l}\text { Very wide yearly fluctuations in camera sales } \\
\text { rate; low import quotas }\end{array}$ \\
\hline Uruguay & $\begin{array}{l}\text { Extreme import controls including quotas, licences, } \\
\text { prohibitions, tariffs, and red tape; inadequate } \\
\text { data }\end{array}$ \\
\hline Burma & $\begin{array}{l}\text { Prohibition of photographic imports; licenses } \\
\text { required for film purchases }\end{array}$ \\
\hline Ceylon & Prohibition of photographic imports since 1962 \\
\hline Greece & $\begin{array}{l}\text { High unexplained variation in sales rate; poss- } \\
\text { ible large unknown variations in tariffs, } \\
\text { taxes and import controls }\end{array}$ \\
\hline Hong Kong & $\begin{array}{l}\text { Extremely high tourist sales; parcel post imports } \\
\text { not included in the data; inadequate data on } \\
\text { explanatory variables }\end{array}$ \\
\hline India & $\begin{array}{l}\text { Low import quotas; inadequate data on internal } \\
\text { production; extensive black market; very low } \\
\text { measured camera sales rate }\end{array}$ \\
\hline Indonesia & $\begin{array}{l}\text { Low import quotas; extreme tariffs (over } 350 \% \text { ); } \\
\text { extensive smuggling; low quality of data on } \\
\text { most variables }\end{array}$ \\
\hline South Korea & $\begin{array}{l}\text { Prohibitions in 1963; large second hand market } \\
\text { from sales through U.S. Armed Forces; low } \\
\text { quality of data for some explanatory variables; } \\
\text { large unexplained variations in sales }\end{array}$ \\
\hline Malaya & $\begin{array}{l}\text { High tourist sales through Singapore; confusion } \\
\text { in data as to political boundaries }\end{array}$ \\
\hline Pakistan & $\begin{array}{l}\text { Low quotas; low quality of data on some explana- } \\
\text { tory data; high tariffs and taxes; large unex- } \\
\text { plained variations in camera sales rate }\end{array}$ \\
\hline Philippines & $\begin{array}{l}\text { Strict import control by licensing; high tariffs } \\
\text { and taxes; low quality data on some explanatory } \\
\text { variables }\end{array}$ \\
\hline
\end{tabular}


TABLE A-1--Continued

\begin{tabular}{|c|c|}
\hline Country CIass & Reasons for Exclusion \\
\hline aiwar & $\begin{array}{l}\text { Extensive smuggling; large unexplained variation } \\
\text { in sales rate; low quality data on some explan- } \\
\text { atory variables }\end{array}$ \\
\hline South Vietnam & $\begin{array}{l}\text { Prohibitions; very low quotas; very high tar- } \\
\text { iffs; inadequate data on explanatory variables; } \\
\text { war }\end{array}$ \\
\hline Syria & $\begin{array}{l}\text { Low quotas; high tariffs; very low camera sales } \\
\text { rate; lack of adequate data on explanatory } \\
\text { variables }\end{array}$ \\
\hline Iran & $\begin{array}{l}\text { Extensive smuggling; severe import controls; } \\
\text { low camera sales rate; lack of adequate data } \\
\text { on explanatory variables }\end{array}$ \\
\hline $\begin{array}{l}\text { United Arab } \\
\text { Republic }\end{array}$ & $\begin{array}{l}\text { Very low quotas; low camera sales } r \\
\text { adequate data on explanatory variab }\end{array}$ \\
\hline Algeria & $\begin{array}{l}\text { quate data on explanatory variables; high } \\
\text { lained variations in the camera sales rate }\end{array}$ \\
\hline Morocco & $\begin{array}{l}\text { Inadequate data on explanatory variables; low } \\
\text { camera sales rate; use of restrictive licenses; } \\
\text { high tariffs }\end{array}$ \\
\hline Sudan & $\begin{array}{l}\text { Inadequate data on explanatory variables; low } \\
\text { camera sales rate; strict import controls }\end{array}$ \\
\hline $\begin{array}{l}\text { Bulgaria } \\
\text { Hungary }\end{array}$ & No data on camera sales rate \\
\hline $\begin{array}{l}\text { Czeckoslovakia } \\
\text { East Germany } \\
\text { Poland } \\
\text { Rumania } \\
\text { Russia }\end{array}$ & $\begin{array}{l}\text { Different quality mix of cameras available; } \\
\text { difficulty in obtaining data on ability to pur- } \\
\text { chase which would be comparable with rest of } \\
\text { sample; strict import controls }\end{array}$ \\
\hline
\end{tabular}

Class 2--Countries Retained on Tentative Basis

\begin{tabular}{l|l|c} 
Country & Reservations about Data & Prediction of Net Effect \\
\hline Brazil & $\begin{array}{l}\text { Possibility of black market } \\
\text { due to heavy tariffs and } \\
\text { controls on imports; price } \\
\text { estimates too high due to } \\
\text { black market }\end{array}$ & \\
Guatemala & $\begin{array}{l}\text { Iow camera sales rate; low } \\
\text { quality data on some ex- } \\
\text { planatory variables }\end{array}$ & \multicolumn{1}{|l}{} \\
Peru & $\begin{array}{l}\text { Import controls may be } \\
\text { very restrictive } \\
\text { Possible controls on for- } \\
\text { eign goods }\end{array}$ & $\begin{array}{l}\text { Trade and production } \\
\text { figures too low } \\
\text { Trade and production } \\
\text { figures too low }\end{array}$
\end{tabular}


TABLE A-I--Continued

\begin{tabular}{|c|c|c|}
\hline Country ${ }^{\text {Class }}$ & Reservations about Data & Prediction of Net Effect \\
\hline Iraq & $\begin{array}{l}\text { Data on literacy subject } \\
\text { to much uncertainty; } \\
\text { strong controls on imports }\end{array}$ & $\begin{array}{l}\text { Trade and production } \\
\text { figures too low }\end{array}$ \\
\hline Israel & Very high tariffs and taxes & $?$ \\
\hline New Zealand & $\begin{array}{l}\text { Wide variations in yearly } \\
\text { sales rate; poor data on } \\
\text { some explanatory variables }\end{array}$ & ? \\
\hline South Africa & $\begin{array}{l}\text { Restrictive licensing; } \\
\text { wide variations in yearly } \\
\text { sales; uncertainty on } \\
\text { estimate of literacy }\end{array}$ & $\begin{array}{l}\text { Trade and production } \\
\text { figures too low }\end{array}$ \\
\hline Thail and & $\begin{array}{l}\text { Ability-to-buy under- } \\
\text { estimated }\end{array}$ & $\begin{array}{l}\text { Predicted sales too } \\
\text { low }\end{array}$ \\
\hline
\end{tabular}

Class 3--Countries with Minor Reservations

Country

Ireland

Italy

Austria

Belgium-Lux.

France

W. Germany

Spain

Sweden

Switzerland

Japan
Reservations about Data Uncertainty on literacy data; high unexplained variation

Possibility of extensive smuggling from Ger. and Switz.; subjective estimates of sales from insufficient data

Possibility of restrictive controls through 1964

Large unexplained shift in 1963

Subjective estimate of sales from incomplete data

Private survey indicated that official statistics are overstated

Subjective estimates on sales from insufficient data

Possibility of high tourist sales

Possibility of high tourist sales; smuggling to Italy

Quota on color film; questionable data on exports high
Prediction of Net Effect ?

Measured sales too low

Measured sales too low ?

?

Measured sales too high

$$
\text { ? }
$$

Measured sales too high

Measured sales too high

Predicted sales too 


\begin{tabular}{l|l|l}
\hline \multicolumn{2}{|c|}{ Class } & \\
Country & Reservations about Data & Prediction of Net Effect \\
\hline Argentina & $\begin{array}{l}\text { Possibility of black market } \\
\text { due to high prices; in- } \\
\text { equality of income distri- } \\
\text { bution }\end{array}$ & Measured sales too high \\
Mexico & $\begin{array}{l}\text { (1962 data excluded); } \\
\text { possible use of import lic- } \\
\text { enses to restrict; subjec- } \\
\text { tive estimate on production }\end{array}$ & Measured sales too low \\
Venezuela & $\begin{array}{l}\text { Possible use of license } \\
\text { Vesigh }\end{array}$ & Measured sales too low
\end{tabular}

- Class 4--Countries with No Prior Reservations

Denmark, Finland, Netherlands, Norway, Portugal, United Kingdom, Canada, United States, Australia 
1. International Price Data

The intemational price data were comprised of a price index and five predictor variables. They are presented in Table 7-2. Sources and notes on these data are presented below. a. Retail Prices of Camera Goods

A survey of importers or sales managers for a U.S. photographic firm was utilized to obtain data on the prices of camera goods. The following questions were asked:

"We are interested in learning the typical price paid by consumers in your country for the camera models listed on the table on the next page. If the exact model named is not available in your country, would you please provide the brand, model number, and price of a similar type of camera which is readily obtainable. If there. is discounting in your country, and the discount price is different from the typical price, please fill in the appropriate column."

"In the columns at the far right of the table, would you specify how much of the price for each camera is tax that is recognizable, and what type of tax it is."

As the result of a persistent follow-up, responses were obtained from 26 of 27 countries in the sample survey. The responses were obtained over the latter part of 1966.

An examination of the results indicated a number of problems. Most of the camera goods on the questionnaire were not widely available over the 26 countries. In addition, some confusion appeared to exist about product definitions-e.g. did the price for a Kodak model \#104 include the whole kit? Was processing included in the price of the films? To handle the first problem attention was restricted to three 


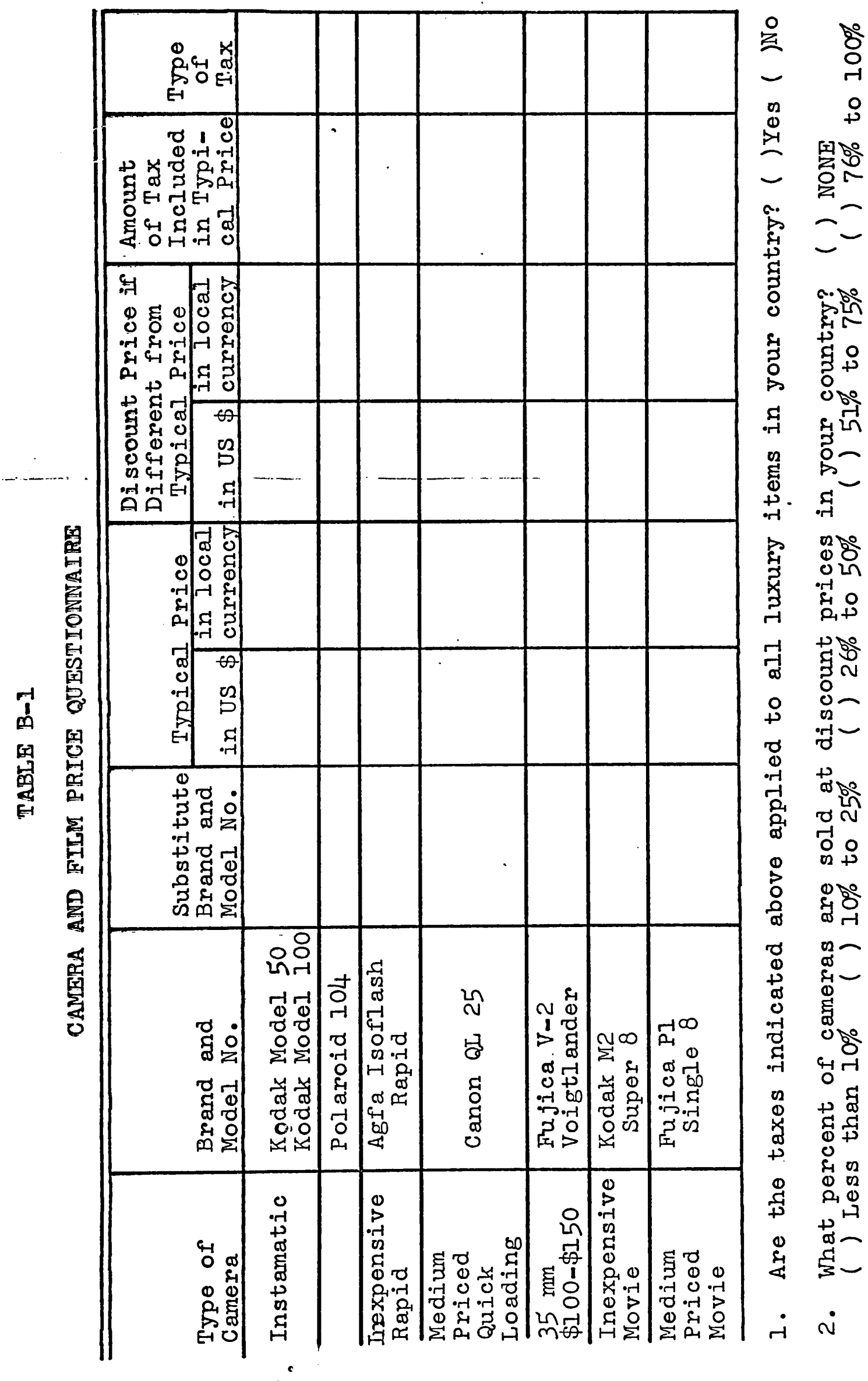




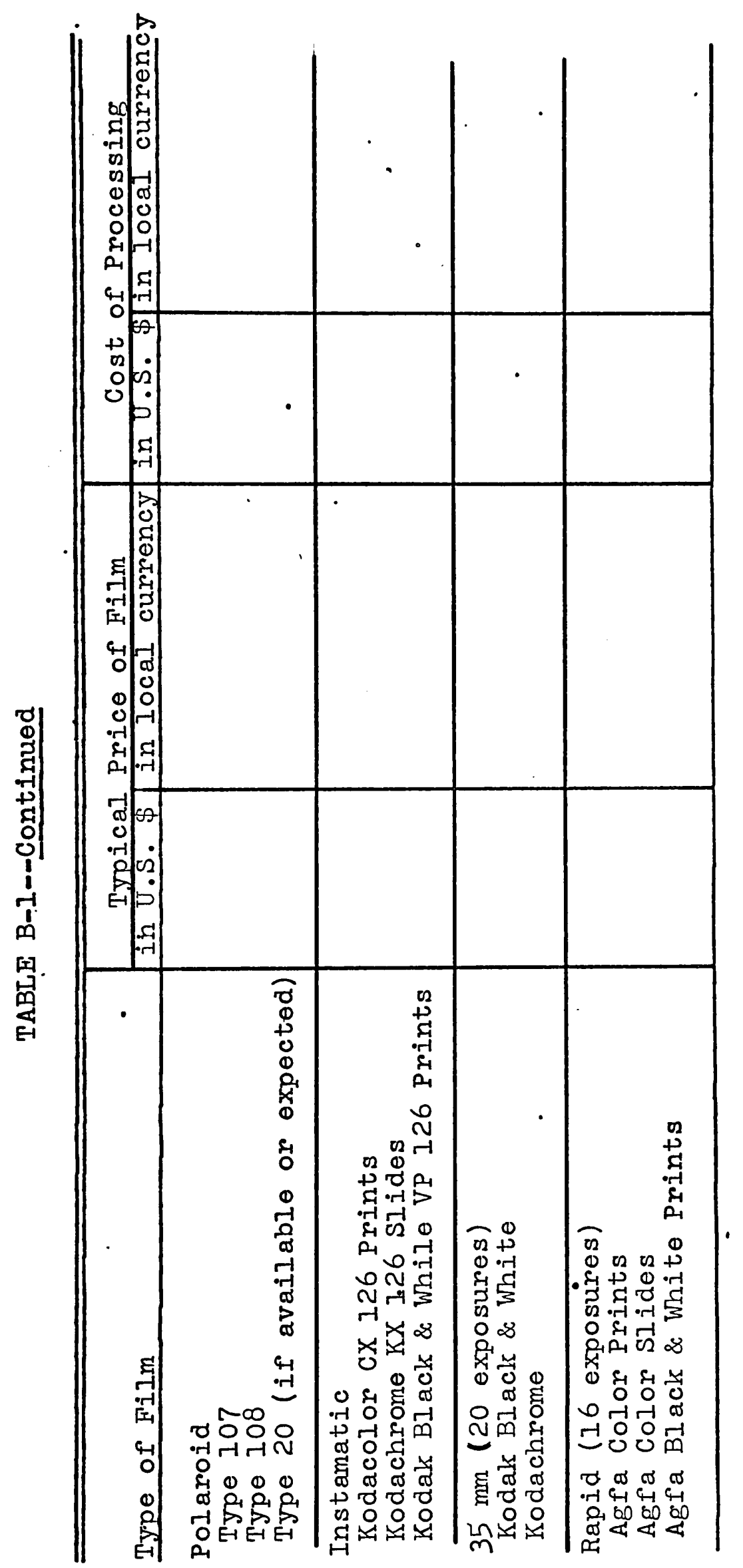


brand categories which appeared to have wide distribution. These included Kodak, Polaroid and Canon. These selections also appeared to mitigate the second problem since these three brands did not show some of the extreme fluctuations among countries which had appeared among other brands. Further efforts to control the definition problem were carried out by looking only at the price of black and white film (to avoid the problem of "processing costs") and by muning a second survey which clarified the wording on the Kodak models by emphasizing that"kits" not be included.

The second survey provided an opportunity to test the reliability of the questionnaire. This survey requested less information and concentrated on Kodak and Polaroid products. The surveys were sent to the same organizations that had completed the first surveys. Returns from 20 countries were received in early 1967. In most cases, these returns matched exactly with the first survey. Where discrepancies existed, the differences were usually small in percentage terms. It was not known whether these differences were due to response error or to actual changes from late 1966 to early 1967. Results from the two surveys were averaged. Table B-2 presents the retail price data. b. Factors Affecting Camera Prices

The factors causing variations in camera prices were obtained from numerous sources:

Technological Change was estimated primarily on the basis of data from Sears-Roebuck catalogues. Table B-3 presents the original data. Year to year changes were obtained for the 
TABLE $B-2$

AVERAGE RETAIL PRICES OF CAMERAS AND FILM BY COUNTRY: $1966-67$ (U.S. DOLLARS)

\begin{tabular}{|c|c|c|c|c|c|}
\hline \multirow[b]{2}{*}{ Country } & \multicolumn{2}{|c|}{ Kodak } & \multicolumn{2}{|c|}{ Polaroid } & \multirow{2}{*}{$\begin{array}{c}\text { Canon } \\
\text { Camera } \\
\text { Type QL25 }\end{array}$} \\
\hline & $\begin{array}{l}\text { Camera } \\
\text { Type } 104\end{array}$ & $\begin{array}{l}\text { Film } \\
\text { Tỹpe VPI26 }\end{array}$ & $\begin{array}{c}\text { Camera } \\
\text { Type } 104 \\
\end{array}$ & $\begin{array}{c}\text { Film } \\
\text { Type } 107\end{array}$ & \\
\hline $\begin{array}{l}\text { Austria } \\
\text { Belgium-Iux } \\
\text { Denmark } \\
\text { Finland } \\
\text { France } \\
\text { W.Germany } \\
\text { Greece } \\
\text { Ireland } \\
\text { Italy } \\
\text { Netherlands } \\
\text { Norway } \\
\text { Portugal } \\
\text { Spain } \\
\text { Sweden } \\
\text { SwitzerIand } \\
\text { U.Kingdom } \\
\text { Canada } \\
\text { U. S. } \\
\text { Argentina } \\
\text { Brazil } \\
\text { Mexico } \\
\text { Venezuela } \\
\text { Australia } \\
\text { Hong Kong } \\
\text { Japan } \\
\text { S.Africa }\end{array}$ & $\begin{array}{l}14 \cdot 90 \\
17 \cdot 90 \\
12 \cdot 00 \\
15 \cdot 90 \\
15 \cdot 00 \\
15 \cdot 80 \\
15 \cdot 50 \\
15 \cdot 70 \\
15 \cdot 50 \\
14 \cdot 40 \\
15 \cdot 30 \\
18 \cdot 40 \\
15 \cdot 00 \\
12 \cdot 50 \\
12 \cdot 20 \\
15 \cdot 40 \\
17 \cdot 10 \\
14 \cdot 80 \\
17 \cdot 50 \\
27 \cdot 20 \\
15 \cdot 00 \\
15 \cdot 30 \\
14 \cdot 50 \\
10.40 \\
14 \cdot 00 \\
15.00\end{array}$ & $\begin{array}{l}.58 \\
.70 \\
.49 \\
.64 \\
.45 \\
.55 \\
.60 \\
.68 \\
.56 \\
.55 \\
.66 \\
.67 \\
.51 \\
.57 \\
.60 \\
.62 \\
.72 \\
.47 \\
. .14 \\
.95 \\
.72 \\
.77 \\
.72 \\
.42 \\
.46 \\
.63\end{array}$ & $\begin{array}{r}83.30 \\
80.00 \\
72.00 \\
95.00 \\
64.00 \\
70.00 \\
120.00 \\
78.00 \\
69.00 \\
63.00 \\
90.00 \\
-1 .-10 \\
70.00 \\
78.00 \\
61.00 \\
77.60 \\
60.70 \\
50.00 \\
156.00 \\
180.00 \\
96.40 \\
82.00 \\
71.00 \\
54.60 \\
67.00 \\
80.00\end{array}$ & $\begin{array}{l}3.20 \\
2.90 \\
2.80 \\
4.50 \\
2.50 \\
3.00 \\
4.50 \\
2.80 \\
3.10 \\
2.70 \\
3.00 \\
-.-5 \\
3.40 \\
2.70 \\
3.00 \\
2.80 \\
3.00 \\
2.20 \\
5.50 \\
6.30 \\
3.90 \\
3.00 \\
3.30 \\
1.90 \\
3.60 \\
2.80\end{array}$ & 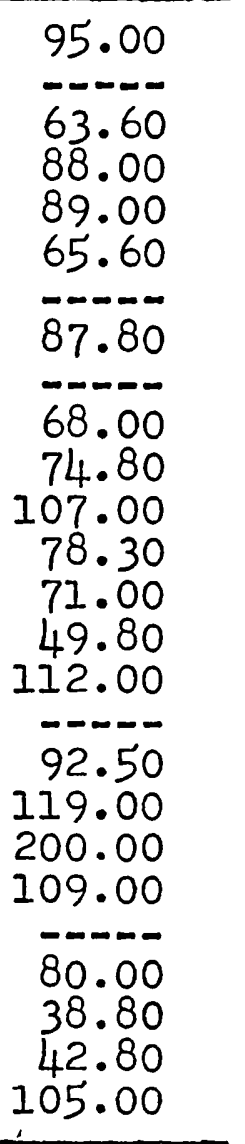 \\
\hline
\end{tabular}

Estimated on basis of a "comparable" model.

same camera models. As many cameras were used as possible. The prices were adjusted by a general price index to convert to constant dollars. Percentage changes for each camera type were then aggregated by use of a geometric mean to yield a single change index for each year. (Percentage data were used so that expensive cameras would not be weighted more heavily than inexpensive cameras.) For the film data, the raw prices for the two components were aggregated by an arithmetic mean 
TABLE B-3

SEARS CATALOGUE: PRICES OF CAMERAS AND FILM OVER TIME: 1960-65

\begin{tabular}{|c|c|c|}
\hline \multirow[b]{2}{*}{ Years } & \multirow{2}{*}{$\begin{array}{l}\text { Still Cameras } \\
\text { Item (without case) }\end{array}$} & $\begin{array}{l}\text { List } \\
\text { Price }\end{array}$ \\
\hline & & $1964 \quad 1965$ \\
\hline $1964-5$ & $\begin{array}{l}\text { Tower 20B } \\
\text { Tower 10B } \\
\text { Tower } 37 \mathrm{~A} \\
\text { Polaroid 110B }\end{array}$ & $\begin{array}{rr}\$ 84.50 & \$ 84.50 \\
49.00 & 49.50 \\
98.95 & 88.00 \\
159.95 & 164.95\end{array}$ \\
\hline $1963-4$ & $\begin{array}{l}\text { Tower } 18 \mathrm{~B} \\
\text { Tower } 20 \mathrm{~B} \\
\text { Tower } 47 \\
\text { Tower } 37 \mathrm{~A} \\
\text { Tower } 55 \mathrm{~B} \\
\end{array}$ & $\begin{array}{l}\frac{1963}{64.22} \\
83.95 \\
64.22 \\
98.95 \\
19.50 \\
\end{array}$ \\
\hline $1962-3$ & $\begin{array}{l}\text { Polaroid J66 } \\
\text { Tower } 32 \mathrm{~A} \\
\text { Tower Automatic } 35 \mathrm{~mm} \\
\text { Polaroid } 900\end{array}$ & $\begin{array}{r}1962 \\
83.93 \\
143.95 \\
44.47 \\
142.93 \\
\end{array}$ \\
\hline $1961-2$ & $\begin{array}{l}\text { Polaroid } 900 \\
\text { Tower } 55 \\
\text { Argus Twin-Lens Rerlex Kit } \\
\text { Tower Automatic } 127 \\
\text { Tower } 57 \mathrm{~A} \\
\end{array}$ & $\begin{array}{r}1961 \\
125.93 \\
17.95 \\
29.50 \\
17.50 \\
34.44 \\
\end{array}$ \\
\hline $1960-1$ & Tower 55 & $\frac{1960}{17.95}$ \\
\hline
\end{tabular}

35 Film Prices

Years. 20-Exposure B\&W 20-Exposure Color Price Deflator ${ }^{2}$

$1965^{\circ}$

1964

1963

1962

1961

1960
.64

.70

.70

.70

.70

.70
2.19

2.15

2.15

1.94

1.94

2.06
108.9

107.4

106.1

104.9

103.9

102.9

Apersonal Consumption Expenditures Price Deflator for all goods from Economis Report of the President, January, 1967.

Notes: (I) In 1965, the quality of films was improved as the film speed was increased. (2) The films in this index are of foreign manufacture except for color film in 1960 and 1961. In these years the prices of Kodachrome 1 film were reduced by $\$ 1.05$ (the margin from later years) to put them on a "foreign film basis". (3) The prices of color film include processing costs but the black and white film price does not. 
since the unit sales of black and white film are roughy equal to those for color film.

Tariff information was ohtained primarily from Duoanos (International Customs Journal). Data were not, however, available for all countries nor were the Journals always of recent issue. As a result, supplementary data were collected from the Overseas Business Reports (formerly known as World Trade Information), from Business International publications, from correspondence with the United States Department of Commerce, from the survey of importers (used to obtain price data above), from International Commerce (all weekly issues from 1960 through 1965 were surveyed), and from Topping (1963). These sources were used to construct the pattern of tariff changes from 1960 through 1965.

The collection of tariff data was very time consuming. Unfortunately, correspondence with some of the major photographic companies indicated that they did not keep historical data on tariffs. It would seem that the quality of these data could be substantially improved by careful collection of the data over time. In general, tariff changes may be noted in much greater detail as they occur.

Tariffs for cameras and films were combined by a simple arithmetic average which weighted the camera tariff four times as heavily as the film tariff.

Information on Sales Taxes included all government taxation which applied to both domestic and imported cameras. The sources here were, in general, the same as those used for tariffs. The key problem area, as for tariffs, was in 
obtaining comparable data across countries. All taxes were expressed as a percent of duty-paid value and a single index was obtained by weighting taxes on cameras four times as heavily as taxes on films.

Resale Price Maintenance was treated as nominal data-oither it existed at a point in time or it did not. In retrospect, this approach probably led to a loss of information which outweighed the gain in statistical convenience. It was difficult to categorize many countries--a three-way split would have made the classifications much easier. (These comments apply only to the cross-sectional data; degrees of change were estimated when changes over time were examined). Information about changes in RPM was gathered from Edwards (1966), from various publications by the U.S. Department of Commerce, from Business International publications and from the survey of photographic importers. The survey approach would appear to be most useful if further work were to be conducted in this area. Yearly surveys of the photographic distribution system could provide information on the strength of RPM.

Information on non-tariff import controls was obtained from the same sources as was information on tarifis. These controls included quotas, licenses, foreign exchange restrictions and prior deposits. The measurement problem here was so serious that the data were of little value. Countries with no serious import restrictions were easy to identify. For other countries, however, there was a wide variety of types and of severity of the controls. As in the case of 
RPM, the two-way classification led to problems. The percent of imports of total camera sales was estimated by using the proportion of imports in each country over the period 1960-65.

\section{c. Changes in Factors Affecting Camera Prices}

The sources listed in the previous section were used to describe changes in the causal factors for the price model over the period 1960-67. These data are presented in Table B-4.

\section{International Sales Data}

\section{a. Sales Data}

Data on unit still camera sales were collected for nine years. The sources of these data were varied. With few exceptions, however, the sources were all supplied by the U.S. Department of Commerce in Washington, D.C. Since this Department will do the search for data there seems to be little need to provide a bibliography. In addition, the United Nations is now in the process of gathering all of the data into one source (see Walker, 1963).

The data on still camera sales are presented in Table B-5. The notes provide information on sources other than the Department of Commerce and on any a priori adjustments of the data.

The apparent precision of the data implied by the number of non-zero digits is misleading. Estimates of camera sales were rather crude and contain a good deal of subjective input. 
TABLE B-4

DATA ON PRICE DETERMINANTS (1960-67)

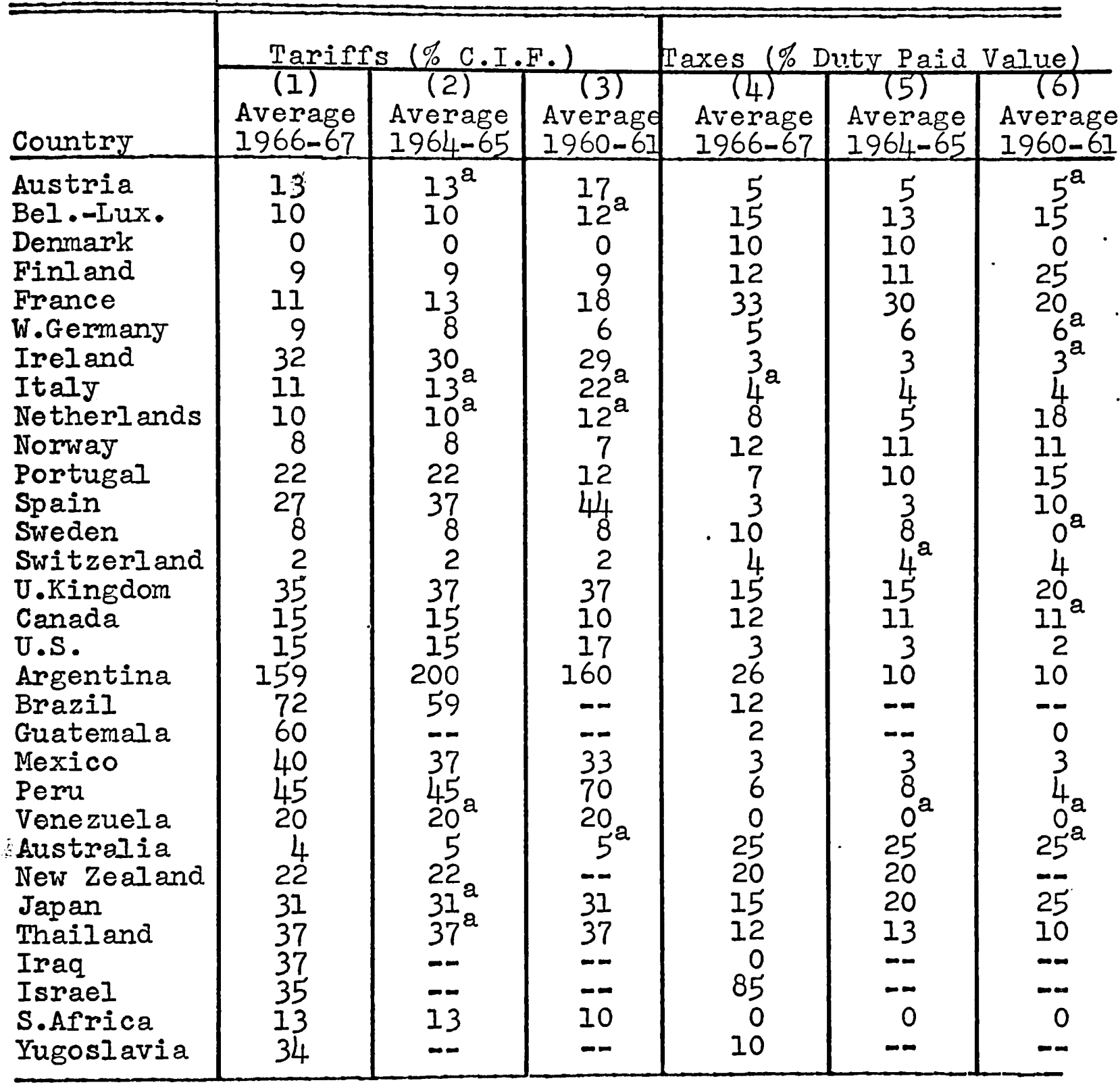

Designates countries which were estimated on very limited information. In most cases, the data were not available for the exact time periods. 
TABLE B-4--Continued

\begin{tabular}{|c|c|c|c|c|c|c|}
\hline \multirow[b]{2}{*}{ Country } & \multicolumn{3}{|c|}{$\begin{array}{c}\text { Resale Price Maintenance } \\
S=\text { Strong } W=\text { Weak }\end{array}$} & \multicolumn{3}{|c|}{$\begin{array}{l}\text { Non-Tariff Import Controls } \\
S=\text { Strong } \quad W=\text { Weak }\end{array}$} \\
\hline & $1966-67$ & $1964-65$ & $1960-61$ & $1966-67$ & $1964-65$ & $1960-61$ \\
\hline $\begin{array}{l}\text { Austria } \\
\text { Bel.-Iux. } \\
\text { Denmark } \\
\text { Finland } \\
\text { France } \\
\text { W.Germany } \\
\text { Ireland } \\
\text { Italy } \\
\text { Netherlands } \\
\text { Norway } \\
\text { Portugal } \\
\text { Spain } \\
\text { Sweden } \\
\text { Switzerland } \\
\text { U.Kingdom } \\
\text { Canada } \\
\text { U.S. } \\
\text { Argentina } \\
\text { Brazil } \\
\text { Guatemala } \\
\text { Mexico } \\
\text { Peru } \\
\text { Venezuela } \\
\text { Australia } \\
\text { New Zealand } \\
\text { Japan } \\
\text { Thailand } \\
\text { Iraq } \\
\text { Israel } \\
\text { S.Africa } \\
\text { Yugoslavia }\end{array}$ & $\begin{array}{l}S \\
S \\
W \\
S \\
W \\
W \\
S- \\
W \\
W \\
W \\
S- \\
S \\
W \\
W \\
W \\
S \\
W \\
W \\
S \\
S- \\
W \\
W \\
W \\
W \\
S \\
W \\
W \\
W \\
W \\
S \\
S\end{array}$ & $\begin{array}{l}S \\
S \\
W \\
S \\
S- \\
S- \\
S \\
W \\
W \\
S- \\
S- \\
S \\
W \\
S- \\
S \\
S \\
W \\
W \\
- \\
- \\
W \\
- \\
W \\
W \\
- \\
W \\
W \\
- \\
- \\
- \\
-\end{array}$ & $\begin{array}{l}S \\
S \\
S \\
S \\
S- \\
S \\
S \\
W \\
S- \\
S \\
S- \\
S \\
S \\
S \\
S \\
S \\
W \\
W \\
- \\
- \\
W \\
- \\
W \\
W \\
- \\
W \\
W \\
- \\
- \\
- \\
-\end{array}$ & $\begin{array}{l}S- \\
W \\
W \\
W \\
W \\
W \\
S- \\
S- \\
S- \\
W \\
W \\
W \\
S- \\
W \\
W \\
W \\
S- \\
W \\
W \\
S \\
W \\
W \\
S \\
W \\
W \\
S \\
W \\
W \\
S \\
W \\
S \\
S\end{array}$ & $\begin{array}{l}S- \\
W \\
W \\
W \\
S- \\
S- \\
S- \\
S- \\
S- \\
W \\
W \\
W \\
S- \\
W \\
W \\
W \\
S- \\
W \\
W \\
S \\
\bar{W} \\
\bar{W} \\
W \\
W \\
W \\
W \\
\bar{W} \\
S \\
S\end{array}$ & $\begin{array}{l}S \\
W \\
W \\
W \\
S \\
S \\
S- \\
S \\
W \\
S- \\
W \\
S \\
W \\
S- \\
S \\
S- \\
W \\
S \\
- \\
\bar{W} \\
S \\
W \\
W \\
S \\
W \\
W \\
S \\
S \\
S- \\
S\end{array}$ \\
\hline
\end{tabular}

${ }^{a_{S e e}}$ previous page for this footnote.

Notes: The minuses are rough indicators of the intensity of the effect. The S- indicates effect of roughly half of S. The blanks (-) are unknown and no estimate was made. 
TABLE B-5

INDUSTRY SALES: STILL .CANERA UNITS BY COUNTRY

(1953-55; 1960-65)--ALL FIGURES IN HUNDREDS

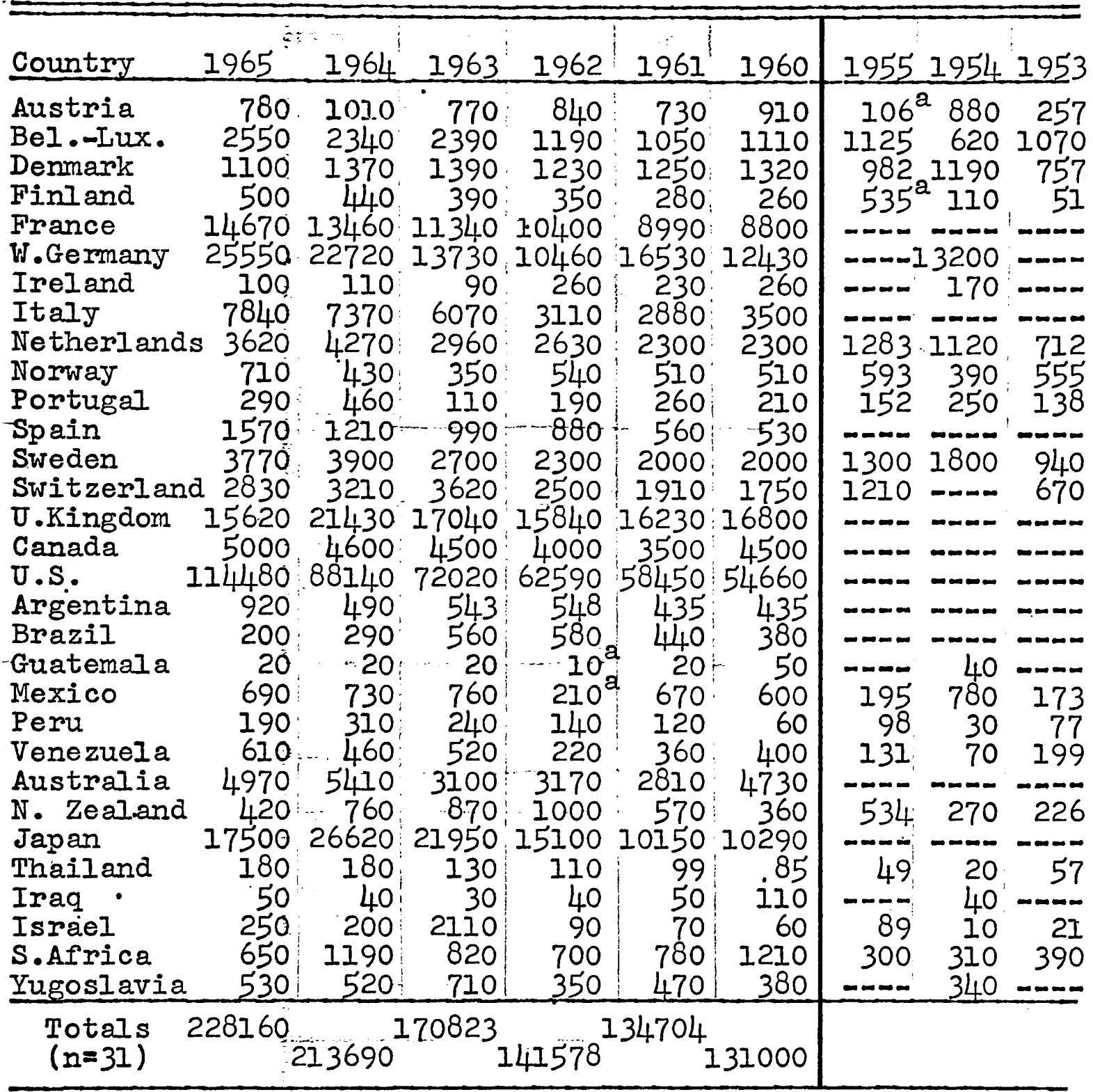

Notes: I. Items designated by (a) were excluded from all calculations. Primary reason for exclusion was presence of strong import controls.2. Source of U.S. estimates was Photo Dealer Annual Statistical Report. Adjustments of +10\% for 1960,6I \& 62 were made to include cameras under $\$ 5.00$. 3.Japan estimates are from the Japanese Ministry of Trade and Industry MITI). Supporting evidence from Far Eastern Economic Review used to adjust the data for inventory changes (200,000 units per jear reduction) and for inclusion of lenses only in MITI figures ( $5.7 \%$ reduction). Japan is based on a 7-year average 1959-65. Sales in 1959 were 10,360. 4.Blanks indicate no information. 1953 to 1955 production data were very difficult to obtain. 5. Argentina estimates are from the National Association of Photographic Manufacturers 
b. Factors Causing Variations in Camera Sales Among Countries ${ }^{1}$

The following notes apply to the independent variables

used in the international measurement models.

\section{Number of Potential Buyers}

(1) Population data were obtained from the World Handbook of Political and Social Indicators (Russett etal., 1964), 2 Table 1. These data were for mid-1961. They were adjusted to represent the end of 1962. Included in these figures were "the total number of persons present in the country at the time of the census, excluding foreign military, naval and diplomatic personnel and their families located in the country but including military, naval, and diplomatic personnel of the country and their families located abroad...". The World Handbook estimated that the average error for the countries in the sample was $=5 \%$ but there was a wide range in quality across countries.

(2) Average Annual Percentage Rate of Change in Population was estimated by Business International (1967) and W: a: based on chainges from 1955 to 1965 .

(3) Percentage of Total Population Aged 15 through 64 was obtained from Table 2 in the World Handbook. It claimed to have paid particular attention to ensuring the comparability of the data across countries as the original data suffered from problems of varying age breakdowns. The data are for mid-1961.

(4) Percent Iiterate of Population Aged 15 and Over was used as an estimate of the desired statistic related to percent literate of those 15 through 64. Definition was a very serious problem here. The intent was to include only those who can both read and write. In some countries either one or the other was sufficient to have the person classified as literate. The data were obtained from Table 64 of the World Handbook and were adjusted to represent the end of 1962. The quality of the data varied widely with the largest errors expected in countries where literacy was low.

(5) Average Annual Change in Percentage Literate of Population Aged 15 and Over was obtained from the World Handbook, Table 65. The data were from selected years-usaally from 1930 to 1950. The rate of change could be determined more accurately for countries with high literacy levels since they hardly show any change.

\footnotetext{
${ }_{\text {Numbers preceding description refer to column number }}$ in Table 7-8. Handbook.

$2_{\text {This book will hereafter be referred to as the World }}$
} 
(6) Percentage of Labor Force Employed in Agriculture was obtained from Table 50 in the World Handbook. These data were adjusted to the end of 1962. Measurement of this variable was subject to a great amount of uncertainty.

(7) Average Annual Change in Percentage of Labor Force Employed in Agriculture was obtained from Table 51 in the World Handbook. Changes were based on time spans of from 10 years to 30 Jears (generally from the period 1920 to 1950).

\section{Ability to Buy}

(8) Personal Consumption Expenditures Per Capita for each country. This measure was available from numerous sources. We used Stanford Research Report \#196.

(9) Beckerman's Index of the Standard of Living is based on a regression of private consumption in dollars versus steel consumption, cement production, domestic letters sent, stock of radio receivers, stock of telephones, stock of road vehicles and meat consumption. The "predicted" values for each country are used as the standard of living measures. These figures may be found in Table 5 of Beckerman (1966). The 1960 figures were adjusted to represent the end of 1962 .

(10) In order to measure the Rate of Change of Ability to Buy, two indicators were obtained--the rate of change in PCE per capita from 1960 through 1964 from Business International (December, 1966) and the rate of change in per capita product at constant prices from 1959 through 1964 from the United Nations Statistical Yearbook (1967). The latter data are given in constant prices while the former were adjusted by the 1960-64 cost of living index obtained from the Gallatin Statistical Annual (1966). While both of the indicators would be expected to move together there were significant differences between them for some countries (e.g. Venezuela was growing at less than $1 \%$ by one indicator and more than $3 \%$ on the other). Since the reasons for the discrepancies were not known, a decision was made to combine the two measures by averaging the percentage changes.

(11) Prices of Camera Goods for 1966-67 were obtained from the survey of importers as discussed in Appendix $B$ section 1. The data were ad justed to represent mid-1962. These adjustments were made by means of the price model. The values of the price determinants for mid-1962 were obtained by averaging the 1960-61 data with the 1964-65 data from Table B-4.

(12) Urbanization was based on the proportion of the population in cities over 20,000 inhabitants. Data were obtained from Table 9 in the World Handbook. 
Consumer Needs

(13) The Index of Buying Units was based on the number of households per adult. Data on the number of households were obtained from the United Nations Statistical Yearbook for 1965. These data were generally for 1961. If not, estimates were made to put them alI on a 1961 basis. The number of adults was estimated.from data gathered above (total population times proportion of population between 15 and 64 ). These estimates of households per adult were assumed to be constant for the $1960-65$ period since this variable changes rather slowly.

(14) \& (15). Two measures of climate were used. Data on the Average Number of Inches of Rainfall per Year for a major city in each country were obtained from World Weather Reports 1947-50 by the U.S. Department of Commerce. Data on the Average Yearly Temperature (in degrees Farenheit) for a major city were obtained from the Gallatin Statistical Annual (1966).

(16) The Percentage of Children in the Population was estimated by using data on the percentage of the population under 15. In order to obtain data for all countries a number of sources were used. The prime source was the United Nations Demographic Yearrbook. Al so used were the UNESCO Statistical Yearbooks for 1963 and 1964.

\section{Consumer Survey Data}

The data which were analyzed were from the 1960-61 Bureau of Labor Statistics' study of consumer expenditures (Iinden, 1965). Table B-6 summarizes the original data.

TABLE B-6.

EXPENDITURES ON CAMERA GOODS BY HOUSEHOLDS (U.S.) (1960-61)

\begin{tabular}{|c|c|c|c|c|}
\hline $\begin{array}{l}\text { Camera Goods } \\
\text { Expenditures } \\
\text { (HH/Year) }\end{array}$ & $\begin{array}{l}\text { Income } \\
\text { Category }\end{array}$ & $\begin{array}{l}\text { Proportion } \\
\text { HH Head } \\
\text { Between } \\
25 \text { and } 54\end{array}$ & $\begin{array}{l}\text { Prioportion } \\
\text { HH Head } \\
\text { with HS } \\
\text { Education }\end{array}$ & $\begin{array}{c}\text { Sample } \\
\text { Size }\end{array}$ \\
\hline $\begin{array}{l}0.25 \\
2.25 \\
5.03 \\
7.10 \\
10.34 \\
13.07\end{array}$ & $\begin{array}{l}\text { Under } \$ 3,000 \\
3,000-5,000 \\
5,000-7,500 \\
7,500-10,000 \\
10,000-15,000 \\
15,000 \text { and over }\end{array}$ & $\begin{array}{l}.274 \\
.563 \\
.721 \\
.778 \\
.806 \\
.698\end{array}$ & $\begin{array}{l}.340 \\
.596 \\
.735 \\
.806 \\
.863 \\
.903\end{array}$ & $\begin{array}{l}2700 \\
2500 \\
3150 \\
1950 \\
1300 \\
450\end{array}$ \\
\hline
\end{tabular}




\section{APPENDIX C}

NOTES ON METHODS

Appendix C contains brief discussions of some unrelated subjects. Factor analysis is considered because of its use in the study of international data; details are provided on the use of a gross index to measure retail prices of cameras; and, finally, background information is provided on the estimates used in Chapter 1 to estimate the value of improved accuracy.

\section{Factor Analysis}

Factor analysis is currently receiving a substantial amount of attention from social scientists who analyze international data. The approach has generally been an empirical one where, for example, one hundred measures for one hundred countries will be dumped into a principal components program. This approach is termed exploratory by many researchers using it. (Examples of this approach are Sawyer, 1967; Schnore, 1961; Cattell, 1949.)

Most of the factor analysis studies interpret one of their resulting factors as a measure of the economic level. Such a measure would, it seems, be useful for the camera study. Unfortunately, the factor analytic approach has some limitations which make it unsuitable for this study. In fact, it appears that use of factor analysis by some social scientists has been misdirected. The rationale for factor analysis is that the observed variables are derived from underlying constructs. The variables which have been put 
into the factor analysis of international data include measures of population, income, trade, arable land, letters sent, newspaper circulation, etc. These are measures of well defined events. There does not seem to be any reason to view them as measures of some underlying construct. The fact that some of the variables tend to vary together over countries does not mean that they are measuring the same concept. There are many reasons why they might vary together. One reason is that direct causal relationships exist among some of the variables. Another reason is that some of the variables are logically connected to other variables by definition (e.g. GNP and population have a direct relationship with GNP per capita).

Problems with the factor analytic approach have been outlined in more detail elsewhere (e.g. Armstrong, 1967; Armstrong and Soelberg, 1967). Perhaps a simple example will help to illustrate the reason why existing factor analysis studies offer us little help. If we desire a factor that will indicate standard of living it would seem that climate should be included in our analysis. If two countries are alike in all other respects except that one country is located in a very severe climate and the other in a mild climate, then surely the latter country has a higher standard of living as they spend less for heating, less on housing, etc. But why should climate vary over countries with the other measures of standard of living? ${ }^{I}$ Climate does not purport to give us

IIt is true, of course, that income and mean temperature are correlated. But the correlation is negative and the reason for the correlation is far from clear. If there is a causal relationship between income and temperature then the use of factor analysis would seem to be misleading. 
an indication of an underlying unidimensional concept called standard of living. It may, by virtue of our theory, be considered as a component of the standard of living--but this makes no assumptions that it should be correlated to the other components over countries.

\section{The Use of a GIobal Index for Camera Prices}

Consideration was given to the possibility that the measurement of camera prices could be improved by use of a global index which utilized prices as measured by the survey and prices as predicted by a regression over 26 countries. (See discussion in Chapter 10.) The details of this investigation are preserted below. The analysis was performed on the II countries of the validation sample for 1960-65.

If the true price lies between measured price and that predicted by the model then a positive residual (measured) predicted) indicates that the measured price is too high. If this is true then the camera sales model which is based on measured price will underestimate actual sales (or measured sales would tend to be more than predicted--i.e. a positive residual in the sales model). Similar reasoning leads us to predict that negative residuals in the price model would be associated with negative residuals in the sales model.

The results are consistent with the hypothesis. There was a correlation of +0.44 between the two sets of residuals. Thus, use of the global price index would have led to improved 
predictions in the salos model. ${ }^{1}$

TABLE $\quad C-1$

BVALUATION OF GLOBAI PRICE INDEX

\begin{tabular}{lccc}
\hline \hline Country & $\begin{array}{c}\text { Residual from } \\
\text { Price Model }\end{array}$ & $\begin{array}{c}\text { Residual from } \\
\text { Sales Model }\end{array}$ & $\begin{array}{c}\text { Agree with } \\
\text { Hypothesis? }\end{array}$ \\
\hline Ireland & -114 & 2 & No \\
Venezuela & 160 & 48 & Yes \\
Austria & -35 & -35 & Yes \\
Bel.-Iux. & 20 & -13 & Yes \\
Sweden & -1 & -31 & Yes \\
France & -93 & -15 & Nes \\
W.Germany & -54 & -13 & No \\
Finland & 34 & -60 & Yes \\
Denmark & 48 & -29 & Yes \\
Australia & 42 & 43 & \\
U.Kingdom & 65 & 50 & \\
\hline
\end{tabular}

Data given in natural logs $x 1000$.

$b_{\text {Data }}$ in $\%$ error (from Table 8-1).

The Value of Improved Accuracy in Long-Range Forecasting

The example used in Chapter 1 was based on a number of subjective estimates. These estimates are presented in graphical form below (Figure $C-I$ ). The reader could alter any or all of these estimates in order to re-calculate potential savings (the interest rate could also be revised, of course).

$I_{\text {This }}$ result would not be statistically significant at the $5 \%$ level if compared to a classical null hypothesis-i.e. that the global index does not do any good. But then this is a pretty uninteresting null hypothesis. 
(spuresnot7 UT) s.outas tetTOd

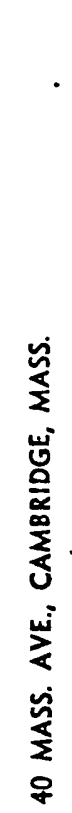

0 (o)

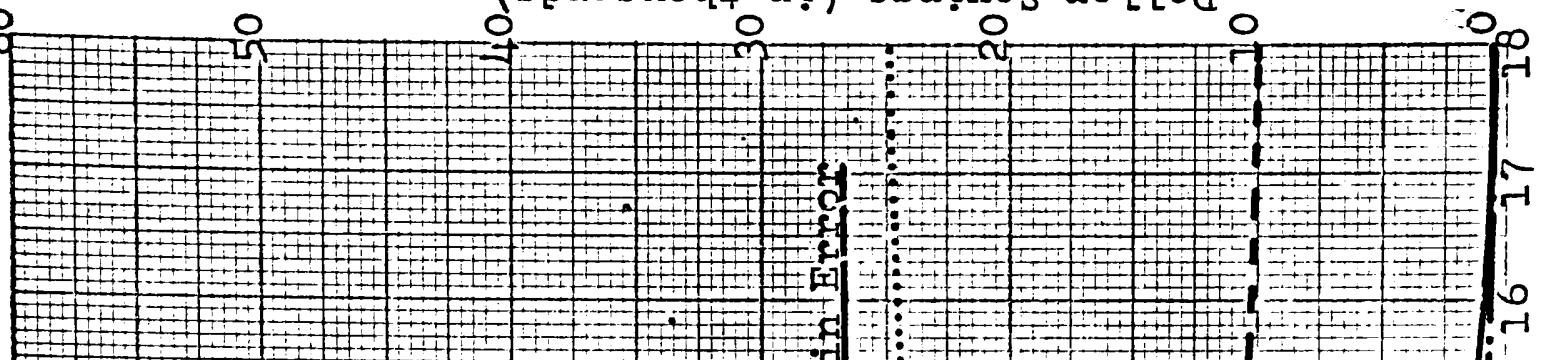

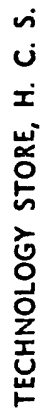

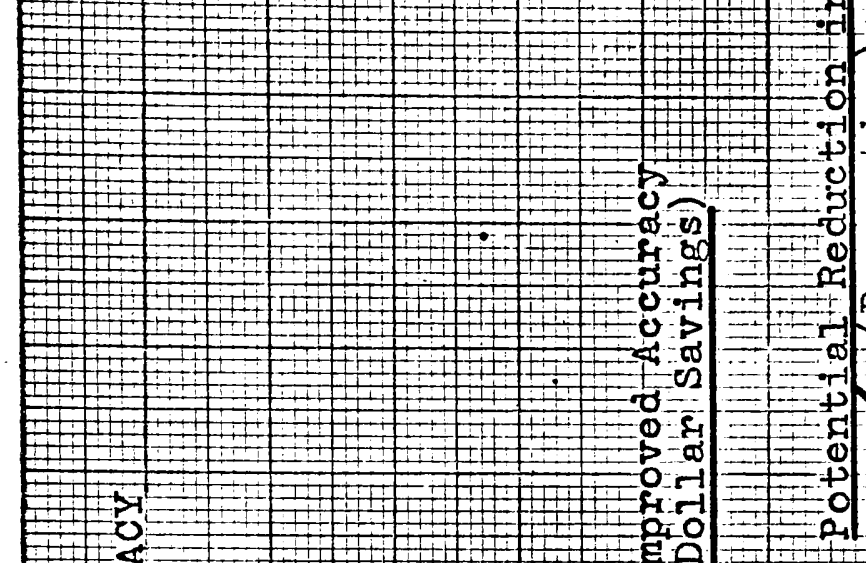

द्व:

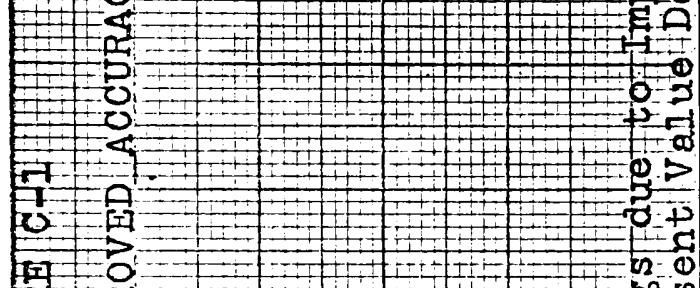

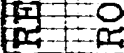

$5=$

है

$0+1+1+1+1$
$0+1$

$\stackrel{+}{+}$

\section{店 \\ 4
40
10
17}

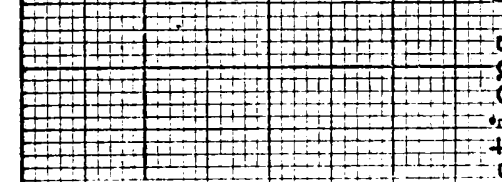

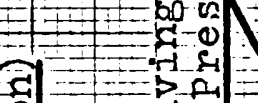

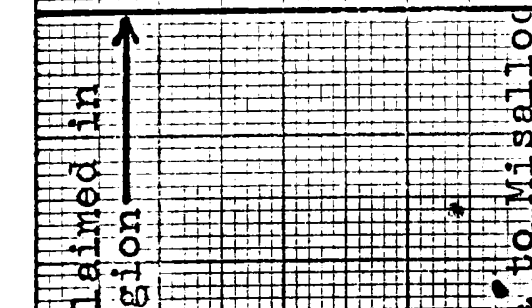

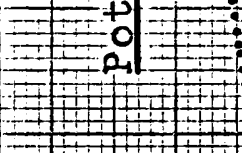




\section{RESEARCH METHODS}

Armstrong, J. Scott. "The Derivation of Theory by Means of

Factor Analysis." The American Statistician, 21 (1967),

17-21.

, and Soelberg, Peer. "A Note on the Interpretation of Factor Analysis." M.I.T. Working Paper No. 254-67.

Bain, A.D. "The Growth of Demand for New Commodities." Journal of the Royal Statistical Society. Series A, $126(1963), 285-299$.

- The Growth of Television Ownership in the United Kingdom. Cambridge: Cambridge University Press, 1964.

Bakan, David. "The Test of Significance in Psychological Research." Psychological Bulletin, 66 (December, 1966), 423-37.

Ball, G.H. "Data Analysis in the Social Sciences: What About the Details?" Proceedings Fall Joint Computer Conference, $1965,533-59$.

Bandeen, R.A. "Automobile Consumption 1940-1950." Econometrica, 25 (1957), 239.

Barten, A.P. "Evidence on the Slutsky Conditions for Demand Analysis." Review of Economics and Statistics, 49 (February, 1967), 77-84.

Beardsley, Monroe C. Practical Logic. New York: Prentice Hall, 1950.

Bennion, E.G. "The Cowles Commission's Simultaneous Equations Approach: A Simplified Explanation." Review of Economics and Statistics, 34 (1952), 49-56.

Binder, Arnold. "Statistical Theory." Annual Review of Psychology, 15 (1964), 277-310.

Blalock, Hubert M. Jr. Social Statistics. New York: McGraw Hill, 1960.

"Evaluating the Relative Importance of Variables." American Sociological Review, 26 (December, 1961), 866-74.

"Making Causal Inferences for Unmeasured Variables from Correlations Among Indicators.! American Journal of Sociology, 69 (1963), 53-62. 
Blalock, Hubert M. Jr. "Correlated Independent Variables: The Problem of liulticollinearity." Social Forces, 42 (December, 1963), 233-37.

- Causal Inferences in Non-experimental Research. Chapel Hill: University of North Carolina Press, 1964.

Brown, D.A.; Buck, S.F.; and Pyatt, F.G. "Improving the Sales Forecast for Consumer Durables." Journal of Marketing Research, 2 (August, 1965), 229-34.

Brown, L.0. "Quantitative Market Analysis--Multiple Correlation; Accuracy of the Methods." Harvard Business Review, 16.

(Autumn 16, 1937), 62-73.

- "Quantitative Market Analysis Scope and Uses." Harvard Business Review, 15 (Spring, 1937), 233-44.

Brown, R.G. Statistical Forecasting for Inventory Control. New York: McGraw-Hill, 1959.

Brownlee, K.A. Statistical Theory and Methodology in Science and Engineering. New York: Wiley, 1965.

Bulmer, M. Principles of Statistics. Cambridge: M.I.T. Press, 1965.

Burstein, M.I. "The Demand for Household Refrigeration in the United States." The Demand for Durable Goods. Edited by A.C. Harberger. Chicago: Chicago University Press, 1959.

Butler, William F. and Kavesh, R.A. How Business Economists Forecast. Englewood Cliffs, N.J.: Prentice-Hall, 1966.

Campbell, Donald T. and Tyler, Bonnie B. "The Construct Validity of Work-group Morale Measures." Journal of Applied Psychology, 47 (1957)., 91-92.

Cowan, Donald.R.G. "Sales Analysis from the Management Standpoint." Journal of Business, 9 (1936) and 10, (1937).

Curtis, R.F. and Jackson, E.F. "Multiple Indicators in Survey Research." American Journal of Sociology, 68 (1962), 195-204.

Dixon, W.J., ed. BMD: Biomedical Computer Programs. Berkeley: University of Califomia Press, 1967.

Durbin, J. "A Note on Regression When there is Extraneous Information About One of the Coefficients." Journal of American Statistical Association, 48 (1953), 799-808. 
Estes, W.K. "The Problem of Inference from Curves Based on Group Data." Psychological Bulletin, 53 (1956), 134-40.

Farrell, M.J. "The Demand for Motor Cars in the United States." Journal of the Royal Statistical Society, Series A, 117 (1954), 171-98.'

Ferber, R. "Are Correlations any Guide to Predictive Value?" Applied Statistics, 5 (June, 1956), 113-122.

, and Verdoorn, P.J. Research Methods in Economics and Business. New York: Macmillan, 1962.

Fisher, Franklin M. A Priori Information and Time Series Analysis. Amsterdam: North-Holland, 1962.

Francis, R.G. "On the Relations of Data to Theory." Rural Sociology, 22 (1957), 258-66.

Frank, Ronald E. "Use of Transformations." Journal of Marketing Research, 3 (1966), 247-53.

Goreau, I. "Iong Range Projections of Food Consumption." F.A.0. Monthly Bulletin of Agriculture, Economics and Statistics, 6 (June, 1957), 1-18.

Hertz, David B. "Risk Analysis in Capital Investment." Harvard Business Review, 42 (1964), 95-106.

Hogan, Warren P. "Technical Progress and.Production Functions." Review of Economics and Statistics, 40 (1958), 407-11.

Hood, William C. "Empirical Studies of Demand." Canadian Journal of Economics and Political Science, 21 (August, 1955), 309-27.

Houthakker, H.S. "New Evidence on Demand Elasticities." Econometrica, 33 (1965), 277-88.

, and Taylor, I.D. Consumer Demand in the U.S. 1929-1970: Analyses and Projections. Cambridge: Harvard Univorsity Press, 1966.

Hummel, F.E. Market and Sales Potential. New York: Ronald Press Co., 196I.

Janosi, P.E. de. "Factors Influencing the Demand for New Automobiles." Journal of Marketing, 23 (April, 1959), 412-18.

Jantsch, Erich. Technological Forecasting in Perspective. OECD, October, 1966. 
Johnston, J. Econometric Methods. New York: McGraw-Hill, 1963.

Katz, E. and Lazarsfeld, P.F. Personal Influence. New York: Free Press of Glencoe, 1964 .

Kish, L. "Some Statistical Problems in Research Design." American Sociological Review, 24 (June, 1959), 328-38.

, and Lansing, John. "The Family Life Cycle as an Independent Variable." American Sociological Review, XXII (October, 1957), 512-19.

Klein, I.R. An Introduction to Econometrics. Englewood Cliffs, N.J.: Prentice-Hall, 1962.

, and Lansing, J.B. "Decisions to Purchase Consumer Durable Goods." Journal of Marketing, 20 (October, 1955), 109-32.

Koopmans, T.C. "Statistical Estimation of Simultaneous Economic Relations." Journal of American Statistical Association, lio $(1945)$, $448-66$.

, "Measurement Without Theory." Review of Economics and Statistics, 29 (1947), 161-72.

Kuh, E. "The Validity of Cross-Sectionally Estimated Behavior Equations in Time Series Applications." Econometrica, 27 (1959), 197-214.

Iorie, J.H. "Two Important Problems in Sales Forecasting." Journal of Business, XXX (July, 1957), 172-79.

MacGowen, A.C. "Techniques in Forecasting Consumer Dúrable Goods Sales." Journal of Marketing, 16 (October, 1952), 156.

Mack, R.P. Factors Influencing Consumption: An Experimental Analysis of Shoe Buying. New York: National Bureau of Economic Research, Technical Paper No. 10, 1954.

Malinvaud, E. Statistical Methods of Econometrics. Chicago: Rand McNally \& Co., 1966.

Meyer, J.R. and Glauber, R.R. Investment Decisions, Economic Forecasting and Public Policy. Cambridge: Harvard University, 1964 .

, and Kuh, E. "How Extraneous are Extraneous Estimators?" Econometrica, (1957), 380-93.

Montgomery, D.B. and Armstrong, J.S. "Consumer Response to a Iegitimated Brand Appeal." Insights into Consumer Behavior. Edited by Johan Arndt, Boston: Allyn \& Bacon, (To be published in 1968). 
Morgan, James N. and Sonquist, John A. "Problems in the Analysis of Survey Data, and a Proposal." Journal of American Statistical Association, 58 (June, 1963), 415-34.

Morgenstern, Oskar. On the Accuracy of Economic Observations. Princeton: Princeton University Press, 1963.

Murdick, R.G. and Schaefer, A.E. Sales Forecasting for Lower Costs and Higher Profits. Englewood Cliffs, N.J.: Prentice-Hall, 1967.

National Industrial Conference Board. Forecasting Sales. Studies in Business Policy \#106, New York, 1963.

Nerlove, M. "Prof. Suits on Automobile Demand." Review of Economics and Statistics, 42 (1960), 102-05.

Platt, John R. "Strong Inference." Science, 146 (October, 1964), 347-53.

Pool, I.; Abelson, R.P.; and Popkin, S.I. Candidates Issues and Strategies. Cambridge: MIT Press, 1965.

Prais, S.J. and Houthakker, H.S. The Analysis of Family Budgets. Cambridge: Cambridge University Press, 1955.

Price, D.J. de Solla. Iittle Science, Big Science. New York: Columbia University Press, 1963.

Quandt, R.E. "Estimating the Effectiveness of Advertising: Some Pitfalls in Econometric Methods." Journal of Marketing Research, 1 (May, 1964), 51-60.

Reichard, Robert S. Practical Techniques of Sales Forecasting. New York: McGraw-Hill, 1966.

Rogers, Everett M. Diffusion of Innovations. New York: Free Press of Glencoe, 1962 .

- Bibliography on the Diffussion of Innovations. Department of Communication, Michigan State University, East Lansing, Michigan, July, 1966.

Roos, C.F. "Survey of Economic Forecasting $\mathrm{T}_{e}$ chniques." Econometrica, 23 (1955), 363-95.

- Dynamics of Economic Growth: The American Economy 1957-1975. Farmingdale, N.Y.: Anderson-Franklyn, Inc. 1957.

Rosenzweig, J.E. The Demand for Aluminum: A Case Study in Business Forecasting. Champaign, IIlinois: University of IIIinois, Bureau of Economics and Business Research, 1957. 
Ruggles, Richard. "Measuring the Cost of Quality." Challenge, 10 (November, 1961), 6-9.

Sawyer, Jack. "Dimensions of Nations: Size, Wealth, and Politics." American Journal of Sociology, 73 (September, 1967), 145-72.

Schipper, Lewis. Consumer Discretionary Behavior. Amsterdam: North-Holland Pub. Co., 1964 .

Schnore, I.F. "The Statistical Measurement of Urbanization and Economic Development." Land Economics, 37 (August, 1961), 230-45.

Sheehan, Robert. "The Kodak Picture--Sunshine and Shadow." Fortune, 71, May, 1965, pp. 126-29.

Smith, P.E. "The Demand for Durable Goods: Permanent or Transitory Income?" Journal of Political Economy, 70 - (october, - 1962), -500-004. -

Solow, R.M. "Technical Change and the Aggregate Production Function." Review of Economics and Statistics, 39 (August, 1957), 312-20.

Stekler, H.0. "Forecasting and Analysis with an Econometric Model: Comment." American Economic Review, 56 (December, 1966), 1241-88.

Stevens, S.S. "Measurement, Psychophysics, and Ütility." Measurement: Definitions and Theories. Edited by C. West Churchman and Philburn Ratoosh. New York: wiley, 1959.

Stone, Richard. Mathematics in the Social Sciences and Other Essays. Loñdon: Chapman \& Hall, Ltd., 1966.

Suits, D. "The Use of Dummy Variables in Regression Equations." Journal of American Statistical Association, 52 (December, 1957), 548-51.

Sultan, Ralph G.M. An Econometric Analysis of the Demand for Nine Consumer Durables. Thesis, Harvard University, 1965.

Theil, H. and Goldberger, A.S. "On Pure and Mixed Statistical Estimation in Economics." International Economic Review, 2 (1961), 65-78.

Tukey, J.W. "The Future of Data Analysis." Annals of Mathematical statistics, 33 (1962), 1-67.

U.S. Judiciary. Administered Prices: Automobiles. November 1, 1958 . 
Warren, E.K. Long-Range Planning. Englewood Cliffs, N.J.: Prentice-Hall, 1966.

Weld, I.D.H. "The Value of the Multiple Correlation Method in Determining Sales Potentials." Journal of Marketing, 3
(April, 1939), 389-93.

Wellman, H.R. "The Distribution of Selling Effort Among Geographical Areas." The Journal of Marketing, 3 (January, 1939), 225-39.

Whyte, William H., Jr. "The Web of Word-of-Mouth." Fortune, 50, November, 1954, pp. 140-43, 204-12.

Williams, Evan James. Regression Analysis. New York: John Wiley, 1959.

Winston, Clement, and Smith, Mabel A. "Income Sensitivity of Consumption Expenditures." Survey of Current Business. U.S. Department of Commerce, 30 (January, 1950), 17-20.

Wold, Herman and Jureén, Lars. Demand Analysis; A Study in Econometrics. New York: John Wiley \& Sons, 1953.

Wolfe, H.D. Business Forecasting Methods. Now York: Holt, Rinehart, and Winston, 1966.

Woy, James B. Business Trends and Forecasting. Management Information Guide No. 9, Gale Research Co., Detroit, Michigan, 1965.

\section{SOURCES OF DATA}

American Metal Market Co. Metal Statistics. Annual, New York.

Beckerman, Wilfred. International Comparisons of Real Incomes. Organization for Economic Cooperation and Development, Paris, 1966.

Business International Corporation. Investing, Iicensing and Trading Conditions Abroad. New Tork.

Business International. New York: Business International Corporation, December, 1966.

Carson, David. Intemational Marketing; A Comparative Systems Approach. New York: Wiley, 1967.

Converse, P.E. "The Availability and Quality of Sample Survey Data in Archives within the United States." Comparing Nations. Edited by R.I. Merritt, and S. Rokkan. New Haven: Yale University Press, 1966. 
Cseh-Szombarthy, I. "Comparing Synthetic Indicators for International Comparisons of the Standard of Living, Using Index Numbers Expressed in Natural Units of Measure." The Standard of Living. Edited by M. Mód. Budapest: Hungạian Academy of Sciences, 1962 .

Dodd, Allen R., Jr. "The Next Big Thing After Color TV." Printers' Ink, 293 (November 25, 1966), 27-32.

Eastman Kodak Annual Reports. Rochester, N.Y. 1956-1966. Edwards, C.D. Trade Regulations Overseas. Dobbs Ferry, N.Y.:
Oceana, 1966.

Far Eastern Economic Review. Hong Kong, Weekly 1961 - 1967.

Fry Consultants, Inc. The West German Market for Photography in Industry. (Study done for U.S. Department of Commerce on October 20, 1965.)

Funk and Scott Index of Corporations and Industries, 1966. Cleveland: Funk and Scott Pub. Co., 1967.

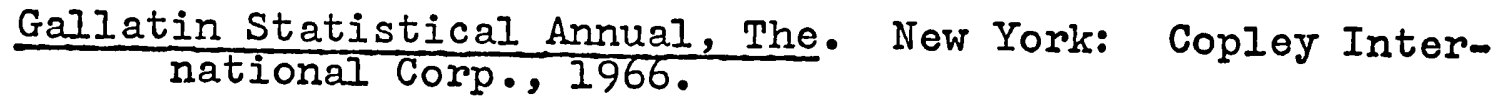

GATT: What it is, hat it Does, How it Works. Geneva, 1966.

Ginsburg, N.S. Atlas of Economic Development. Chicago: University of Chicago Press, 1961.

International Customs Tariffs Bureau. Duoanes. (International Customs Journal), Brussels.

Kravis, Irving. "Intermational Differences in the Distribution of Income." Review of Economics and Statistics, 42 (June, 1960), 408-16.

Lemberg, W.A. Consumer Photographic Survey. Conducted by the Master Photo Dealers' and Finishers' Association. Jackson, Michigan, January, 1964.

Iinden, F., ed. Expenditure Patterns of the American Family. National Industrial Conference Board, New York, 1965.

McGranahan, D.V. "Comparative Social Research in the United Nations." Comparing Nations. Edited by R.I. Merritt, and S. Rokkan. New Haven: Yale University Press, 1966.

Merritt, R.I. and Rokkan, S, eds. Comparing Nations: The Use of Quantitative Data in Cross-National Research. New Haven: Yale University Press, 1966.

New York Times. World Economic Review and Forecast: 1965. New York: Grosset and Dunlap, annual. 
Photo Dealer. March, 1958. June, 1959. December, 1963. December, 1964. December, 1966.

Polaroid Annual Reports. C Cambridge. 1964. 1965. 1966.

Political and Economio Plannirg. Atlantic Tariffs and Trade. 1962 .

Political and Economic Planning. Tariffs and Trade in Western Europe. 1959.

Rummel, R.J. "The Dimensionality of Nations Project." Comparing Nations. Edited by R.I. Merritt and S. Rokkan. New Haven: Yale University Press, 1966.

Russett, B.M., et al., eds. World Handbook of Political and Social Indicators. New Haven: Yale University Press, 1964 .

- "The Yale Political Data Program: Experience and Prospects." Comparing Nations. Edited by R.L. Merritt and S. Rokkan. New Haven: Yale University Press, 1966.

Scheuch, E.K. "Cross-National Comparisons Using Aggregate Data: Some Substantive and Methodological Problems." Comparing Nations. Edited by R.I. Merritt and S. Rokkan. New Haven: Yale University Press, 1966.

Squires, C.K. Inc. Industry and Marketing Survey: Photographic Equipment-aScandanavia. Study done for U.S. Department of Commerce, March, 1965.

Topping, F.K. Comparative Tariffs and Trade; The United States and the European Common Market. New York: Committee for Economic Development, 1963.

Trancu and Associates. Amateur and Professional Photographic. Equipment: A Market Survey of Italy. Done for U.S. Department of Commerce, Washington, August 15, 1963.

United Nations. Demographic Yearbook. 1964.

United Nations. United Nations Statistical Yearbook. 1965.

U.S. Department of Commerce. Bureau of International Commerce. International Commerce (formerly known as Foreign Commerce Weekly). Washington, D.C.: Government Printing Office, 1960-1967.

U.S. Department of Commerce. United States Foreign Trade in Photographic Goods. Washington. 1960-1963.

U.S. Department of Commerce (BSDA). The Development of the West German Photographic Products Indsutry 1954-59. Washington, D.C. 1960 . 
U.S: Department of Commerce. Overseas Business Reports. (formerly known as World Irade InIomation Service). Weekly.

U.S. Department of Commerce. Development of the Japancse Photographic Products Industry. Washington, D.C. 1963.

U.S. Department of Commerce (BIC). Why We Have Export Control. washington, D.C. March, 1965.

U.S. Department of Commerce. What You Should Know About Exporting. Washington, D.C. September, 1965.

World Trade Annu.al. New York: Walker \& Co., 1963.

Worldmark Inclyclopedia of the Nations. New York: Worldmark Press, 1960. 
J. Scott Armstrong was born in Philadelphia, Pennsylvania on March 26, 1937. He is married to the former Kay K. Anderson of Rochester, New York and has one child, Kathy Jean. He has accepted a position as Assistant Professor at the Wharton School, University of Pennsylvania.

Eiducational Background

Ph.D. in Management, SIoan School, M.I.T., June 1968.

M.S. in Industrial Administration, Carnegie-Mellon University (formerly Carnegie Institute of Technology), June 1965.

B.S. in Industrial Engineering, Lehigh University, June 1960.

B.A. in Applied Sciences, Lehigh University, June 1959.

Mt. Lebanon High School, Pittsburgh, Pennsylvania, June 1955.

Teaching Experience

"Statistics for the Behavioral Sciences", M.I.T., Fall 1967-68.

Business Experience

Summer 1966 Polaroid Corporation (Marketing Researcher)

Summer 1965 Carnegie-Melion University (Research Assistant)

Summer 1964 Xerox Corporation (Systems Analyst)

1960 - 1963 Eastman Kodak Company (Industrial Engineer)

Military Experience

U.S. Army: Critical Skills Program (August to December, 1961)

Publications

"The Derivation of Theory by Means of Factor Analysis." The American Statistician, 21 (1967), 17-21.

"Consumer Response to a Legitimated Brand Appeal." (with David B. Montgomery). Insights into Consumer Behavior. Edited by Johan Amdt. Boston: AlIyn and Bacon, to be published in 1968.

"A Note on the Use of Markov Chains in Forecasting Store Choice". (with John U. Farley). M.I.T. Working Paper No. 311-68.

"A Note on the Interpretation of Factor Analysis." (with Peer Soelberg). M.I.T. Working Paper No. 254-67.

April 20, 1968 



